\title{
Effect of Micro-Osteoperforations on Orthodontic Tooth Movement with Clear Aligner Treatment.
}

DoBin Choi

Follow this and additional works at: https://researchrepository.wvu.edu/etd

\section{Recommended Citation}

Choi, DoBin, "Effect of Micro-Osteoperforations on Orthodontic Tooth Movement with Clear Aligner Treatment." (2017). Graduate Theses, Dissertations, and Problem Reports. 8179.

https://researchrepository.wvu.edu/etd/8179

This Thesis is protected by copyright and/or related rights. It has been brought to you by the The Research Repository @ WVU with permission from the rights-holder(s). You are free to use this Thesis in any way that is permitted by the copyright and related rights legislation that applies to your use. For other uses you must obtain permission from the rights-holder(s) directly, unless additional rights are indicated by a Creative Commons license in the record and/ or on the work itself. This Thesis has been accepted for inclusion in WVU Graduate Theses, Dissertations, and Problem Reports collection by an authorized administrator of The Research Repository @ WVU. For more information, please contact researchrepository@mail.wvu.edu. 


\title{
Effect of Micro-Osteoperforations on Orthodontic Tooth Movement with Clear Aligner Treatment
}

\author{
DoBin Choi, D.D.S. \\ Thesis submitted \\ to the School of Dentistry \\ at West Virginia University \\ in partial fulfillment of the requirements for the degree of

\section{Master of Science in Orthodontics} \\ Peter Ngan, D.M.D., Chair \\ Osama Mukdadi, Ph.D., M.S., Co-Chair \\ Chris Martin, D.D.S., M.S. \\ Department of Orthodontics
}

Morgantown, West Virginia

2017

Keywords: Accelerated orthodontics, Micro-osteoperforation, Orthodontic tooth movement, Clear aligner treatment

Copyright 2017 DoBin Choi, D.D.S. 


\section{ABSTRACT \\ Effect of Micro-Osteoperforations on Orthodontic Tooth Movement with Clear Aligner Treatment}

\section{DoBin Choi, D.D.S.}

Background and Objectives: Micro-osteoperforation (MOP) is a relatively noninvasive procedure to expedite the rate of orthodontic tooth movement (OTM) by enahncing naturally occurring inflammatory response. This procedure is often combined with clear aligner treatment (CAT) in order to shorten the duration of aligner wear. However, the question yet remained whether the accuracy of OTM was maintained if the patients switched the aligners more frequently than recommended. The objectives of the study were to investigate the effect of MOPs on the accuracy of anterior OTM and to evaluate the differential effect of MOPs on gender, age, severity of the mal-alignment, and the likelihood of refinement treatment.

Experimental Design and Methods: A de-identified sample of 105 patients who completed CAT and met the inclusion criteria was obtained from the private practice of Thomas Shipley (Peoria, AZ). The experimental group consisted of 46 CAT cases with MOPs and 3-day aligner change, and the control group consisted of 59 CAT cases with 14-day aligner change. For data collection, CloudCompare software was used to superimpose the post-treatment and prediction scans to the pre-treatment scans and to measure the actual and predicted amount of displacement of each anterior tooth of both arches. Using the transformation matrices from tooth-by-tooth alignment, the amount of linear and angular displacement in 3 different planes was obtained and used to calculate the linear discrepancy and the relative errors for the angular discrepancy. The difference of these values between the control and the experimental samples was analyzed using ANOVA, student's t-test, Wilcoxon/Kruskal-Wallis rank sums test, and contingency analysis.

Results: Statistical analyses showed no significant difference between the groups for the accuracy of anterior tooth movement in general, and the type of movement was unaffected by MOPs. No clinically significant difference was found between the predicted and the actual outcomes for varying gender, age, and severity of mal-alignment. On the other hand, a greater percentage of the experimental samples required refinement treatment. Conclusions: Compare to the 14-day aligner wear, the 3-day aligner wear with MOPs did not affect the accuracy of OTM. MOP had a negligible effect on the types of tooth movement, gender, age, and the severity of mal-alignment. The frequency of refinement treatment was higher for the 3-day aligner wear with MOPs possibly due to more severe mal-alignment and greater number of prescribed aligners of the experimental samples. In general, MOP can be a viable procedure to reduce the length of CAT without compromising the quality of the clinical outcome. 


\section{ACKNOWLEDGEMENTS}

I would like to take this opportunity to acknowledge and thank the following people who have played a pivotal role in my specialty training. None of my achievements would have been possible without them.

Dr. Peter Ngan, The opportunity you have given me to become a specialist is priceless. I cannot thank you enough.

Dr. Osama Mukdadi, It has been a true pleasure to work with you as my committee co-chair. Your guidance made this study possible.

Dr. Chris Martin, Thank you for serving as a committee member. Your guidance throughout my training will always be appreciated.

Dr. Thomas Shipley, Thank you for providing me with the data and your input for the study. Your passion for the project has inspired me to push through.

Dr. Gerry Hobbs, You have been so patient and kind throughout the process of data analyses. Thank you.

Dr. Doyoung Choi, You have always been and always will be my role model. I am blessed to have you as my sister, teacher, and friend.

Drs. Tim Tremont, Tom Jarrett, Michael Hazey, Scott Little, Glenn Boyles, Dan Foley, Kerry Kirsch, and Lawrence Wright, Your knowledge and wisdom will always be the lighthouse of my career. Thank you.

Drs. Marina Gonchar and Uyen Nguyen, I am ever so grateful to have you as my classmates. Thank you for being my inspiration and support.

Nick, Jen, Travis, Martin, Tim, Jason, MacKenzie, Tyler, Amer, Ghaddy, Carl, and Niki, You all are the best co-residents that I could ask for. I will always remember the great times. 


\section{TABLE OF CONTENTS}

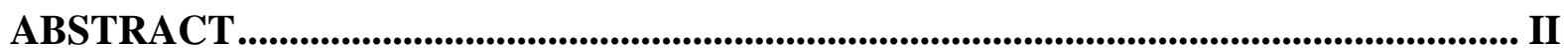

ACKNOWLEDGEMENTS ...................................................................................................II

TABLE OF CONTENTS ............................................................................................................ IV

LIST OF TABLES .................................................................................................................

LIST OF FIGURES ............................................................................................................ VIII

LIST OF EQUATIONS ...................................................................................................

CHAPTER 1: INTRODUCTION......................................................................................................1

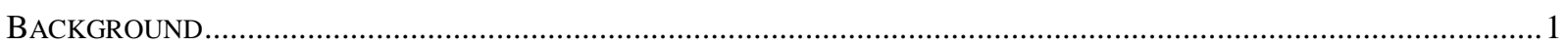

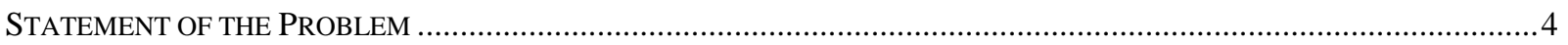

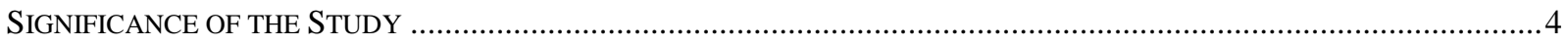

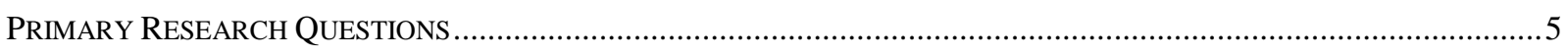

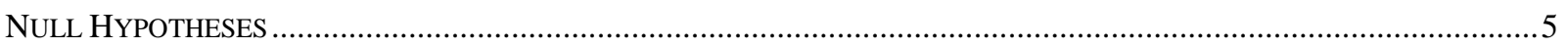

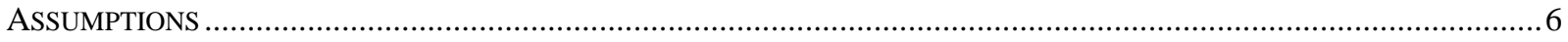

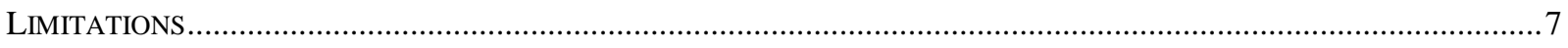

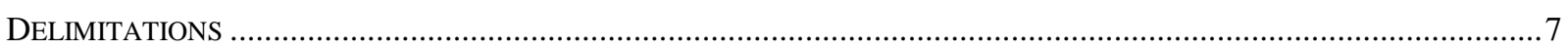

CHAPTER 2: REVIEW OF THE LITERATURE..........................................................9

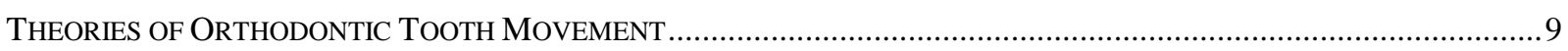

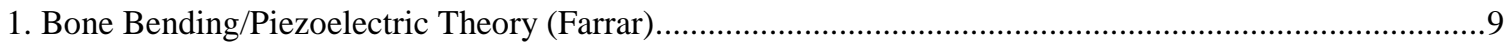

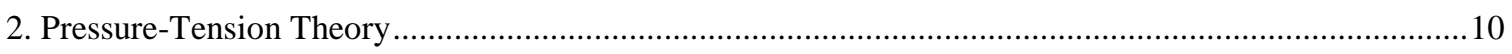

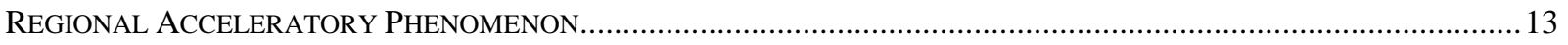

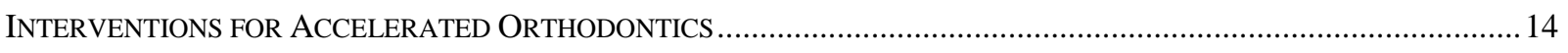

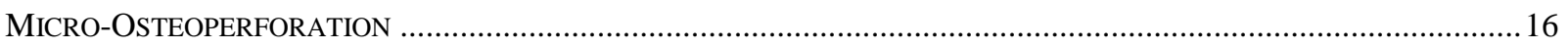

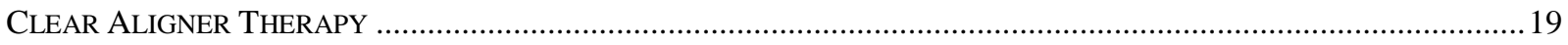

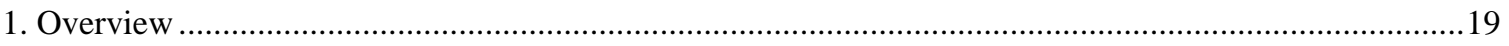

2. Factors Affecting the Tooth Movement with Clear Aligner Treatment ……............................................20

3. Accuracy of Orthodontic Tooth Movement with Clear Aligner Treatment ............................................21 


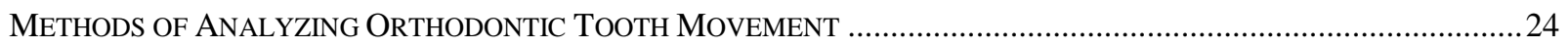

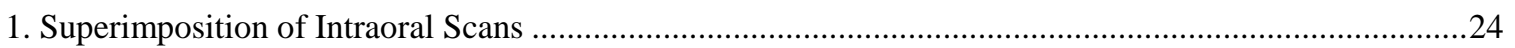

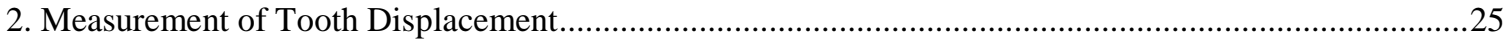

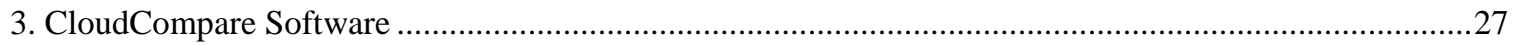

CHAPTER 3: EXPERIMENTAL DESIGN AND METHODS.............................................29

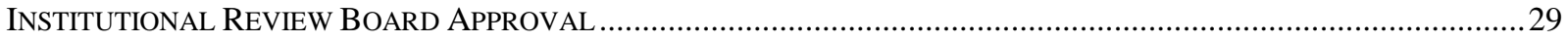

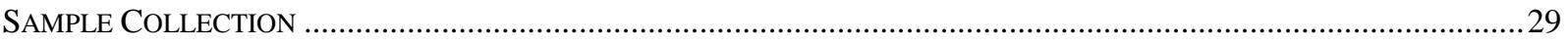

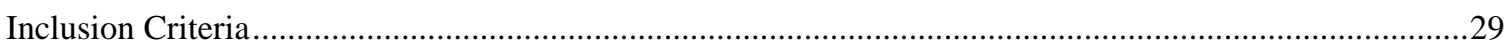

SUPERIMPOSITION OF SCANS AND ESTABLISHING COORDINATE SYSTEM .............................................................. 31

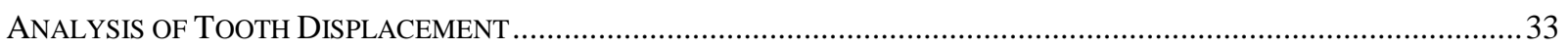

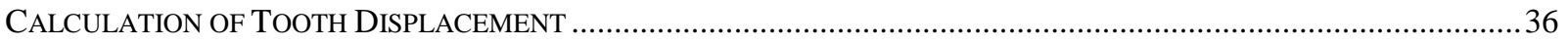

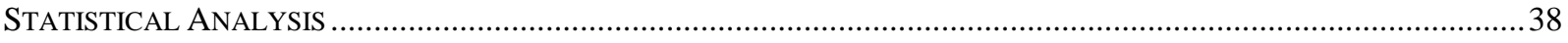

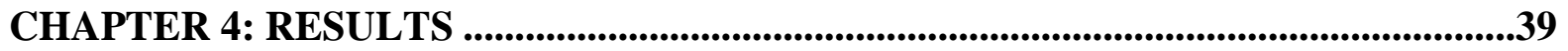

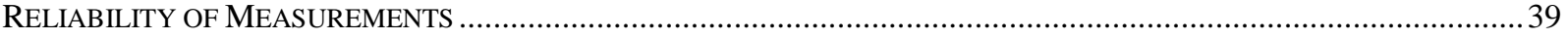

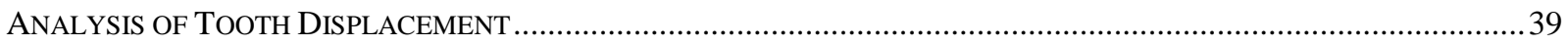

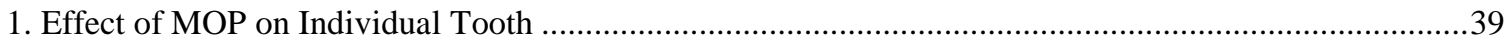

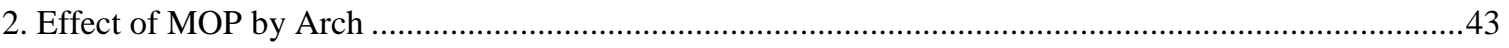

3. Effect of MOP on the Types of Orthodontic Tooth Movement ……........................................................45

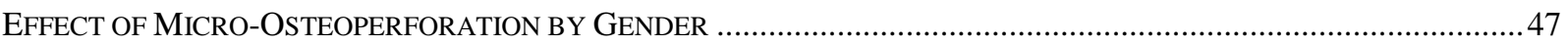

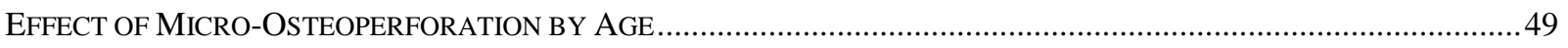

EFFECT OF MICRO-OSTEOPERFORATION BY SEVERITY OF ANTERIOR MALALIGNMENT ..........................................51

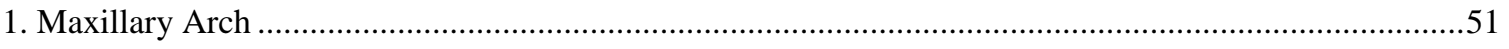

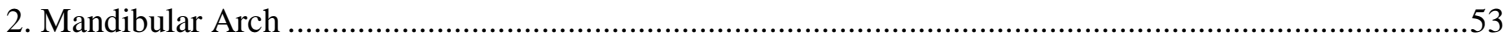

EFFECT OF MICRO-OSTEOPERFORATION ON THE FREQUENCY OF REFINEMENT .........................................................55

CHAPTER 5: DISCUSSION ...........................................................................................57

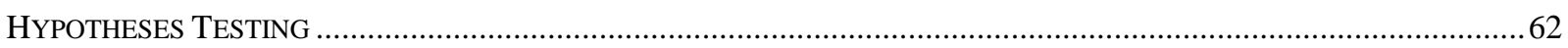

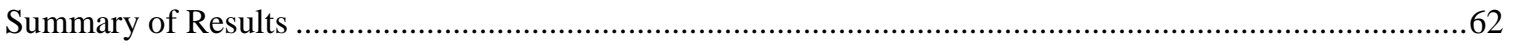

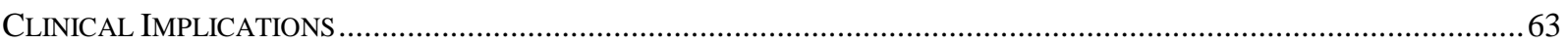


CHAPTER 6: SUMMARY AND CONCLUSIONS ................................................................66

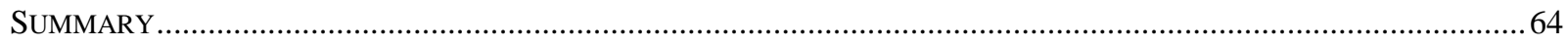

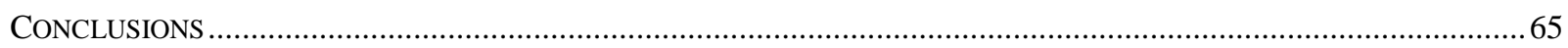

CHAPTER 7: RECOMMENDATIONS FOR FUTURE RESEARCH...........................66

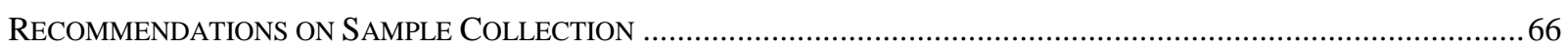

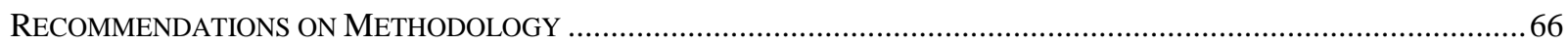

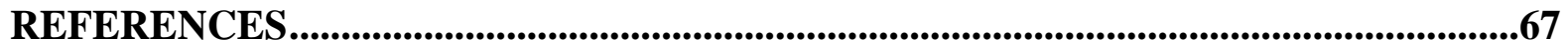

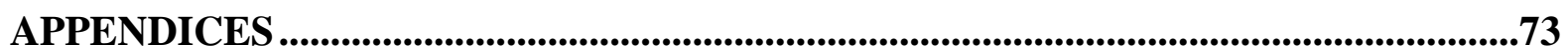

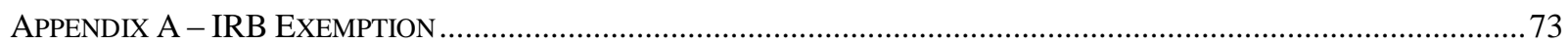

APPENDIX B - LETTER OF PERMISSION TO CONDUCT RESEARCH ................................................................................. 75

APPENDIX C - HIPAA DATA USE AGREEMENT For LIMITEd DATA SETS..........................................................76

APPENDIX D - HIPAA WAIVER OF RESEARCH AUTHORIZATION FORM ...........................................................

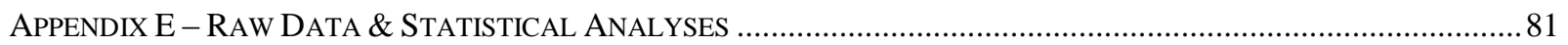

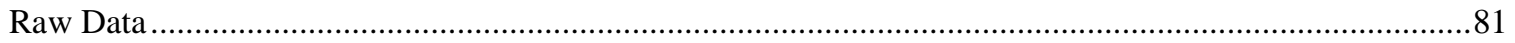

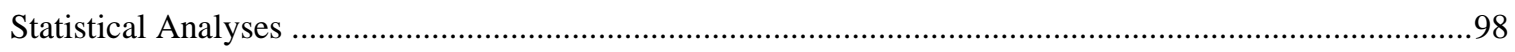

APPENDIX F - ELECTRONIC THESIS AND DISSERTATION SIGNATURE FORM ……..............................................24 


\section{LIST OF TABLES}

Table 1. Mean values of the linear $(\Delta \mathrm{V})$ and angular discrepancies $\left(\Delta \mathrm{x}^{\circ}, \Delta \mathrm{y}^{\circ}, \Delta \mathrm{z}^{\circ}\right)$ of all anterior teeth and the standard deviations for all parameters

Table 2. One-way ANOVA of the linear and angular discrepancies between the actual outcome and the predicted outcome for individual anterior teeth between the control and the experimental samples

Table 3. Mean values of the linear and angular discrepancies of upper, lower, and both arches and the standard deviations for all parameters.

Table 4. One-way ANOVA of the linear and angular discrepancies between the actual outcome and the predicted outcome of upper, lower, and combined arches between the control and the experimental groups

Table 5. The difference in linear and angular discrepancy between the groups and the statistical significance

Table 6. The mean linear and angular discrepancies for male and female subjects of both groups and the significance of the interaction between the gender and the orthodontic tooth movement in clear aligner treatment with or without MOPs.

Table 7. Multi-factorial ANOVA of the significance of the interaction between MOP and the age

of the subjects

Table 8. Multi-factorial ANOVA of the significance of the interaction between MOP and the amount of space available in the upper anterior region

Table 9. Multi-factorial ANOVA of the significance of the interaction between MOP and the amount of space available in the lower anterior region

Table 10. Contingency table of the frequency of refinement treatment needed per group 55 vii 


\section{LIST OF FIGURES}

Figure 1. A schematic of Pressure-Tension Theory of orthodontic tooth movement. ${ }^{74}$ 12

Figure 2. Different designs of the devices specifically designed for Micro-osteoperforation by

PROPEL Orthodontics (Ossining, NY) 18

Figure 3. Normalized 3-D view of the anterior teeth before and after treatment. Black: before treatment; gray: 2 months after treatment.

Figure 4. Coordinate system for analyzing tooth movement by automatic registration. (a) Before registration, (b) after registration. The coordinate systems ( $\left.\mathrm{x}^{\prime}, \mathrm{y}^{\prime}, \mathrm{z}^{\prime}\right)$ and (x, y, z) correspond to before and after tooth movement, respectively. 27

Figure 5. An example of a composite of intraoral scans obtained from OrthoCAD ..... 31

Figure 6. An example of a composite of prediction models obtained from ClinCheck Pro 31

Figure 7. Initial alignment and registration of pre-treatment and post-treatment scans using “Align/Point Pairs Picking” function on CloudCompare 32

Figure 8. Visual verification of the initial alignment of pre-treatment and post-treatment scans 33 Figure 9. Aligned scans were uploaded on CloudCompare to analyze the displacement of each tooth 34

Figure 10. Tooth-to-tooth alignment using the "Align/Point Pair Picking" function 34

Figure 11. Visual verification of the alignment of the tooth and the resultant transformation matrix 35

Figure 12. An example of a transformation matrix 36

Figure 13. Mean linear discrepancy $(\Delta V)$ and relative errors for angular displacement $\left(\Delta \mathrm{x}^{\circ}, \Delta \mathrm{y}^{\circ}\right.$, $\left.\Delta z^{\circ}\right)$ for upper anterior teeth (\#6-\#11) for the experimental (MOP) and control samples 41

Figure 14. Mean linear discrepancy $(\Delta \mathrm{V})$ and relative errors for angular displacement $\left(\Delta \mathrm{x}^{\circ}, \Delta \mathrm{y}^{\circ}\right.$, viii 
$\left.\Delta \mathrm{z}^{\circ}\right)$ for lower anterior teeth (\#22-\#27) for the experimental (MOP) and control samples 42

Figure 15. Mean linear discrepancy and relative errors for angular displacement for upper, lower, and combined arches for the experimental (MOP) and control samples. 44

Figure 16. Comparison of mean tooth displacement by different types of orthodontic tooth movement 46

Figure 17. Means of linear and angular discrepancies by gender with the groups combined ...... 48 Figure 18. Least Squares Means Plot of gender versus the linear discrepancy $(\Delta \mathrm{V})$ between the actual and the predicted outcomes for both control and experimental samples combined. 48 Figure 19. Regression plot of the linear discrepancy $(\Delta V)$ and age and the fit lines for control and experimental groups

Figure 20. Regression analysis of the amount of upper anterior crowding or spacing versus the angular discrepancy about the $\mathrm{x}$-axis $\left(\Delta \mathrm{x}^{\circ}\right)$ between the actual and the predicted tooth displacements. 52

Figure 21. Regression analysis of the amount of lower anterior crowding or spacing versus the linear discrepancy $(\Delta \mathrm{V})$ between the actual and the predicted tooth displacements 54 Figure 22. Mosaic Plot of the frequency of refinement treatment necessary at the completion of the prescribed aligner wear for control and experimental samples.

\section{LIST OF EQUATIONS}

Equation 1. Cost function as the mean of the least-square distances from the vertices of one data set to the other ( $\mathrm{M}$ is a rigid transformation matrix, $\mathrm{N}$ is the number of points, $\mathrm{x}_{\mathrm{i}}$ is the vertex of the first data set, and $\mathrm{p}_{\mathrm{i}}$ is the vertex of the second data)....... 25 


\section{CHAPTER 1: INTRODUCTION}

\section{Background}

Prolonged orthodontic treatments are associated with a higher risk of several adverse effects, such as enamel decalcification, external root resorption, gingival inflammation, decrease in patient compliance, and poorer quality of treatment outcome as a result. ${ }^{2,13-16}$ Hence, the current trend in orthodontics is incorporation of methods to expedite the treatment while achieving a satisfactory outcome by increasing the rate of orthodontic tooth movement as well as increasing treatment efficiency. In an attempt to accelerate the rate of orthodontic tooth movement, many studies have investigated the biological mechanism of orthodontic tooth movement and how to manipulate the physiology.

Orthodontic tooth movement is an inflammatory phenomenon. A mechanical force applied to a target tooth creates a pressure side and a tension side of the tooth root, which stimulates the production and activation of various inflammatory mediators. These inflammatory factors in turn activate bone-remodeling cells, including osteoblasts and osteoclasts in the periodontal ligament (PDL) space. ${ }^{8}$ This idea that orthodontic tooth movement is an inflammatory phenomenon is empirically supported by a higher level of an inflammatory mediator, $\mathrm{PGE}_{2}$, found in gingival crevicular fluid of patients undergoing orthodontic treatment. ${ }^{10}$ Also, Bartzela et al. reported in the systematic review that experimental administration of inflammatory mediators, such as leukotriene, prostaglandin, and prostacyclin, significantly increased the rate of orthodontic tooth movement in non-human subjects. ${ }^{11}$ On the other hand, substances that inhibit the activities of bone remodeling cells, such as bisphosphonates, are capable of inhibiting the orthodontic tooth movement, and anti- 
inflammatory substances have been shown to decrease the rate of tooth movement. ${ }^{11,12}$ These results suggest that enhanced inflammatory response in the periodontal ligament space may promote bone resorption and bone deposition, encouraging rapid tooth movement within alveolus.

Induction of inflammation to increase the tooth movement is not a novel concept. In 1983, Frost first used a term "regional acceleratory phenomenon" to describe a tissue reaction to noxious stimuli by increasing the production of inflammatory mediators. ${ }^{25}$ Noxious stimuli can be any chemical or mechanical agents that can cause "trauma" to the periodontal ligament, thus increasing the production of inflammatory factors within the PDL space. These factors in turn will activate and recruit osteoblasts and osteoclasts involved in remodeling of the bone around the tooth. Increased bone remodeling during orthodontic treatment will result in an increased tooth movement. Other dental procedures, such as tooth extraction, periodontal surgery, or even orthognathic surgery, are considered noxious stimuli, and a faster tooth movement and shortened treatment duration can be observed following invasive dental procedures.

Inspired by the regional acceleratory phenomenon, researchers have made numerous efforts to utilize this phenomenon to deliberately increase the rate of orthodontic tooth movement and shorten the treatment duration. Studies have evaluated various surgical and non-surgical interventions to induce inflammation to increase the rate of orthodontic tooth movement. These efforts range from low-level laser therapy and pulsed electromagnetic fields to corticotomy and distraction osteogenesis. ${ }^{17-23}$ Nevertheless, only a few of these procedures are found to be effective. Surgical procedures, such as full-thickness flap elevation with extensive decortications, corticotomies, piezopunctures, and periodontal and dento-alveolar distractions, are shown to increase the rate of orthodontic tooth movement by activating inflammatory mediators, thus 
increasing the osteoclastic and osteoblastic activities in the alveolar bone. ${ }^{1,3-6,9}$ However, the most notable drawbacks of these methods lie in their invasive nature, possibility of surgeryrelated morbidity, and impracticality of a routine application.

Micro-osteoperforation (MOP) is a newly introduced technique that can easily be performed in an office setting with minimal patient discomfort to increase the rate of orthodontic tooth movement. MOP is a shallow intentional puncture wound through soft tissue into the cortical plate around a target tooth using a stainless steel mini-screw of a 2-mm diameter and 7mm length. According to Alikhani et al., a resultant localized inflammatory response seems to recruit and stimulate surrounding bone remodeling cells to increase the rate of bone resorption and deposition, thus increasing the rate of tooth movement and shortening the treatment duration. ${ }^{7}$ Unlike the aforementioned surgical techniques, MOPs can be applied under topical anesthesia, minimizing patient discomfort and surgery-related morbidities. Moreover, a simple, cost-effective protocol may allow a more frequent application in comprehensive treatment with fixed appliances as well as clear aligner treatment (CAT). ${ }^{24}$

An aesthetic alternative to the traditional fixed appliance treatment, CAT is a series of removable vacuum-formed polyurethane appliances that are designed to apply a point pressure to move teeth to a desired position in small increments. This is not a new treatment concept; in fact, many practitioners have used this technique to achieve a minor tooth movement. In 2001, Align Technology incorporated computer-aided designing/computer aided manufacturing (CAD/CAM) stereolithographic technology to CAT, which allowed CAT to be an aesthetic treatment option for more complex cases. However, many studies revealed that the efficiency of orthodontic tooth movement via CAT is less than ideal with the average accuracy of tooth movement between 29 to 57 percent. $^{26-28}$ In addition, many clinicians have incorporated accelerated tooth movement 
into CAT, claiming that the duration of clear aligner treatment can be shortened by half or even a third of the usual treatment duration (3-day aligner wear versus 14-day aligner wear) while maintaining the quality of the outcome.

\section{Statement of the Problem}

Attempts have been made to increase the accuracy of the tooth movement as well as the rate of the tooth movement with clear aligner treatment. With the emergence of new techniques to accelerate the rate of tooth movement, clinicians and researchers are investigating the effects of MOP in clear aligner treatments. Until present, there have been no organized studies that systematically investigated the effect of MOPs in clear aligner therapy.

\section{Significance of the Study}

A relatively non-invasive method, MOP has been shown to increase the rate of tooth movement and reduce the duration of orthodontic treatment. Understanding the effectiveness and efficiency of this procedure on clear aligner therapy may provide orthodontists an added armamentarium to reduce the duration of orthodontic treatment with the same or similar accuracy in orthodontic tooth movement. The present study will shed light on whether the use of MOP can reduce the length of time in changing from one aligner to the next and the ability of the aligners to track the tooth movement accurately in three planes of space. 


\section{Primary Research Questions}

1. Can the addition of the MOP procedure help in reducing the length of time changing from one aligner to the next?

2. How close can the aligners track the tooth movement in the experimental group treated with the addition of the MOP procedure compared to the control group?

3. Is there a difference in the aligner's ability to track different types of tooth movement (tipping, rotation, and torque movements) in either the experimental or the control group?

4. Is there a difference in the effect of MOP for different gender, age, or the severity of mal-alignment?

5. Is there a difference in the frequency of refinement treatment at the completion of the prescribed aligner treatment with or without the use of MOP?

\section{Null Hypotheses}

Compared to the conventional clear aligner therapy alone, the fast-tracked clear aligner therapy with micro-osteoperforation will show:

1. No significant difference in tooth movements of the anterior teeth predicted by the ClinCheck compared to the actual treatment between the experimental and control groups.

2. No significant difference in the tooth movements of anterior teeth predicted by the ClinCheck compared to the actual treatment outcome among different types of tooth 
movement (i.e. linear displacement and angular displacement in mesiodistal, faciolingual, and occlusogingival directions).

3. No significant difference in the tooth movements of anterior teeth predicted by the ClinCheck compared to the actual treatment outcome between genders.

4. No significant difference in the tooth movements of anterior teeth predicted by the ClinCheck compared to the actual treatment outcome among different age groups.

5. No significant difference in the tooth movements of anterior teeth predicted by the ClinCheck compared to the actual treatment outcome for varying severity of anterior malalignment.

6. No significant difference in the frequency of refinement treatments at the completion of the prescribed aligner treatment.

\section{Assumptions}

The following were assumed for the purpose of the study:

1. Same algorithm developed by Align Technology is used for treatment planning of all cases.

2. Each aligner is designed to move the tooth at a fixed increment in distance and rotation.

3. All MOPs are completed equally to perforate the full thickness of the buccal cortical plate around the anterior teeth.

4. The effect of interarch elastics on anterior alignment is insignificant. 
5. Landmarks are accurately identified for necessary measurements and superimposition of the intraoral scans.

\section{Limitations}

1. Samples are limited to the subject database provided by one of the co-investigators Dr. Thomas Shipley (Peoria, AZ).

2. There is no sample of patients with CAT with 3-day aligner wear without MOPs.

3. There is patient-related variability - demographics, bone physiology, types of malocclusion, amount of crowding, and the level of compliance.

4. There is treatment-related variability - types and amount of required tooth movement, amount of interproximal reduction, and the use of auxiliary devices.

5. Measurements are affected by intra-operator variability and margin of error.

\section{Delimitations}

1. Control samples that were treated in the same time period (January 2013 to July 2016) as the experimental samples were selected to eliminate any variables in treatment planning algorithm or treatment philosophy. 
2. Samples were selected to include a similar distribution of patient-related variability, such as age range, race, gender distribution, types of malocclusion, and high compliance level, for both groups.

3. Samples were selected to include a similar distribution of treatment-related variability, such as types and amount of required tooth movement, amount of interproximal reduction, and the use of auxiliary devices, for both groups.

4. Ten samples in each group were randomly selected for intra-operator reliability test to calculate the margin of error and the reliability of the measurements. 


\section{CHAPTER 2: REVIEW OF THE LITERATURE}

\section{Theories of Orthodontic Tooth Movement}

Discoveries of the evidence of orthodontic tooth movement in ancient Egyptian mummies suggest the long history of practice of orthodontics. However, the physiology of orthodontic tooth movement is a topic of relatively recent studies. These studies introduce several theories of orthodontic tooth movement.

\section{Bone Bending/Piezoelectric Theory (Farrar)}

In 1888, Farrar first introduced Piezoelectric Theory, also known as Bone Bending Theory, to describe the mechanism of orthodontic tooth movement. ${ }^{36}$ Piezoelectricity is an electric charge that occurs due to a mechanical deformation of a crystalline object, such as mucopolysaccharide, collagen, hydroxyapatite, or collagen-hydroxyapatite interface in bone. The piezoelectricity will create micro-currents throughout the object, stimulating the bone remodeling cells, such as osteoblastic and osteoclastic activities. ${ }^{37}$ The theory explains that any mechanical stress that causes bending of any of these crystalline structures will generate electric signals, increasing the cellular activities in the matrix. Yasuda et al. found differential charges on different surfaces of the deformed bone. When a pressure was applied on a femur, they detected a callus formation in the periosteum and endosteum as well as negative piezoelectric charges on the compression side and positive piezoelectric charges on the tension side. ${ }^{38}$ The negative charge is generally associated with an increased osteoclastic activity, and the positive charge is associated with an increased osteoblastic activity.

Studies also suggest that increasing the amount of bone deflection may cause an increase 
in piezoelectricity. ${ }^{39,43}$ The inverse of this phenomenon was also shown to be true when an increased osteogenic activity and an accelerated bone repair were observed in animals with an application of an electric current. ${ }^{40,41}$ This concept can be applied to the tooth movement where a force to a tooth causes bending of the alveolar bone surrounding the tooth and creates differential piezoelectric currents within the PDL space. These currents will stimulate osteoclasts and osteoblasts necessary for bone remodeling and in turn, orthodontic tooth movement. Shapiro and his colleagues noted a sustained tooth movement when a pulsed electric current was applied to a maxillary molar of a female patient. ${ }^{42}$

One of the main drawbacks to this theory to explain the physiology of orthodontic tooth movement is the quick decay rate of piezoelectricity. When a force is applied to a tooth, a piezoelectric current is created; however, the electric signal quickly dissipates to zero even with a sustained force application. Moreover, another unusual characteristic of piezoelectricity is that once the force is released, an equal and opposite piezoelectric signal is created. ${ }^{44}$ Thus, this may imply that after the force is released, the resorptive area shows bone deposition and vice versa. Also, studies indicate that the piezoelectricity is responsible for bone remodeling due to stressgenerated electric signals. Yet, this phenomenon does not fully explain the physiology of tooth movement when the orthodontic force application is maintained, which frequently occurs in orthodontic treatments with fixed appliances. Nevertheless, studies suggest that a pulsed force application with a careful removal of force may stimulate a unidirectional orthodontic tooth movement.

\section{Pressure-Tension Theory}

Pressure-tension theory is based on the concept that orthodontic tooth movement is an 
inflammatory process. When orthodontic force is applied to a tooth in a certain direction, a catabolic-pressure side and an anabolic-tension side are created in the PDL space. Depending on the side of the tooth, cellular activities are distinctly different. On the pressure side, histochemical findings indicate that compressive force within the PDL space significantly increases the expression of cyclooxygenase $(\mathrm{COX}) .{ }^{8} \mathrm{COX}$ is derived from arachidonic acid, one of the components of cell membrane phospholipids. COX enzyme is responsible for the production of prostaglandins (PG), especially $\mathrm{PGE}_{1}$ and $\mathrm{PGE}_{2}$. Studies have indicated the bone resorptive effect of $\mathrm{PGE}_{1}$ and $\mathrm{PGE}_{2}$ via their effect on other molecules. ${ }^{45,46}$ These factors activate receptor activator of nuclear factor kappa B ligand (RANKL), whose action is to aid in differentiation, function, and survival of bone-resorbing osteoclasts. These PGs are also involved in initiating the cyclic adenosine monophosphate (cAMP) pathway. ${ }^{47}$ This pathway eventually leads to an increased production of cellular components necessary to sustain an increased cellular activity of bone remodeling cells.

At the same time, PGs lower the osteoprotegerin (OPG) level, altering the ratio of RANKL/OPG to favor the formation of functional osteoclasts. ${ }^{30,31}$ Compressive force also increases the expression of interleukin (IL)-17, whose action is to activate bone-forming osteoblasts. $^{29}$ In addition, there is a differential expression of various inflammatory cytokines, such as IL-1, IL-6, tissue necrosis factor (TNF)- $\alpha$, and interferon- $\gamma$, which are also associated with osteoblast and osteoclast activation. The combined actions of these inflammatory factors and the cells they stimulate on the pressure side will aid in bone remodeling and bone modeling necessary for the tooth to move into the newly created space.

On the tension side, similar molecules and cells are involved but at a different level of activity, thus producing a different phenomenon. The major factor associated with the anabolic 
side is transforming-growth factor (TGF)- $\beta 1$. TGF- $\beta 1$ is a chemotactic molecule involved in proliferation, differentiation, survival, and function of osteoblasts, which are the cells responsible for bone formation. Osteoblasts will deposit bone on the tension side of the socket once the tooth is moved away from the original position. ${ }^{32,33}$ Studies indicate an increased level of TGF- $\beta 1$ in the PDL space upon application of tensile force, increasing the osteoblastic activity. ${ }^{34}$ In addition, upon the force application, there is an increased level of vascular endothelial growth factor (VEGF). This is another factor that is associated with the enhanced survival and activity of osteoblasts. ${ }^{35}$ Also, as mentioned earlier, the ratio of RANKL/OPG affects the osteoclast formation. With a tensile force, OPG level is increased, lowering the RANKL/OPG ratio and decreasing the production of functional osteoclasts. ${ }^{32}$ Overall there is an increased osteoblastic activity and a decreased osteoclastic activity, thus increasing the rate of bone deposition in the tension side of the PDL space. The Pressure-Tension Theory explains the biologic mechanism of orthodontic tooth movement by presenting the evidence of altered level of inflammatory mediators caused by orthodontic force application to a tooth.

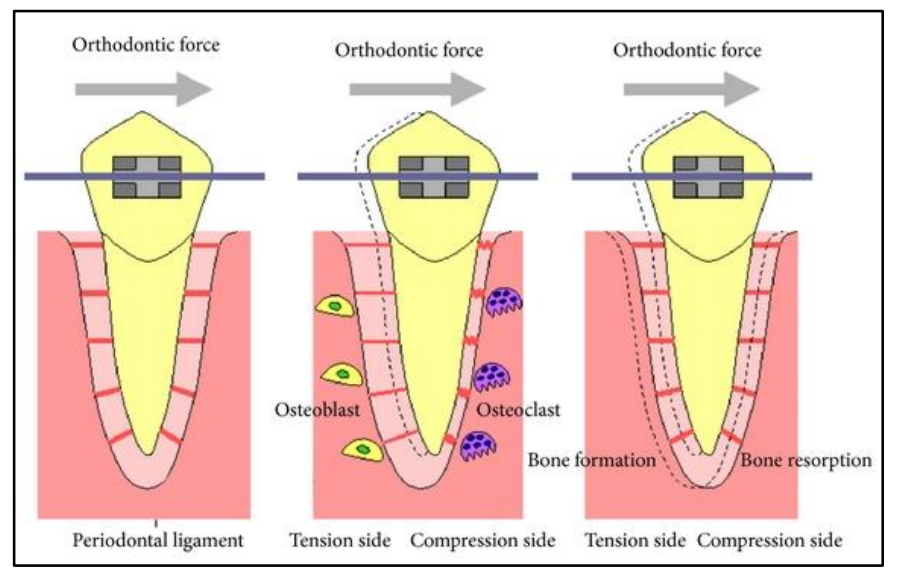

Figure 1. A schematic of Pressure-Tension Theory of orthodontic tooth movement. ${ }^{74}$ 


\section{Regional Acceleratory Phenomenon}

First described by Frost in 1983, the regional acceleratory phenomenon (RAP) is used to describe a tissue response to a noxious stimulus that results in an increased cellular activity. ${ }^{25}$ It is understood as a necessary reaction of the affected tissue to counter the disturbance and increase the healing capacity. Without the RAP reaction, healing capacity is compromised, and the tissue becomes more prone to infection. ${ }^{52}$ This phenomenon of accelerated healing occurs not just in soft tissue, but also in hard tissue, such as bone and cartilage. ${ }^{48}$ According to Verna, the extent of the elicited response is directly proportional to the magnitude and the nature of the noxious stimuli, which can include a variety of external factors, both chemical and mechanical. For example, soft or hard tissue infection, any type of fractures, surgical procedures, and inflammatory processes are all capable of inducing the RAP. ${ }^{51}$

Verna explains that the RAP affects the variety of cellular activities, such as the differentiation of precursor cells and the metabolism of the already differentiated cells within the bone multicellular unit (BMU). The BMU consists of the cells depositing, resorbing, and maintaining the bone in a cyclical sequence. The sequence of bone remodeling during the RAP is activation, resorption, reversal, and formation. First, activation phase is initiated by binding of RANKL to its receptors present on the surface of preosteoblasts. This reaction results in the emergence and differentiation of preosteoclasts from the bone marrow into osteoclasts. The mature osteoclasts will begin the second phase, bone resorption. After the second phase, osteoclasts undergo apoptosis, and the further resorption is carried out and completed by mononucleated phagocytes. At the same time, during the reversal phase, preosteoblasts are differentiated into mature osteoblasts, which secret OPG to discourage the differentiation and activities of osteoclasts. During the last phase of bone formation, mature osteoblasts deposit 
osteoids, which eventually complete mineralization in three to four months. ${ }^{51}$ The bone modeling/remodeling sequence is a normal process of bone turnover, but becomes heightened during the state of injury via the RAP.

Histologic studies have supported the above process that in an injured bone tissue, the RAP is characterized by augmented osteoblastic and osteoclastic activities that lead to an increased formation of unorganized woven bone, which subsequently becomes organized into

lamellar bone. ${ }^{49-51}$ As a result, the rate of bone modeling and remodeling is increased, eventually leading to bone healing. Dental pathologies that can cause the RAP include fractures of the bone and periodontal diseases, and dental procedures that can cause this phenomenon include tooth extraction, orthognathic surgery, implant placement, and orthodontic tooth movement. Experimental results suggest that the RAP in general lasts between four and eight months, but the scope of the tissue response depends on the severity of the dental disease processes or the extent of the dental procedures. ${ }^{51}$ In orthodontic tooth movement, since the RAP stimulates both the osteoblastic and the osteoclastic activities, it can be assumed that this phenomenon occurs on both the tension and the pressure sides.

\section{Interventions for Accelerated Orthodontics}

Once the connection between the orthodontic tooth movement and the RAP has been established, numerous studies have been conducted to develop methods to accelerate the rate of orthodontic tooth movement. The main idea is to induce the regional inflammatory response around the target tooth to increase the RAP, thus increasing the rate of tooth movement. Researchers have investigated various methods to utilize and enhance the RAP, both surgical and 
non-surgical, and several systematic reviews that analyzed these studies are available.

Long and his colleagues reviewed five procedures discussed in nine studies that met their inclusion criteria in their systematic review. ${ }^{1}$ Among the five procedures were low-level laser therapy (LLLT), corticotomy, electrical current, pulsed electromagnetic fields (PEMF), dentoalveolar and periodontal distraction. First, from the two qualifying studies, the authors concluded that corticotomy could reliably accelerate orthodontic tooth movement. The authors noted a report of transiently compromised gingival health in the corticotomy samples, possibly due to the difficulty maintaining an adequate oral hygiene following the surgery. Nevertheless, the authors agreed that corticotomy is a relatively safe and effective method of increasing the rate of orthodontic tooth movement.

Another study included in this systematic review was by Kharkar et al. that investigated the effectiveness of dentoalveolar and periodontal distractions. ${ }^{9}$ This study reported a faster rate of orthodontic tooth movement with dentoalveolar distraction compared to periodontal distraction. Despite the limitations of the experimental design of this study, the authors suggested that dentoalveolar distraction was a safe, promising procedure in clinical practice. The last three procedures, LLLT, electrical current, and pulsed electromagnetic fields, were also investigated for their efficacy. However, the authors were unable to find any definitive evidence that these procedures were effective in accelerating orthodontic tooth movement.

A more recent systematic review by Hoogeveen et al. reviewed eighteen studies that evaluated corticotomy, periodontal ligament distraction, and dentoalveolar distraction. ${ }^{53}$ Unlike the previous study, Hoogeveen et al. found the evidence of the efficacy of both distraction methods. They concluded that all three procedures, corticotomy, PDL distraction, and dentoalveolar distraction were methods that can temporarily, but reliably increase the orthodontic 
tooth movement with minimal risks of periodontal damage, root resorption, and pulp devitalization. However, the authors noted that the level of evidence to support this claim is limited due to the moderate to high level of bias of evidence currently available.

Another systematic review by Gkantidis and his associates reviewed eighteen articles that evaluated the efficacy of five surgical and non-surgical interventions, namely corticotomy, interseptal bone reduction, photobiomodulation, LLLT, and PEMF. ${ }^{54}$ The authors concluded that corticotomy was the only procedure that reliably increased the rate of orthodontic tooth movement without any significant adverse effect. They found no evidence to support the efficacy of interseptal bone reduction, photobiomodulation, and PEMF. On the other hand, several studies included in this review indicated some evidence of effectiveness of LLLT. However, a careful interpretation of the data concerning LLLT was recommended since the effectiveness of the procedure was indicated only in the studies with a moderate risk of bias, whereas the studies with a low risk of bias failed to show the effectiveness. Along with the aforementioned reviews, other systematic reviews and comparison studies have also concluded that corticotomy is a reliable and safe method of elevating the rate of orthodontic tooth movement, whereas other procedures lack evidence to support the efficacy. ${ }^{4,19,20,55}$

\section{Micro-Osteoperforation}

Inspired by findings of the RAP in orthodontic tooth movement, MicroOsteoperformation (MOP) is a technique recently incorporated in orthodontics to accelerate the rate of orthodontic tooth movement. MOPs are done by creating shallow perforations using a mini-implant-like device or a small round bur and a hand-piece through the gingiva into the 
buccal cortical plate of a target tooth. ${ }^{55}$ The idea is to induce regional inflammatory response via intentional bone injuries to increase the bone remodeling activities, thus accelerating the rate of orthodontic tooth movement. The perforation process is similar to that of corticotomy, which is one of few procedures that are shown to be effective in accelerating the rate of orthodontic tooth movement. However, corticotomy involves an extensive gingival flap procedure, which may increase the healing time and patient discomfort level and negatively impact the patient acceptance rate. On the other hand, MOPs do not require laying a gingival flap. Instead, the small perforations are completed directly through the soft tissue.

The animal study conducted by Teixeira and her associates reported a significantly higher rate of orthodontic tooth movement in rats with orthodontic force and MOPs $(0.62 \mathrm{~mm})$, compared to the rats with orthodontic force only $(0.29 \mathrm{~mm})$. Also, histochemical studies indicated that on the MOP side, the authors observed a 1.6- to 2.8-fold increase in the level of cytokines and chemokines as well as a 3-fold increase in the number of osteoclasts in the experimental side. ${ }^{55}$ The results indicate that in rats, the injury caused by MOPs illicit a regional inflammatory response, leading to an accelerated rate of orthodontic tooth movement through the RAP. Similarly, another animal study by Tsai et al. investigated the effect of MOPs and corticision on the rate of tooth movement in rats. ${ }^{56}$ They concluded that compared to the control samples that received orthodontic force only, both experimental samples (MOPs and corticision) experienced an increased rate of tooth movement and the difference between the two experimental groups was insignificant. Histologic studies indicated that the bone density was significantly lower around the tooth with the MOPs. In addition, the number of osteoclasts present around the target tooth was significantly higher in both experimental samples. The authors concluded that these minimally invasive procedures resulted in an induction of a 
localized inflammatory process and an increase in the rate of orthodontic tooth movement in rats.

Lastly, Alikhani et al. investigated the effect of MOPs on the rate of canine retraction in human subjects. ${ }^{7}$ All of the subjects underwent maxillary first premolar extraction and canine retraction, and the subjects in the experimental group received MOPs with a mini-implant-like device. The results indicated an increased rate of tooth retraction by 2.3 -fold in the subjects who received MOPs, compared to the control samples. Moreover, the gingival crevicular fluid study indicated a significantly increased level of cytokine expression in the experimental samples. The authors explained that MOPs were capable of inducing a localized inflammatory response, thus recruiting and stimulating the surrounding bone remodeling cells to increase the rate of bone resorption and deposition to aid in the accelerated tooth movement.

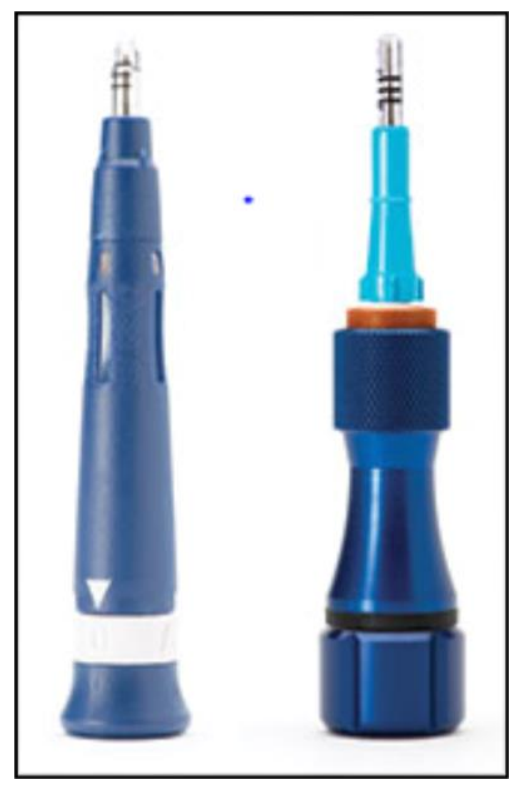

Figure 2. Different designs of the devices specifically designed for Micro-osteoperforation by PROPEL Orthodontics (Ossining, NY $)^{75}$ 


\section{Clear Aligner Therapy}

\section{Overview}

Clear aligner therapy (CAT) is an aesthetic treatment alternative to conventional orthodontic treatment with fixed appliances. The treatment is rendered through a series of clear removable vacuum-formed polyurethane aligners to accomplish minor tooth movement as each aligner moves the teeth by fixed distances. ${ }^{56}$ First introduced by Kesling in 1945 as a flexible tooth-positioning device, CAT is not a new concept. Traditionally, the aligners were fabricated by manually altering the tooth position in small increments on a stone model, thus limiting the scope of CAT to only minor tooth movement, such as mild rotations and mal-alignment of anterior teeth up to $2 \mathrm{~mm} .{ }^{57}$ If more dental movement was desired, additional stone models with the altered tooth position had to be manually fabricated.

Recent development of Invisalign ${ }^{\circledR}$ (Align Technology, Santa Clara, CA) incorporated the $\mathrm{CAD} / \mathrm{CAM}$ technology into CAT, which dramatically changed the ability of the clear aligners to treat more complex malocclusion. Instead of fabricating each dental cast by hand, the practitioners can simply submit polyvinyl siloxane impressions or 3-dimensional digital intraoral scans, which are used to virtually design a desired treatment outcome. ${ }^{57}$ Computer program then develops a sequence of tooth movements that will be achieved by each aligner to reach the desired outcome. Thus, each stage of the treatment can be visualized and modified before ever starting the treatment. ${ }^{56}$ Moreover, the traditional method of producing the physical models is replaced by stereolithography, a method to print a solid three-dimensional object, in this case a dental model, from liquid plastic. This method allows a mass production of dental casts so that the sequential models and corresponding clear aligners can be easily manufactured. ${ }^{57}$ The incorporation of $\mathrm{CAD} / \mathrm{CAM}$ technology allows the $\mathrm{CAT}$ to be a viable, aesthetic treatment 
option for more complex malocclusion.

\section{Factors Affecting the Tooth Movement with Clear Aligner Treatment}

Orthodontic tooth movement with CAT depends on several external and internal factors, including the physical properties of thermoplastic materials and the characteristics of attachments. Materials used in CAT differ according to manufacturers and stages of the treatment. ${ }^{58}$ Depending on the physical property of the polymers or the fabrication method of the aligners, the force level and the activation rate may differ significantly. ${ }^{59}$ According to Ercoli et al., an aligner system that uses poly-vinyl chloride (PVC) material with pronounced elastics characteristics when subjected to a moderate load may require less optimal wear time due to the characteristic force that the PVC material can apply to the tooth. On the other hand, an aligner system that uses polyethylene terephthalate glycol may be more resistant to time and wear and allow more gradual tooth movement. ${ }^{60}$ Another study by Simon and the colleagues investigated the forces and moments generated by Invisalign's proprietary aligner material. They observed the exponential force decay during the aligner wear. Their results indicated that the force systems varied throughout the aligner treatment despite a treatment plan with a constant tooth movement. Also, the authors recommended using attachments to maximize the moment transfer. ${ }^{59}$ Likewise, different materials exert different effects on tooth, which may translate into varying efficiency of orthodontic tooth movement.

Another factor that can affect the efficiency of tooth movement is the activation time, or aligner-wear time. An in-vivo study by Clements et al. evaluated the effect of varying activation time on the quality of the outcome determined by peer assessment rating and incisor irregularity index. ${ }^{56}$ Among the four protocols with differing types of material and aligner wear time (1-week 
activation with soft material, 1-week activation with hard material, 2-week activation with soft material, and 2-week activation with hard material), the authors did not find any statistically significant difference among the 4 protocols in the rate of space closure or anterior alignment. However, they noted a general trend with a 2-week activation having a higher rate of extraction space closure and anterior alignment, compared to the 1-week activation. Similarly, Drake and his colleagues investigated the effect of a duplicate aligner for the second week of aligner wear, compared to the conventional protocol of 2-week aligner wear on the total amount of orthodontic tooth movement. ${ }^{61}$ The results showed no statistically significant difference between the two protocols, indicating that the material fatigue was not a major determinant of the amount of orthodontic tooth movement.

In addition to the treatment-related factors, Chisari et al. evaluated patient-related factors that may affect orthodontic tooth movement, such as age, sex, root length, bone levels, and bone quality. The results indicated a negative correlation between age and tooth movement as well as a significant negative correlation between locations of center of resistance, determined by root length and bone levels, and tooth movement. However, bone quality had little effect on orthodontic tooth movement. Sex of the patients, the authors reported, may have a complex contribution to orthodontic tooth movement. ${ }^{27}$ Furthermore, tooth movement via clear aligner treatment is considerably affected by patient compliance. Therefore, controlling orthodontic tooth movement with clear aligners is a complex process, and the amount and rate of tooth movement is rather unpredictable.

\section{Accuracy of Orthodontic Tooth Movement with Clear Aligner Treatment}

Studies have shown that the efficiency of orthodontic tooth movement with CAT is 
affected by patient-related factors as well as treatment-related factors. ${ }^{26-28}$ A recent systematic review evaluated current available literatures on the efficacy of clear aligners in controlling orthodontic tooth movement. Their search concluded that the efficacy of the treatment with clear aligners is comparable to that of the fixed appliances with straight-wire technique in general. However, the selected articles indicated certain differences in the efficacy of CAT compared to the straight-wire technique (SWT). Compared to SWT, CAT was more effective in leveling and aligning, anterior intrusion, controlling posterior buccolingual inclination, and upper molar distalization up to $1.5 \mathrm{~mm}$. On the other hand, this treatment modality was less effective in anterior extrusion, controlling anterior buccolingual inclination, and rotation of rounded teeth. ${ }^{62}$ Therefore, due to these deficiencies in the ability to control certain orthodontic tooth movement, CAT becomes less predictable than fixed appliance treatment with SWT.

The predictability of clear aligner treatment was tested using several different methods. Buschang et al. utilized the standardized grading system to objectively evaluate the quality of the actual outcome and compare to that of the prediction. ${ }^{26}$ ClinCheck feature of Invisalign system, which allows the practitioners to visualize the predicted outcome, was used as the predicted outcome of each case. The authors graded the outcomes of selected CAT cases using the American Board of Orthodontics (ABO) Objective Grading System (OGS), and compared the scores of the predicted outcomes to those of the actual outcomes. The results showed that the OGS scores of the predicted outcomes were lower than those of the actual outcomes, indicating that the quality of the ClinCheck prediction was more acceptable than that of the actual outcome. The authors supported the idea that the ClinCheck prediction was not entirely an accurate representation of the actual outcome observed clinically. Their conclusion agreed with the aforementioned systematic review in that the discrepancy between the OGS scores of the actual 
outcomes and those of the predicted was mainly due to deficiencies in the ability of CAT to control alignment, buccolingual inclinations, occlusal contacts, and occlusal relations.

Another method of evaluating the accuracy of orthodontic tooth movement with clear aligners is to compare the amount of tooth movement that actually occurred to the anticipated amount of tooth movement. Kravitz and his colleagues used Invisalign's proprietary software, ToothMeasure to answer the question, "How well does Invisalign work?". The authors evaluated the efficiency of seven different types of tooth movements of over 400 anterior teeth by superimposing the intraoral scans of the achieved outcome to the predicted outcome. The results indicated the mean accuracy of tooth movement was $41 \%$, the most accurate movement being lingual constriction of maxillary incisors (47.1\%) and the least being extrusion of maxillary incisors $(18.3 \%)$. They also observed a significant loss of control of maxillary canine rotation greater than fifteen degrees. ${ }^{28}$ These results are in general agreement with other studies that reported the lack of control of orthodontic tooth movement with clear aligners.

In 2011, Krieger and her colleagues utilized the same software to determine the accuracy of Invisalign treatments in the anterior region. They compared the prediction models to the final models by measuring the changes in overjet, overbite, and dental midline shift in upper and lower arches. The results revealed deviations in all parameters: overjet $0.4 \mathrm{~mm}(\mathrm{SD} \pm 0.7)$, overbite $0.9 \mathrm{~mm}(\mathrm{SD} \pm 0.9)$, and dental midline shift $0.4 \mathrm{~mm}(\mathrm{SD} \pm 0.5) .{ }^{63}$ Similarly, the same authors evaluated the efficiency of CAT in further details. Using ToothMeasure, the accuracy of Invisalign treatments was evaluated in terms of the change in anterior crowding, anterior arch length, intercanine distance, overjet, overbite, dental midline deviation, and Little's irregularity index. The authors found that the clear aligner treatment was effective in resolving anterior crowding by increasing the arch length and intercanine distance. The results were comparable to 
their previous study where they observed slight discrepancies between the ClinCheck prediction and the actual outcome in all parameters. Although the change in overbite was the least effective $(-0.7 \mathrm{~mm} \pm 0.87)$, the authors concluded that the discrepancies were clinically insignificant. ${ }^{64}$ The reported deviations between the predicted outcome and the actual outcome may necessitate the practitioners to incorporate overcorrection in their treatment plan to achieve the desired amount of tooth movement.

\section{Methods of Analyzing Orthodontic Tooth Movement}

As intraoral-scanning and mesh-analyzing technology advances, many studies have been done to analyze orthodontic tooth movement occurring during CAT. Some studies used a certain company's proprietary software to superimpose the intraoral scans and measure the

discrepancies. ${ }^{28,63,64}$ Others used commercially available CAD software to reach a similar goal. ${ }^{65-}$

${ }^{68}$ With any type of software, the steps involve superimposing the scanned models and measuring the tooth movement in terms of translation and rotation in three planes (mesiodistal, buccolingual, and occlusogingival).

\section{Superimposition of Intraoral Scans}

3D models of the dentition can be obtained via either directly scanning the teeth using any commercially available intraoral scanner or laser scanning the stone models of teeth obtained from an alginate or polyvinyl siloxane (PVS) impression. These intraoral scans can be uploaded on any CAD software with an alignment function. In order to compare orthodontic tooth movement between two 3D models, the scans have to be superimposed using stable structures as 
references. According to Jang et al., anatomic structures, such as palatal rugae, that are known to be stable throughout orthodontic treatment can be used as a reliable registration point. ${ }^{69}$ Mandibular superimposition may involve superimposing on chin, which is a stable skeletal structure. ${ }^{67}$ Implants can also be placed in areas that are not affected by tooth movement to be used as stable references for superimposition. ${ }^{70}$ Others have utilized teeth that underwent no orthodontic movement. ${ }^{65,66}$ Whatever the structure is used, superimposition can be valid as long as the structures are stable between the two time points that the intraoral scans are obtained.

Once the stable registration points are identified, most CAD programs use iterative closest point (ICP) algorithm, where the distances between one point to its closest point on the two registered scans are calculated, using the least-squares method as shown in Equation 1. ${ }^{68}$ Based on the unchanged structures found in both scans, software computes the optimal transformation to align one set of data points to the other set of data points by calculating the smallest possible differences of the two data sets. ${ }^{67}$ As a result, the transformation matrix is obtained where the two scans can be best aligned.

$$
f(M)=\frac{1}{N} \sum_{i}\left\|x_{i}-M p_{i}\right\|^{2}
$$

Equation 1. Cost function as the mean of the least-square distances from the vertices of one data set to the other (M is a rigid transformation matrix, $N$ is the number of points, $x_{i}$ is the vertex of the first data set, and $p_{i}$ is the vertex of the second data set)

\section{Measurement of Tooth Displacement}

In order to measure the amount of tooth displacement through superimposing the pretreatment and post-treatment scans, numerous methods can be used to measure the 3-dimensional 
changes. Many studies utilize the 3-plane coordinate system to calculate the displacement in translation and rotation in $\mathrm{x}-, \mathrm{y}-$, and z-axes. ${ }^{65-68}$ Once two scans are aligned and oriented in a common coordinate system, each axis is defined to represent mesiobuccal, faciolingual, and occlusogingival planes. Depending on the goal of the study, some studies record the coordinates of the same anatomic structures, e.g. cusp tips, of the scans to calculate the linear displacement in three diretions. ${ }^{65,66}$ This method does not include any rotational changes.

On the other hand, the ICP algorithm that was used to initially align the two scans can be used again to calculate the direction and the extent of tooth movement. After the scans are oriented in a common coordinate system, the tooth in question can be superimposed in three dimensions to the corresponding tooth in the other model, using the same method with a different transformation matrix that is unique to each tooth. This transformation matrix represents the movement by a translation vector and a rotation matrix. ${ }^{67,68}$ This method will provide a linear displacement as well as a rotational displacement.

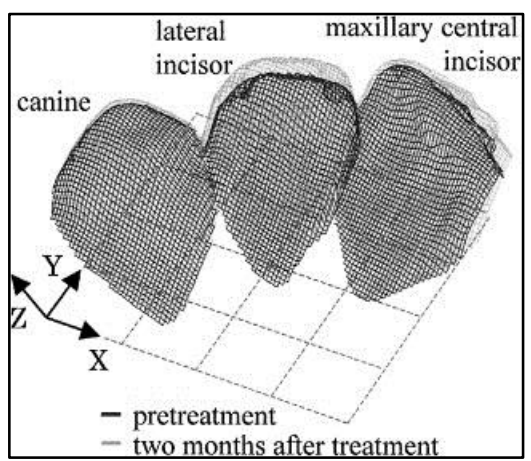

Figure 3. Normalized 3-D view of the anterior teeth before and after treatment. Black: before treatment; gray: 2 months after treatment. $^{68}$ 


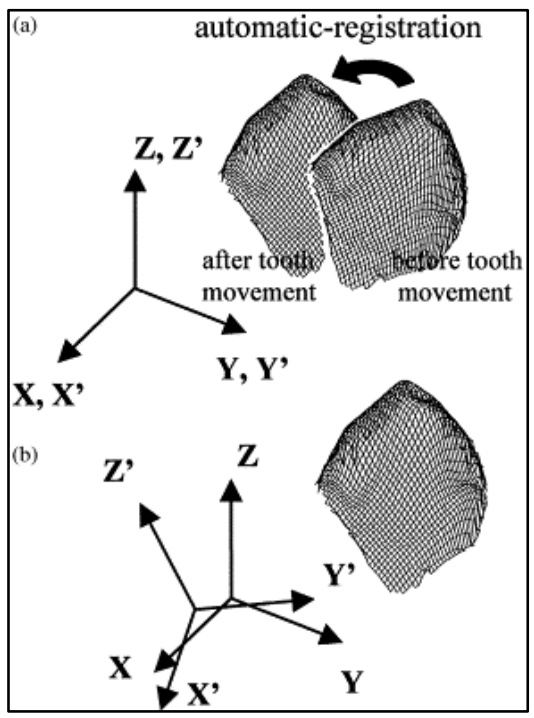

Figure 4. Coordinate system for analyzing tooth movement by automatic registration. (a) Before registration, (b) after registration. The coordinate systems $\left(x^{\prime}, y^{\prime}, z^{\prime}\right)$ and $(x, y, z)$ correspond to before and after tooth movement, respectively. ${ }^{68}$

\section{CloudCompare Software}

CloudCompare (http://www.danielgm.net/cc/) is open source 3-dimensional point cloud and mesh processing software. Designed mainly to compare between two point clouds or meshes, the software can carry out advanced algorithms, including registration, resampling, statistics computation, sensor management, and segmentation. ${ }^{71}$ With these functions, CloudCompare can be applied to tasks that require high sensitivity and specificity in comparing two 3-dimensional objects. Manuel and his colleagues utilized CloudCompare to validate their comparison study of the steady state geometry of the finite element model of the nasal tip deformation. The comparison of the models was made by evaluating the distance between the subset of points. Their results indicated that there was a good agreement with the two undeformed models as well as a good overlap between the point cloud from 3D reconstruction and the finite element model from computed tomography image. Using CloudCompare, the authors 
could validate the finite element models with a clinical significance. ${ }^{72}$

Likewise, another study employed CloudCompare in identifying the unique anatomical features of frontal sinus. Beani and his colleagues obtained 3D configurations of frontal sinus of twenty subjects. Using CloudCompare, the authors calculated the difference between the two meshes and performed a qualitative comparison of the two. The results indicated that the accuracy of the comparison was up to $100 \%$, and the study concluded that the $3 \mathrm{D}$ anatomy of frontal sinus can be used to identify different individuals. ${ }^{73}$ Therefore, CloudCompare is used in a variety of researches that require a meticulous comparison of $3 \mathrm{D}$ point clouds and meshes. The software can perform advanced algorithms to derive a conclusion with reasonable reliability. 


\section{CHAPTER 3: EXPERIMENTAL DESIGN AND METHODS}

\section{Institutional Review Board Approval}

In an effort to protect the participants' human right, the protocol was reviewed and approved by West Virginia University Institutional Review Board for human research protection (Protocol \#1606156142). (See Appendix A)

\section{Sample Collection}

For this retrospective study, permission to use the patient records was obtained from one of the co-investigators, Thomas Shipley (Peoria, AZ), who provided the necessary patient data. (See Appendix B) The records of all patients who completed treatment with clear aligners between January 1, 2013 and July 1, 2016 were reviewed. Cases that did not have pre-treatment or post-treatment (or pre-refinement) scans were not included in the study. Among 426 clear aligner cases reviewed, a total of 105 cases met the following inclusion criteria and were included in the study.

\section{Inclusion Criteria}

1) Complete permanent dentition excluding third molars

2) Age between 13 and 80

3) Non-smoker

4) No gender or race predilection 
5) ClinCheck treatment plan included a minimum of 10 aligners

6) Complete pre-treatment and post-treatment (or pre-refinement) records, including intraoral scans

7) No fixed appliances or auxiliary devices were used

8) Non-extraction treatment

9) Planned treatment involved minimal molar movement

10) All of the prescribed aligners were completed without refinement or alterations of the treatment plan

For the experimental group, a total of 46 consecutively treated clear aligner cases with MOPs were selected. These patients switched the aligners every 3 days after receiving MOPs in the anterior region for both arches. For the control group, a total of 59 consecutively treated clear aligner cases without MOPs were selected. These patients did not undergo MOPs and switched the aligners every 14 days. Each subject was given a random identification number, and all protected healthy information identifiers were removed for de-identification purposes.

Using OrthoCAD (http://www.mycadent.com), the pre-treatment as well as the posttreatment intraoral scans of the maxillary and mandibular arches of each patient were obtained in STL file format (Figure 5). The prediction models were also obtained in STL file format via ClinCheck Pro v.5.0 (http://www.invisalign.com/us/support/pages/clincheckpro.aspx) (Figure 6). For the study, tooth displacement of only the permanent maxillary and mandibular incisors and canines were considered. 


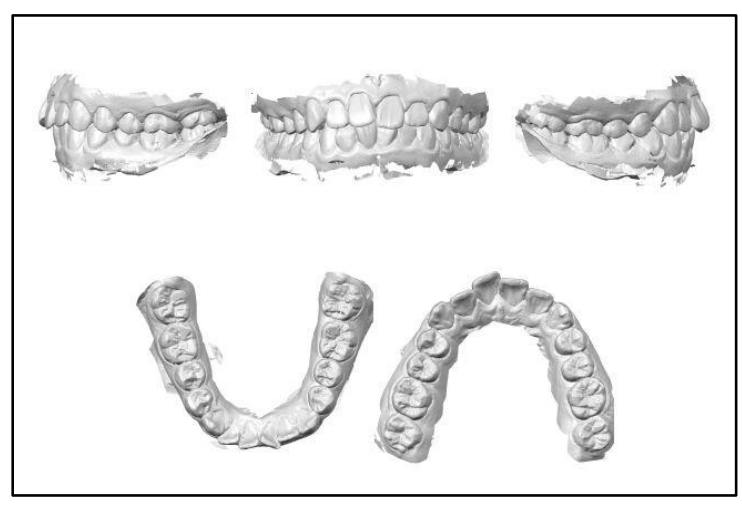

Figure 5. An example of a composite of intraoral scans obtained from OrthoCAD

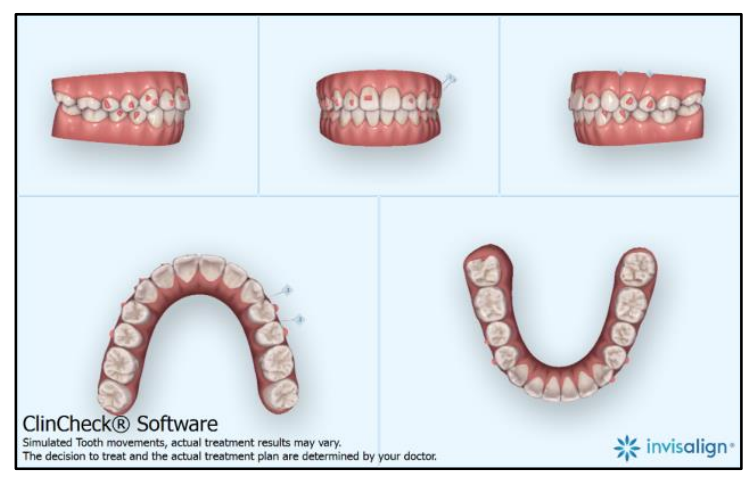

Figure 6. An example of a composite of prediction models obtained from ClinCheck Pro

\section{Superimposition of Scans and Establishing Coordinate System}

For each case, a pre-treatment scan and a post-treatment scan of the same arch were uploaded on the CloudCompare software. Using "Align/Point Pairs Picking" function of the software, 3 or more easily identifiable anatomical landmarks on unmoved posterior teeth, such as cusp tips and fossae of the molars, were selected on the post-treatment scan (i.e. "Reference"). The corresponding landmarks were also selected on the pre-treatment scan (i.e. "Align") in the same order (Figure 7). 


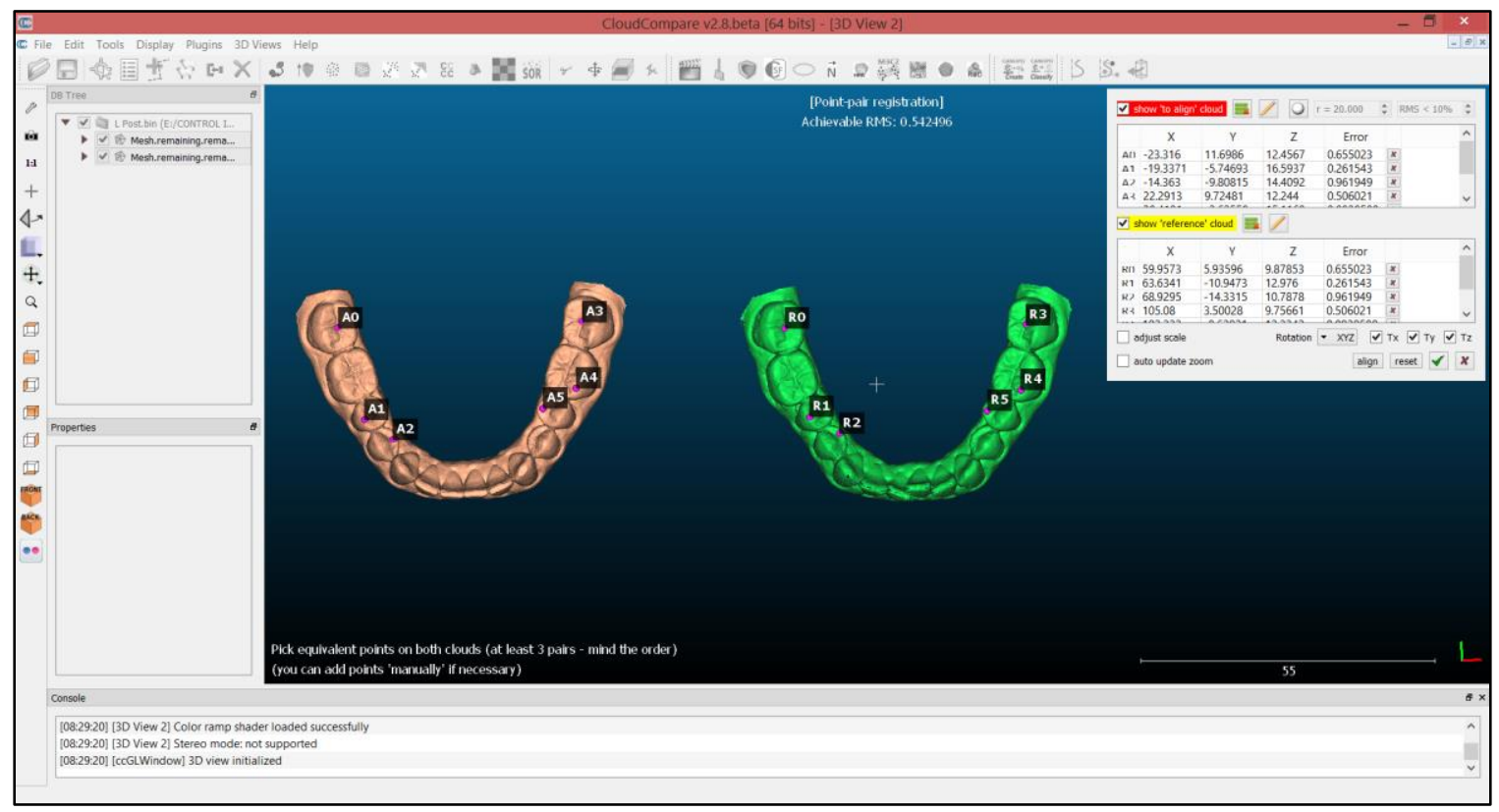

Figure 7. Initial alignment and registration of pre-treatment and post-treatment scans using "Align/Point Pairs Picking" function on CloudCompare

With the Root Mean Square (RMS) <10\%, the pre-treatment scan was superimposed onto the post-treatment scan. The alignment was visually inspected to verify the correct positioning of the scans (Figure 8). The aligned scans were saved as a CloudCompare project.

Next, the same pre-treatment scan was uploaded; this time, it was aligned to the ClinCheck prediction model using the same method. This process was repeated for both upper and lower arches. For each sample, maxillary and mandibular pre-treatment, post-treatment, and prediction scans were aligned and saved separately as CloudCompare projects. 


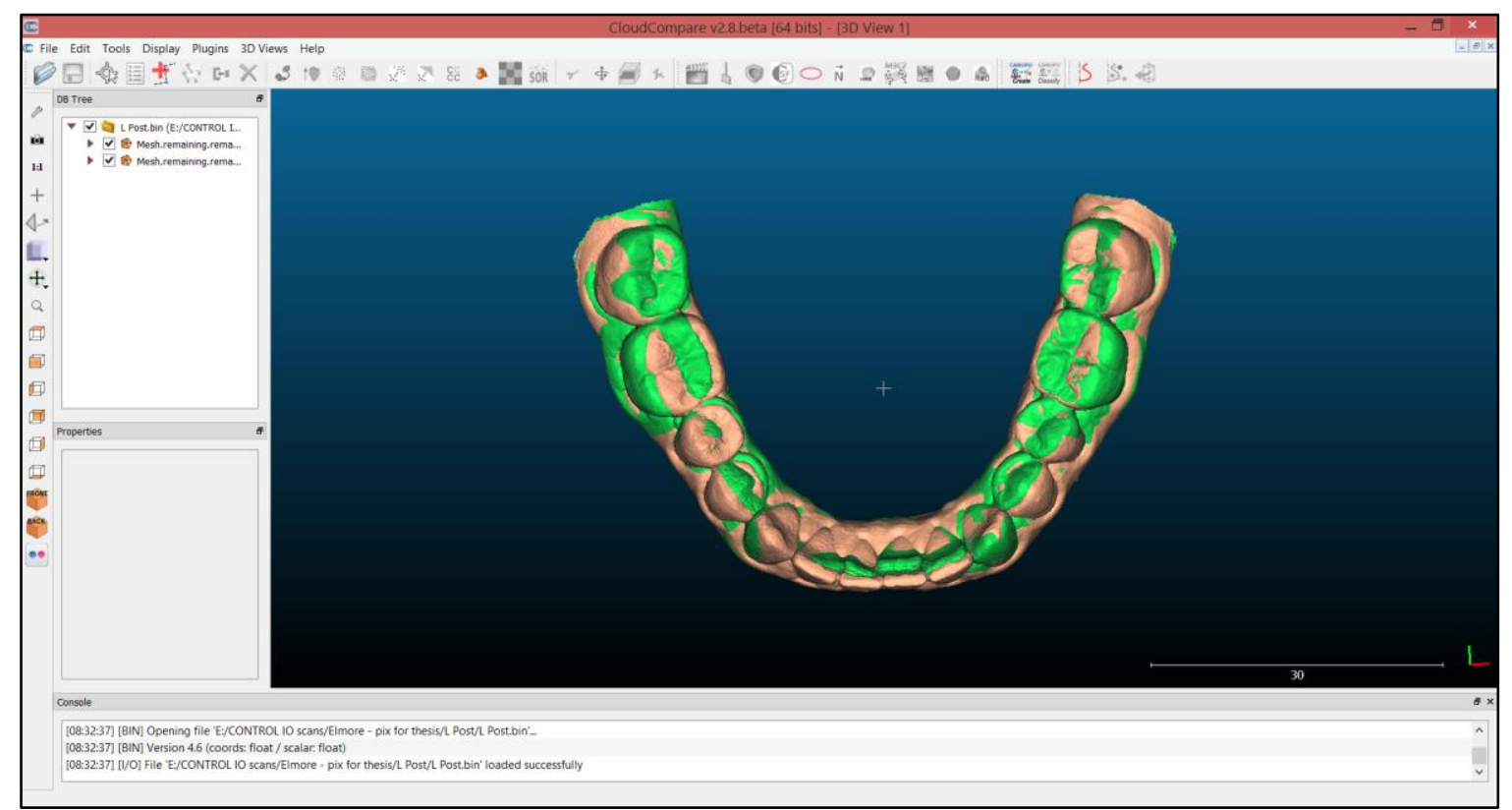

Figure 8. Visual verification of the initial alignment of pre-treatment and post-treatment scans

\section{Analysis of Tooth Displacement}

For the study, the amount of displacement of only the incisors and canines of each arch were considered. The previously saved project of the aligned arches was uploaded onto CloudCompare (Figure 9).

Using the "Align/Point-Pairs Picking" function with RMS $<10 \%$, the pre-treatment scan was selected as the "Align" point cloud, and either the post-treatment scan or the prediction model was selected as the "Reference" point cloud (Figure 10). The scans were re-aligned at one of the anterior teeth by selecting three or more easily recognizable anatomical structures on a particular tooth. 


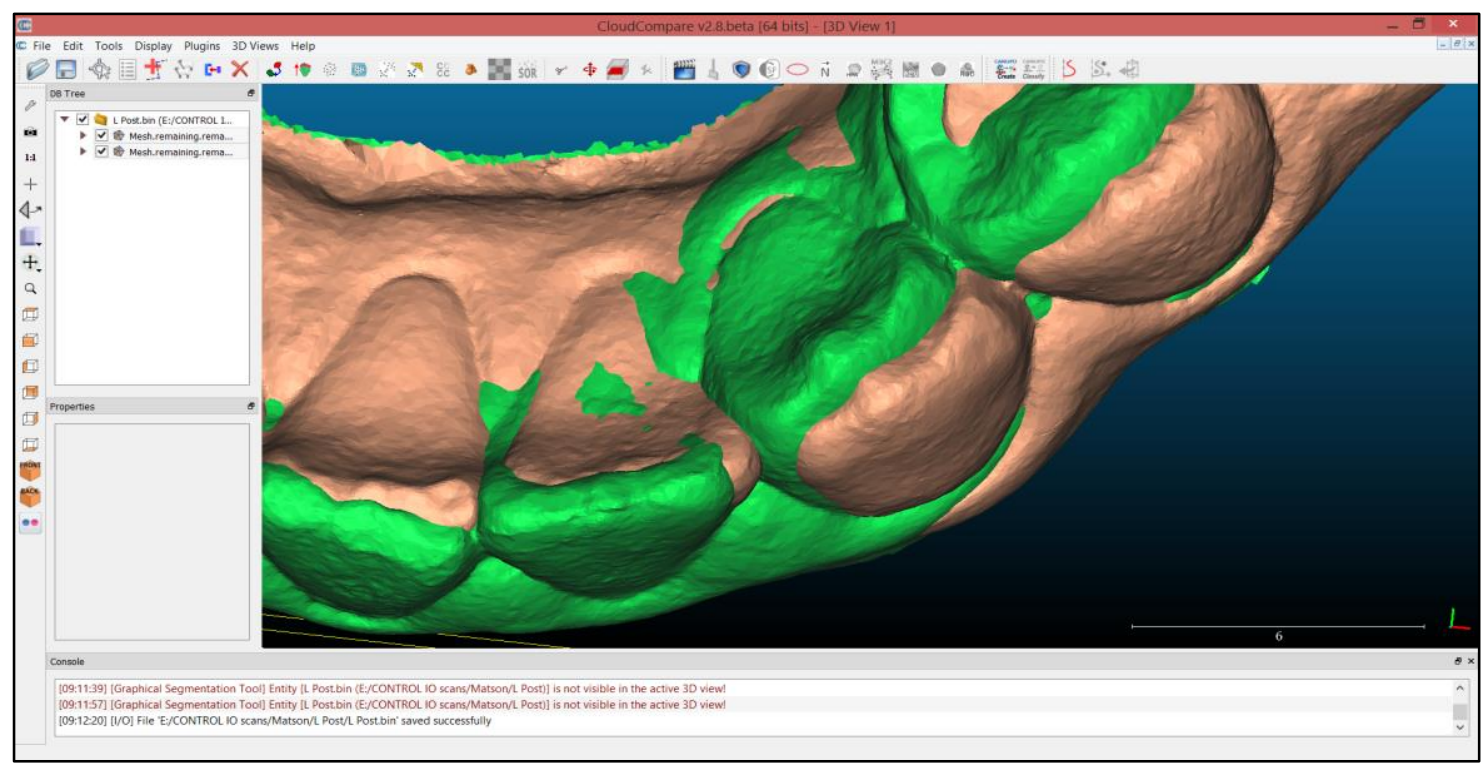

Figure 9. Aligned scans were uploaded on CloudCompare to analyze the displacement of each tooth

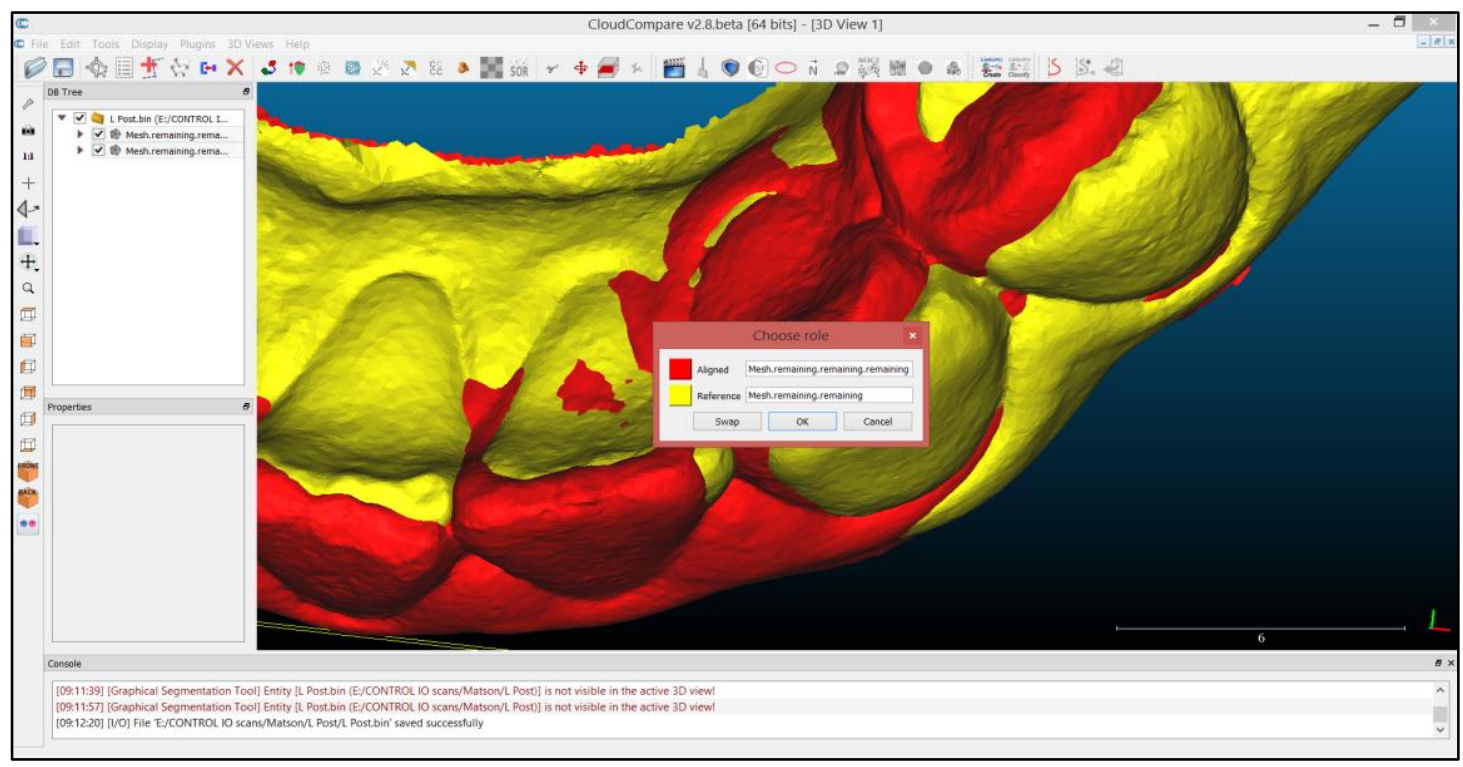

Figure 10. Tooth-to-tooth alignment using the "Align/Point Pair Picking" function 
Unlike the initial alignment of the arches, the information of the direction and the magnitude of the transformation was important for the tooth-to-tooth alignment. Thus, after the alignment at the particular tooth was visually verified, the resultant transformation matrix was saved in a text format (Figure 11). The same process was repeated for all incisors and canines of both arches for all of the pre-treatment/post-treatment and pre-treatment/prediction projects.

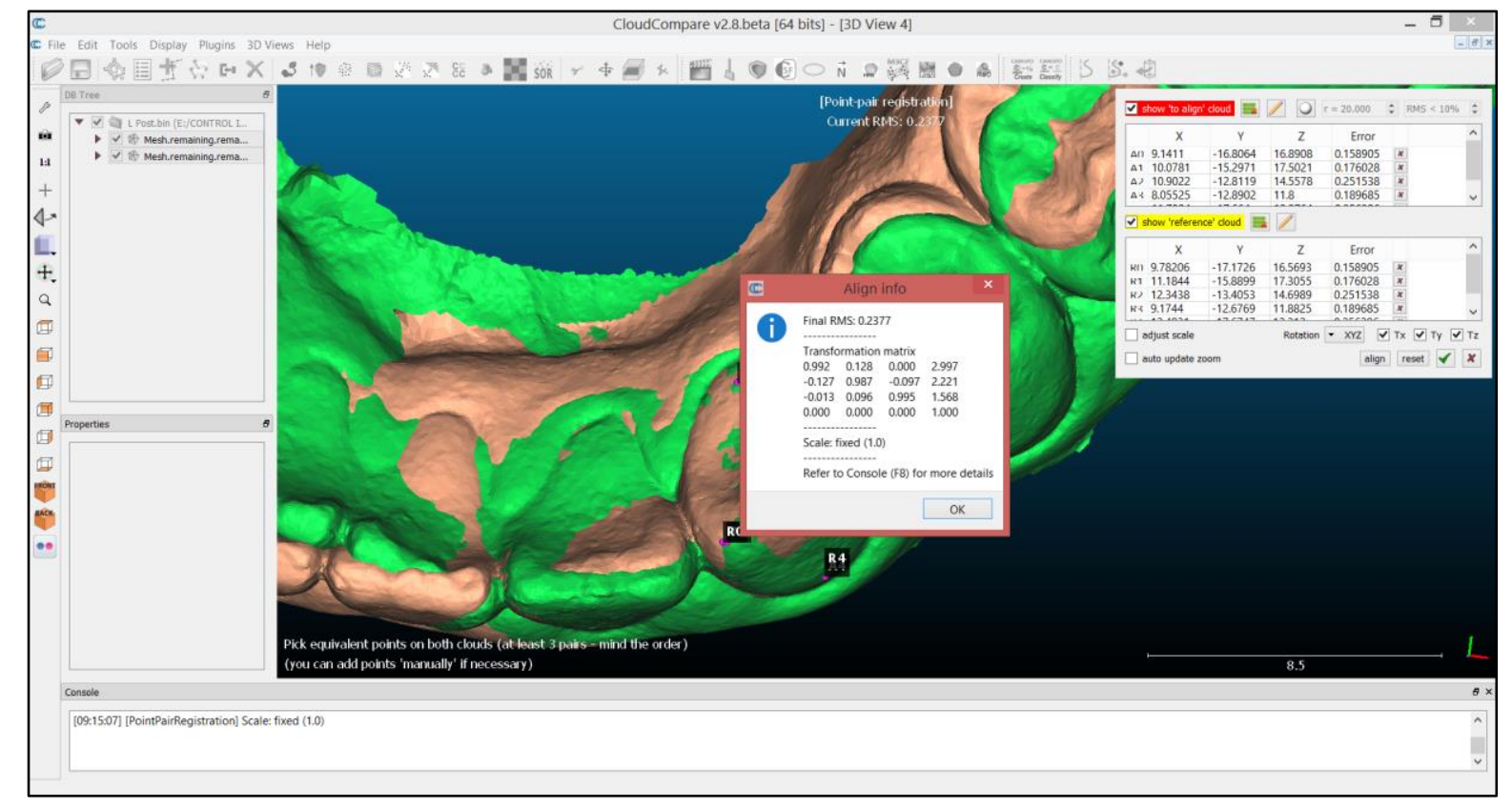

Figure 11. Visual verification of the alignment of the tooth and the resultant transformation matrix 


\section{Calculation of Tooth Displacement}

Each transformation matrix (Figure 12) was applied to a formula on Microsoft Excel spreadsheet to calculate the angular changes about the $\mathrm{x}-, \mathrm{y}-$, and $\mathrm{z}$-axes as well as the linear changes in $\mathrm{x}-, \mathrm{y}-$, and z-planes.

\begin{tabular}{|llll|}
\hline \multicolumn{3}{l}{ Final RMS: 0.2377} \\
\hline \multicolumn{3}{l}{ Transformation matrix } \\
0.992 & 0.128 & 0.000 & 2.997 \\
-0.127 & 0.987 & -0.097 & 2.221 \\
-0.013 & 0.096 & 0.995 & 1.568 \\
0.000 & 0.000 & 0.000 & 1.000 \\
---------- & & \\
Scale: fixed (1.0) \\
\hline
\end{tabular}

Figure 12. An example of a transformation matrix

From the transformation matrix, the magnitude of the linear and angular displacement of each tooth could be calculated using the components of the matrix. The transformation matrix is expressed as $4 \times 4$ matrix as:

Transformation Matrix

$$
=\left[\begin{array}{cccc}
\cos \beta \cos \gamma & -\cos \beta \sin \gamma & \sin \beta & d x \\
\cos \alpha \sin \gamma+\cos \gamma \sin \alpha \sin \beta & \cos \alpha \cos \gamma-\sin \alpha \sin \beta \sin \gamma & -\cos \beta \sin \alpha & d y \\
\sin \alpha \sin \gamma-\cos \alpha \cos \gamma \sin \beta & \cos \gamma \sin \alpha+\cos \alpha \sin \beta \sin \gamma & \cos \alpha \cos \beta & d z \\
0 & 0 & 0 & 1
\end{array}\right]
$$

or

$$
\text { Transformation Matrix }=\left[\begin{array}{cccc}
R_{11} & R_{12} & R_{13} & d x \\
R_{21} & R_{22} & R_{23} & d y \\
R_{31} & R_{32} & R_{33} & d z \\
0 & 0 & 0 & 1
\end{array}\right]
$$

where, $\alpha=\tan ^{-1}\left(-\frac{R_{23}}{R_{33}}\right) ; \quad \beta=\tan ^{-1}\left(\frac{R_{13}}{\sqrt{R_{23}^{2}+R_{33}^{2}}}\right) ; \quad \gamma=\tan ^{-1}\left(-\frac{R_{12}}{R_{11}}\right)$. 
From the transformation matrix, the rotation matrices about $\mathrm{x}-, \mathrm{y}-$, and $\mathrm{z}$-axes are calculated, respectively:

$$
\begin{aligned}
\operatorname{Rot}_{x} & =\left[\begin{array}{ccc}
1 & 0 & 0 \\
0 & \cos \alpha & -\sin \alpha \\
0 & \sin \alpha & \cos \alpha
\end{array}\right] \\
\operatorname{Rot}_{y} & =\left[\begin{array}{ccc}
\cos \beta & 0 & \sin \beta \\
0 & 1 & 0 \\
-\sin \beta & 0 & \cos \beta
\end{array}\right] \\
\operatorname{Rot}_{z} & =\left[\begin{array}{ccc}
\cos \gamma & -\sin \gamma & 0 \\
\sin \gamma & \cos \gamma & 0 \\
0 & 0 & 1
\end{array}\right]
\end{aligned}
$$

The translational vector $t$ is:

$$
\{t\}=\left\{\begin{array}{l}
d x \\
d y \\
d z
\end{array}\right\}
$$

Thus, the linear distance and the angular changes of each tooth in 3 planes were derived from the transformation matrices and recorded for every project. By the nature of the CloudCompare software, any linear change along the $\mathrm{x}$-axis represents mesiodistal direction, $\mathrm{y}$ axis represents faciolingual direction, and z-axis represents occlusogingival direction of the tooth movement. Also, any rotation about the x-axis represents faciolingual tipping, any rotation about the $y$-axis represents mesiodital tipping, and any rotation about the z-axis represents rotation about the long axis of the tooth.

For the discrepancy in linear displacement, the difference in the magnitude of the vectors was calculated using the formula, where $\mathrm{x}_{1}, \mathrm{y}_{1}$, and $\mathrm{z}_{1}$ denote the linear magnitude of an actual tooth displacement vector in 3 different planes, and $\mathrm{x}_{2}, \mathrm{y}_{2}$, and $\mathrm{z}_{2}$ denote the linear magnitude of a predicted tooth displacement vector in 3 different planes:

$$
\text { Linear discrepancy }(\Delta \mathrm{V})=\sqrt{\left(\left(x_{1}-x_{2}\right)^{2}+\left(y_{1}-y_{2}\right)^{2}+\left(z_{1}-z_{2}\right)^{2}\right.}
$$


For the discrepancy in angular displacement, the relative error of the angular change in each direction was calculated using the formula:

$$
\text { Relative Error for Angular Change }\left(\Delta \mathrm{x}^{\circ}, \Delta \mathrm{y}^{\circ}, \Delta \mathrm{z}^{\circ}\right)=\left|1-\left(\frac{\text { Actual Value }}{\text { Predicted Value }}\right)\right|
$$

The resultant relative errors have no unit. All of the values would approach zero as the actual tooth displacement approximated closer to the predicted amount of tooth displacement.

\section{Statistical Analysis}

Tooth movements for each tooth in all three directions were analyzed using analysis of variance, Student's t-test, Wilcoxon/Kruskal-Wallis rank sums test, and contingency analysis. Significance of results was determined as p-value $<0.05$ (95\% Confidence Interval). The intraoperator correlation test was performed to evaluate the intra-operator error. 


\section{CHAPTER 4: RESULTS}

\section{Reliability of Measurements}

Intra-rater reliability test was performed to evaluate the operator's reliability with initial alignment of the scans, superimposition of the anterior teeth, and measurement of the tooth displacement. Twenty measurements were repeated seven days apart. The intra-rater reliability of the investigator was $98.8 \%$.

\section{Analysis of Tooth Displacement}

\section{Effect of MOP on Individual Tooth}

The linear and angular discrepancies of the individual tooth were compared between the control samples and the experimental samples using one-way analysis of variance (ANOVA) supplemented by Wilcoxon/Kruskal-Wallis Rank Sums test. The mean values of all data were presented in Table 1. The average values for $\Delta \mathrm{V}, \Delta \mathrm{x}^{\circ}, \Delta \mathrm{y}^{\circ}$, and $\Delta \mathrm{z}^{\circ}$ of individual tooth ranged from 1.9138 to 3.5393 , from 1.0386 to 2.5315 , from 0.8844 to 3.9326 , and from 0.5938 to 1.8373, respectively. However, the standard deviations for all parameters ranged from 0.4470 to 14.6098, indicating a broad range of discrepancy values. The broad range of the values can be visually confirmed when these mean values were plotted in bar graphs according to teeth and parameters $\left(\Delta \mathrm{V}, \Delta \mathrm{x}^{\circ}, \Delta \mathrm{y}^{\circ}\right.$, and $\left.\Delta \mathrm{z}^{\circ}\right)$.

The mean values showed a noticeable variability among teeth, parameters, or arches (Figures 13 and 14). The figures indicate no consistent pattern between the groups where no 
mean value of a certain parameter is consistently higher in one group than the other. For example, the control group's mean relative error of the rotation about the y-axis $\left(\Delta y^{\circ}\right)$ for upper right central incisors (3.9326 \pm 2.2639$)$ was greater than twice the experimental group's value (1.9114 \pm 2.8025$)$. On the other hand, for the same parameter, the mean relative errors for lower right canines (\#27) show an opposite pattern, where the experimental value (1.5885 \pm 2.5676$)$ is almost double the control value $(0.8844 \pm 2.2146)$. Likewise, the figures do not readily exhibit any tendency for other parameters of the rest of the anterior teeth.

Table 1. Mean values of the linear $(\Delta V)$ and angular discrepancies $\left(\Delta x^{\circ}, \Delta y^{\circ}, \Delta z^{\circ}\right)$ of all anterior teeth and the standard deviations for all parameters

\begin{tabular}{|c|c|c|c|c|c|c|c|c|c|}
\hline & \multicolumn{2}{|c|}{$\Delta \mathbf{V}$} & \multicolumn{2}{|c|}{$\Delta \mathbf{x}^{\circ}$} & \multicolumn{2}{|c|}{$\Delta \mathbf{y}^{\circ}$} & \multicolumn{2}{|c|}{$\Delta \mathbf{z}^{\circ}$} \\
\hline & & Mean & Std Dv & Mean & Std Dv & Mean & Std Dv & Mean & Std Dv \\
\hline \multirow{2}{*}{ \#6 } & Control & 2.7242 & 0.9866 & 1.6015 & 1.6681 & 1.2881 & 2.2489 & 0.8774 & 3.5278 \\
\hline & MOP & 3.5393 & 1.4669 & 1.0988 & 1.9814 & 1.5790 & 2.6037 & 0.9594 & 7.9788 \\
\hline \multirow{2}{*}{ \#7 } & Control & 2.7672 & 1.0244 & 1.9361 & 1.6694 & 2.0734 & 2.2613 & 0.9025 & 3.5645 \\
\hline & MOP & 3.2902 & 1.5055 & 1.4042 & 1.9906 & 1.4716 & 2.6446 & 0.8104 & 8.0522 \\
\hline \multirow{2}{*}{ \#8 } & Control & 2.7395 & 1.0966 & 1.4863 & 1.6705 & 3.9326 & 2.2639 & 0.5938 & 3.7776 \\
\hline & MOP & 3.4710 & 1.5105 & 2.5315 & 1.9931 & 1.9114 & 2.8025 & 0.7343 & 9.8747 \\
\hline \multirow{2}{*}{ \#9 } & Control & 2.6373 & 1.1554 & 2.3918 & 1.7157 & 1.2886 & 2.2783 & 0.8459 & 3.9076 \\
\hline & MOP & 3.3507 & 1.5155 & 2.1857 & 2.0453 & 1.4127 & 2.8044 & 1.4923 & 14.6098 \\
\hline \multirow{2}{*}{$\# 10$} & Control & 3.0536 & 0.4470 & 1.9469 & 1.5314 & 2.4048 & 2.0591 & 0.9430 & 2.8251 \\
\hline & MOP & 3.2301 & 1.1609 & 1.2121 & 1.7197 & 1.6645 & 2.2995 & 0.8124 & 4.4877 \\
\hline \multirow{2}{*}{$\# 11$} & Control & 2.6453 & 0.5761 & 1.7060 & 1.5373 & 1.0201 & 2.0762 & 1.1353 & 2.9449 \\
\hline & MOP & 2.8778 & 1.1962 & 2.3236 & 1.7677 & 1.3125 & 2.3816 & 1.3372 & 4.7342 \\
\hline
\end{tabular}




\begin{tabular}{|c|c|c|c|c|c|c|c|c|c|}
\hline \multirow{2}{*}{ \#22 } & Control & 3.0861 & 0.6026 & 1.2583 & 1.5487 & 2.8260 & 2.1010 & 1.7371 & 3.0960 \\
\hline & MOP & 2.7090 & 1.2279 & 1.4935 & 1.7918 & 1.2024 & 2.4453 & 0.7758 & 5.3465 \\
\hline \multirow{2}{*}{ \#23 } & Control & 2.2611 & 0.6718 & 1.0386 & 1.5759 & 1.0461 & 2.1107 & 0.9315 & 3.1101 \\
\hline & MOP & 2.2687 & 1.2439 & 1.2320 & 1.7984 & 0.9379 & 2.5035 & 1.0233 & 5.4802 \\
\hline \multirow{2}{*}{ \#24 } & Control & 2.3523 & 0.6999 & 1.4854 & 1.5944 & 1.0071 & 2.1187 & 0.7418 & 3.1664 \\
\hline & MOP & 1.9138 & 1.2867 & 1.0705 & 1.8280 & 1.5060 & 2.5053 & 0.7991 & 5.6427 \\
\hline \multirow{2}{*}{ \#25 } & Control & 2.0561 & 0.7600 & 1.8523 & 1.5970 & 1.2406 & 2.1297 & 0.6830 & 3.1909 \\
\hline & MOP & 2.3261 & 1.3779 & 1.3244 & 1.8581 & 1.8509 & 2.5256 & 1.1071 & 6.1317 \\
\hline \multirow{2}{*}{ \#26 } & Control & 2.3759 & 0.7970 & 1.1473 & 1.6209 & 1.0799 & 2.1898 & 0.9189 & 3.2412 \\
\hline & MOP & 2.0885 & 1.3889 & 1.6533 & 1.9313 & 1.4454 & 2.5607 & 1.1816 & 6.3562 \\
\hline \multirow{2}{*}{ \#27 } & Control & 3.0149 & 0.9632 & 1.9657 & 1.6465 & 0.8844 & 2.2146 & 1.8373 & 3.5182 \\
\hline & MOP & 2.5751 & 1.4369 & 1.3916 & 1.9386 & 1.5885 & 2.5676 & 0.7304 & 7.8771 \\
\hline
\end{tabular}

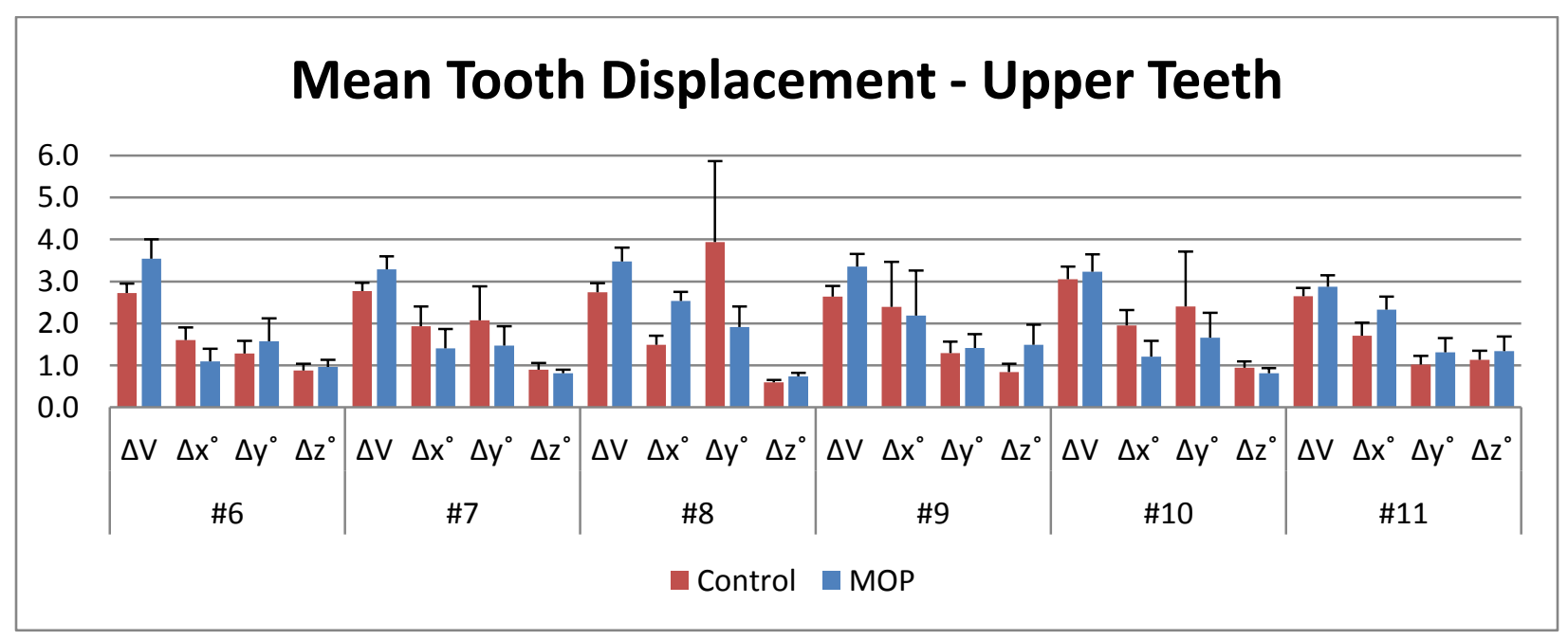

Figure 13. Mean linear discrepancy $(\Delta V)$ and relative errors for angular displacement $\left(\Delta x^{\circ}, \Delta y^{\circ}, \Delta z^{\circ}\right)$ for upper anterior teeth (\#6-\#11) for the experimental (MOP) and control samples with standard errors, where $\Delta \mathrm{V}$ is millimeter, and the angular parameters are dimensionless. 


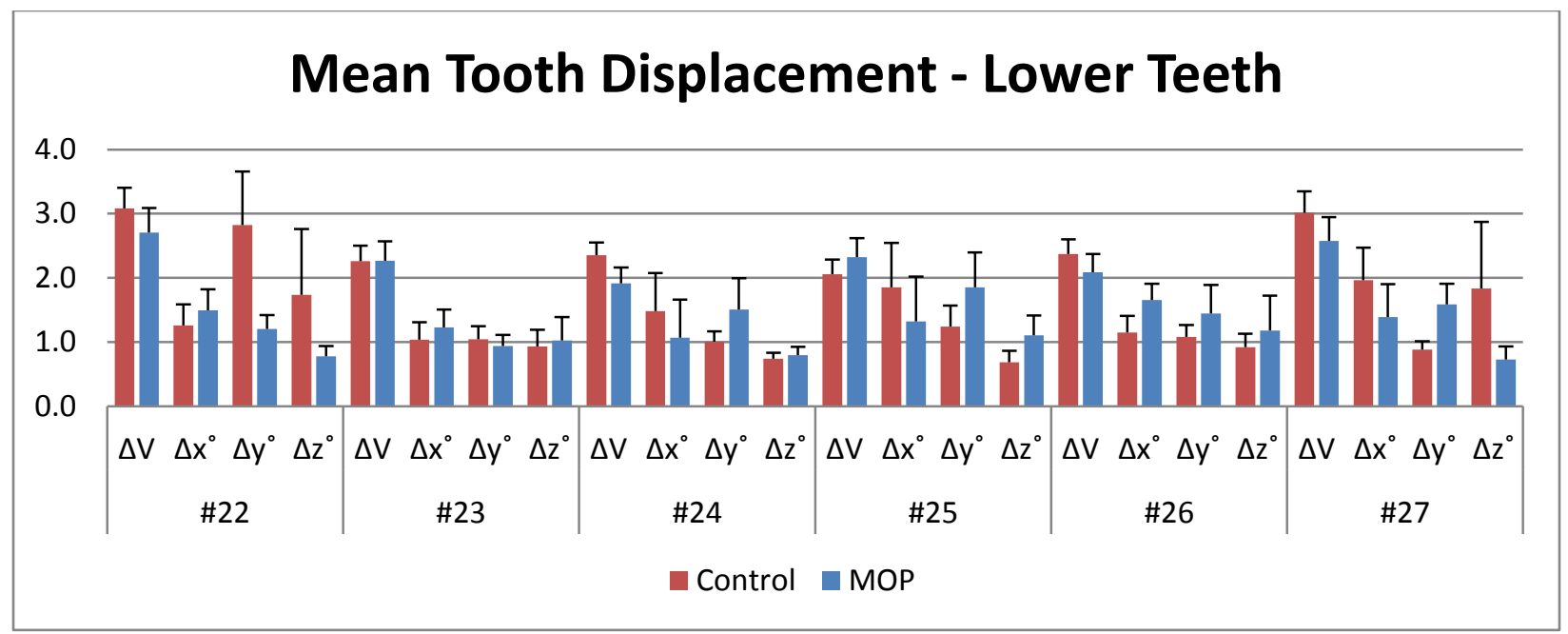

Figure 14. Mean linear discrepancy $(\Delta V)$ and relative errors for angular displacement $\left(\Delta x^{\circ}, \Delta y^{\circ}, \Delta z^{\circ}\right)$ for lower anterior teeth (\#22-\#27) for the experimental (MOP) and control samples with standard errors, where $\Delta \mathrm{V}$ is millimeter, and the angular parameters are dimensionless.

As shown in Table 2, one-way ANOVA revealed that the only significant difference was found in the rotational discrepancy about the $y$-axis $\left(\Delta \mathrm{y}^{\circ}\right)$ of lower right canines $(\mathrm{p}=0.0189 *)$. The mean relative error value of the particular tooth movement for the control samples was $0.8844 \pm 2.2146$, and that of the experimental samples was $1.5885 \pm 2.5676$. In other words, the mean value of the experimental group for the particular parameter was almost twice the value of the control group. However, due to a large number of comparisons $(m=48)$ tested, Bonferroni correction was applied in order to counteract the increasing likelihood of incorrectly rejecting a null hypothesis. At the corrected significance level of $\alpha=0.05 \div 48=0.001$, the difference between the groups for $\# 27 \Delta \mathrm{y}^{\circ}$ is no longer statistically significant. In fact, the means of all values were found to be not statistically different between two groups. In addition, for all the parameters with a wide range of data values, the Wilcoxon/Kruskal-Wallis Rank Sums test was performed, which found no significant difference between the groups as well. 
Table 2. One-way ANOVA of the linear and angular discrepancies between the actual outcome and the predicted outcome for individual anterior teeth between the control and the experimental samples

\begin{tabular}{|c|c|c|c|c|c|c|c|c|}
\hline & \multicolumn{2}{|c|}{$\Delta \mathbf{V}$} & \multicolumn{2}{c|}{$\Delta \mathbf{x}^{\circ}$} & \multicolumn{2}{c|}{$\Delta \mathbf{y}^{\circ}$} & \multicolumn{2}{c|}{$\Delta \mathbf{z}^{\circ}$} \\
\cline { 2 - 9 } & p value & S/NS & p value & S/NS & p value & S/NS & p value & S/NS \\
\hline$\# \mathbf{6}$ & 0.0926 & NS & 0.1680 & NS & 0.6169 & NS & 0.7333 & NS \\
\hline$\# 7$ & 0.1419 & NS & 0.3660 & NS & 0.5623 & NS & 0.6495 & NS \\
\hline$\#$ \#8 & 0.0631 & NS & 0.1773 & NS & 0.3758 & NS & 0.1835 & NS \\
\hline$\# 10$ & 0.0733 & NS & 0.8772 & NS & 0.7751 & NS & 0.1703 & NS \\
\hline$\# 11$ & 0.4782 & NS & 0.4565 & NS & 0.4447 & NS & 0.6099 & NS \\
\hline \hline$\# 22$ & 0.4443 & NS & 0.6158 & NS & 0.1454 & NS & 0.4814 & NS \\
\hline$\# 23$ & 0.9842 & NS & 0.7010 & NS & 0.7179 & NS & 0.8364 & NS \\
\hline$\# 24$ & 0.1654 & NS & 0.6046 & NS & 0.2427 & NS & 0.7135 & NS \\
\hline$\# 25$ & 0.4645 & NS & 0.5835 & NS & 0.3095 & NS & 0.2044 & NS \\
\hline$\# 26$ & 0.4236 & NS & 0.4734 & NS & 0.3846 & NS & 0.5978 & NS \\
\hline$\# 27$ & 0.3825 & NS & 0.4340 & NS & $0.0189 *$ & NS & 0.4384 & NS \\
\hline
\end{tabular}

\section{Effect of MOP by Arch}

The mean linear discrepancy and the relative errors for angular displacement were combined for the upper arch, the lower arch, and the entire dentition for all samples. The mean values for the parameters ranged between 0.8830 and 3.2932, and the standard deviations ranged from 0.0085 to 2.0470 (Table 3). Unlike the mean values and standard deviations for individual teeth, the values combined by the arch showed a smaller range and less variation. However, the values exhibited no pattern amongst themselves; neither group showed consistently higher mean 
value than the other. This can be visually verified in Figure 15.

Table 3. Mean values of the linear and angular discrepancies of upper, lower, and both arches and the standard deviations for all parameters

\begin{tabular}{|c|c|c|c|c|c|c|c|c|c|}
\hline \multirow{2}{*}{} & \multicolumn{2}{|c|}{$\Delta V$} & \multicolumn{2}{c|}{$\Delta x^{\circ}$} & \multicolumn{2}{c|}{$\Delta y^{\circ}$} & \multicolumn{2}{c|}{$\Delta z^{\circ}$} \\
\cline { 3 - 10 } & Mean & Std Dv & Mean & Std Dv & Mean & Std Dv & Mean & Std Dv \\
\hline \multirow{3}{*}{ Mx } & Control & 2.7607 & 0.0859 & 1.8421 & 0.0713 & 1.9964 & 0.0206 & 0.8830 & 0.0486 \\
\cline { 2 - 10 } & MOP & 3.2932 & 0.2332 & 1.7961 & 2.0470 & 1.5595 & 0.2124 & 1.0236 & 0.7969 \\
\hline \multirow{3}{*}{ Md } & Control & 2.5244 & 0.4176 & 1.4584 & 0.0085 & 1.3449 & 0.0680 & 1.1422 & 0.0106 \\
\cline { 2 - 10 } & MOP & 2.3135 & 0.2958 & 1.3611 & 0.8331 & 1.4198 & 0.3133 & 0.9378 & 0.5990 \\
\hline \multirow{3}{*}{ Total } & Control & 2.6428 & 0.4354 & 1.6514 & 0.0967 & 1.6743 & 0.0315 & 1.0123 & 0.0363 \\
\cline { 2 - 10 } & MOP & 2.8034 & 0.5712 & 2.5284 & 1.7139 & 1.4872 & 0.2659 & 1.2967 & 0.6891 \\
\hline
\end{tabular}

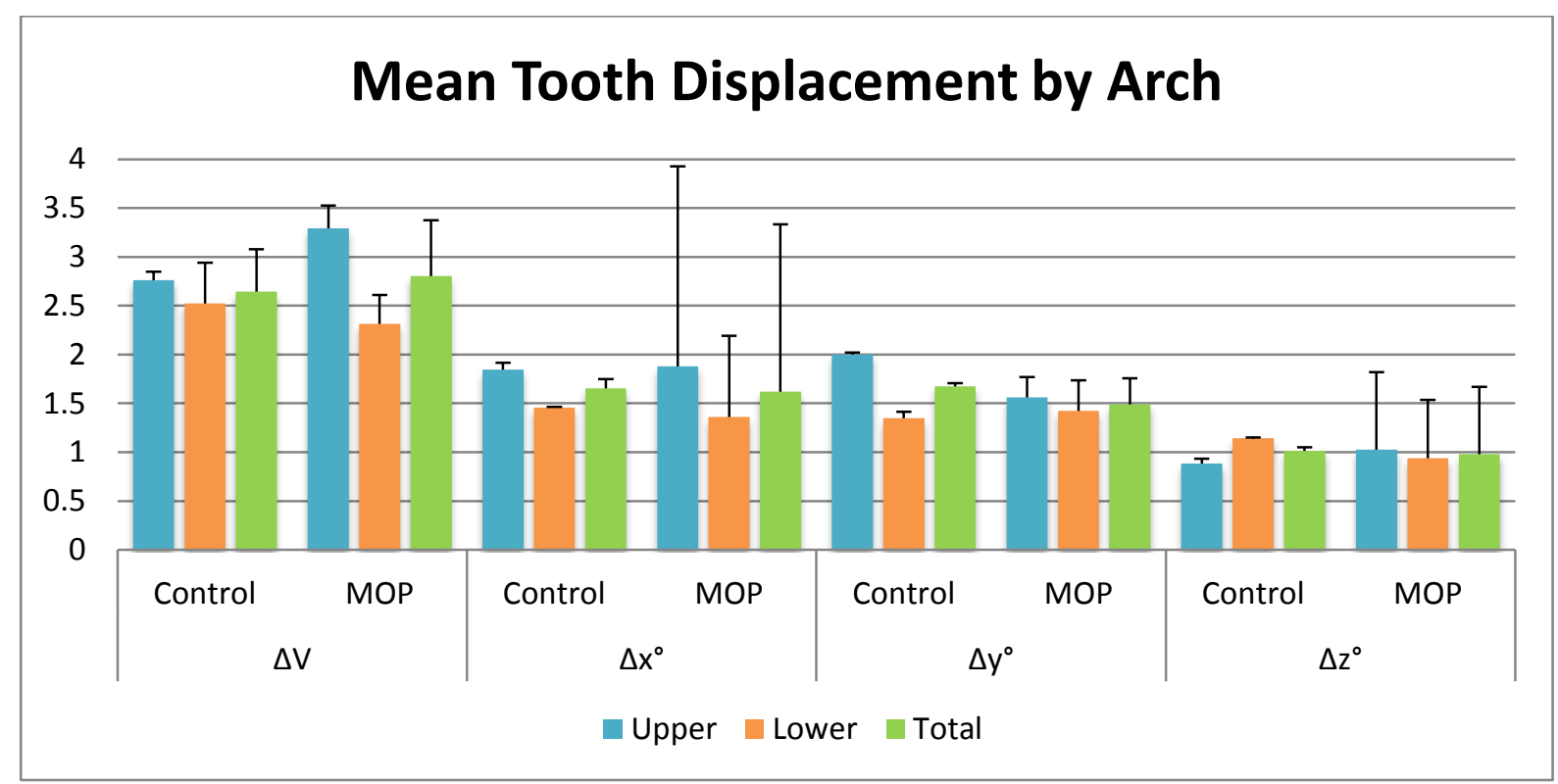

Figure 15. Mean linear discrepancy and relative errors for angular displacement for upper, lower, and combined arches for the experimental (MOP) and control samples and standard errors, where $\Delta \mathrm{V}$ is millimeter, and the angular parameters are dimensionless. 
One-way ANOVA revealed that there was a statistically significant difference between the groups when the linear discrepancy $(\Delta \mathrm{V})$ of the upper anterior teeth was considered $\left(\mathrm{p}=0.0015^{*}\right)$. The mean value of the linear discrepancy of the upper teeth for the control samples $(2.7607 \pm 0.0859)$ was lower than that of the experimental samples $(3.2932 \pm 0.2332)$. For some parameters, the control samples exhibited higher mean values than the experimental samples. However, no significant difference between the control and the experimental groups was found for the rest of the parameters when the teeth were combined by the arches (Table 4).

Table 4. One-way ANOVA of the linear and angular discrepancies between the actual outcome and the predicted outcome of upper, lower, and combined arches between the control and the experimental groups

\begin{tabular}{|c|c|c|c|c|c|c|c|c|}
\hline \multirow{2}{*}{} & \multicolumn{2}{|c}{$\Delta \mathbf{V}$} & \multicolumn{2}{c|}{$\Delta \mathbf{x}^{\circ}$} & \multicolumn{2}{c|}{$\Delta \mathbf{y}^{\circ}$} & \multicolumn{2}{c|}{$\Delta \mathbf{z}^{\circ}$} \\
\cline { 2 - 9 } & p value & S/NS & p value & S/NS & p value & S/NS & p value & S/NS \\
\hline Mx & $0.0015^{*}$ & S & 0.8864 & NS & 0.3949 & NS & 0.2466 & NS \\
\hline Md & 0.2088 & NS & 0.7374 & NS & 0.7607 & NS & 0.5572 & NS \\
\hline Total & 0.4073 & NS & 0.6874 & NS & 0.5233 & NS & 0.8130 & NS \\
\hline
\end{tabular}

\section{Effect of MOP on the Types of Orthodontic Tooth Movement}

Table 5 shows the difference between the mean values of the groups according to the types of OTM and the statistical significance of the differences for upper and lower arches. As shown in Figure 16, the linear discrepancy and the angular relative errors are generally similar for both groups. Neither group has a consistently higher value for any parameter. However, the greatest discrepancy between the mean values of the groups was found in the translational movement $(\Delta \mathrm{V})$ of the upper anterior teeth, which was 0.8770 (MOP: $2.5284 \pm 1.7139$, Control: 
$1.6514 \pm 0.0967)$. The difference in the mean values between the groups for all other movements was within 0.55 . Multi-factor ANOVA indicated that the differences between the groups according to the types of orthodontic tooth movement were not statistically significant indicated by the p-values presented in Table 5.

Table 5. The difference in linear and angular discrepancy between the groups and the statistical significance

\begin{tabular}{|c|c|c|c|c|c|c|c|c|c|}
\hline & \multicolumn{2}{|r|}{$\Delta \mathbf{V}$} & \multicolumn{2}{|c|}{$\Delta x^{\circ}$} & \multicolumn{2}{|c|}{$\Delta \mathbf{y}^{\circ}$} & \multicolumn{2}{|c|}{$\Delta \mathbf{z}^{\circ}$} \\
\hline & & Mean & Difference & Mean & Difference & Mean & Difference & Mean & Difference \\
\hline \multirow{2}{*}{$\mathbf{M x}$} & Control & 2.7607 & \multirow{2}{*}{0.5325} & 1.8421 & \multirow{2}{*}{0.0460} & 1.9964 & \multirow{2}{*}{0.4369} & 0.8830 & \multirow{2}{*}{0.1406} \\
\hline & MOP & 3.2932 & & 1.7961 & & 1.5595 & & 1.0236 & \\
\hline \multirow{2}{*}{ Md } & Control & 2.5244 & \multirow{2}{*}{0.2109} & 1.4584 & \multirow{2}{*}{0.0973} & 1.3449 & \multirow{2}{*}{0.0749} & 1.1422 & \multirow{2}{*}{0.2044} \\
\hline & MOP & 2.3135 & & 1.3611 & & 1.4198 & & 0.9378 & \\
\hline \multirow{2}{*}{ Total } & Control & 2.6428 & \multirow{2}{*}{$\begin{array}{c}0.1606 \\
(\mathrm{p}=0.4073)\end{array}$} & 1.6514 & \multirow{2}{*}{$\begin{array}{c}0.8770 \\
(\mathrm{p}=0.6873)\end{array}$} & 1.6743 & \multirow{2}{*}{$\begin{array}{c}0.1871 \\
(\mathrm{p}=0.5233)\end{array}$} & 1.0123 & \multirow{2}{*}{$\begin{array}{c}0.2844 \\
(\mathrm{p}=0.8130)\end{array}$} \\
\hline & MOP & 2.8034 & & 2.5284 & & 1.4872 & & 1.2967 & \\
\hline
\end{tabular}

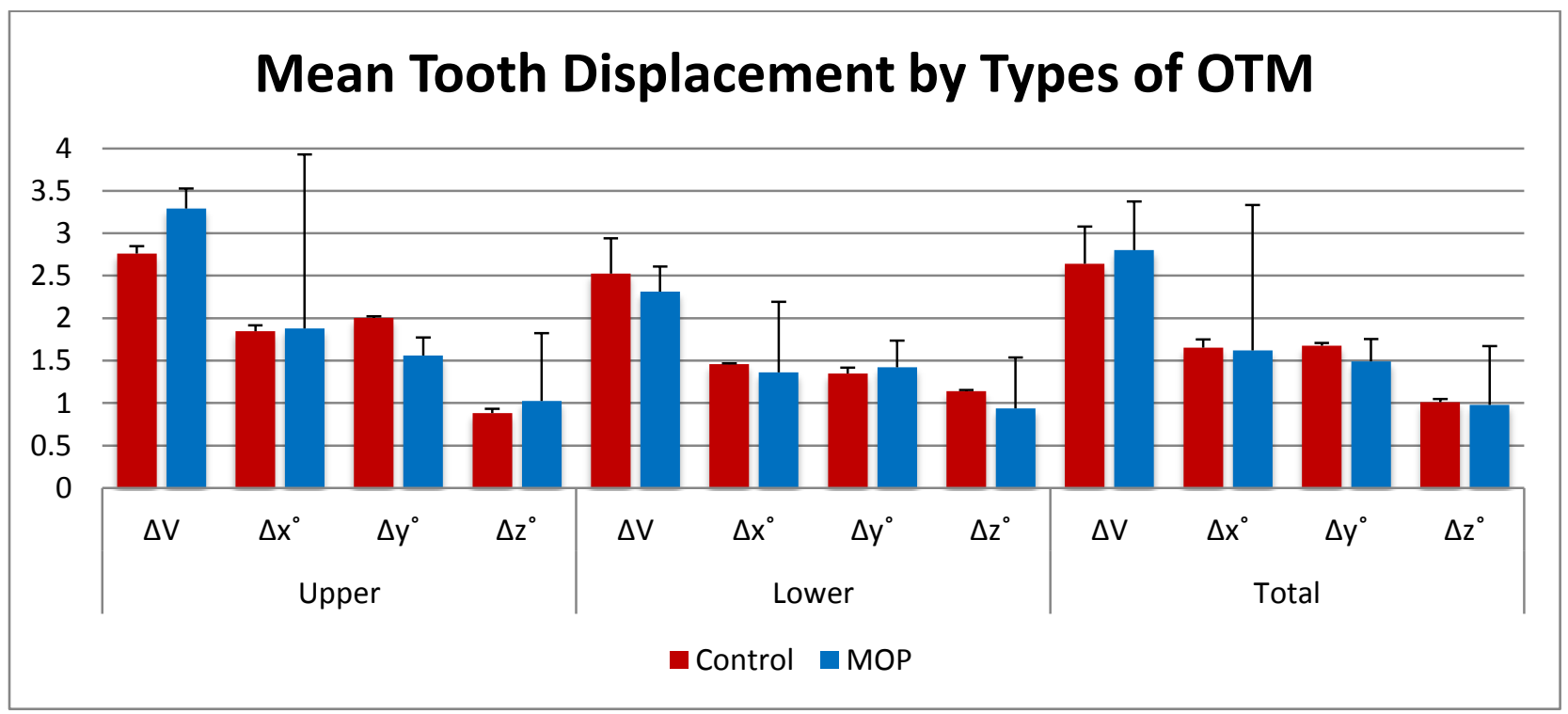

Figure 16. Comparison of mean tooth displacement by different types of orthodontic tooth movement with standard deviations, where the $\Delta \mathrm{V}$ is millimeter, and the angular parameters are dimensionless. 


\section{Effect of Micro-Osteoperforation by Gender}

The control group consisted of 23 male (39.0\%) and 36 female (61.0\%) subjects. The experimental group consisted of 13 male (28.3\%) and 33 female (71.7\%) subjects. Both groups had noticeably more female subjects, but the control group had a slightly higher rate of male subjects.

The effect of micro-osteoperforation in relation to gender of the subjects was analyzed using regression analysis with the least squares means. All anterior teeth were combined, but each parameter was analyzed separately. When gender was considered separately for all samples in both groups, linear displacement was the only parameter that was found significantly different between genders $\left(\mathrm{p}=0.0005^{*}\right)$. For both groups, females had smaller linear and angular discrepancies between the predicted and the actual tooth positions, compared to males in the same group. As visually represented in Figure 18, males (mean $=2.98 \pm 0.11)$ showed a greater linear discrepancy $(\Delta \mathrm{V})$ than females $($ mean $=2.57 \pm 0.07)$ with the difference of approximately 0.41 when both the control and experimental samples were considered together. A similar pattern was observed in all other parameters. (See Appendix E) However, if the gender effect was combined with the effect of MOP, the interaction was only suggestive of statistical significance $(\mathrm{p}=0.0526)$. On the other hand, the analyses of the angular parameters showed no significant difference between the genders or between the groups (Table 6). 


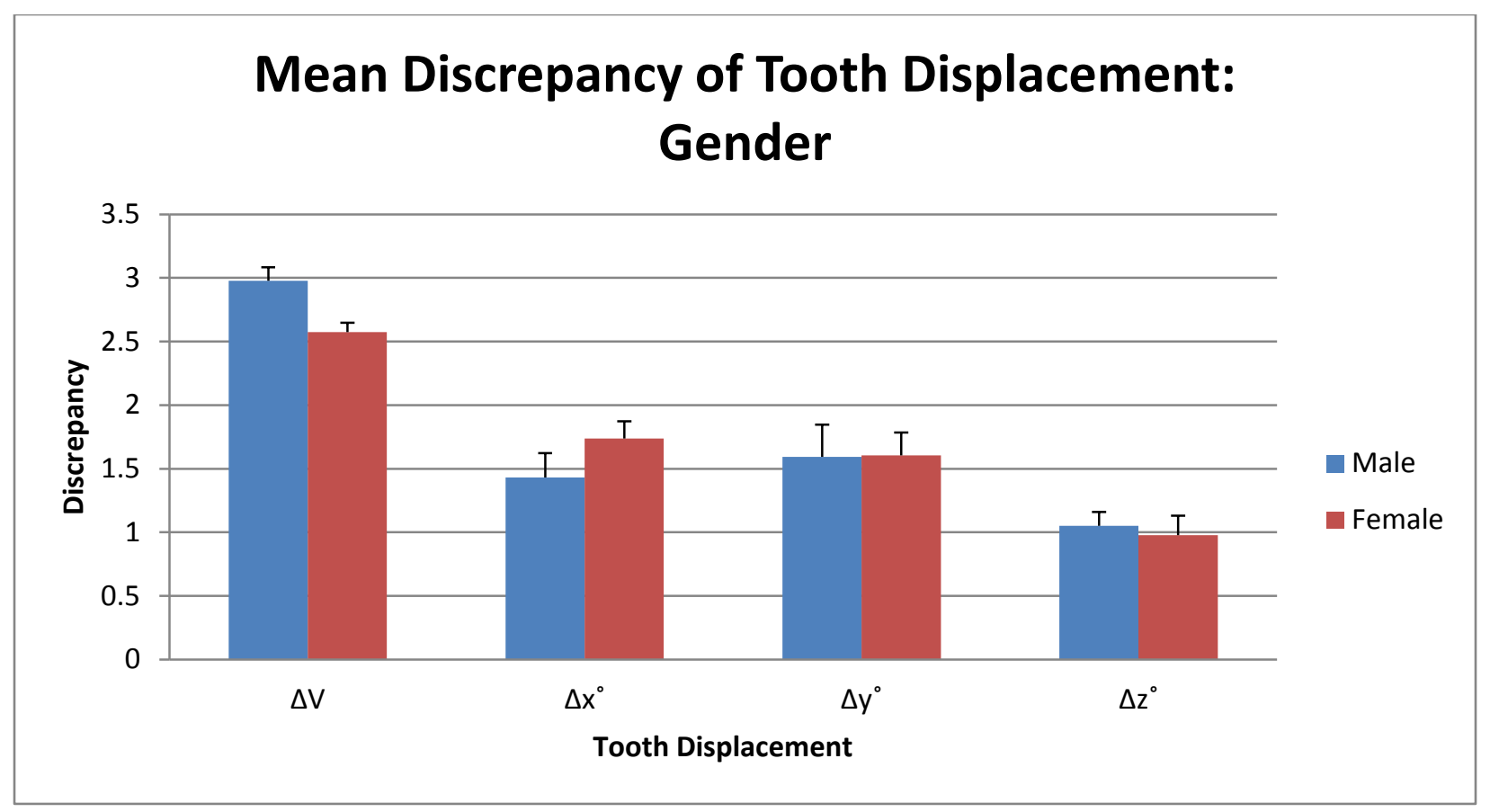

Figure 17. Means of linear and angular discrepancies by gender with the groups combined with standard deviations, where the $\Delta \mathrm{V}$ is millimeter, and the angular parameters are dimensionless.

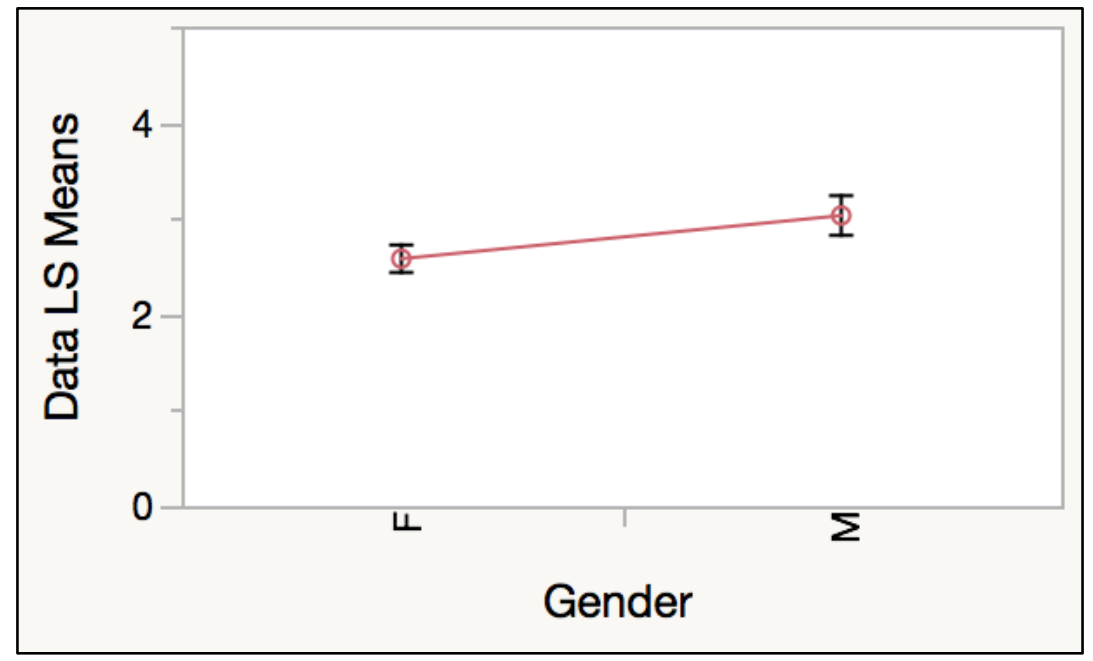

Figure 18. Least Squares Means Plot of gender versus the linear discrepancy $(\Delta V)$ between the actual and the predicted outcomes for both control and experimental samples combined 
Table 6. The mean linear and angular discrepancies for male and female subjects of both groups and the significance of the interaction between the gender and the orthodontic tooth movement in clear aligner treatment with or without MOPs

\begin{tabular}{|c|c|c|c|c|c|c|c|c|}
\hline \multirow{2}{*}{ Parameter } & \multicolumn{2}{|c|}{ Gender Mean } & \multirow{2}{*}{$\begin{array}{l}\text { Gender } \\
\text { p-value }\end{array}$} & \multicolumn{4}{|c|}{ Gender*Group Mean } & \multirow{2}{*}{$\begin{array}{c}\text { Gender } \\
\text { \& Group } \\
\text { p-value }\end{array}$} \\
\hline & Male & Female & & $\begin{array}{l}\text { Male \& } \\
\text { Control }\end{array}$ & $\begin{array}{c}\text { Female \& } \\
\text { Control }\end{array}$ & $\begin{array}{c}\text { Male } \\
\text { \& MOP }\end{array}$ & $\begin{array}{l}\text { Female } \\
\text { \& MOP }\end{array}$ & \\
\hline$\Delta \mathbf{V}$ & 2.97916 & 2.57532 & $0.0005^{*}$ & 2.84341 & 2.51387 & 3.21356 & 2.64188 & 0.0526 \\
\hline$\Delta \mathbf{x}^{\circ}$ & 1.43202 & 1.73846 & 0.2149 & 1.41367 & 1.79470 & 1.46792 & 1.66174 & 0.6862 \\
\hline$\Delta \mathbf{y}^{\circ}$ & 1.59172 & 1.60492 & 0.9388 & 1.56108 & 1.73319 & 1.65034 & 1.43021 & 0.5303 \\
\hline$\Delta \mathbf{z}^{\circ}$ & 1.04956 & 0.97762 & 0.8025 & 1.09690 & 0.93612 & 0.95796 & 0.99749 & 0.6457 \\
\hline
\end{tabular}

\section{Effect of Micro-Osteoperforation by Age}

The mean age for the control group was 29.3 years, ranging from 11.3 to 89.4 years. The mean age for the experimental group was 34.1 years, ranging from 17.1 to 60.2 years. Although the mean age was slightly higher for the experimental group, the range was smaller than that of the control group.

The relationship between MOPs and the age of the subjects was analyzed using multifactorial ANOVA. As shown in Figure 19, the fit line of the experimental group has a negative slope between the linear discrepancy $(\Delta \mathrm{V})$ and the age of the patients, but the fit line of the control group has a slightly positive, almost flat slope. As indicated by the difference in the slopes, the negative correlation between the age and the linear discrepancy is more pronounced in the MOP group (estimated difference $=0.0204$ ), while the linear discrepancy tends to increase 
as the age increases for the control group. The analyses showed that the difference between the groups was statistically significant for $\Delta \mathrm{V}$ that was affected by the age of the patients $\left(\mathrm{p}<0.0001^{*}\right)($ Table 7$)$. There is a minimal difference in the linear discrepancy values between groups where the fit lines intersect around the age of 38. Nevertheless, as the age of the subjects increased, the MOP samples showed less linear discrepancy between the post-treatment and the prediction compared to the control.
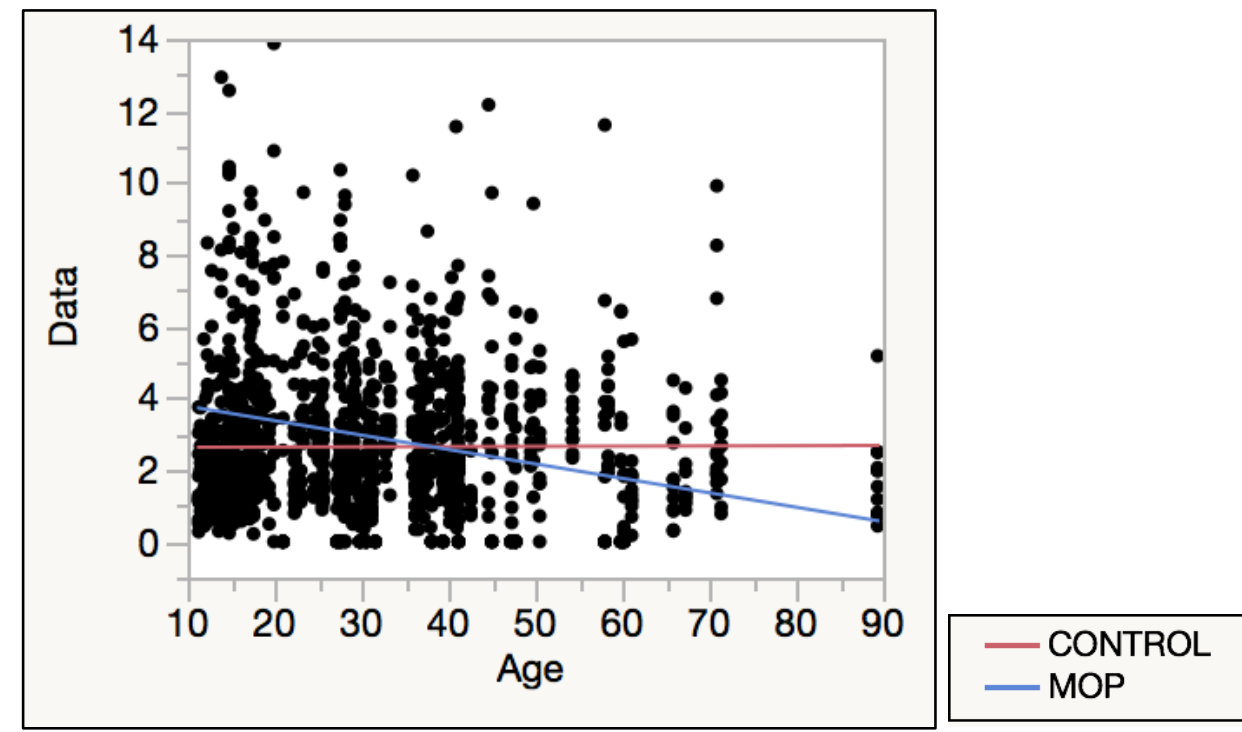

Figure 19. Regression plot of the linear discrepancy $(\Delta V)$ and age and the fit lines for control and experimental groups

Table 7. Multi-factorial ANOVA of the significance of the interaction between MOP and the age of the subjects

\begin{tabular}{|c|c|c|c|}
\hline Parameter & Estimated Difference & $\mathbf{p}$-value & Significance \\
\hline$\Delta \mathbf{V}$ & 0.0204 & $<0.0001^{*}$ & $\mathrm{~S}$ \\
\hline$\Delta \mathbf{x}^{\circ}$ & -0.0126 & 0.1803 & NS \\
\hline$\Delta \mathbf{y}^{\circ}$ & 0.0232 & 0.0672 & NS \\
\hline$\Delta \mathbf{z}^{\circ}$ & -0.0016 & 0.8366 & NS \\
\hline
\end{tabular}




\section{Effect of Micro-Osteoperforation by Severity of Anterior Malalignment}

\section{Maxillary Arch}

Multi-factorial ANOVA was performed to analyze the relationship between the effect of MOP and the severity of anterior mal-alignment, indicated by the amount of crowding or spacing present in the anterior region. As shown in the regression analysis of $\Delta \mathrm{x}^{\circ}$ and the space available in the anterior region in Figure 20, the blue fit line that represents the experimental group has a negative slope. This negative slope indicated a negative correlation between the space available in the anterior region and the angular discrepancy between the actual and the predicted tooth displacement about the $\mathrm{x}$-axis. As more space became available, the experimental samples showed that the actual amount of rotation about $\mathrm{x}$-axis was closer to the predicted amount. On the other hand, the red fit line in the same regression analysis showed a slightly positive slope, indicating a mildly positive correlation between the space available in the anterior region and the angular discrepancy between the actual and the predicted tooth movement.

Regression analyses of the linear and other angular discrepancy values exhibited a similar pattern, where the MOP fit lines showed a negative correlation and the control fit lines showed a slightly positive correlation (See Appendix E). However, as shown in Table 8, the analyses indicated no statistically significant difference between the control and the experimental groups for the translational movement $(\mathrm{p}=0.1470)$ and the rotational movement about the $\mathrm{y}$ - and $\mathrm{z}$-axes $(\mathrm{p}=0.5316$ and $\mathrm{p}=0.3322$, respectively). The rotational movement about the $\mathrm{x}$-axis was the only movement in the maxillary anterior region that the analysis indicated a statistically different between the groups $(\mathrm{p}=0.0201 *)$. 


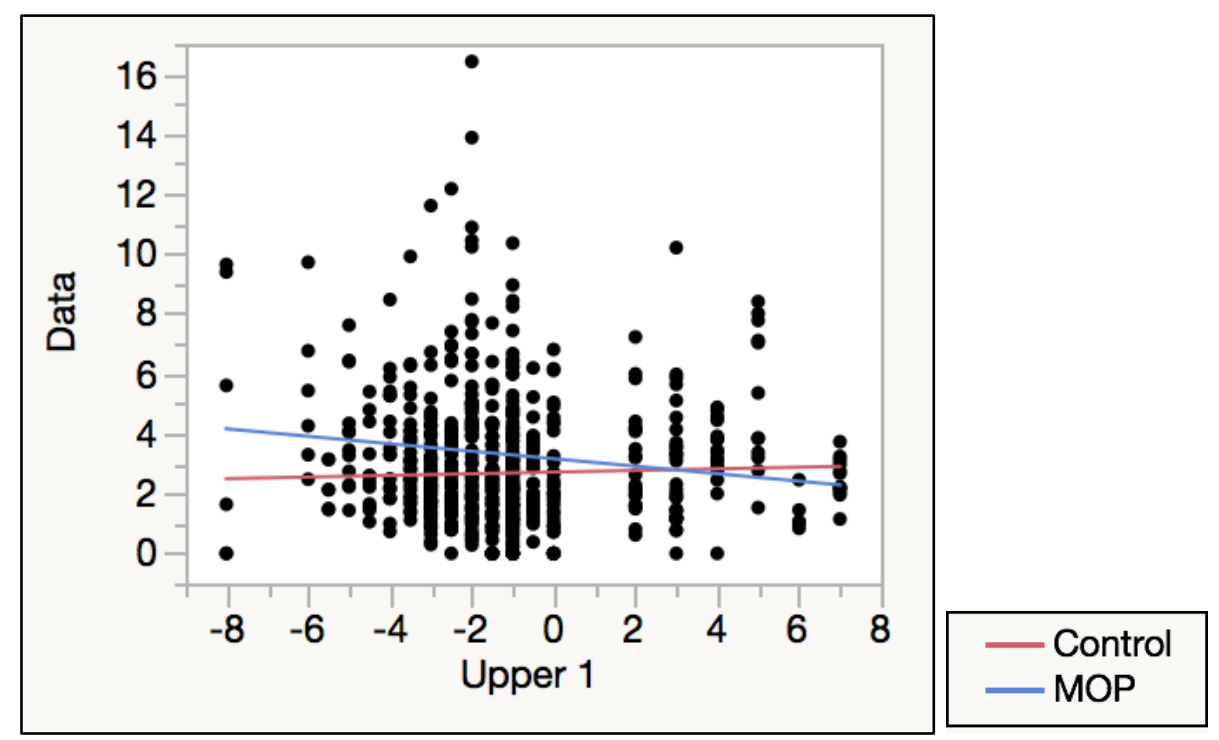

Figure 20. Regression analysis of the amount of upper anterior crowding or spacing versus the angular discrepancy about the $\mathrm{x}$-axis $\left(\Delta \mathrm{x}^{\circ}\right)$ between the actual and the predicted tooth displacements

Table 8. Multi-factorial ANOVA of the significance of the interaction between MOP and the amount of space available in the upper anterior region

\begin{tabular}{|c|c|c|c|}
\hline Parameter & Estimated Difference & $\mathbf{p}$-value & Significance \\
\hline$\Delta \mathbf{V}$ & -0.0487 & 0.1470 & NS \\
\hline$\Delta \mathbf{x}^{\circ}$ & 0.3993 & $0.0201^{*}$ & S \\
\hline$\Delta \mathbf{y}^{\circ}$ & 0.0638 & 0.5316 & NS \\
\hline$\Delta \mathbf{z}^{\circ}$ & 1.3921 & 0.3322 & NS \\
\hline
\end{tabular}




\section{Mandibular Arch}

Multi-factorial ANOVA was performed to analyze the relationship between the amount of space available in the lower anterior region and the effect of micro-osteoperforations. In Figure 21, the regression plot shows a negative correlation between the linear discrepancy $(\Delta \mathrm{V})$ and the amount of space available in the lower anterior sextant for both groups. As the space became more available, samples in both groups resulted in a translational movement that was closer to the predicted movement. With a greater amount of crowding, both groups showed a greater discrepancy between the actual outcome and the predicted outcome. Although the difference is slight, the slope of the experimental fit line is steeper than that of the control, indicating that the experimental samples resulted in even less linear discrepancies with an increased amount of spacing compared to the control samples. Due to the point where two fit lines intersect (-3mm of crowding), the difference is more pronounced with more spacing. The regression plots of the angular discrepancies $\left(\Delta \mathrm{x}^{\circ}, \Delta \mathrm{y}^{\circ}\right.$, and $\left.\Delta \mathrm{z}^{\circ}\right)$ showed a similar pattern where the fit lines were sloping downwards as the amount of available space increased. (See Appendix E) However, as reported in Table 9, the ANOVA indicated that the only statistically significant difference in the slopes between the groups was found with the linear discrepancy $(\mathrm{p}<0.0001 *)$. The groups showed no statistically significant difference in terms of angular discrepancies in mesiodistal, faciolingual, and occlusogingival directions $(\mathrm{p}=0.1733,0.8701$, and 0.6158 , respectively). 


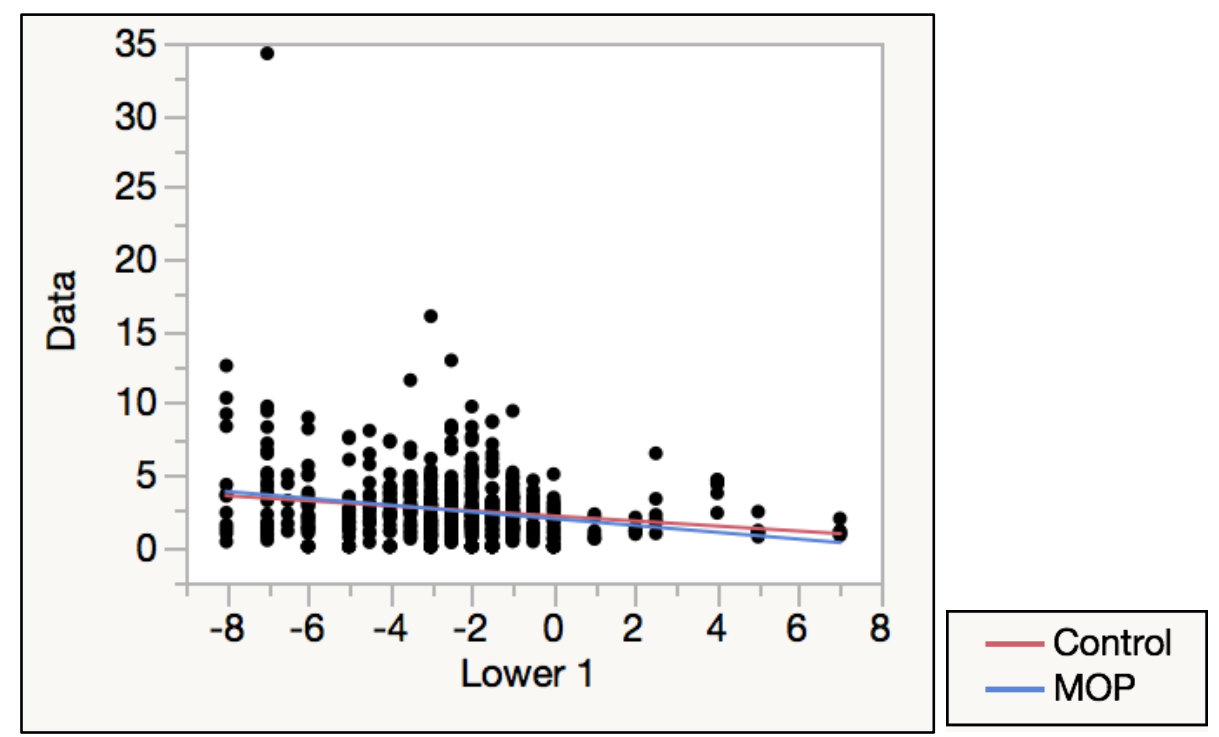

Figure 21. Regression analysis of the amount of lower anterior crowding or spacing versus the linear discrepancy $(\Delta \mathrm{V})$ between the actual and the predicted tooth displacements

Table 9. Multi-factorial ANOVA of the significance of the interaction between MOP and the amount of space available in the lower anterior region

\begin{tabular}{|c|c|c|c|}
\hline Parameter & Estimated Difference & $\mathbf{p}$-value & Significance \\
\hline$\Delta \mathbf{V}$ & -0.2067 & $<0.0001^{*}$ & $\mathrm{~S}$ \\
\hline$\Delta \mathbf{x}^{\circ}$ & 0.3168 & 0.1733 & $\mathrm{NS}$ \\
\hline$\Delta \mathbf{y}^{\circ}$ & -0.3431 & 0.8701 & NS \\
\hline$\Delta \mathbf{z}^{\circ}$ & -0.1713 & 0.6158 & NS \\
\hline
\end{tabular}




\section{Effect of Micro-Osteoperforation on the Frequency of Refinement}

Contingency analysis was performed to analyze the effect of MOPs on the frequency of refinement treatment as determined at the end of the prescribed aligners (T.S.). As seen in Table 10,49 out of 59 control samples $(83.05 \%)$ required refinement treatment at the conclusion of the prescribed aligners. On the other hand, 42 out of 44 experimental samples $(95.65 \%)$ required refinement. Out of the 105 samples included in the study, more control samples $(9.52 \%)$ completed the treatment without requiring a treatment than the experimental samples $(1.90 \%)$. As seen in Figure 22, the analysis showed that the difference in the frequency of the refinement between the groups is significant $\left(\mathrm{p}=0.0343^{*}\right)$, indicating that the refinement was more likely with the 3-day aligner wear protocol with the MOPs, compared to the 14-day aligner wear protocol.

Table 10. Contingency table of the frequency of refinement treatment needed per group

\begin{tabular}{|c|c|c|c|}
\hline $\begin{array}{c}\text { Count } \\
\text { Total \% } \\
\text { Col \% }\end{array}$ & Completed Cases (C) & Refinement Needed (R) & Total \\
Row \% & & & \\
\hline & 10 & 49 & 59 \\
Control & 9.52 & 46.67 & 56.19 \\
& 83.33 & 52.69 & \\
& 16.95 & 83.05 & 46 \\
& 2 & 44 & 43.81 \\
\hline Experimental & 1.90 & 41.90 & 105 \\
& 16.67 & 47.31 & \\
\hline \multirow{2}{*}{ Total } & 4.35 & 95.65 & 93 \\
& 11.43 & 88.57 & \\
\hline
\end{tabular}




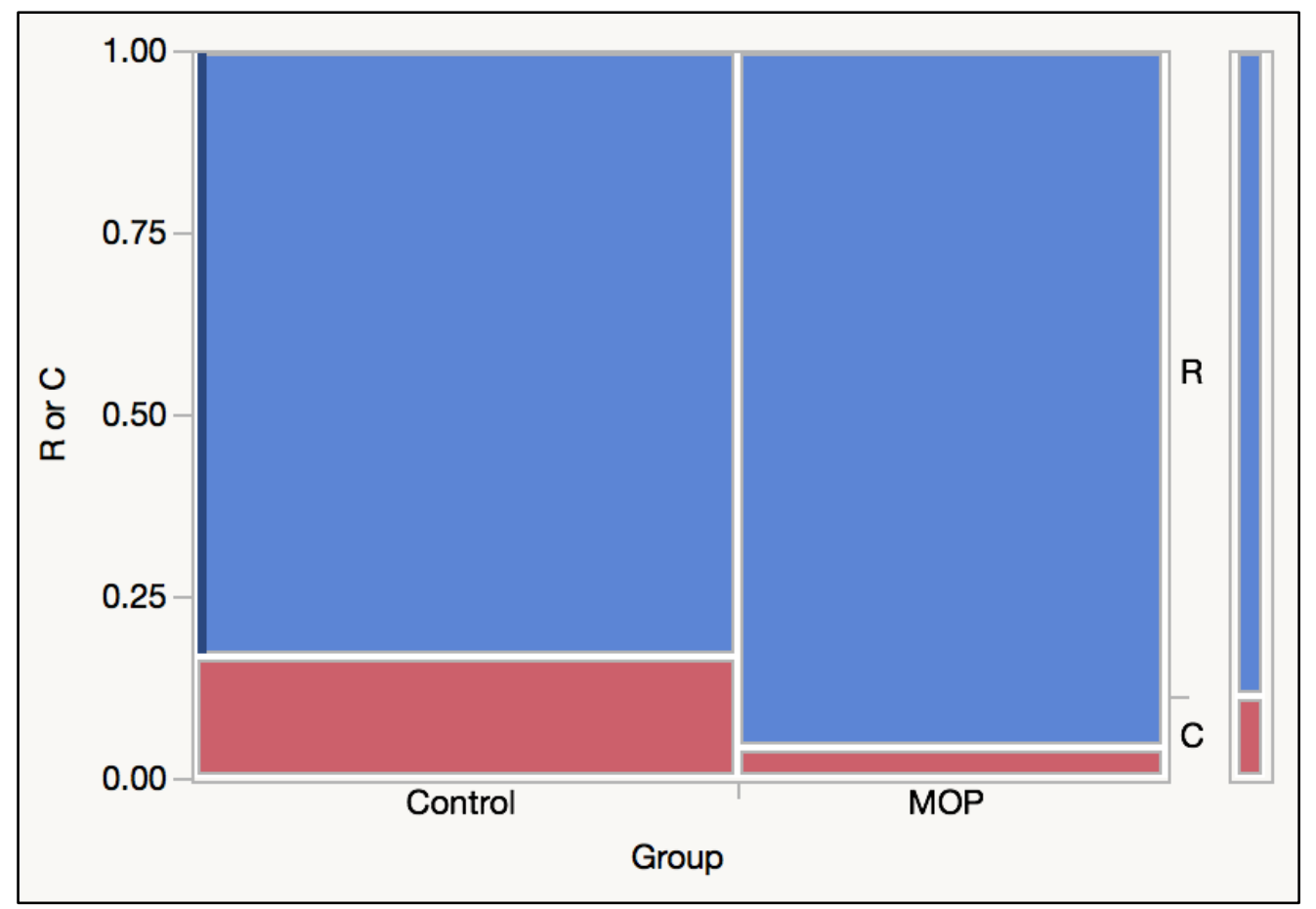

Figure 22. Mosaic Plot of the frequency of refinement treatment necessary at the completion of the prescribed aligner wear for control and experimental samples 


\section{CHAPTER 5: DISCUSSION}

The ability of clear aligners to improve the alignment of the anterior teeth and the effects of MOPs on the accuracy of anterior tooth movement with CAT was examined by comparing the actual amount of tooth displacement to the predicted amount of tooth displacement. The information gained through this study will shed light on whether clinicians can shorten the treatment duration when using clear aligners in conjunction with MOP. The linear discrepancy was represented by the difference in the magnitude of the ClinCheck prediction and the actual treatment outcomes. The angular discrepancy was represented by the relative error of the angular displacement about three different axes (x-, $\mathrm{y}-$, and $\mathrm{z}$-axes). When the discrepancy between the prediction and the actual outcome of individual teeth was analyzed in three separate planes, the difference between the control and the experimental samples in all of the values was found to be statistically insignificant. When these movements for each individual anterior tooth were considered, the linear and angular discrepancies between the actual outcome and the predicted outcome in the experimental samples with MOPs were comparable to those of the control samples without MOP.

On the other hand, the analyses indicated that the only value that was found to be statistically significant at $\alpha=0.05$ was the difference in the relative error of angular movement in faciolingual directions of lower right cuspids. This seemingly significant difference between the groups exists in other parameters. However, as a result of the high variability of the values as indicated by the standard deviations, the differences in these parameters were found to be statistically insignificant. In fact, when Bonferroni correction was applied due to a large number of comparisons performed for all teeth in all 3 dimensions, the difference between the groups for 
$\Delta y^{\circ}$ of $\# 27$ was found to be not statistically significant. Thus, the data indicate that the 3-day aligner wear combined with MOPs resulted in a clinically comparable accuracy of anterior tooth movement.

When six anterior teeth were considered together, the analyses indicated a statistically significant difference between the groups with the linear discrepancy of the maxillary anterior teeth. Since the formula to obtain the linear discrepancy is a square root of the sum of the differences in the distances of the vectors, the magnitude of the difference between the actual and the predicted outcome may not be clinically significant despite the statistical significance. In fact, the numerical difference between the groups for this parameter was around $0.3 \mathrm{~mm}$ per dimension, which may not be clinically significant. Likewise, the differences in all other parameters for the upper and lower teeth between the two groups were neither clinically nor statistically significant, indicating that the 3-day aligner wear protocol did not adversely affect the aligners' ability to control orthodontic tooth movement if combined with MOPs.

When the mean discrepancies were considered according to the different types of orthodontic tooth movement, the analyses indicated no statistically significant difference between the control and the experimental groups. Moreover, the effect of MOP is nondiscriminatory towards the types of tooth movement, such as rotation and translation. However, this result is not in full agreement with the currently available literature, which reported that the most accurate tooth movement was lingual tipping (47.1\%) and the least accurate was extrusion $(29.6 \%) .{ }^{28}$ Due to the method utilized to calculate the discrepancy of the orthodontic tooth movement in the current study, a direct comparison with the referenced study may not be applicable. Nevertheless, the results of this study show that the discrepancies in the accuracy of tooth movement also vary per parameter, suggesting differences in the accuracy of tooth 
movement with clear aligners although the difference may be statistically insignificant.

Once the data were arranged according to the gender of the subjects, the statistical analysis indicated that females achieved a translational tooth movement that was significantly closer to the prediction compared to males. However, for other parameters, the data did not exhibit this trend or show any statistically significant difference between the genders. This is partially consistent with the study by Chisari et al., which showed a combined effect of age and gender on the accuracy of OTM in CAT. ${ }^{27}$ Nevertheless, the gender differences presented in this study failed to indicate any clinical significance. In addition, the data indicate no significant interaction between the effects of MOP and gender. MOPs may have a favorable effect on translational tooth movement, possibly increasing the tracking ability for female subjects; however, the analysis is merely suggestive of a possible differential effect of MOP on gender. If the age of the subjects was considered, a statistically significant effect of MOPs on the translational movement was observed with the increasing age of the subjects. The effect of MOP became more favorable as the patient's age increased, approximating the predicted tooth movement closer than the 14-day aligner wear protocol. This may be interpreted as a minimal effect of MOPs in younger individuals. As reported by Ren et al. in their animal study, younger samples exhibit a faster orthodontic tooth movement compared to older individuals especially during the initial phase of orthodontic treatment. ${ }^{76}$ Thus, the effect of MOP may be masked by a naturally elevated bone turnover observed in younger patients. However, as the rate of orthodontic tooth movement becomes impeded in adult patients, an intervention to increase the rate of tooth movement may be more desirable. As supported by the results of the current study, increasing age may be an indication for MOPs.

The differential effect of MOPs on severity of anterior mal-alignment was measured by 
the amount of crowding or spacing present initially. Regardless of the application of MOPs, the actual outcome seems to approximate closer to the prediction with anterior spacing compared to crowding. On the other hand, as the amount of crowding increases, the subjects who received MOPs were associated with slightly greater linear and angular discrepancies between the predicted and the actual outcomes for both upper and lower anterior teeth. This may be explained by the varying severity of mal-alignment in each group. In general, crowding greater than $4 \mathrm{~mm}$ is considered severe, often necessitating extraction or a substantial amount of interproximal reduction, expansion, and proclination to resolve the crowding. For the samples included in the study, a total of $31 \%$ of the experimental group had severe crowding in either one or both arches, whereas $22 \%$ of the control group had crowding greater than $4 \mathrm{~mm}$. On the contrary, the control group had a higher rate $(60 \%)$ of minimal crowding or spacing (i.e. less than $1 \mathrm{~mm}$ crowding or spacing) compared to the experimental group (45\%). In other words, the conclusion that MOPs may adversely affect the outcome of clear aligner treatment with severe crowding may be misleading. Nevertheless, the results mostly indicate that the outcome of CAT with or without MOPs is not significantly affected by the severity of anterior mal-alignment.

Lastly, when the frequency of refinement treatment at the completion of prescribed aligners was measured, the results revealed that the majority of the CAT cases considered in this study required refinement treatment, indicating that the actual treatment outcome did not satisfactorily approximated the predicted outcome for most cases. This is somewhat in agreement with the current studies that reported the efficiency of clear aligner treatment was anywhere between less than ideal and clinically unacceptable. ${ }^{26-28,63,64}$ The overall frequency reported in this study $(88.57 \%)$ is slightly higher than that reported by Kravitz (70-80\%). ${ }^{26}$ However, the slight difference between the survey result and the samples used in the current study can be 
explained by the different standards that may be used to evaluate the final outcome to decide the need for refinement treatment. Nevertheless, both studies agree that the majority of CAT cases often do not result in a satisfactory outcome.

Moreover, the experimental group was more likely to proceed with refinement treatment (95.65\% versus $83.05 \%)$. Several explanations are possible: First, the 3-day aligner wear may result in slightly greater discrepancies in all three dimensions per aligner than the 14-day aligner wear, which may accumulate to a noticeable gap between the actual and the predicted outcome, necessitating a refinement. Although most of the analyses showed no statistical difference between the control and the experimental groups, many of the parameters showed a higher discrepancy for the experimental samples. The cumulative discrepancy between the actual and the predicted outcomes, though unnoticeable individually, may lead to a need for a refinement treatment. Second possible explanation is the difference in the severity of malocclusion, which can be extrapolated from the severity of mal-alignment and the number of prescribed aligners. The patients with a more severe malocclusion may be more inclined to elect an interventional procedure in an effort to increase the rate of tooth movement and shorten the treatment duration. Thus, the experimental group might have inadvertently included more severe cases with more complicated tooth movement. As mentioned earlier, a greater percentage of the experimental samples started with more severe anterior crowding. Additionally, the average number of prescribed aligners was higher for the experimental group (mean 24.7 aligners, ranging from 15 to 50) compared to the control group (mean 21.2 aligners, ranging from 10 to 46). Therefore, the sheer complexity of the cases might have resulted in a higher frequency of refinement treatment. 


\section{Hypotheses Testing}

\section{Summary of Results}

1. ACCEPTED: There was no significant difference between the groups in tooth movements of the anterior teeth predicted by the ClinCheck compared to the actual treatment between the experimental and control groups.

2. PARTIALLY ACCEPTED: There was no significant difference between the groups in the tooth movements of anterior teeth predicted by the ClinCheck compared to the actual treatment outcome among angular movements. However, there was a statistically significant difference in the linear tooth movement of upper anterior teeth predicted by the ClinCheck compared to the actual treatment outcome.

3. ACCEPTED: There was no statistically significant difference between the groups in the accuracy of tooth movements of anterior teeth predicted by the ClinCheck compared to the actual treatment outcome between genders. However, there was a statistically significant difference for the translational movements between genders when samples from both groups were combined. There was no significant difference in the interaction of MOPs and gender for the accuracy of anterior tooth movement.

4. REJECTED: There was a statistically significant difference between the groups in the accuracy of the tooth movements of anterior teeth predicted by the ClinCheck compared to the actual treatment outcome among different age groups.

5. PARTIALLY ACCEPTED: There was a statistically significant difference between the groups in the rotational tooth movements of upper anterior teeth and in the linear tooth movements of lower anterior teeth predicted by the ClinCheck compared to the actual 
treatment outcome for varying severity of anterior mal-alignment. No other tooth movements showed any statistical difference between the groups.

6. REJECTED: There was a statistically significant difference between the groups in the frequency of refinement treatments at the completion of the prescribed aligner treatment.

\section{Clinical Implications}

The addition of MOP in clear aligner treatment seems to be a viable option to shorten the treatment duration without adversely affecting the quality of treatment outcome. The approximation of the actual tooth movement to the predicted tooth movement seems to be minimally affected by a significant shortening in the duration of the aligner wear ( 3 days versus 14 days). By shortening the treatment duration, the patients will more likely to maintain a high level of compliance throughout the treatment without exposing themselves to damaging side effects associated with prolonged orthodontic treatment.

For more complicated tooth movement, MOPs may be combined with a longer aligner wear to increase the efficiency of tooth movement. In cases where the impeded tooth movement becomes an evident concern, such as in older patients and male patients, MOP can be offered not just as a method of shortening the treatment duration, but also as an auxiliary to increase the accuracy of the orthodontic tooth movement with the longer duration of aligner wear. 


\section{CHAPTER 6: SUMMARY AND CONCLUSIONS}

\section{Summary}

Accelerated CAT can offer many benefits to the clinicians and the patients. However, the accuracy of orthodontic tooth movement with the shorter aligner-wear with MOPs needed to be verified. In this retrospective study, the effect of MOP on the accuracy of tooth movement was examined by comparing the actual treatment outcomes to the prediction models of 49 experimental samples (3-day aligner wear and MOPs) and 56 control samples (14-day aligner wear without MOPs). Using CloudCompare software, the pre-treatment, post-treatment intraoral scans, and prediction models were superimposed to each other, and the differences between the predicted and the actual tooth position of the anterior teeth in both arches were measured. The results indicated that the accuracy of orthodontic tooth movement was not significantly affected by the shortened duration of the aligner wear if the treatment was combined with MOPs. Although the correlation was not strong, and most of the differences were clinically insignificant, MOPs seemed to be more effective in aligning anterior teeth in males, older patients, and anterior spacing cases, compared to CAT with the 14-day aligner protocol. On the other hand, the refinement treatment was more frequently considered for the experimental group, possibly due to the higher complexity of the cases included in the experimental group than the control. Thus, the current study suggests that the CAT 3-day aligner wear with MOPs may be a viable option to accelerate OTM without negatively affecting the quality of the treatment outcome. 


\section{Conclusions}

Based on the results of the study, following conclusions can be made:

- The reduction of the duration of aligner wear from 14 days to 3 days with MOPs did not negatively affect the accuracy of the linear and angular tooth movement in clear aligner treatment.

- The types of orthodontic tooth movement were not significantly influenced by the effect of MOP on the accuracy of tooth movement.

- MOPs had a clinically insignificant effect on gender, age, and the severity of malalignment.

- There is a significant increase in the frequency of refinement treatment in the CAT with MOPs probably due to a higher number of aligners and a greater amount of anterior crowding seen in the experimental samples.

- Patients with more severe mal-alignment or longer treatment plan are more likely to elect an auxiliary procedure to accelerate orthodontic tooth movement.

- The complexity of the treatment mechanics may need to be considered when determining the duration of the aligner wear despite the auxiliary procedure to increase the rate of orthodontic tooth movement. 


\section{CHAPTER 7: RECOMMENDATIONS FOR FUTURE RESEARCH}

\section{Recommendations on Sample Collection}

The current study can yield a more definitive conclusion if the samples included the CAT with 3-day aligner wear without MOP and the CAT with 14-day aligner wear with MOP. However, this was not possible in this retrospective study due to the ethical reasons and the limitation of the available data. Moreover, Align Technology recently announced a change in the protocol, promoting a 7-day aligner wear instead of 14. It may be worthwhile to investigate the accuracy of tooth movement within 7 days and compare to the current data of the 3-day aligner wear CAT combined with MOPs.

\section{Recommendations on Methodology}

Visual verification to align the post-treatment and the prediction scans with the pretreatment scans may introduce some variability in the interpretation of the direction and the magnitude of tooth movement. For future research, the same samples can be analyzed using software that can consistently superimpose the scans using a programmed algorithm to reduce the variability in overlaying of the scans. Also, the chosen method with the CloudCompare software introduces a fair amount of variability indicated by the reported standard deviations. Software that is more sensitive with small measurements can be used instead to reduce the variability in the angular and linear measurements of the tooth displacement. 


\section{REFERENCES}

1. Long H, Pyakurel U, Wang Y, Lioa L, Zhou Y, Lai W. Interventions for accelerating orthodontic tooth movement: A systematic review. Angle Orthod. 2013;83(1)164-71.

2. Segal GR, Schiffman PH, Tuncay OC. Meta analysis of the treatment-related factors of external apical root resorption. Orthod Craniofacial Res 7, 2004;71-8.

3. Cruz DR, Kohara EK, Ribeiro MS, Wetter NU. Effects of low-intensity laser therapy on the orthodontic movement velocity of human teeth: a preliminary study. Lasers Surg Med. 2004;35:117-20.

4. Fischer TJ. Orthodontic treatment acceleration with corticotomy-assisted exposure of palatally impacted canines. Angle Orthod 2007;77:417-420.

5. Kim DH, Park YG, Kang SG. The effects of electrical current from a micro-electrical device on tooth movement. Korean J Orthod. 2008;38:337-46.

6. Kim YS, Kim, SJ, Yoon HJ, Lee PJ, Moon W, Park YG. Effect of piezopuncture on tooth movement and bone remodeling in dogs. Am J Orthod Dentofacial Orthop. 7, 2013;144(1):2331.

7. Alikhani M, Raptis M, Zoldan B, Sangsuwon C, Lee YB, Alyami B, Corpodian C, Barrera LM, Alansari S, Khoo E, Teixeira C. Effect of micro-osteoperforations on the rate of tooth movement. Am J Orthod Dentofacial Orthop. 11, 2013;144(5):639-48.

8. Huang H, Williams RC, Kyrkanides S. Accelerated orthodontic tooth movement: Molecular mechanisms. Am J Orthod Dentofacial Orthop 2014;146:620-32.

9. Kharkar VR, Kotraschetti SM, Kulkarni P. Comparative evaluation of dento-alveolar distraction and periodontal distraction assisted rapid retraction of the maxillary canine: A pilot study. Int J Oral Maxillofac Surg. 2010;39:1074-9.

10. Shetty N, Patil AK, Ganeshkar SV, Hedge S. Comparison of the effects of ibuprofen and acetaminophen on $\mathrm{PGE}_{2}$ levels in the GCF during orthodontic tooth movement: a human study. Prog Orthod. 2013;14:6.

11. Bartzela T, Turp JC, Motschall E, Maltha JC. Medication effects on the rate of orthodontic tooth movement: A systemic literature review. Am J Orthod Dentofacial Orthop. 2009;135:1626.

12. Toro EJ, Zuo J, Guiterrez A, La Rosa RL, Gawron AJ, Bradaschia-Correa V, Arana-Chavez V, Dolce C, Rivera MF, Kesavalu L, Bhattacharyya I, Neubert JK, Holliday LS. Bis-enoxacin 
inhibits bone resorption and orthodontic tooth movement. J Dent Res. 2013 Oct;92(10):925-31.

13. Richter AE, Arruda AO, Peters MC, Sohn W. Incidence of caries lesions among patients treated with comprehensive orthodontics. Am J Orthod Dentofacial Orthop. 2011;139(5):657-64.

14. Brezniak N, Wasserstein A. Root resorption after orthodontic treatment: Part 1. Literature review. Am J Orthod Dentofacial Orthop. 1993;103(1):62-6.

15. Royko A, Denes Z, Razouk G. The relationship between the length of orthodontic treatment and patient compliance. Fogorv Sz. 1999;92:79-86.

16. Zachrisson S, Zachrisson BU. Gingival condition associated with orthodontic treatment. Angle Orthod. 1972;42(1):26-34.

17. Cruz DR, Kohara EK, Ribeiro MS, Wetter NU. Effects of low-intensity laser therapy on the orthodontic movement velocity of human teeth: a preliminary study. Lasers Surg Med.

2004;35:117-120.

18. Yamaguchi M, Hayashi M, Fujita S, et al. Low-energy laser irradiation facilitates the velocity of tooth movement and the expressions of matrix metalloproteinase-9, cathepsin $\mathrm{K}$, and alpha(v) beta(3) integrin in rats. Eur J Orthod. 2010;32:131-139.

19. Hassan AH, Al-Fraidi AA, Al-Saeed SH. Corticotomy-assisted orthodontic treatment: review. Open Dent J. 2010;4:159-164.

20. Aboul-Ela SM, El-Beialy AR, El-Sayed KM, Selim EM, El-Mangoury NH, Mostafa YA. Miniscrew implant-supported maxillary canine retraction with and without corticotomyfacilitated orthodontics. Am J Orthod Dentofacial Orthop. 2011;139:252-259.

21. Liou EJ, Huang CS. Rapid canine retraction through distraction of the periodontal ligament. Am J Orthod Dentofacial Orthop. 1998;114:372-382.

22. Sayin S, Bengi AO, Gurton AU, Ortakoglu K. Rapid canine distalization using distraction of the periodontal ligament: a preliminary clinical validation of the original technique. Angle Orthod. 2004;74:304-315.

23. Iseri H, Kisnisci R, Bzizi N, Tuz H. Rapid canine retraction and orthodontic treatment with dentoalveolar distraction osteogenesis. Am J Orthod Dentofacial Orthop. 2005;127: 533-541.

24. Shipley TS. The use of Propel to increase the rate of aligner progression. Orthod Practice US. March 22, 2014. http://orthopracticeus.com/magazine-articles/columns/the-use-of-propel-toincrease-the-rate-of-aligner-progression.

25. Frost HM. The regional acceleratory phenomenon: a review. Henry Ford Hops Med J. 1983; 31(1):3-9. 
26. Buschang PH, Ross M, Shaw SG, Crosby D, Campbell PM. Predicted and actual end-oftreatment occlusion produced with aligner therapy. Angle Orthod. 2015; 85(5): 723-727.

27. Chisari JR, McGorray SP, Nair M, Wheeler TT. Variables affecting orthodontic tooth movement with clear aligners. Am J Orthod Dentofacial Orthop. 2014; 145(4): 82-91.

28. Kravitz ND, Kusnoto B, BeGole E, Obrez A, Agran B. How well does Invisalign work? A prospective clinical study evaluating the efficacy of tooth movement with Invisalign. Am J Orthod Dentofacial Orthop. 2009; 135(1): 27-35.

29. Nishijima Y, Yamaguchi M, Kojima T, Aihara N, Nakajima R, Kasai K. levels of RANKL and OPG in gingival crevicular fluid during orthodontic tooth movement and effect of compression force on releases from periodontal ligament cells in vitro. Orthod Craniofac Res. 2006; 9:63-70.

30. Toygar HU, Kircelli BH, Bulut S, Sezgin N, Tasdelen B. Osteoprotegerin in gingival crevicular fluid under long-term continuous orthodontic force application. Angle Orthod. 2008; 78:988-993.

31. Kanzaki H, Chiba M, Shimizu Y, Mitani H. Periodontal ligament cells under mechanical stress induce osteoclasogenesis by receptor activator of nuclear factor kappaB ligand upregulation via prostaglandin E2 synthesis. J Bone Miner Res. 2002; 17:210-220.

32. Janssens K, ten Dijke P, Janssens S, Van Hul W. Transforming growth factor-beta 1 to the bone. Endocr Rev. 2005; 26:743-774.

33. Uematsu S, Mogi M, Edguchi T. Increase of transforming growth factor-beta 1 in gingival crevicular fluid during human orthodontic tooth movement. Arch Oral Biol. 1996; 41: 10911095.

34. Wang LL, Zhu H, Liang T. Changes of transforming rowth factor beta 1 in rat periodontal tissue during orthodontic tooth movement. Chin J Dent Res. 2000; 3:19-22.

35. Street J, Lenehan B. Vascular endothelial growth factor regulates osteoblast survival evidence for an autocrine feedback mechanism. J Orthop Surg Res. 2009; 4:19.

36. Krishnan V, Davidovitch Z. Cellular, molecular, and tissue-level reactions to orthodontic force. 2006; 129: 469e.1-460e.32).

37. Bassett CAL. Biologic significance of piezoelectricity. Tissue Res. 1968; 1:252-272.

38. Yasuda I, Nogucki K, Sata T. Dyanamic calluls and electrical callus. J Bone joint Surg. 1955; 37A: 1291-1293.

39. Grimm FM. Bone bending, a feature of orthodontic tooth movement. Am J Orthod. 1972; 62: 
384-393.

40. Levy DD. A pulsed electrical stimulation technique for inducing bone growth. Ann NY Acad Sci. 1974; 238:478-490.

41. Friedenberg ZB, Andrews ET, Smolensky BQ, Pearl BW, Brighton CT. Bone reaction to varying amounts of direct current. Surg Gynecol Obstet. 1970; 131:894-899.

42. Shapiro E, Roeber FW, Klempner LS. Orthodontic movement using pulsating force-induced piezoelectricity. Am J Orthod. 1979; 76:59-66.

43. Fukada E, Yasuda I. On the piezoelectric effect of bone. J Physiol Soc Jpn. 1957; 12:11581162.

44. Proffit WR. The biologic basis of orthodontic therapy. In: Proffit WR, Fields HW, Sarver DM, editors. Contemporary Orthodontics. $5^{\text {th }}$ ed. St. Louis: Mosby; 2013.

45. Lee W. Experimental study of the effect of prostaglandin administration on tooth movement with particular emphasis on the relationship to the method of $\mathrm{PGE}_{1}$ administration. Am J Orthod Dentofacial Orthop. 1990; 98:238-241.

46. Leiker BJ, Nanda RS, Currier GF, Howes RI, Sinha PK. The effects of exogenous prostaglandins on orthodontic tooth movement in rats. Am J Orthod Dentofacial Orthop. 1995; 108:380-388.

47. Krishnan V, Davidovitch Z. Cellular, molecular, and tissue-level reactions to orthodontic force. Am J Orthod Dentofacial Orthop. 2006; 129:469e.1-460e.32.

48. Verna C. Regional acceleratory phenomenon. Front Oral Biol. 2016; 18:28-35.

49. King GJ, Keeling SD, Wronski TJ. Histomorphometric study of alveolar bone turnover in orthodontic tooth movement. Bone. 1991; 12:401-409.

50. Melsen B. Bioligcal reaction of alveolar bone to orthodontic tooth movement. Angle Orthod. 1999; 69:151-158.

51. Verna C. Zaffe D, Siciliani G. Histomorphometric study of bone reactions during orthodontic tooth movement in rats. Bone. 1999;24:371-379.

52. Frost HM. Wolff's law and bone's structural adaptations to mechanical usage: an overview for clinicians. Angle Orthod. 1994; 64:175-188.

53. Hoogeveen EJ, Jansma J, Ren Y. Surgically facilitated orthodontic treatment: a systematic review. Am J Orthod Dentofacial Orthop. 2014; 145:51-64. 
54. Gkantidis N, Mistakidis I, Kouskoura T, Pandis N. Effectiveness of non-conventional methods for accelerated orthodontic tooth movement: a systematic review and meta-analysis. $\mathrm{J}$ Dent. 2014; 42(10): 1300-1319.

55. Teixeira CC, Khoo E, Tran J, Chartres I, Liu Y, Thant LM, Khabensky I, Gart LP, Cisneros G, Alikhani M. Cytokine expression and accelerated tooth movement. J Dent Res. 2010; 89:1135-1141.

56. Clements KM, Bollen AM, Huang G, King G, Hujoel P, Ma T. Activation time and material stiffness of sequential removable orthodontic appliances. Part 2: Dental improvements. Am J Orthod Dentofacial Orthop. 2003; 124:502-508.

57. Wong BH. Invisalign A to Z. Am J Orthod Dentofacial Orthop. 2002; 121:540-541.

58. Dasy H, Dasy A, Asatrian G, Rozsa N, Lee HF, Kwak JH. Effects of variable attachment shapes and aligner material on aligner retention. Angle Orthod. 2015; 85:934-940.

59. Simon M, Keilig L, Schwarze J, Jung BA, Bourauel C. Forces and moments generated by removable thermoplastic aligners: Incisor torque, premolar derotation, and molar distalization. Am J Orthod Dentofacial Orthop. 2014; 145:728-736.

60. Ercoli F, Tepedino M, Parziale V, Luzi C. A comparative study of two different clear aligner systems. Progress in Orthodontics. 2014; 15:31.

61. Drake CT, McGorray SP, Dolce C, Nair M, Wheeler TT. Orthodontic tooth movement with clear aligners. ISRN Dentistry. 2012; 657973.

62. Rossini G, Parrini S, Castroflorio T, Deregibus A, Debernardi CL. Efficacy of clear aligners in controlling orthodontic tooth movement: A systematic review. Angle Orthod. 2015; 85:881889.

63. Krieger E, Seiferth J, Saric I, Jung BA, Wehrbein H. Accuracy of Invisalign treatments in the anterior tooth region: First results. J Orthof Orthop. 2011; 72:141-149.

64. Krieger E, Seiferth J, Marinello I, Jung BA, Wriedt S, Jacobs C, Wehrbein H. Invisalign treatment in the anterior region: Were the predicted tooth movements achieved? J Orofac Orthop. 2012; 73:365-376.

65. Cha BK, Lee JY, Jost-Brinkmann PG, Yoshida N. Anaylsis of tooth movement in extraction cases using three-dimensional reverse engineering technology. Eur J Orthod. 2007; 29:325-331.

66. Lee SJ, Jang SY, Chun YS, Lim WH. Three-dimensional analysis of tooth movement after intrusion of a supraerupted molar using a mini-implant with partial-fixed orthodontic appliances. Angle Orthod. 2013; 83:274-279. 
67. Chen J, Li S, Fang S. Quantification of tooth displacement from cone-beam computed tomography images. Am J Orthod Dentofacial Orthop. 2009; 136:393-400.

68. Hayashi K, Araki Y, Uechi J, Ohno H, Mizoguchi I. A novel method for the threedimensional (3-D) analysis of orthodontic tooth movement - calculation of rotation about and translation along the finite helical axis. J Biomech. 2002; 35:45-51.

69. Jang I, Tanaka M, Koga Y, ligima S, Yozgatian JH, Cha BK, Yoshida N. A novel method for the assessment of three-dimensional tooth movement during orthodontic treatment. Angle Ortho. 2009; 79:447-453.

70. Hayashi K, Uechi J, Lee SP, Mizoguchi I. Three-dimensional analysis of orthodontic tooth movement based on XYZ and finite helical axis systems. Eur J Orthod. 2007; 29:589-595.

71. CloudCompare. http://www.danielgm.net/cc/.

72. Manuel CT, Harb R, Badran A, Ho D, Wong BJF. Finite element model and validation of nasal tip deformation. Ann Biomed Eng. 2016. DOI: 10.1007/s10439-016-1729-9.

73. Beaini TL, Duailibi-Neto EF, Chilvarquer I, Melani RFH. Human idenfitication through frontal sinus 3D superimposition: Pilot study with cone beam computer tomography. J Forensic Leg Med. 2015; 36: 63-69.

74. Kitaura, H, Kimura K, Ishida M, Takano-Yamamoto T. Effect of cytokines on osteoclast formation and bone resorption during mechanical force loading of the periodontal membrane. Scientific World J. 2014(5):617032.

75. PROPEL Orthodontics. http://propelorthodontics.com

76. Ren Y, Maltha JC, Van't Hof MA, Kuijpers-Jagtman AM. Age effect on orthodontic tooth movement in rats. J Dent Res. 2003;82(1):38-42. 


\section{APPENDICES}

\section{Appendix A - IRB Exemption}

\begin{tabular}{|c|c|}
\hline \multirow{2}{*}{\multicolumn{2}{|c|}{ Acknowledgement Letter Exempt Initial Protocol Review }} \\
\hline & \\
\hline \multirow{6}{*}{$\begin{array}{l}\text { Action Date } \\
\text { To } \\
\text { From } \\
\text { Approval Date } \\
\text { Expiration Date } \\
\text { Subject }\end{array}$} & 08/24/2016 \\
\hline & Peter Ngan \\
\hline & WVU Office of Research Integrity and Compliance \\
\hline & $08 / 24 / 2016$ \\
\hline & 08/23/2019 \\
\hline & Acknowledgement Letter Exempt Initial Protocol Review \\
\hline \multirow{2}{*}{$\begin{array}{l}\text { Protocol Number } \\
\text { Title }\end{array}$} & 1606156142 \\
\hline & $\begin{array}{l}\text { Effect of Micro-Osteoperforation on Orthodontic Tooth Movement in Clear } \\
\text { Aligner Therapy }\end{array}$ \\
\hline \multicolumn{2}{|c|}{$\begin{array}{l}\text { The above-referenced study was reviewed by the West Virginia University Institutional Review Board IRB and } \\
\text { was granted exemption in accordance with } 45 \text { CFR } 46.101 .\end{array}$} \\
\hline \multicolumn{2}{|c|}{$\begin{array}{l}\text { - This research study was granted an exemption in accordance with Research on existing data, documents, } \\
\text { records, pathological specimens, or diagnostic specimens [ } 45 \text { CFR } 46.101(4) \text { ]. In accordance with } \\
\text { the Health Insurance Portability and Accountability Act, a waiver of research authorization has been } \\
\text { granted. Please fulfill the subject accounting requirements associated with the granting of this waiver. } \\
\text { All exemptions are only good for three years. If this research extends more than three years beyond the } \\
\text { approved date, then the researcher will have to request another exemption. The following documents have } \\
\text { been acknowledged for use in this study and are available in the WVU+kc system: }\end{array}$} \\
\hline \multicolumn{2}{|c|}{ Documents reviewed and/or approved as part of this submission: } \\
\hline \multicolumn{2}{|c|}{ Signed HIPAA Data Use Agreement.pdf: 2016-08-22-04:00 } \\
\hline \multicolumn{2}{|c|}{ HIPAA Waiver Form.pdf: 2016-08-22-04:00 } \\
\hline \multicolumn{2}{|c|}{ Letter of Permission to Conduct Research Signed.pdf: 2016-08-22-04:00 } \\
\hline \multicolumn{2}{|c|}{ Data Collection Sheet.rlsx: 2016-08-22-04:00 } \\
\hline
\end{tabular}


Documents for use in this study have been acknowledged and are available in the WVUkc system in the Notes and Attachments section of your protocol.

The Office of Research Integrity and Compliance is here to provide assistance to you from the initial submission of an IRB protocol and all subsequent activity. Please feel free to contact us by phone at 304.293 .7073 with any question you may have. Thank you.

WVU Office of Research Integrity and Compliance

Date:08/24/2016

Signed:

Avoton nagner

Afton Wagner IRB Administrator 


\section{Letter of Permission to Conduct Research}

I, Dr. Thomas Shipley, owner of Shipley Orthodontics, give my permission for Dr. DoBin Choi to conduct her study entitled "Effect of Micro-Osteoperforation on Orthodontic Tooth Movement with Clear Aligner Therapy" at Shipley Orthodontics in Peoria, AZ.

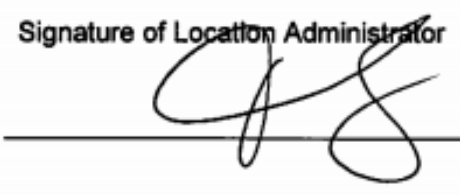

Printed Location Administrator Name

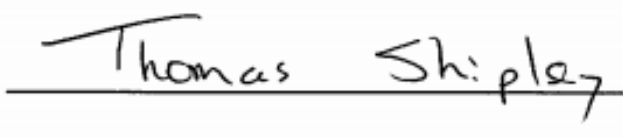

Date

$2 / 4 / 2016$ 


\section{Appendix C-HIPAA Data Use Agreement for Limited Data Sets}

\section{DATA USE AGREEMENT FOR LIMITED DATA SETS}

This Data Use Agreement ("Agreement"), effective as of October 23,2015 ("Effective Date"), is entered into by and between Dr. DoBin Choi ("Recipient") and Dr. Thomas Shipley ("Covered Entity"). The purpose of this Agreement is to provide Recipient with access to a Limited Data Set ("LDS") for use in the following titled research project: The Effect of Micro-osteoperformation on Orthodontic Tooth Movement with Clear Aligner Therapy (Project Name) under the direct supervision of Dr. Peter Ngan (Principal Investigator) in accord with the HIPAA Regulations.

1. Definitions. Unless otherwise specified in this Agreement, all capitalized terms used in this Agreement not otherwise defined have the meaning established for purposes of the "HIPAA Regulations" codified at Title 45 parts 160 through 164 of the United States Code of Federal Regulations, as amended from time to time.

2. Preparation of the LDS. Covered Entity shall prepare and furnish to Recipient a LDS in accord with the HIPAA Regulations or Covered Entity shall retain Recipient as a Business Associate (pursuant to an appropriate Business Associate Agreement) and direct recipient, as its Business Associate, to prepare such LDS. NOTICE: This agreement is valid only if the Data do not include any of the following "Prohibited Identifiers": Names; postal address information other than town, cities, states and zip codes; telephone and fax numbers; email addresses, URLs and IP addresses; social security numbers; certificate and license numbers; vehicle identification numbers; device identifiers and serial numbers; biometric identifiers (such as voice and fingerprints); and full face photographs or comparable images.

3. Minimum Necessary Data Fields in the LDS. In preparing the LDS, Covered Entity or its Business Associate shall include the data fields specified by the parties from time to time, which are the minimum necessary to accomplish the purposes set forth in Section 5 of this Agreement.

4. Responsibilities of Recipient. Recipient agrees to:

a. Use or disclose the LDS only as permitted by this Agreement or as required by law;

b. Use appropriate safeguards to prevent use or disclosure of the LDS other than as permitted by this Agreement or required by law;

c. Report to Covered Entity any use or disclosure of the LDS of which it becomes aware that is not permitted by this Agreement or required by law, including the presence of prohibited identifiers in the LDS;

d. Require any of its subcontractors or agents that receive or have access to the LDS to agree to the same restrictions and conditions on the use and/or disclosure of the LDS that apply to Recipient under this Agreement; and 
e. Not use the information in the LDS, alone or in combination to identify or contact the individuals who are data subjects.

5. Permitted Uses and Disclosures of the LDS. Recipient may use and/or disclose the LDS only for the Research described in this Agreement or as required by law.

6. Term and Termination.

a. Term. The term of this Agreement shall commence as of the Effective Date and terminate 5 years from Effective Date. Should the Recipient desire to keep the LDS for a longer period, a justification in writing should be made to the Covered Entity.

b. Termination by Recipient. Recipient may terminate this agreement at any time by notifying the Covered Entity and returning or destroying the LDS.

c. Termination by Covered Entity. Covered Entity may terminate this agreement at any time by providing thirty $(30)$ days prior written notice to Recipient.

d. For Breach. Covered Entity shall provide written notice to Recipient within ten (10) days of any determination that Recipient has breached a material term of this Agreement. Covered Entity shall afford Recipient an opportunity to cure said alleged material breach upon mutually agreeable terms. Failure to agree on mutually agreeable terms for cure within thirty $(30)$ days shall be grounds for the immediate termination of this Agreement by Covered Entity.

e. Effect of Termination. Sections 1, 4, 5, 6(e) and 7 of this Agreement shall survive any termination of this Agreement under subsections c or d.

\section{Miscellaneous.}

a. Change in Law. The parties agree to negotiate in good faith to amend this Agreement to comport with changes in federal law that materially alter either or both parties' obligations under this Agreement. Provided however, that if the parties are unable to agree to mutually acceptable amendment(s) by the compliance date of the change in applicable law or regulations, either Party may terminate this Agreement as provided in section 6.

b. Construction of Terms. The terms of this Agreement shall be construed to give effect to applicable federal interpretative guidance regarding the HIPAA Regulations.

c. No Third Party Beneficiaries. Nothing in this Agreement shall confer upon any person other than the parties and their respective successors or assigns, any rights, remedies, obligations, or liabilities whatsoever.

d. Counterparts. This Agreement may be executed in one or more counterparts, each of which shall be deemed an original, but all of which together shall constitute one and the same instrument. 
IN WITNESS WHEREOF, each of the undersigned has caused this Agreement to be duly executed in its name and on its behalf.

COVERED ENPTYY

By:

Print Nameit Thanas Shiploy

Print Title: orshidactst

$2 / 4 / 2016$
RECIPIENT

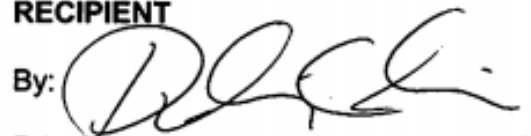

Print Name: DoBin Choi, DDS

Print Title: Orthodontic Resident 


\section{Appendix D - HIPAA Waiver of Research Authorization Form}

\author{
W. WesthirginiaUniversity \\ Office of Research Integrity and Compliance
}

\author{
Health Insurance Portability and \\ Accountability Act (HIPAA) \\ Request for Waiver of Research
} Authorization

It is the responsibility of the Principal Investigator to ensure that the West Virginia University, as required, has on file a written account of all records accessed under this waiver of research authorization.

Indicate what will determine the termination of this waiver:

Upon study termination

Enter the waiver of research authorization end date: _April 19, 2017

If you answered "Other" above, please explain:

Who will disclose, receive, and/or use the information?

The information will be provided by one of the co-investigators, Dr. Thomas Shipley from Shipley Orthodontics (Peoria, AZ). The information is received and analyzed by Dr. DoBin Choi and Dr. Peter Ngan.

What information will be used or disclosed?

The information used for the study involve pre- and post-treatment intraoral scans, intraoral scans of predicted treatment outcome, and pre- and post-treatment CBCT scans in addition to general demographic information, such as age, gender, and race.

Who will have access to, or use of, the Private Health Information (PHI)?

Only Dr. Thomas Shipley will have the access to the information of the subjects involved in the study. However, any of the personal/identifiable information will NOT be transferred to other investigators who are involved in data analysis.

How will the PHI be used or disclosed?

No identifiable information will be used or disclosed for the study.

Please describe the security measures to protect the HIPAA PHI:

Each subject will be assigned to a random ID number, which will be used to transfer the data instead of any identifiable information. The data transferred will not include any protected health information to protect the HIPAA PHI and ensure confidentiality of the subjects included in the study. 
W. WesthrginiaUniversity

Otilice of Research Integrity and Complance
Health Insurance Portability and Accountability Act (HIPAA)

Request for Waiver of Research Authorization

When do you plan to destroy the HIPAA PHI?

The patient information will be destroyed at the conclusion of the study, April 19, 2017.

How do you plan to destroy the HIPAA PHI?

The data will be in a digital form, which will be permanently deleted.

Why would the research be impracticable without the waiver of research authorization? Analysis of the intraoral scans and CBCT images is an essential part of the study.

With respect to the waiver, you are only allowed to review the relevant minimum necessary information required in order to complete the study.

$\checkmark$ Please check this box to assure the Institutional Review Board (IRB) that this is the minimum necessary information needed to conduct the study with this waiver. 


\section{Appendix E-Raw Data \& Statistical Analyses}

Raw Data

Control

\begin{tabular}{|c|c|c|c|c|c|c|c|}
\hline \multicolumn{4}{|c|}{ \#6 } & \multicolumn{4}{|c|}{$\# 7$} \\
\hline$\Delta \mathrm{V}$ & $\Delta x^{\circ}$ & $\Delta y^{\circ}$ & $\Delta z^{\circ}$ & $\Delta \mathrm{V}$ & $\Delta x^{0}$ & $\Delta y^{\circ}$ & $\Delta z^{\circ}$ \\
\hline 2.049096 & 1.756936 & 0.361499 & 0.95196 & 2.157742 & 1.308557 & 0.746785 & 0.838368 \\
\hline 1.450983 & 0.522909 & 6.478438 & 1.452057 & 0.984109 & 0.522497 & 0.555256 & 1.344574 \\
\hline 4.787782 & 1.048626 & 0.105975 & 0.567682 & 1.649083 & 0.289595 & 1.238961 & 0.743022 \\
\hline 1.995202 & 0.683417 & 0.027499 & 0.319329 & 3.443079 & 2.806072 & 3.323187 & 2.279155 \\
\hline 4.350422 & 1.431219 & 1.128356 & 1.756287 & 3.613649 & 0.213732 & 0.294004 & 1.08581 \\
\hline 3.229938 & 3.970314 & 0.829701 & 0.000744 & 2.053435 & 0.622711 & 0.696667 & 0.504289 \\
\hline 2.634639 & 3.08932 & 4.637364 & 0.63511 & 3.461342 & 0.757185 & 12.88682 & 2.161923 \\
\hline 0.848152 & 0.32796 & 0.098684 & 0.693938 & 2.750289 & 0.869971 & 1.124417 & 8.769427 \\
\hline 0.792549 & 1.055538 & 0.140161 & 98 & 6.895034 & 18.88837 & 2.941783 & 1.781111 \\
\hline 2.196869 & 1.910957 & 4.571517 & 0.132927 & 0.807661 & 1.306757 & 1.301276 & 0.647371 \\
\hline 1.149922 & 0.410011 & 0.369812 & 0.313097 & 5.638871 & 0.344924 & 45.35777 & 1.042123 \\
\hline 4.276363 & 1.555788 & 0.790307 & 0.729122 & 0.485087 & 1.020621 & 1.125705 & 0.584998 \\
\hline 1.85771 & & & & & & & 1.044166 \\
\hline 3.066178 & 3.467783 & 0.935138 & 0.462539 & 2.832669 & 3.290714 & 0.466849 & 0.10771 \\
\hline 2.231194 & 0.622546 & 3.157655 & 0.137701 & 1.859488 & 0.228888 & 0.911062 & 0.84801 \\
\hline 2.013071 & 0.759917 & 0.149292 & 0.490558 & 1.108284 & 0.516254 & 0.222115 & 0.099836 \\
\hline 2.656224 & 0.897132 & 0.971092 & 0.548337 & 3.355949 & 0.848009 & 0.498775 & 0.624137 \\
\hline 3.878567 & 0.70423 & 0.253998 & 0.31601 & 2.431444 & 0.909437 & 0.457205 & 1.597374 \\
\hline 1.832655 & 4.476667 & 1.097565 & 0.964344 & 3.409833 & 0.683413 & 2.022379 & 0.798754 \\
\hline 2.835404 & 3.25411 & 1.036119 & 1.677988 & 2.235568 & 1.840137 & 0.077498 & 0.401145 \\
\hline 5.402112 & 0.863831 & 0.654403 & 0.89572 & 3.291214 & 0.165361 & 0.971827 & 0.92704 \\
\hline 4.139003 & 1.245245 & 0.894382 & 1.128684 & & & & \\
\hline 6.318498 & 0.795082 & 0.957237 & 3.57483 & 3.802987 & 0.706163 & 0.103104 & 0.757253 \\
\hline 2.508384 & 0.877889 & 0.665125 & 0.536873 & 1.890797 & 1.570985 & 1.030102 & 0.166313 \\
\hline 7.434493 & 1.449887 & 0.459638 & 0.685259 & 3.085863 & 0.323328 & 2.682984 & 0.258727 \\
\hline 3.17788 & 1.288952 & 1.391584 & 1.227952 & 2.859587 & 1.172098 & 0.879213 & 0.016334 \\
\hline 5.087044 & 0.694415 & 0.873556 & 0.701217 & 4.725453 & 0.948556 & 0.609116 & 0.379559 \\
\hline 2.122073 & 0.607006 & 0.005785 & 0.49614 & 3.130209 & 0.307433 & 1.861487 & 0.178138 \\
\hline 1.169507 & 0.408329 & 0.417527 & 0.242675 & 1.419468 & 2.599519 & 0.698153 & 2.206525 \\
\hline 1.361124 & 5.555127 & 0.267269 & 0.054589 & 1.841306 & 1.170989 & 1.302916 & 0.25701 \\
\hline
\end{tabular}




$\begin{array}{rrrrrrrr}6.956593 & 1.073728 & 1.301938 & 0.960405 & 3.884771 & 0.109468 & 0.699686 & 1.351152 \\ 0.892341 & 15.75109 & 7.22571 & 1.117234 & 5.993379 & 0.961363 & 0.517234 & 0.905058 \\ 0.398883 & 0.08433 & 0.12424 & 3.036422 & 2.392079 & 3.379229 & 0.655337 & 0.282435 \\ 1.799886 & 0.787782 & 0.813904 & 0.154629 & 4.219237 & 0.488566 & 4.805526 & 0.909718 \\ 1.174583 & 0.338093 & 0.317347 & 0.271742 & 1.884892 & 0.841597 & 0.220273 & 0.582115 \\ 1.451107 & 6.17037 & 0.456701 & 0.511062 & 2.313279 & 1.060909 & 2.921241 & 0.734761 \\ 2.185136 & 0.959223 & 13.50475 & 1.519192 & 2.695793 & 0.49241 & 1.769523 & 0.182766 \\ 1.953102 & 0.636674 & 1.225381 & 0.53216 & 1.266603 & 19.41111 & 0.77895 & 0.453795 \\ 0.238051 & 0.023128 & 0.203292 & 0.017418 & 2.816849 & 0.540312 & 3.712196 & 0.443385 \\ 0.835677 & 0.304113 & 1.216899 & 0.051817 & 1.036909 & 1.800932 & 0.382119 & 0.538635 \\ 3.227008 & 0.038127 & 5.227369 & 0.032402 & 3.879173 & 0.605109 & 0.599348 & 0.30864 \\ 2.438809 & 1.764116 & 2.180872 & 0.329563 & 1.139859 & 0.707028 & 3.791008 & 0.030393 \\ 0.726818 & 0.058216 & 0.424921 & 0.070538 & 1.236344 & 1.122928 & 0.080911 & 0.507456 \\ 1.144021 & 0.060384 & 0.170725 & 0.549354 & 0.791855 & 5.172108 & 0.67968 & 0.200898 \\ 5.027946 & 1.730685 & 0.000985 & 0.432678 & 0.604556 & 0.76073 & 0.074163 & 0.303108 \\ 3.252003 & 1.939435 & 0.188305 & 0.390999 & 4.198485 & 5.290341 & 0.374309 & 1.491154 \\ 1.525424 & 0.663366 & 0.147982 & 7.569257 & 3.827691 & 1.123312 & 1.87105 & 0.871284 \\ 1.105356 & 0.434966 & 0.312023 & 0.351875 & 1.353727 & 2.000001 & 0.379374 & 0.492253 \\ 5.351674 & 1.458417 & 0.851144 & 0.702504 & 7.102558 & 1.252337 & 1.436688 & 0.765057 \\ 1.308666 & 2.650987 & 0.368135 & 0.324306 & 1.945197 & 0.29058 & 0.179877 & 1.242205 \\ 3.993698 & 1.200638 & 0.518764 & 0.790432 & 2.283317 & 3.09739 & 0.057062 & 0.256517 \\ 5.055615 & 0.808658 & 0.528155 & 0.516139 & 2.684846 & 0.701959 & 0.577675 & 0.675672 \\ 3.23397 & 1.776669 & 0.144205 & 1.600453 & 3.72544 & 1.285709 & 0.260507 & 1.423666 \\ 1.651448 & 0.936455 & 0.039278 & 0.268757 & 1.519953 & 1.255024 & 0.05168 & 0.714964 \\ 4.995333 & 2.992391 & 0.770358 & 0.864086 & 5.309003 & 0.964055 & 1.092193 & 0.809208 \\ 4.260628 & 0.715337 & 0.261075 & 0.915531 & 2.231164 & 1.212439 & 0.639663 & 0.262206 \\ 0.995346 & 0.838317 & 1.367059 & 0.075151 & 4.044867 & 2.673072 & 0.069006 & 0.51679 \\ 1.96966 & 0.828557 & 0.382012 & 4.89519 & 2.484561 & 0.778082 & 1.706562 & 1.736717\end{array}$

\begin{tabular}{|c|c|c|c|c|c|c|c|}
\hline \multicolumn{4}{|c|}{ \#8 } & \multicolumn{4}{|c|}{$\# 9$} \\
\hline$\Delta \mathrm{V}$ & $\Delta \mathrm{x}^{\circ}$ & $\Delta y^{\circ}$ & $\Delta z^{\circ}$ & $\Delta \mathrm{V}$ & $\Delta x^{\circ}$ & $\Delta y^{\circ}$ & $\Delta z^{\circ}$ \\
\hline 3.176327 & 0.958168 & 0.250471 & 0.576432 & 1.512504 & 0.604136 & 0.015443 & 0.547967 \\
\hline 1.305187 & 0.431741 & 0.57813 & 1.279594 & 1.877008 & 0.647929 & 1.546015 & 0.366142 \\
\hline 2.212921 & 0.572228 & 0.152411 & 0.266893 & 2.583212 & 0.53747 & 14.1954 & 0.387381 \\
\hline 4.442844 & 4.102828 & 3.208358 & 1.165359 & & & & \\
\hline 3.621599 & 5.912757 & 1.429554 & 0.938246 & 2.113509 & 0.299153 & 0.761315 & 0.639706 \\
\hline 1.908621 & 0.55146 & 0.796165 & 0.533889 & 0.606196 & 0.33557 & 3.134427 & 0.436299 \\
\hline 1.755153 & 1.135631 & 0.873687 & 0.622658 & 0.80816 & 0.257713 & 0.372745 & 0.567152 \\
\hline 1.738121 & 0.149143 & 0.165229 & 0.066416 & 0.295737 & 0.02023 & 0.378919 & 0.237735 \\
\hline
\end{tabular}




\begin{tabular}{|c|c|c|c|c|c|c|c|}
\hline & & & & & & & \\
\hline 44 & 582 & & & & & & \\
\hline & 1606 & 57 & & & & & \\
\hline 6135 & 072366 & 57 & 289 & 36 & 003 & 791 & 2 \\
\hline 085121 & 577857 & .117984 & 0.513543 & 3.366035 & & 3.489283 & 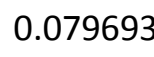 \\
\hline 371851 & 182992 & 67.89788 & 0.180664 & & & 0.433312 & .69450 \\
\hline 976607 & 0.362792 & 0.35366 & 0.447667 & 1.306504 & 7286 & 439 & 211 \\
\hline 904338 & .921207 & 0.843456 & 0.894 & 0.93 & 57 & 86 & \\
\hline 731262 & .824131 & 673 & 715 & 4.605 & & & \\
\hline & 876 & & 331 & & & & 026 \\
\hline 431921 & 0.917435 & 2.518127 & 656 & 168 & 753 & 818 & 730 \\
\hline 373783 & 671799 & 0.418452 & 0.850815 & 2.62 & 078 & 9622 & 481 \\
\hline 42 & & 629 & 32 & 4.40 & 321 & & 619 \\
\hline 97 & 4.21 & & & 0.78 & & & 36 \\
\hline 079722 & 1.26125 & .427428 & 958 & 6.25 & 809 & 635 & 420 \\
\hline 110082 & 0.803992 & 0.555208 & 18 & 1.61 & 656 & 24 & 185 \\
\hline 810934 & 0.67296 & 75 & 37 & 2.29 & & & 420 \\
\hline 575906 & 1.54 & 09 & & 4.78 & & & \\
\hline & 0.752109 & & & & & & \\
\hline 3.13866 & 0.109865 & 0.325918 & 0.46 & 9275 & & & 224 \\
\hline 784177 & & 1.565 & & 2.92 & & & 596 \\
\hline 862 & 0.422778 & & 35 & 0.3 & & & \\
\hline & & & & & & & \\
\hline 53 & 1.15 & 32 & 49 & & & & 25 \\
\hline & 2.25 & 93 & 24 & 3.0 & & & 91 \\
\hline 657724 & 0.3 & 29 & & & & & \\
\hline & 1.40 & & & & & & \\
\hline & & & & & & & \\
\hline & 0.46 & 95 & & & & & 247 \\
\hline 1.604886 & 0.043704 & 0.606 & 0.219942 & 1.415 & & & 351 \\
\hline & 3.85 & 91 & 68 & & & & 0 \\
\hline 1000 & & & & & & & \\
\hline \multirow[t]{2}{*}{1.91248} & 3.971234 & 0.057754 & 0.19254 & 10.22508 & & 912 & .5439 \\
\hline & & & & 1.28 & & 28 & 319 \\
\hline 445281 & 0.19 & 12.3 & 0.80 & & & & 0.4 \\
\hline & 0.638173 & 0.514939 & & & & & \\
\hline & 0.783394 & & & 2.977828 & & & 12010 \\
\hline 990985 & 0.569689 & 0.434788 & 0.993756 & 3.187755 & & 1.473066 & \\
\hline & & 0.103394 & 0.876413 & 3.851511 & & 0.744382 & \\
\hline 163707 & 6.125282 & 0.130223 & 0.237585 & 4.27922 & 3.770413 & 0.423463 & 0.3832 \\
\hline
\end{tabular}




$\begin{array}{rrrrrrrr}7.030072 & 1.34128 & 1.250187 & 0.550449 & 8.006138 & 1.261092 & 3.957293 & 0.214438 \\ 0.816553 & 0.509459 & 1.953555 & 0.405663 & 4.055225 & 1.161791 & 1.273688 & 0.534521 \\ 0.645925 & 0.504299 & 1.801717 & 0.678745 & 2.525481 & 2.301752 & 3.146523 & 0.452072 \\ 4.132305 & 0.8963 & 0.390536 & 0.626568 & 4.308706 & 0.622346 & 0.212154 & 0.566595 \\ 3.11422 & 1.513405 & 0.033071 & 0.198762 & 2.665379 & 1.514881 & 0.509344 & 0.074325 \\ 2.022233 & 4.36825 & 0.770266 & 1.23105 & 0.381709 & 60.60309 & 0.143988 & 5.113005 \\ 2.551127 & 0.703263 & 0.621165 & 0.462472 & 2.248179 & 0.866259 & 1.525144 & 1.23692 \\ 1.755788 & 0.022844 & 0.235125 & 0.470893 & 3.154203 & 0.432761 & 0.521685 & 8.217527 \\ 2.143899 & 2.506783 & 0.61653 & 0.363925 & 2.486045 & 4.804778 & 0.617302 & 0.746839 \\ 5.170052 & 1.144886 & 1.072179 & 0.716406 & 1.534898 & 0.898336 & 1.374345 & 0.737063\end{array}$

\begin{tabular}{|c|c|c|c|c|c|c|c|}
\hline \multicolumn{4}{|c|}{$\# 10$} & \multicolumn{4}{|c|}{ \#11 } \\
\hline$\Delta \mathrm{V}$ & $\Delta x^{\circ}$ & $\Delta y^{\circ}$ & $\Delta \mathrm{z}^{\circ}$ & $\Delta \mathrm{V}$ & $\Delta x^{\circ}$ & $\Delta y^{\circ}$ & $\Delta \mathrm{z}^{\circ}$ \\
\hline 3.05174 & 1.041862 & 0.410113 & 0.652494 & 1.766487 & 1.327408 & 0.417848 & 0.73714 \\
\hline 1.765522 & 0.417356 & 2.404407 & 1.839437 & 1.115592 & 0.840085 & 2.424687 & 3.445692 \\
\hline 1.05503 & 0.305242 & 74.63278 & 0.483459 & 2.593243 & 0.924083 & 0.944272 & 0.339833 \\
\hline 3.805674 & 1.914052 & 1.231103 & 0.410939 & 3.803603 & 1.453366 & 0.117634 & 0.334534 \\
\hline 3.895745 & 6.385894 & 0.126998 & 0.762698 & 4.31905 & 7.099233 & 1.296653 & 0.772088 \\
\hline 1.200331 & 0.23056 & 0.499105 & 0.439208 & 1.385236 & 1.682022 & 0.870474 & 0.675559 \\
\hline 1.585067 & 1.715843 & 0.352008 & 0.484631 & 4.348677 & 0.315497 & 0.946675 & 0.827588 \\
\hline 4.492801 & 12.84832 & 0.291771 & 5.228709 & 1.730578 & 1.414081 & 1.269645 & 0.330557 \\
\hline 2.979769 & 0.788258 & 1.006044 & 0.16656 & 1.320792 & 0.700049 & 0.256624 & 0.339083 \\
\hline 4.141654 & 0.497644 & 0.520975 & 0.70 & 1.94307 & 1.174423 & 11.36268 & 0.61963 \\
\hline 1.994165 & 1.107915 & 0.375775 & 0.721154 & 1.465511 & 1.131374 & 0.579105 & 0.35272 \\
\hline 1.966356 & 0.233206 & 0.72033 & 1.530365 & 1.980041 & 0.572593 & 0.512825 & 1.579406 \\
\hline 9.90659 & & & & & & & \\
\hline 3.908418 & 2.935257 & 6.987703 & 6.876848 & 2.865772 & 0.422996 & 0.490455 & 0.499647 \\
\hline 0.722644 & 0.613852 & 0.280564 & 0.639263 & 2.011854 & 4.547892 & 0.504733 & 0.311113 \\
\hline 2.32997 & 0.65698 & 0.403029 & 1.382049 & 1.410999 & 0.706715 & 0.116764 & 0.915905 \\
\hline 2.150617 & 0.89021 & 0.525467 & 0.410637 & 3.133421 & 13.27413 & 0.517035 & 0.463888 \\
\hline 3.707721 & 0.841245 & 0.512207 & 1.390677 & 5.536776 & 3.178841 & 0.111345 & 0.356198 \\
\hline 1.316531 & 1.013957 & 1.117135 & 1.00914 & 1.611488 & 0.848481 & 0.218861 & 0.685386 \\
\hline 3.186689 & 0.269112 & 0.655202 & 0.5676 & 4.157205 & 1.138437 & 0.37928 & 5.14923 \\
\hline 6.167893 & 0.983001 & 1.08663 & 0.982217 & 8.467115 & 1.029838 & 0.90854 & 0.898277 \\
\hline 0.959593 & 1.767996 & 1.041756 & 1.519295 & 2.656792 & 0.888714 & 0.781144 & 1.062104 \\
\hline 4.847455 & 0.23329 & 0.339179 & 0.452887 & 2.500746 & 0.632758 & 0.62337 & 4.152598 \\
\hline 1.636965 & 0.584086 & 0.31407 & 0.36327 & 2.309988 & 0.939728 & 0.524326 & 6.766727 \\
\hline 1.59799 & 0.267052 & 0.196626 & 0.496103 & 2.190061 & 2.499088 & 0.166848 & 1.089645 \\
\hline
\end{tabular}




\begin{tabular}{|c|c|c|c|c|c|c|c|}
\hline 3522 & 6245 & 9969 & 0.947283 & 2.793318 & 135 & 7969 & \\
\hline 1.118438 & 3.430506 & 0.712293 & 0.924558 & 2.191054 & 0.956454 & 2.552737 & .938733 \\
\hline .456717 & .112098 & 0.623431 & 0.214302 & 2.123567 & 0.625193 & 0.399508 & 862 \\
\hline 1.146619 & 2.23681 & 0.295784 & 0.828327 & 1.316226 & 0.476285 & 779376 & 0.063078 \\
\hline 0.982852 & 2.899932 & 0.091091 & 0.180004 & 1.608022 & 1.099283 & 161814 & \\
\hline 1.944046 & 0.100455 & 0.653159 & 0.523048 & 1.684268 & 3.395927 & 0.323206 & 0.497349 \\
\hline 3.115789 & 1.386273 & 0.971276 & 0.451874 & 3.309743 & 0.012038 & 4.219487 & 1.52 \\
\hline 6.283119 & 5.1458 & 0.062278 & 0.533884 & 1.959528 & 0.497812 & 1.025882 & 0.20 \\
\hline \multirow[t]{2}{*}{6.416451} & 0.850198 & 1.776097 & 1.31308 & & 2.821033 & & \\
\hline & & & & 0.756018 & 0.787322 & 1.022723 & \\
\hline .741829 & 0.243373 & 0.855 & 0.888931 & 3.854765 & 1.98462 & 0.641884 & 0.77 \\
\hline 0.964082 & 0.640032 & 1.061769 & 0.366054 & 1.28427 & 4.264106 & 1.003368 & 0.588745 \\
\hline 1.858128 & 4.314424 & 0.757338 & 0.335 & 85 & 1.010665 & 2.483742 & \\
\hline 3.094 & 1.363596 & 0.866822 & & & & & \\
\hline 1.446029 & 0.693001 & 9.013699 & 0.024361 & 2.454 & 1.931269 & 345 & 0.0 \\
\hline 10.44026 & 0.824106 & 2.268454 & 2.371622 & 0.759886 & 0.973 & 795 & 0.0 \\
\hline 0.615595 & 0.06139 & 0.16 & 56 & 3.74 & 328 & 501 & 0.9 \\
\hline $0.8 \varepsilon$ & 0.54 & & & & & & \\
\hline 3.522303 & 0.235063 & 1.194772 & & & & & \\
\hline 1.076332 & 1.249856 & 0.347085 & 0.318507 & 1.608528 & 0.412589 & 74 & \\
\hline 7.220785 & 5.165866 & 1.375178 & 0.522793 & 4.152125 & 1.13 & 5284 & $0.4 C$ \\
\hline 3.198319 & 0.96188 & 0.348304 & 0.60 & $3.367 €$ & 0.376623 & 2.123478 & \\
\hline 0.88037 & 3.173 & 0.259414 & 56 & & 49 & & \\
\hline 8.39954 & 1.2438 & 0.97 & & & & & \\
\hline 6.400668 & 14.67397 & 0.198674 & 0.643435 & 3.684864 & 0.568737 & 0.279558 & 0.5565 \\
\hline 1.615118 & 3.278627 & 0.484193 & 0.01273 & 2.827844 & 0.809762 & 0.054998 & 0.474564 \\
\hline 2.275046 & 7.934284 & 6.193514 & 1.550617 & 1.505948 & 0.549575 & 0.368973 & 0.427181 \\
\hline 1.953133 & 2.418223 & 1.009908 & 0.712082 & 2.195271 & 2.753233 & 0.130462 & \\
\hline 2.336942 & 0.695319 & 1.332155 & 0.05118 & 1.342212 & 11.35997 & 1.137517 & 0.4563 \\
\hline 4.178421 & 0.513148 & 0.98752 & 0.831782 & 3.92686 & 0.267486 & 1.487471 & $0.8241 C$ \\
\hline 1.537288 & 0.113705 & 0.721387 & 0.307583 & 4.274942 & 1.072578 & 0.984937 & 0.9432 \\
\hline 2.198825 & 2.366249 & 0.094568 & 0.295725 & 3.280929 & 0.498087 & 0.390989 & 0.2343 \\
\hline 2.505779 & 0.803011 & 3.474341 & 2.016501 & 2.059473 & 0.824536 & 1.404526 & 1.195802 \\
\hline
\end{tabular}

\begin{tabular}{|ccccccccc|}
\hline \multicolumn{3}{|c|}{$\# 22$} & \multicolumn{4}{c|}{$\# 23$} \\
\hline$\Delta \mathrm{V}$ & $\Delta \mathrm{x}^{\circ}$ & $\Delta \mathrm{y}^{\circ}$ & $\Delta \mathrm{z}^{\circ}$ & $\Delta \mathrm{V}$ & $\Delta \mathrm{x}^{\circ}$ & $\Delta \mathrm{y}^{\circ}$ & $\Delta \mathrm{z}^{\circ}$ \\
4.277382 & 0.573176 & 0.75396 & 0.773651 & 3.831018 & 0.501756 & 0.549248 & 0.816146 \\
2.244759 & 0.009559 & 1.177029 & 0.36993 & 1.175931 & 0.590531 & 0.126766 & 0.205297 \\
1.212753 & 2.995774 & 0.181232 & 0.235403 & 0.673987 & 0.26922 & 0.037709 & \\
\hline
\end{tabular}




\begin{tabular}{|c|c|c|c|c|c|c|c|}
\hline & & & & & & & \\
\hline 98 & 336 & 9 & & & & & \\
\hline & 82 & & & & & & \\
\hline 99 & 83 & 38 & & 509 & & & \\
\hline & & & & & & & \\
\hline & & & & & & & \\
\hline & .064681 & & & & & & \\
\hline 719 & 541451 & 773 & 190985 & 245 & 443 & 68 & \\
\hline 699 & 75 & 1.14 & & & & & \\
\hline 2 & 85 & 0.8 & & 11 & & & \\
\hline 7 & & & & 34 & & & \\
\hline 84 & 3.83 & 0.3 & 225 & 506 & & & \\
\hline 508 & .09 & 2.2 & & 0.570606 & & & $\theta$ \\
\hline 14 & 0.0 & 0.8 & & & & & \\
\hline 08 & & & & & & & \\
\hline 3.48 & & 0.1 & 565 & 558 & & & \\
\hline 512 & & 0.664 & 51 & 89 & 381 & & \\
\hline 4 & 5 & 0.1 & & 58 & & & \\
\hline & & & & & & & \\
\hline 513 & & & & & & & \\
\hline 75 & 2 & & & 27 & & & \\
\hline 51 & & 0.7 & & & & & \\
\hline 12 & & 0.4 & & & & & \\
\hline & & & & & & & \\
\hline 9 & & 2 & & & & & \\
\hline & & & & & & & \\
\hline 18 & & & & & & & \\
\hline 9 & & & & & & & \\
\hline & & & & & & & \\
\hline & & & & & & & \\
\hline 55 & & & & & & & \\
\hline 3 & & & & & & & \\
\hline & & & & & & & \\
\hline & & & & & & & \\
\hline 47 & 41 & 28.6 & & 981 & & 81 & \\
\hline 01 & & & & & 289 & & \\
\hline & & & & & & & \\
\hline & & & & & & & \\
\hline & 1.145494 & & & & & & \\
\hline & & & & & & & \\
\hline 410744 & 0.317806 & 11.86448 & 1.427367 & 0.878012 & 0.785458 & 0.622156 & 0.8698 \\
\hline
\end{tabular}




$\begin{array}{rrrrrrrr}0.572893 & 1.420977 & 3.712045 & 0.66996 & 0.437828 & 0.007048 & 0.643361 & 0.16826 \\ 1.579386 & 2.526552 & 0.331834 & 0.147982 & 2.38338 & 0.219181 & 0.613345 & 0.155539 \\ 1.293701 & 1.025195 & 1.387448 & 1.457942 & 2.689509 & 0.928387 & 0.820225 & 0.154091 \\ 0.49336 & 2.824074 & 0.274579 & 0.332238 & 3.029174 & 0.868872 & 0.439488 & 1.554432 \\ 1.274417 & 0.848843 & 0.055747 & 0.345911 & 1.94452 & 0.735915 & 0.138597 & 1.374255 \\ 2.510305 & 0.966338 & 6.488917 & 0.741782 & 3.036865 & 0.846624 & 1.389782 & 1.079546 \\ 6.443606 & 1.09089 & 1.293076 & 0.514893 & 2.061023 & 0.469045 & 0.576043 & 0.540174 \\ 3.019185 & 0.589338 & 1.511922 & 0.118995 & 2.777954 & 0.481701 & 1.255182 & 1.122317 \\ 4.89333 & 0.757478 & 0.802221 & 1.05262 & 3.68371 & 0.218875 & 0.152828 & 0.497436 \\ 1.024809 & 0.316805 & 3.532924 & 0.559185 & 1.298217 & 0.974293 & 0.458338 & 0.941007 \\ 1.486295 & 0.382404 & 0.009156 & 0.190072 & 2.176284 & 0.681358 & 0.173965 & 2.708501 \\ 10.31727 & 0.927767 & 0.932421 & 0.889993 & 2.344529 & 0.395351 & 0.983451 & 1.012604 \\ 4.742654 & 1.155231 & 0.752558 & 0.794426 & 11.55601 & 0.875286 & 0.804753 & 0.975643 \\ 4.279638 & 1.215506 & 0.039708 & 0.293882 & 1.764325 & 14.74713 & 3.675996 & 0.01078 \\ 0.808377 & 3.20539 & 15.89919 & 0.378832 & 0.783294 & 1.131882 & 0.416934 & 0.615694\end{array}$

\begin{tabular}{|c|c|c|c|c|c|c|c|}
\hline \multicolumn{4}{|c|}{$\# 24$} & \multicolumn{4}{|c|}{ \#25 } \\
\hline$\Delta \mathrm{V}$ & $\Delta \mathrm{x}^{\circ}$ & $\Delta y^{\circ}$ & $\Delta z^{\circ}$ & $\Delta \mathrm{V}$ & $\Delta x^{\circ}$ & $\Delta y^{\circ}$ & $\Delta z^{\circ}$ \\
\hline 2.182289 & 0.534194 & 0.565229 & 0.643319 & 2.363731 & 0.65732 & 0.390523 & 0.695286 \\
\hline 1.839466 & 0.333515 & 1.618665 & 0.814677 & 0.174057 & 1.043546 & 0.582195 & 1.079708 \\
\hline 2.649999 & 0.216418 & 0.127296 & 0.289539 & 3.469605 & 0.106091 & 0.324381 & 0.278019 \\
\hline 3.322474 & & 0.062679 & 1.658812 & 2.558796 & 3.032146 & 0.701867 & 0.922988 \\
\hline 5.154721 & 0.677292 & 0.718231 & 1.420333 & 4.799354 & 3.994433 & 0.185578 & 0.671533 \\
\hline 1.105221 & 0.714644 & 1.329004 & 0.258008 & 2.229282 & 0.648246 & 451 & 1.249813 \\
\hline 1.786195 & 0.577789 & 0.948887 & 2.263531 & 2.508286 & 3.340459 & 0.113168 & 0.251688 \\
\hline 3.625191 & 0.503568 & 0.295409 & 0.346724 & 0.914261 & 0.448368 & 0.932854 & 0.067988 \\
\hline 4.381914 & 0.25238 & 7.234854 & 0.827463 & 2.297521 & 0.050361 & 1.146608 & 0.416677 \\
\hline 2.594228 & 0.459418 & 0.034668 & 9 & 1.980994 & 1.216891 & 0.237498 & 0.828877 \\
\hline 1.070174 & 0.377444 & 0.107575 & 0.298591 & 0.80289 & 0.918072 & 1.059249 & 1.166281 \\
\hline 0.379378 & 0.629928 & 1.403124 & 0.783309 & 3.699927 & 1.374947 & 0.957043 & 1.181787 \\
\hline 3.303928 & 0.871012 & 0.939499 & 0.99757 & 1.238602 & 7.125203 & 0.553253 & 0.733851 \\
\hline 1.921428 & 0.552408 & 0.192082 & 0.807011 & 2.044783 & 0.268669 & 0.030185 & 0.967294 \\
\hline 4.390566 & 31.35324 & 0.144515 & 0.029801 & 4.637821 & 37.87329 & 0.622449 & 0.179297 \\
\hline 1.852025 & 0.232351 & 0.692024 & 1.233821 & 0.945513 & 0.442011 & 0.313789 & 0.211414 \\
\hline 0.593987 & 0.205534 & 0.333559 & 4.036575 & 0.765011 & 0.08792 & 0.244104 & 0.322979 \\
\hline 1.732705 & 0.842621 & 0.042288 & 0.265792 & 2.434033 & 0.528507 & 1.831951 & 0.644007 \\
\hline 2.32119 & 0.74778 & 0.115425 & 0.377096 & 2.658633 & 0.513647 & 0.898231 & 0.587038 \\
\hline 6.099451 & 1.849906 & 1.881957 & 0.6927 & 1.815347 & 0.037774 & 2.001302 & 0.693382 \\
\hline 2.895334 & 0.427818 & 5.034074 & 0.415207 & 1.690524 & 0.465237 & 8.069392 & 0.7394 \\
\hline
\end{tabular}




\begin{tabular}{|c|c|c|c|c|c|c|c|}
\hline & & & & & & & \\
\hline & 2 & & & & & & \\
\hline & & & & & & & \\
\hline 72 & & 767 & & & & & \\
\hline & & & & & & & \\
\hline & & & & & & & \\
\hline & .552172 & & & & & & \\
\hline 157071 & 295698 & 881 & 3148 & 47834 & 112 & 063 & \\
\hline 318 & 001 & & 14 & 73 & & & \\
\hline 84 & 6 & & & & & & \\
\hline & 0.60 & & & & & & \\
\hline 541 & 1.0 & 541 & 646 & 1176 & & 164 & \\
\hline 8 & $15.8 \varepsilon$ & 59 & 78 & & & & \\
\hline & 5 & & & & & & \\
\hline & 1.56 & & & & & & \\
\hline 3 & 0.4 & & & & & & \\
\hline 9 & 0.1 & & & & & & \\
\hline & c & & & & & & \\
\hline & & & & & & & \\
\hline & & & & & & & \\
\hline 43 & 24 & & & & & & \\
\hline & 4 & & & & & & \\
\hline & & & & & & & \\
\hline & & & & & & & \\
\hline & & & & & & & \\
\hline & 6 & & & & & & \\
\hline 2.069 & 3 & & & & & & \\
\hline & & & & & & & \\
\hline & & & & & & & \\
\hline & 23 & & & & & & \\
\hline .295056 & 0.459246 & .866146 & 0.434734 & & 376 & & \\
\hline 41 & 0.25 & & & & & & \\
\hline & & & & & & & \\
\hline & 1.317117 & & & & & & \\
\hline 289949 & 0.877377 & 0.919021 & 1.459838 & & & & \\
\hline 6.463429 & 0.763405 & & 0.482102 & & 0.522988 & & \\
\hline & & & & & & & \\
\hline סובובי1.1. & כונכס.0 & 0.63011 & 1.236261 & 0.439291 & 0.504867 & 0.089627 & 0.001 \\
\hline
\end{tabular}




\begin{tabular}{|c|c|c|c|c|c|c|c|}
\hline$\Delta \mathrm{V}$ & $\Delta \mathrm{x}^{\circ}$ & $\Delta y^{\circ}$ & $\Delta z^{\circ}$ & $\Delta \mathrm{V}$ & $\Delta x^{\circ}$ & $\Delta \mathrm{y}^{\circ}$ & $\Delta z^{\circ}$ \\
\hline 4.120809 & 0.564565 & 0.036419 & 0.451254 & 7.264307 & 1.127722 & 0.772298 & 0.844474 \\
\hline 0.694114 & 0.024144 & 0.449468 & 1.242084 & 5.631887 & 0.431585 & 1.737456 & 0.507576 \\
\hline 1.475498 & 0.380437 & 0.473701 & 0.667185 & 1.651017 & 0.279636 & 0.007249 & 0.375854 \\
\hline 3.44737 & & 0.325959 & & 1.166518 & & 0.596607 & \\
\hline 3.794371 & 3.057991 & 8.24617 & 0.337342 & 2.380055 & 0.957387 & 0.780694 & 0.349115 \\
\hline 2.258518 & 0.691048 & 0.950976 & 1.025636 & 2.291138 & 1.161486 & 0.325171 & 0.007577 \\
\hline 2.017881 & 0.371 & 0.21 & 0.3 & 2.22 & 29 & 506 & 369 \\
\hline 3.507297 & 0.20 & 23 & $0.6 \varepsilon$ & 0.32 & & 303 & 709 \\
\hline & & & & & & & \\
\hline 2.796894 & 0.377502 & 0.042827 & 0.31 & 0.492279 & 0.064023 & 622 & 0.196901 \\
\hline 2.40998 & 0.212033 & .96919 & 0.170086 & 1.447955 & 1.492091 & 245 & 0.230461 \\
\hline 1.0849 & 0.83 & $0.87 €$ & & 2.20 & 339 & 746 & 836 \\
\hline & $0.4 \varepsilon$ & & & & & & \\
\hline 2.41 & 3.577965 & 0.351135 & 0.31 & 8.248374 & & & 931 \\
\hline 4.591127 & 8.923771 & 1.425403 & 0.024741 & 3.696905 & 2.447979 & 089 & 95964 \\
\hline 0.784275 & 0.210423 & 7.246717 & 1.30881 & 2.81 & 9913 & 881 & 492 \\
\hline 1.272479 & 0.43 & & & & & 554 & 625 \\
\hline & 3.069 & & & & & & \\
\hline 1.490464 & 0.39841 & 3.234244 & 0.118193 & 2.448386 & 0.103512 & 0.030383 & 0.339336 \\
\hline 5.001054 & 0.109924 & 1.319738 & 2.028014 & 1.744035 & 0.185499 & 0.350216 & 0.715035 \\
\hline 1.288148 & 0.517086 & 0.844344 & 0.329219 & 5.196328 & 22.19433 & 0.625433 & 61491 \\
\hline & & & & & & & 0504 \\
\hline 2.692162 & 0.279752 & & & & & & \\
\hline 2.773915 & 0.296884 & 0.757775 & 0.41116 & 2.327134 & 0.89153 & 0.469929 & 0.446274 \\
\hline 1.602128 & 0.676988 & 0.655206 & 0.42449 & 0.850524 & 0.552602 & 1.960864 & 1.194324 \\
\hline 4.86341 & 0.968011 & & & & & & 0.770672 \\
\hline 2.453212 & 1.081798 & & & & & & 0.68038 \\
\hline 2.473832 & 3.04383 & 0.458279 & & 1.728819 & 0.833663 & 0.426628 & 1.052328 \\
\hline 4.078007 & 0.614799 & 3.059361 & 0.466037 & 4.120722 & 0.61103 & 1.577057 & 0.20683 \\
\hline 2.525783 & 0.129263 & 0.391411 & & 3.2336 & 0.781876 & 4.918 & 0.375209 \\
\hline 0.339317 & 0.691448 & 0.75841 & 0.184234 & & 1.745257 & 1.683933 & 0.775305 \\
\hline & 0.767275 & 0.938096 & & & 0.896672 & 0.912909 & 0.63139 \\
\hline 7.547024 & 0.762577 & 0.641098 & 1.166177 & 2.793528 & 1.353927 & 1.308807 & 0.166718 \\
\hline 1.104754 & 1.29524 & 1.277257 & 0.25743 & 0.841406 & 0.397212 & 0.478526 & 0.0495 \\
\hline 1.154053 & 1.091927 & 1.39933 & 0.081812 & 6.104702 & 0.681887 & 1.001299 & 2.131101 \\
\hline 0.68669 & 0.992347 & 0.51819 & 0.326783 & 2.116297 & 1.142807 & 1.12626 & 2.544065 \\
\hline 3.710817 & 0.010557 & 0.876252 & 0.568107 & 2.120658 & 0.743945 & 0.367387 & 0.336753 \\
\hline 0.714215 & 0.275016 & 0.485042 & 0.362978 & 1.778598 & 1.252069 & 0.946102 & 0.143673 \\
\hline 2.776897 & 0.05003 & 0.583842 & 0.077366 & 1.70738 & 6.369141 & 0.090387 & 0.708083 \\
\hline
\end{tabular}




$\begin{array}{rrrrrrrr}1.71933 & 0.329135 & 0.971137 & 1.735438 & 1.213914 & 0.900694 & 0.109786 & 0.080064 \\ 0.913011 & 1.667151 & 0.32037 & 0.119744 & 0.766862 & 18.96939 & 0.431938 & 0.393419 \\ 5.61912 & 0.023469 & 0.158398 & 0.394028 & 3.150601 & 0.533961 & 0.63454 & 0.416204 \\ 0.507246 & 0.230663 & 0.36992 & 1.609982 & 3.025173 & 4.130975 & 2.408031 & 0.267916 \\ 1.03505 & 1.102516 & 0.995492 & 11.24081 & 1.002791 & 0.233296 & 0.852432 & 0.114743 \\ 1.039903 & 0.320307 & 0.966489 & 2.095901 & 0.567132 & 10.35076 & 2.317176 & 0.377792 \\ 1.728323 & 0.299007 & 0.805472 & 0.619821 & 3.001222 & 0.933316 & 0.044566 & 0.279549 \\ 4.598999 & 0.820244 & 0.642242 & 0.504269 & 3.901341 & 5.247696 & 1.140369 & 1.094439 \\ 3.322769 & 1.021308 & 1.182051 & 2.656164 & 1.328307 & 0.433371 & 0.141 & 3.61173 \\ 1.393403 & 0.666212 & 0.004912 & 0.359524 & 2.163088 & 0.69633 & 0.276544 & 0.317948 \\ 2.231656 & 1.22895 & 0.987802 & 1.03279 & 2.853152 & 0.674366 & 0.880789 & 0.820808 \\ 0.895179 & 0.53654 & 0.772448 & 0.188305 & 8.047017 & 0.819006 & 0.384994 & 0.627259 \\ 0.709709 & 0.311778 & 1.119737 & 0.956017 & 1.291979 & 0.653468 & 0.424224 & 5.916578 \\ 0.528868 & 11.50978 & 0.520406 & 0.370525 & 2.837138 & 1.834832 & 0.532689 & 0.539373 \\ 1.069336 & 0.614613 & 0.645033 & 0.093032 & 0.852689 & 0.381413 & 0.43732 & 0.066413 \\ 0.700548 & 0.347683 & 0.040436 & 0.618801 & 1.283603 & 0.264768 & 0.198552 & 0.268383 \\ 8.348646 & 0.889283 & 1.009253 & 1.024528 & 9.207369 & 0.902126 & 0.914272 & 0.90283 \\ 1.385479 & 0.322194 & 0.703379 & 0.326283 & 4.888359 & 1.65355 & 0.20387 & 0.18495 \\ 0.890865 & 0.022657 & 2.722465 & 0.186315 & 2.88353 & 1.435754 & 0.220782 & 0.372099 \\ 1.981094 & 1.092187 & 0.9381 & 1.904644 & 0.719076 & 0.666721 & 4.675806 & 6.618709\end{array}$

Experimental

\begin{tabular}{|c|c|c|c|c|c|c|c|}
\hline \multicolumn{4}{|c|}{ \#6 } & \multicolumn{4}{|c|}{$\# 7$} \\
\hline$\Delta \mathrm{V}$ & $\Delta x^{\circ}$ & $\Delta y^{\circ}$ & $\Delta \mathrm{z}^{\circ}$ & $\Delta \mathrm{V}$ & $\Delta \mathrm{x}^{\circ}$ & $\Delta y^{\circ}$ & $\Delta \mathrm{z}^{\circ}$ \\
\hline 3.440625 & 0.839239 & 1.218498 & 0.187924 & 6.667263 & 1.084499 & 0.824798 & 0.870908 \\
\hline 0 & & & & 0 & & & \\
\hline 3.092129 & 0.624368 & 1.146749 & 0.258936 & 6.187275 & 3.638518 & 0.765209 & 0.16715 \\
\hline 0.616787 & 0.401034 & 1.318718 & 0.387451 & 1.54373 & 6.243448 & 6.735225 & 0.605573 \\
\hline 2.074229 & 0.54158 & 1.853475 & 1.066822 & 2.918066 & 0.846361 & 0.19474 & 0.768491 \\
\hline 3.107353 & 1.104968 & 0.598042 & 1.055186 & 5.284727 & 0.710966 & 0.028241 & 0.743584 \\
\hline 1.933664 & 0.563147 & 0.452233 & 0.477987 & 4.404483 & 2.454173 & 0.823375 & 0.721933 \\
\hline 4.907295 & 0.72592 & 0.682862 & 0.652896 & 3.251113 & 1.248913 & 0.356404 & 1.398174 \\
\hline 4.698148 & 1.012851 & 5.089697 & 0.890086 & 4.467338 & 0.338665 & 0.832737 & 0.741216 \\
\hline 2.975149 & 2.256525 & 0.808174 & 0.731529 & 2.750136 & 0.423711 & 0.549808 & 0.509671 \\
\hline 0 & & & & 0 & & & \\
\hline 2.374469 & 1.068771 & 0.441688 & 0.113971 & 1.451003 & 0.40669 & 0.459505 & 0.103069 \\
\hline 2.28483 & 0.896683 & 0.682345 & 0.6593 & 2.217818 & 0.278308 & 0.649925 & 0.908908 \\
\hline 3.026913 & 1.747875 & 1.277411 & 0.571618 & 2.425091 & 5.744494 & 0.347234 & 0.076185 \\
\hline 3.4928 & 1.940116 & 0.656778 & 0.276615 & $\begin{array}{c}1.831698 \\
90\end{array}$ & 5.802647 & 0.010146 & 0.368902 \\
\hline
\end{tabular}




\begin{tabular}{|c|c|c|c|c|c|c|c|}
\hline 3.219041 & 0.05507 & 0.097794 & 0.938347 & 3.342901 & 0.141176 & 1.135525 & 1.806017 \\
\hline 3.29195 & 0.196249 & 0.727547 & 0.809558 & 5.431108 & 0.657943 & 0.834191 & 0.79935 \\
\hline 2.422228 & 1.090263 & 0.465873 & 0.59047 & 5.763985 & 0.985226 & 0.30162 & 1.319514 \\
\hline 1.844301 & 0.542967 & 0.522186 & 0.263726 & 3.897934 & 1.304578 & 2.884079 & 0.970115 \\
\hline 9.638285 & 0.922287 & 0.683328 & 0.24557 & 0 & & & \\
\hline 5.973581 & 1.064638 & 0.909159 & 0.975338 & 3.323546 & 1.27221 & 0.020089 & 0.819281 \\
\hline 2.312816 & 0.715761 & 0.771317 & 0.493869 & 7.686208 & 1.264852 & 0.298049 & 0.587161 \\
\hline 2.784714 & 0.74209 & 0.440534 & 1.668229 & 0.921686 & 0.209412 & 3.480961 & 0.514291 \\
\hline 3.922804 & 0.387336 & 0.89038 & 0.740861 & 3.752085 & 0.666729 & 18.23627 & 0.918158 \\
\hline 13.87161 & 3.072709 & 0.772675 & 0.95906 & 7.724437 & 2.856741 & 0.67947 & 1.685232 \\
\hline 11.60085 & 1.205389 & 0.84834 & 0.764998 & 3.251211 & 1.898301 & 1.313514 & \\
\hline 2.059142 & 1.76687 & 0.583616 & 0.32631 & 0 & & & \\
\hline 3.134326 & 0.920158 & 0.514697 & 2.143882 & 1.901753 & 0.10653 & 0.669647 & 0.297575 \\
\hline 1.569772 & 2.91764 & 0.571015 & 1.926442 & 2.16826 & 0.3684 & 0.582 & 3.42018 \\
\hline 12.16346 & 1.213448 & 1.681156 & 0.968945 & 3.932858 & 1.322732 & 1.374799 & 0.666861 \\
\hline 2.740087 & 1.304205 & 1.04282 & & 3.671444 & 2.937138 & 1.203766 & 1.118183 \\
\hline 5.273046 & 0.833308 & 0.849843 & 0.907113 & 1.982559 & 0.11071 & 0.088229 & 0.466221 \\
\hline 2.462971 & 1.204669 & 0.041248 & 1.212272 & 3.953249 & 1.605527 & 1.522733 & 1.065997 \\
\hline 0.713494 & 0.863101 & 1.479076 & 0.691916 & 3.038992 & 0.819819 & 1.275254 & 0.713107 \\
\hline 1.732842 & 1.017331 & 0.770492 & 0.094407 & 4.004565 & 0.63879 & 1.950876 & 1.307509 \\
\hline 0.962117 & 1.524333 & 0.797653 & 6.511793 & 2.637769 & 1.046039 & 0.716997 & 0.310476 \\
\hline 8.431273 & 1.209275 & 1.155357 & 0.979976 & 8.237087 & 1.39283 & 3.351686 & 0.820559 \\
\hline 0 & & & & 0 & & & \\
\hline 1.616791 & 2.064543 & 0.618512 & 3.646382 & 0.913604 & 0.119517 & 0.331505 & 0.113835 \\
\hline 1.377226 & 0.835402 & 1.534492 & 0.751737 & 2.472058 & 0.554021 & 0.77761 & 0.584468 \\
\hline 4.547888 & 1.065418 & 23.46908 & 0.239494 & 3.932788 & 1.712311 & 0.855316 & 0.749037 \\
\hline 1.021555 & 0.539989 & 1.444999 & 1.919991 & 3.542008 & 0.788037 & 0.433188 & 0.658899 \\
\hline 4.529873 & 0.89191 & 0.828684 & 0.770369 & 5.037198 & 0.897472 & 0.772306 & 0.919396 \\
\hline 0.417895 & 2.39028 & 0.772013 & 0.175846 & 1.24648 & 1.416039 & 0.932883 & 0.704515 \\
\hline 4.338318 & 0.364721 & 5.398219 & 0.817546 & 4.035581 & 0.658272 & 1.533674 & 0.383524 \\
\hline 4.80796 & 0.604991 & 0.990078 & 0.431705 & 4.145346 & 0.598567 & 0.203723 & 0.391064 \\
\hline
\end{tabular}

\begin{tabular}{|c|c|c|c|c|c|c|c|}
\hline \multicolumn{4}{|c|}{$\# 8$} & \multicolumn{4}{|c|}{ \#9 } \\
\hline$\Delta \mathrm{V}$ & $\Delta \mathrm{x}^{\circ}$ & $\Delta y^{\circ}$ & $\Delta \mathrm{z}^{\circ}$ & $\Delta \mathrm{V}$ & $\Delta x^{\circ}$ & $\Delta \mathrm{y}^{\circ}$ & $\Delta \mathrm{z}^{\circ}$ \\
\hline 6.265865 & 0.738978 & 0.932467 & 0.719932 & 4.87707 & 0.784572 & 1.342451 & 0.855635 \\
\hline 0 & & & & 0 & & & \\
\hline 3.02884 & 26.37862 & 4.995803 & 2.039486 & 3.081352 & 4.874138 & 2.162173 & 1.610328 \\
\hline 2.276785 & 24.71878 & 3.363323 & 0.528453 & 2.017281 & 3.041806 & 1.081532 & 6.336705 \\
\hline 4.621341 & 0.935213 & 0.124805 & 0.635149 & 2.439594 & 1.459288 & 0.185158 & 0.68046 \\
\hline 4.315523 & 0.944569 & 1.18569 & 0.665185 & $\begin{array}{c}3.027347 \\
91\end{array}$ & 0.920064 & 0.729391 & 0.787651 \\
\hline
\end{tabular}




\begin{tabular}{|c|c|c|c|c|c|c|c|}
\hline & 61 & & 952 & & & 824 & \\
\hline 351 & 322601 & .822752 & 0.326661 & 6.161373 & 1.432649 & 0.661963 & 1.914966 \\
\hline 32035 & 341493 & 940843 & 470508 & 42674 & 1.70701 & 512 & 6664 \\
\hline 2.1836 & 503005 & 0.76506 & & 2.049589 & & & \\
\hline 0 & & & & 0 & & & \\
\hline 396228 & 0.699677 & .742875 & 0.396727 & 5.394632 & 9015 & 3221 & 0.440496 \\
\hline .449065 & 0.425152 & 0.391466 & 0.476671 & 3.262657 & 0.422327 & 075 & 18.98676 \\
\hline .459291 & 0.545165 & .928272 & 252 & 1698 & & 9927 & 832 \\
\hline & 0.9503 & & 0.449684 & 1.830099 & & & 274 \\
\hline 10.20074 & 0.379826 & & 3419 & 4.13 & & & 756 \\
\hline 6.758823 & 1.12289 & 235 & 1.906124 & 4.255883 & 185 & 284 & 266 \\
\hline 2.643804 & & 0.12 & 169 & 3.605569 & 1.585656 & 3563 & 0.16 \\
\hline 04 & 0.795478 & 0.54 & 3205 & 1.37 & & 326 & 0.31 \\
\hline 5.60 & .344924 & & & & & & \\
\hline 3.084 & 0.861218 & 14.52 & 2.922403 & 3.700235 & 418 & 932 & 162 \\
\hline 2.586223 & 0.621134 & 1.036299 & 0.078627 & 2.85521 & 0.698413 & 0.72481 & 0.330742 \\
\hline 2.240 & 0.476924 & 12.3 & 0.759179 & 2.299088 & 1.06 & 176 & 0.44 \\
\hline 5.980657 & 1.332324 & 0.690691 & 0.744497 & 4663 & & & \\
\hline 7.332305 & 0.835988 & 0.107 & 0.932962 & & & & \\
\hline 1.807392 & 0.878411 & 0.353 & 0.175373 & 368 & 1.28771 & 8124 & 0.65 \\
\hline 6.39693 & 0.836579 & 1.24 & 0.344225 & 1615 & 1.074445 & 775 & 0.70 \\
\hline 2.832021 & 0.557847 & 0.19 & 1.039413 & 2.465885 & 0.47 & 332 & 1.106 \\
\hline 1.653463 & 5.546252 & 0.116 & & & & & \\
\hline 1.764073 & 0.841529 & 0.631 & 0.024603 & 621 & 2.7012 & & 2.62 \\
\hline 3.287741 & 1.143901 & 0.115 & 0.703299 & 2.917453 & 0.522226 & 0.023216 & 0.30 \\
\hline 1.101417 & 0.331446 & 0.251 & 0.235352 & 2.883628 & 0.260148 & 0.19483 & 0.373606 \\
\hline 2.40757 & 1.307738 & 0.096194 & 0.8397 & 2.298539 & & 647 & 547 \\
\hline 1.622309 & 0.7143 & 0.68 & & & & & \\
\hline 3.192342 & 0.956237 & 0.969981 & 0.779385 & 3.630329 & 1.028676 & 3.184151 & 0.402602 \\
\hline 6.456959 & 1.139057 & 0.514508 & 0.338026 & 2.635551 & 0.627312 & 1.273584 & 0.469683 \\
\hline 4.64071 & 0.064003 & 0.206301 & 0.813943 & 8.95286 & 0.950711 & 1.194169 & 0.780354 \\
\hline 0 & & & & & & & \\
\hline 1.843633 & 8.802877 & 0.704424 & & & & & \\
\hline 1.633241 & 1.107699 & 0.703379 & 0.49504 & 4.221894 & 0.873606 & 1.618589 & 1.844871 \\
\hline 5.217097 & 3.285766 & 0.641596 & 0.491462 & 3.487537 & 0.943058 & 4.260797 & \\
\hline 2.147163 & 5.256982 & 0.100638 & 0.643844 & 2.183558 & 2.292726 & 0.968317 & 0.239853 \\
\hline 2.677646 & 0.929744 & 0.940326 & & 2.425846 & 0.793396 & 1.082803 & 0.829842 \\
\hline 1.888247 & 0.532763 & 0.460251 & 0.581754 & 1.820378 & 17.43292 & 0.394119 & 0.440217 \\
\hline 7.614341 & 0.60279 & & & 1.438002 & 0.398058 & 0.171306 & 0.386589 \\
\hline 4.952115 & 0.570265 & 1.576189 & 0.076936 & 3.959557 & 0.49294 & 0.956377 & 0.324973 \\
\hline
\end{tabular}




\begin{tabular}{|c|c|c|c|c|c|c|c|}
\hline \multicolumn{4}{|c|}{$\# 10$} & \multicolumn{4}{|c|}{ \#11 } \\
\hline$\Delta \mathrm{V}$ & $\Delta x^{0}$ & $\Delta y^{\circ}$ & $\Delta z^{\circ}$ & $\Delta \mathrm{V}$ & $\Delta x^{0}$ & $\Delta y^{\circ}$ & $\Delta z^{\circ}$ \\
\hline 7.794309 & 1.209529 & 0.812707 & 0.855394 & 2.540114 & 0.896917 & 0.698935 & 0.832707 \\
\hline 0 & & & & 0 & & & \\
\hline 1.89146 & 1.611137 & 0.48066 & 1.07503 & 2.900253 & 1.142479 & 6.007 & 0.696698 \\
\hline 1.487349 & 1.950919 & 0.477117 & 0.731914 & 2.117961 & 0.86058 & 0.818444 & 1.400246 \\
\hline 1.652381 & 0.784224 & 5.63145 & 0.726872 & 2.156574 & 0.090449 & 13.58906 & 1.041072 \\
\hline 1.724745 & 0.40162 & 7.349116 & 0.708998 & 2.116296 & 0.170112 & 0.281262 & 0.455209 \\
\hline 4.06871 & & 1.425713 & 0.45803 & 2.625237 & 2.730466 & 1.218869 & 0.538795 \\
\hline 4.393103 & 1.271418 & 1.261806 & 0.532113 & 4.329838 & 0.71632 & 0.503636 & 0.899181 \\
\hline 2.127627 & 0.182796 & 0.476571 & 0.450702 & 4.409075 & 0.784561 & 1.760284 & 10.08441 \\
\hline 1.145544 & 0.141139 & 0.80149 & 0.279632 & 2.202434 & 2.088718 & 0.986037 & 11.54001 \\
\hline 0 & & & & 0 & & & \\
\hline 1.543132 & 0.35766 & 0.344359 & 0.403572 & 3.31842 & 1.347951 & 0.151108 & 0.902582 \\
\hline 6.392733 & 0.605813 & 0.535104 & 0.951271 & 6.432317 & 0.027704 & 0.995008 & 0.973637 \\
\hline 1.058747 & 0.381531 & 0.298436 & 0.033524 & 4.334881 & 0.327441 & 0.759702 & 3.425145 \\
\hline 0.728865 & 0.141992 & 0.093566 & 0.192955 & 5.26318 & 35.48945 & 0.599621 & 0.643828 \\
\hline 5.848406 & 0.582746 & 0.528146 & 1.403182 & 2.306736 & 0.560882 & 2.629935 & 0.840203 \\
\hline 9.712572 & 2.095208 & 0.881977 & 0.949212 & 2.47511 & 0.512353 & 1.491624 & 0.788693 \\
\hline 4.16739 & 1.621178 & 1.364585 & 0.979868 & 1.809174 & 0.8599 & 0.093248 & 0.113899 \\
\hline 5.484175 & 0.985627 & 0.643373 & 0.89963 & 4.363033 & 1.70947 & 0.836905 & 0.113443 \\
\hline 0 & & & & 1.637491 & 1.441326 & 0.287228 & 0.078602 \\
\hline 1.436227 & 0.312086 & 0.785767 & 0.739025 & 5.100298 & 1.408301 & 1.061449 & 0.88301 \\
\hline 2.768838 & 0.26922 & 0.08567 & 0.58776 & 2.155738 & 0.698746 & 0.106275 & 0.664621 \\
\hline 4.920143 & 1.351385 & 0.522237 & 0.618535 & 1.713412 & 13.25136 & 0.50805 & 0.878032 \\
\hline 4.8056 & 1.0795 & 0.94077 & 0.898804 & 2.173246 & 0.882334 & 0.901447 & 0.747376 \\
\hline 10.88009 & 1.804918 & 1.248875 & 0.913026 & 0 & & & \\
\hline 6.7139 & 1.873205 & 0.587025 & 0.622357 & 3.504713 & 1.27193 & 0.623407 & 0.396123 \\
\hline 0 & & & & 3.185375 & 1.10933 & 1.058 & 1.196064 \\
\hline 1.424413 & 10.26289 & 0.098573 & 0.010074 & 1.114173 & 2.097105 & 0.559934 & 0.284569 \\
\hline 0.921435 & 0.96715 & 2.874117 & 0.533347 & 1.456048 & 1.646755 & 1.692836 & 0.400166 \\
\hline 4.003879 & 0.59418 & 0.85468 & 0.691429 & 7.398546 & 2.762083 & 0.446396 & 0.946161 \\
\hline 4.092571 & 0.32959 & 0.805719 & 0.046454 & 3.39211 & 0.314105 & 0.731852 & 0.963793 \\
\hline 1.637027 & 2.303504 & 0.945374 & 5.037193 & 2.941606 & 0.444953 & 0.372449 & 0.433352 \\
\hline 1.559285 & 1.017734 & 0.126825 & 0.814342 & 3.904454 & 1.188932 & 0.891854 & 0.771418 \\
\hline 2.695431 & 0.516063 & 1.225147 & 0.244618 & 1.772311 & 1.167691 & 0.783504 & 0.774091 \\
\hline 2.308717 & 0.717284 & 0.369825 & 0.840314 & 4.723322 & 1.029787 & 1.893827 & 1.169636 \\
\hline 4.032112 & 0.54459 & 23.46047 & 0.250903 & 2.365729 & 1.144862 & 0.495384 & 0.55251 \\
\hline 10.35163 & 0.670217 & 0.440316 & 0.735357 & 6.219733 & 0.910709 & 2.346473 & 0.943677 \\
\hline & & & & & & & \\
\hline
\end{tabular}




$\begin{array}{rrrrrrrr}6.494476 & 1.269815 & 0.140792 & 1.027049 & 3.931853 & 1.817642 & 0.822978 & 0.355884 \\ 0.905217 & 1.117622 & 0.57372 & 0.390553 & 1.171098 & 0.751333 & 0.139692 & 0.897731 \\ 2.854901 & 1.934977 & 1.51983 & 1.332971 & 3.38905 & 0.751481 & 3.591965 & \\ 0.777927 & 0.883359 & 0.255236 & 1.99629 & 2.052011 & 0.921269 & 0.268837 & 0.461338 \\ 0.899924 & 2.082518 & 0.904954 & 0.804411 & 6.802955 & 1.493066 & 1.013657 & 0.911046 \\ 5.575248 & 1.382968 & 1.022046 & 0.834795 & 0.279057 & 5.768683 & 0.069023 & 2.062427 \\ 4.077625 & 0.239526 & 0.879436 & 0.062522 & 2.73696 & 0.934283 & 0.495951 & 0.383934 \\ 1.228479 & 0.636587 & 4.170843 & 1.643753 & 1.558689 & 2.065592 & 0.540198 & 2.38173\end{array}$

\begin{tabular}{|c|c|c|c|c|c|c|c|}
\hline \multicolumn{4}{|c|}{$\# 22$} & \multicolumn{4}{|c|}{ \#23 } \\
\hline$\Delta \mathrm{V}$ & $\Delta \mathrm{x}^{\circ}$ & $\Delta y^{\circ}$ & $\Delta z^{\circ}$ & $\Delta \mathrm{V}$ & $\Delta \mathrm{x}^{\circ}$ & $\Delta y^{\circ}$ & $\Delta z^{\circ}$ \\
\hline 0 & & & & 0 & & & \\
\hline 1.440992 & 0.284835 & 1.577294 & 0.132825 & 1.257825 & 0.483912 & 0.493747 & 0.209521 \\
\hline 0.338826 & 3.423746 & 0.614983 & 0.831753 & 1.497398 & 0.307018 & 3.317123 & 0.121573 \\
\hline 3.990541 & 0.462834 & 0.73392 & 0.515162 & 1.420503 & 0.201017 & 0.005948 & 0.444707 \\
\hline 0 & & & & 0 & & & \\
\hline 0 & & & & 0 & & & \\
\hline 8.642865 & 2.132574 & 1.457789 & 1.644099 & 2.687355 & 1.208775 & 1.063634 & 0.731191 \\
\hline 0.399008 & 0.570052 & 1.060557 & 0.532722 & 6.768182 & 1.268268 & 0.486175 & 0.517408 \\
\hline 5.697406 & 3.77133 & 0.691901 & 0.466846 & 2.636858 & 0.460702 & 4.697592 & 0.516885 \\
\hline 0.90173 & 0.093373 & 0.020471 & 0.386634 & 1.845689 & 1.238108 & 1.801286 & 0.114881 \\
\hline 1.415147 & 1.964213 & 2.040347 & 1.536981 & 3.487467 & 0.002492 & 0.365882 & 0.703126 \\
\hline 4.934308 & 3.067679 & 0.321078 & 0.484961 & 3.501661 & 0.161498 & 1.407898 & 0.231866 \\
\hline 0 & & & & 0 & & & \\
\hline 2.019712 & 5.033867 & 4.603272 & 0.306331 & 1.058373 & 1.179104 & 0.41682 & 0.272785 \\
\hline 4.227378 & 0.397841 & 6.418218 & 0.641208 & 0.91833 & 0.127757 & 0.234313 & 0.04999 \\
\hline 6.456436 & 1.530506 & 0.924743 & 0.043591 & 3.031072 & 0.960284 & 0.242066 & 0.504041 \\
\hline 0 & & & & 0 & & & \\
\hline 3.611413 & 1.283285 & 0.209895 & 1.864702 & 7.257698 & 0.597369 & 0.780321 & 0.580953 \\
\hline 2.663501 & 1.026201 & 0.933405 & 0.676252 & 3.471787 & 15.46334 & 0.496828 & 0.524011 \\
\hline 2.237208 & 0.604249 & 0.51888 & 0.032786 & 7.168533 & 0.45415 & 0.427638 & 0.388393 \\
\hline 3.039606 & 0.949945 & 0.824964 & 0.943957 & 1.745057 & 0.943631 & 0.738231 & 0.58633 \\
\hline 3.431561 & 0.751405 & 0.95155 & 0.206626 & 2.060121 & 0.595017 & 0.804149 & 1.356454 \\
\hline 2.382976 & 2.943181 & 1.727016 & 0.043222 & 4.320657 & 1.319778 & 3.537611 & 0.415655 \\
\hline 4.928775 & 3.364709 & 1.20542 & 0.855177 & 2.787915 & 1.145633 & 0.772272 & 1.330047 \\
\hline 7.373142 & 1.607053 & 0.192614 & 0.59414 & 3.398789 & 0.028528 & 1.61467 & \\
\hline 0 & & & & 0 & & & \\
\hline 0 & & & & 0 & & & \\
\hline 2.582955 & 0.366746 & 0.645382 & 5.590195 & 6.037009 & 0.573095 & 0.26351 & 0.558199 \\
\hline 0 & & & & 0 & & & \\
\hline
\end{tabular}




$\begin{array}{rrrrrrrr}4.308245 & 1.010552 & 0.678501 & 0.985336 & 3.918965 & 0.535496 & 0.529562 & 0.59032 \\ 3.454068 & 0.909914 & 0.733063 & 0.427871 & 6.149535 & 0.759911 & 1.100014 & 0.628594 \\ 3.536911 & 0.673823 & 0.412346 & 0.524245 & 1.337846 & 0.416524 & 1.202467 & 0.018179 \\ 4.888816 & 5.44157 & 1.432159 & 0.555423 & 2.91216 & & 0.283533 & 0.376408 \\ 3.914308 & 1.180344 & 2.101632 & 1.099832 & 1.620703 & 0.014589 & 0.949022 & 3.733958 \\ 6.449083 & 0.858122 & 1.58094 & 0.829341 & 0.862211 & 0.430582 & 0.832857 & 0.395228 \\ 1.465162 & 0.717365 & 1.370122 & 0.22746 & 2.773189 & 1.717458 & 0.130269 & 0.783721 \\ 0 & & & & 0 & & & \\ 0.998913 & 0.209304 & 0.430879 & 0.330163 & 2.153502 & 1.468851 & 0.649931 & 0.213217 \\ 7.357883 & 1.236308 & 0.563546 & 1.229083 & 4.005106 & 1.748809 & 0.463093 & 0.686366 \\ 3.73271 & 1.822067 & 0.557298 & 0.707721 & 3.000106 & 0.647977 & 0.603983 & 3.952238 \\ 1.233326 & 0.317929 & 0.117268 & 0.135014 & 3.021036 & 0.748936 & 0.599172 & 0.195158 \\ 0 & & & & 0 & & & \\ 0 & & & & 0 & & & \\ 0 & & & & 0 & & & \\ 8.951671 & 0.081082 & 2.926007 & 0.253038 & 2.002963 & 0.029045 & 0.418097 & 0.248741 \\ 1.608195 & 0.691435 & 0.304974 & 0.741709 & 2.242917 & 3.417381 & 0.157529 & 11.78722\end{array}$

\begin{tabular}{|c|c|c|c|c|c|c|c|}
\hline \multicolumn{4}{|c|}{$\# 24$} & \multicolumn{4}{|c|}{ \#25 } \\
\hline$\Delta \mathrm{V}$ & $\Delta x^{\circ}$ & $\Delta y^{\circ}$ & $\Delta \mathrm{z}^{\circ}$ & $\Delta \mathrm{V}$ & $\Delta \mathrm{x}^{\circ}$ & $\Delta \mathrm{y}^{\circ}$ & $\Delta \mathrm{z}^{\circ}$ \\
\hline 0 & & & & 0 & & & \\
\hline 1.22665 & 0.261771 & 0.155534 & 3.655249 & 0.839712 & 0.24443 & 0.62706 & 0.212366 \\
\hline 0.896021 & 0.033547 & 1.130293 & 0.21778 & 2.780136 & 7.60239 & 1.609463 & 0.948864 \\
\hline 1.923813 & 5.175717 & 0.315251 & 0.562838 & 3.850021 & 0.299002 & 0.485884 & 0.664426 \\
\hline 0 & & & & 0 & & & \\
\hline 0 & & & & 0 & & & \\
\hline 1.120946 & 0.56931 & 0.506245 & 0.221207 & 4.003116 & 4.409307 & 0.837496 & 0.517341 \\
\hline 2.829571 & 2.473705 & 0.958565 & 0.894363 & 3.218319 & 1.131553 & 0.66683 & 0.653921 \\
\hline 3.608423 & 0.719099 & 0.833645 & 0.62699 & 4.431707 & 0.676579 & 0.785725 & 3.295064 \\
\hline 2.196468 & 0.453014 & 0.768602 & 0.499987 & 3.302979 & 0.309433 & 0.051509 & 1.026398 \\
\hline 3.570077 & 0.453395 & 1.776285 & 2.404835 & 3.470805 & 0.188337 & 1.889979 & 2.37722 \\
\hline 3.11384 & 0.279688 & 0.676118 & 0.282456 & 1.692604 & 0.312363 & 0.170511 & 0.200449 \\
\hline 0 & & & & 0 & & & \\
\hline 0.542018 & 0.705869 & 0.02578 & 0.19542 & 2.241724 & 0.854464 & 0.12847 & 0.360942 \\
\hline 3.224671 & 0.509866 & 1.270553 & 0.938398 & 0.671504 & 0.144053 & 15.35327 & 0.549989 \\
\hline 5.24512 & 0.357071 & 0.196207 & 0.561018 & 7.119375 & 0.472501 & 0.258475 & 0.558011 \\
\hline 0 & & & & 0 & & & \\
\hline 1.471634 & 1.117343 & 1.351789 & 0.19318 & 1.963071 & 0.394929 & 0.744879 & 0.509558 \\
\hline 2.573475 & 0.537121 & 0.51024 & 0.425376 & 1.823502 & 1.247763 & 1.322079 & 0.148747 \\
\hline 6.674005 & 0.308037 & 0.280693 & 0.524576 & $\begin{array}{c}5.120205 \\
95\end{array}$ & 0.248005 & 0.725421 & 1.707071 \\
\hline
\end{tabular}




$\begin{array}{rrrrrrrr}4.325274 & 0.942488 & 0.272369 & 0.681181 & 3.017287 & 0.973814 & 1.799723 & 1.078042 \\ 1.984522 & 0.600495 & 2.079245 & 1.268685 & 2.593466 & 0.620143 & 1.347589 & 10.26612 \\ 1.1158 & 1.135176 & 0.401672 & 0.548937 & 2.595539 & 1.354958 & 1.144014 & 0.705529 \\ 3.629591 & 0.793897 & 0.373625 & 0.815576 & 3.654894 & 0.957287 & 0.050244 & 1.116326 \\ 1.030994 & 0.500167 & 5.954972 & 0.487301 & 2.439464 & 0.218171 & 0.571888 & 0.390009 \\ 0 & & & & 0 & & & \\ 0 & & & & 0 & & & \\ 2.406007 & 0.585065 & 0.03779 & 0.178045 & 7.619917 & 0.340174 & 1.885125 & 2.795398 \\ 0 & & & & 0 & & & \\ 0.698879 & 0.291511 & 3.827779 & 0.496026 & 2.729201 & 0.523294 & 1.032714 & 1.022166 \\ 4.366253 & 0.524018 & 15.57851 & 2.161143 & 6.080028 & 0.653109 & 7.833475 & 0.066042 \\ 1.687613 & 0.453841 & 0.744674 & 0.54756 & 1.253782 & 0.631686 & 0.123573 & 0.227077 \\ 3.322706 & 7.159284 & 0.352966 & 1.088819 & 1.360094 & 0.346727 & 1.536177 & 0.33091 \\ 2.829528 & 0.624306 & 1.346924 & 2.387033 & 4.855293 & 0.688118 & 0.754307 & 1.539285 \\ 0.780898 & 0.761556 & 0.894345 & 0.441452 & 3.70143 & 1.220634 & 9.638633 & 0.294495 \\ 2.033731 & 1.015128 & 0.519634 & 0.404526 & 1.643671 & 2.566591 & 0.604334 & 0.047485 \\ 0 & & & & 0 & & & \\ 2.260182 & 0.342945 & & 0.32146 & 4.908857 & 0.337573 & 1.489032 & 1.219354 \\ 4.650269 & 5.060417 & 0.589773 & 0.619278 & 1.527049 & 4.47993 & 0.041285 & 0.220466 \\ 2.878643 & 0.549823 & 3.8228 & 0.586024 & 2.856186 & 0.649154 & 0.001947 & 0.311694 \\ 1.772386 & 0.296741 & 0.493857 & 0.362193 & 2.712421 & 0.095087 & 1.127523 & 0.726794 \\ 0 & & & & 0 & & & \\ 0 & & & & 0 & & & \\ 0 & & & & 0 & & & \\ 2.844967 & 0.21018 & 1.637288 & 0.830131 & 1.694302 & 0.217161 & 5.70409 & 0.188357 \\ 3.201634 & 0.594611 & 0.014175 & 0.739543 & 3.227722 & 9.619267 & 0.587067 & 1.366216\end{array}$

\begin{tabular}{|c|c|c|c|c|c|c|c|}
\hline \multicolumn{4}{|c|}{$\# 26$} & \multicolumn{4}{|c|}{$\# 27$} \\
\hline$\Delta \mathrm{V}$ & $\Delta x^{\circ}$ & $\Delta y^{\circ}$ & $\Delta \mathrm{z}^{\circ}$ & $\Delta \mathrm{V}$ & $\Delta x^{\circ}$ & $\Delta \mathrm{y}^{\circ}$ & $\Delta \mathrm{z}^{\circ}$ \\
\hline 0 & & & & 0 & & & \\
\hline 0.431022 & 0.969433 & 0.260348 & 0.057525 & 3.743756 & 0.799812 & 0.48655 & 0.143099 \\
\hline 1.456836 & 0.186294 & 0.98078 & 0.289383 & 2.453886 & 5.182354 & 0.511998 & 0.858647 \\
\hline 0.915934 & 2.266558 & 0.168239 & 18.43283 & 1.258938 & 6.500278 & 1.21537 & 0.791056 \\
\hline 0 & & & & 0 & & & \\
\hline 0 & & & & 0 & & & \\
\hline 2.964973 & 1.047647 & 2.524518 & 0.345856 & 2.024444 & 3.562836 & 0.26403 & 0.327739 \\
\hline 3.480284 & 5.181331 & 0.492002 & 0.544429 & 1.898973 & 1.674471 & 0.385808 & 0.075481 \\
\hline 3.485886 & 0.667227 & 0.643062 & 0.039818 & 2.703279 & 0.451906 & 0.619835 & 0.735593 \\
\hline 1.654172 & 0.928626 & 0.533306 & 0.544282 & 6.468408 & 0.867504 & 0.685831 & 6.797493 \\
\hline 3.410007 & 27.94853 & 6.171814 & 0.105572 & $\begin{array}{c}4.313938 \\
96\end{array}$ & 1.481877 & 5.80492 & 1.544691 \\
\hline
\end{tabular}




\begin{tabular}{|c|c|c|c|c|c|c|c|}
\hline 3.03766 & 0.225976 & 0.469668 & 0.209746 & 2.155846 & 0.209485 & 0.664953 & 0.322984 \\
\hline 0 & & & & 0 & & & \\
\hline 0.776194 & 0.956242 & 0.448191 & 0.161215 & 0.53936 & 0.269098 & 0.86917 & 0.104974 \\
\hline 0.486657 & 0.212586 & 0.871947 & 0.744729 & 3.232758 & 0.535449 & 5.764409 & 0.223334 \\
\hline 1.867638 & 0.203887 & 0.206618 & 0.807928 & 5.177673 & 0.072646 & 1.10451 & 0.428905 \\
\hline 0 & & & & 0 & & & \\
\hline 3.083386 & 0.866749 & 1.197932 & 0.126742 & 2.239198 & 0.848156 & 0.305773 & 1.042683 \\
\hline 2.2247 & 0.526004 & 0.565718 & 0.877811 & 2.176201 & & 0.987626 & 0.412278 \\
\hline 3.184055 & 0.266761 & 0.179988 & 4.899605 & 0 & & & \\
\hline 2.496369 & 0.974425 & 0.596386 & 0.91907 & 1.232257 & 1.895453 & 1.509766 & 0.834973 \\
\hline 2.417864 & 0.619644 & 11.24971 & 0.218205 & 1.934409 & 0.574545 & 1.741793 & 0.488205 \\
\hline 1.864158 & 1.398753 & 0.874159 & 0.007595 & 8.417091 & 0.522147 & 2.714541 & 0.365029 \\
\hline 2.478127 & 0.726196 & 8.916779 & 0.708599 & 7.665421 & 0.684933 & 1.583247 & 0.981633 \\
\hline 1.063067 & 0.507227 & 1.022466 & 1.542871 & 5.038888 & 0.378417 & 1.169079 & 0.520894 \\
\hline 0 & & & & 0 & & & \\
\hline 0 & & & & 0 & & & \\
\hline 7.511171 & 0.561621 & 0.111773 & 0.56254 & 1.219866 & 1.788271 & 1.738955 & 0.127281 \\
\hline 0 & & & & 0 & & & \\
\hline 6.891743 & 0.900739 & 0.414728 & 0.841394 & 1.072738 & 0.39946 & 0.701404 & 1.044561 \\
\hline 5.448023 & 0.763297 & 0.40269 & 0.152994 & 9.723448 & 3.968095 & 0.186224 & 0.362582 \\
\hline 1.213139 & 0.326767 & 0.463848 & 0.953247 & 5.244754 & 0.296978 & 6.734441 & 0.822808 \\
\hline 2.693872 & 0.593981 & 0.292944 & 0.25195 & 4.59017 & 0.483182 & 0.117272 & 0.403113 \\
\hline 5.316245 & 0.590808 & 0.861863 & 0.875695 & 0 & & & \\
\hline 1.667384 & 0.307302 & 5.880138 & 0.453478 & 4.43843 & 0.929198 & 0.990719 & 0.732289 \\
\hline 2.239023 & 0.830167 & 0.007467 & 0.431125 & 2.612103 & 0.88521 & 5.34601 & 0.368254 \\
\hline 0 & & & & 0 & & & \\
\hline 5.238935 & 1.60592 & 0.343346 & 1.658348 & 5.600256 & 1.842351 & 0.482275 & 0.45026 \\
\hline 1.690049 & 1.852387 & 0.283125 & 0.487843 & 3.0987 & 1.252291 & 0.195899 & 0.345506 \\
\hline 4.774339 & 0.650314 & 0.548464 & 0.443636 & 3.393916 & 0.943081 & 0.314296 & 0.301718 \\
\hline 1.759508 & 0.08878 & 0.112044 & 0.010002 & 5.021889 & 2.100998 & 3.630454 & 0.309056 \\
\hline 0 & & & & 0 & & & \\
\hline 0 & & & & 0 & & & \\
\hline 0 & & & & 0 & & & \\
\hline 3.746248 & 0.293318 & 0.610859 & 0.248491 & 5.032579 & 1.675139 & 0.625375 & 0.404299 \\
\hline 3.101242 & 0.166825 & 0.435394 & 1.21944 & 2.731268 & 0.063654 & 1.378439 & 0.701539 \\
\hline
\end{tabular}


Statistical Analyses

\section{DISCREPANCY BY INDIVIDUAL TEETH}

Oneway Analysis of Data By Group parameter $=\Delta V$, Tooth $=\# 10$

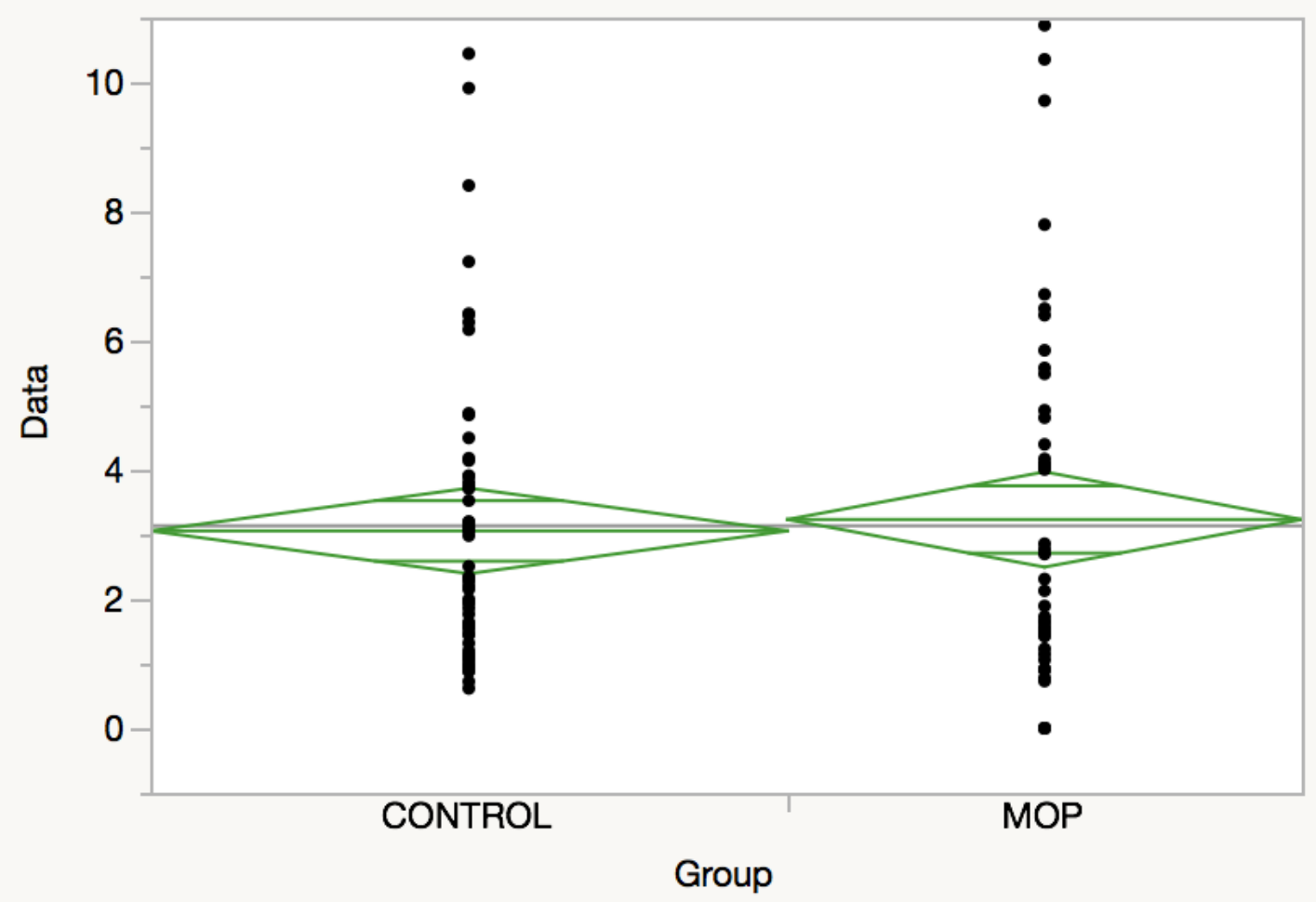

Missing Rows 2

Oneway Anova

Summary of Fit

Rsquare

0.001236

Adj Rsquare

$-0.00865$

Root Mean Square Error

2.519095

Mean of Response

3.132458

Observations (or Sum Wgts)

103 


\section{t Test}

MOP-CONTROL

Assuming equal variances

$\begin{array}{lrr}\text { Difference } & 0.1765 \text { t Ratio } & 0.353526 \\ \text { Std Err Dif } & 0.4993 \text { DF } & 101 \\ \text { Upper CL Dif } & 1.1670 \text { Prob }>|\mathrm{t}| & 0.7244 \\ \text { Lower CL Dif } & -0.8139 \text { Prob }>\mathrm{t} & 0.3622 \\ \text { Confidence } & 0.95 \text { Prob }<\mathrm{t} & 0.6378\end{array}$

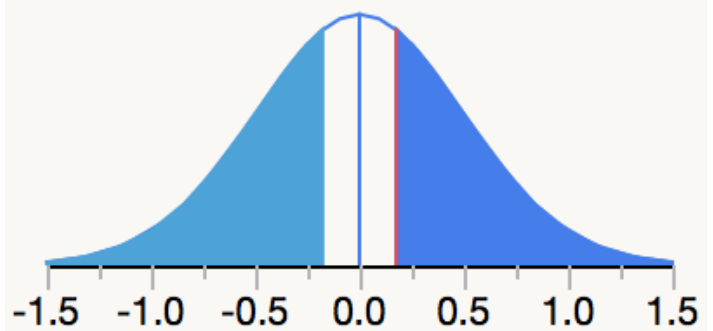

Analysis of Variance

$\begin{array}{lrrrrr}\text { Source } & \text { DF } & \text { Sum of Squares } & \text { Mean Square } & \text { F Ratio } & \text { Prob }>\text { F } \\ \text { Group } & 1 & 0.79311 & 0.79311 & 0.1250 & 0.7244 \\ \text { Error } & 101 & 640.92985 & 6.34584 & & \\ \text { C. Total } & 102 & 641.72296 & & & \end{array}$

Means for Oneway Anova

$\begin{array}{lrrrrr}\text { Level } & \text { Number } & \text { Mean } & \text { Std Error } & \text { Lower 95\% } & \text { Upper95\% } \\ \text { CONTROL } & 57 & 3.05363 & 0.33366 & 2.3917 & 3.7155 \\ \text { MOP } & 46 & 3.23014 & 0.37142 & 2.4933 & 3.9669\end{array}$

Std Error uses a pooled estimate of error variance 
Oneway Analysis of Data By Group parameter $=\Delta V$, Tooth $=\# 11$

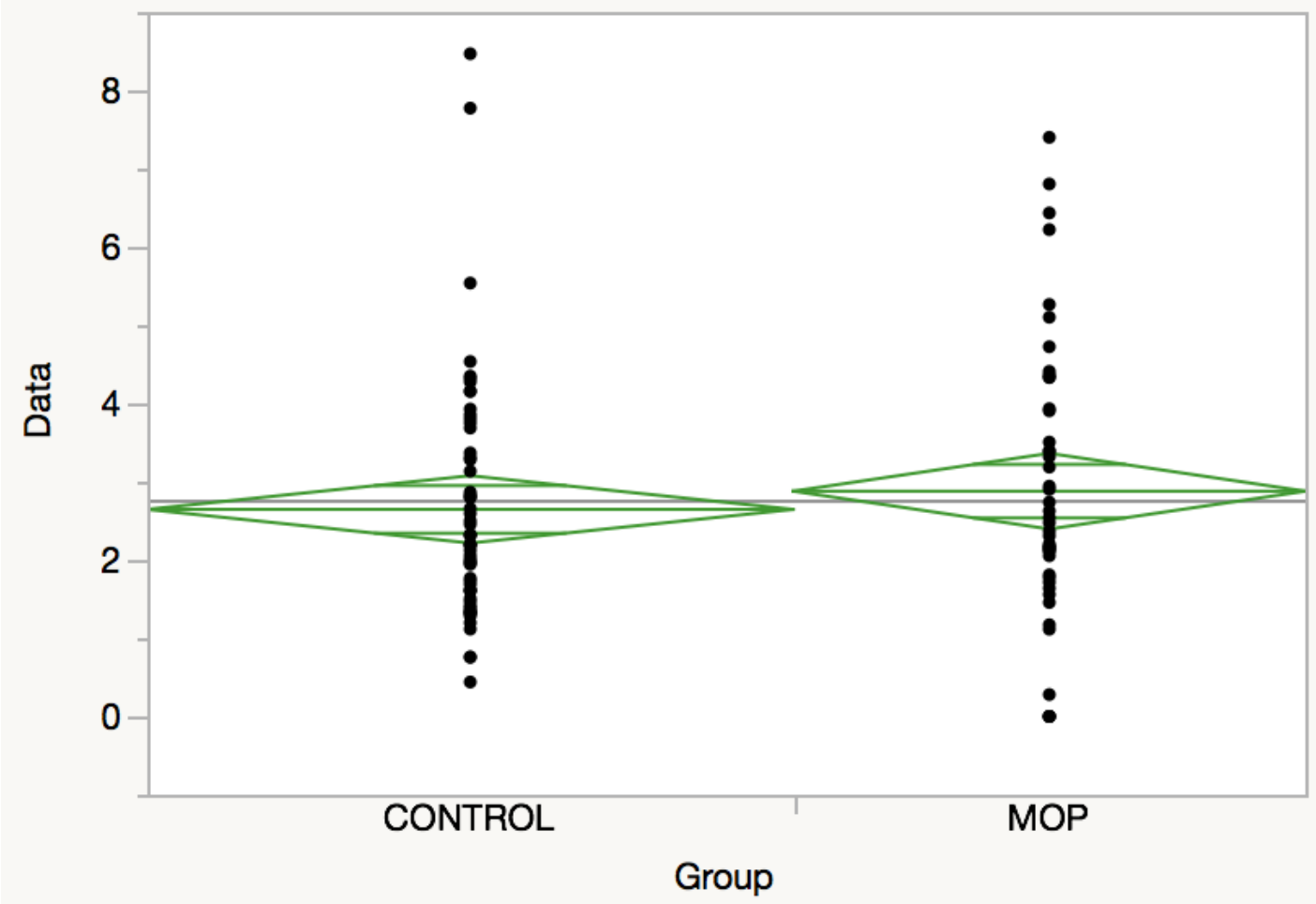

Missing Rows 1

Oneway Anova

Summary of Fit

Rsquare

Adj Rsquare

Root Mean Square Error

Mean of Response

Observations (or Sum Wgts)

t Test

MOP-CONTROL

Assuming equal variances

Difference

0.23253 t Ratio

0.711822 
Std Err Dif

Upper CL Dif

Lower CL Dif

Confidence
0.32666 DF

0.88046 Prob $>|t|$

-0.41541 Prob $>\mathrm{t}$

0.95 Prob $<\mathrm{t}$
102

0.4782

0.2391

0.7609

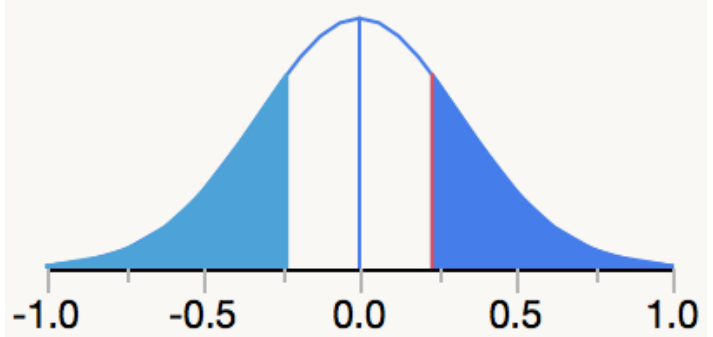

Analysis of Variance

\begin{tabular}{|c|c|c|c|c|c|}
\hline Source & DF & Sum of Squares & Mean Square & F Ratio & Prob $>$ F \\
\hline Group & 1 & 1.38706 & 1.38706 & 0.5067 & 0.4782 \\
\hline Error & 102 & 279.22307 & 2.73748 & & \\
\hline C. Total & 103 & 280.61013 & & & \\
\hline
\end{tabular}

Means for Oneway Anova

$\begin{array}{lrrrrr}\text { Level } & \text { Number } & \text { Mean } & \text { Std Error } & \text { Lower 95\% } & \text { Upper95\% } \\ \text { CONTROL } & 58 & 2.64531 & 0.21725 & 2.2144 & 3.0762 \\ \text { MOP } & 46 & 2.87784 & 0.24395 & 2.3940 & 3.3617\end{array}$

Std Error uses a pooled estimate of error variance 
Oneway Analysis of Data By Group parameter $=\Delta V$, Tooth $=\# 22$

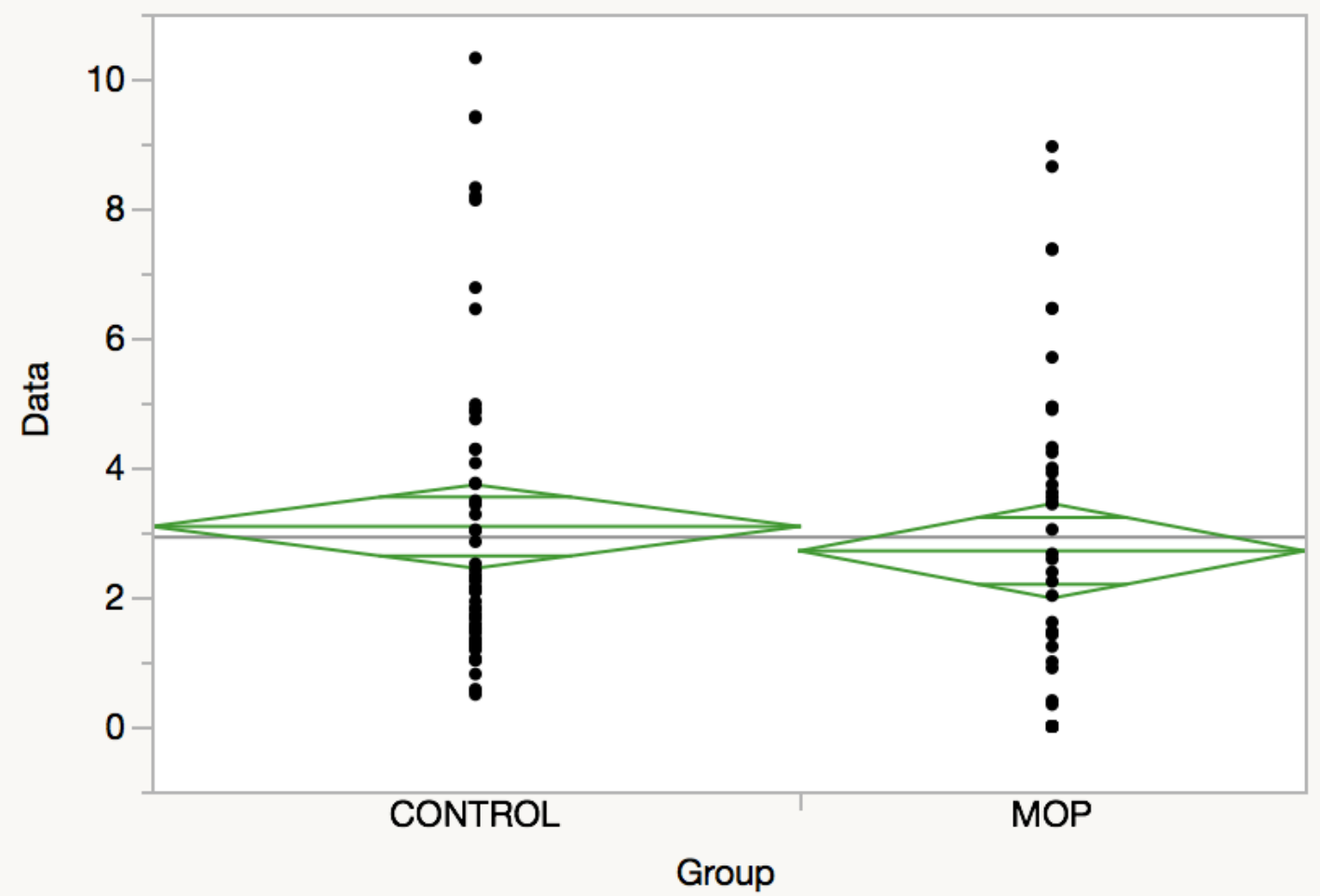

Oneway Anova

Summary of Fit

Rsquare

Adj Rsquare

Root Mean Square Error

Mean of Response

Observations (or Sum Wgts)
0.005693

$-0.00396$

2.496394

2.920902

105

\section{t Test}

MOP-CONTROL

Assuming equal variances

Difference

-0.3771 t Ratio

$-0.76795$ 
Std Err Dif

Upper CL Dif

Lower CL Dif

Confidence
$0.4910 \mathrm{DF}$

$$
0.5967 \text { Prob }>|t|
$$

-1.3509 Prob >t

0.95 Prob $<\mathrm{t}$
103

0.4443

0.7779

0.2221

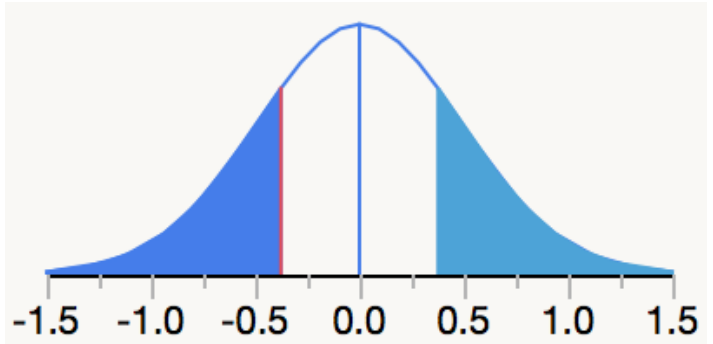

Analysis of Variance

$\begin{array}{lrrcrc}\text { Source } & \text { DF } & \text { Sum of Squares } & \text { Mean Square } & \text { F Ratio } & \text { Prob > F } \\ \text { Group } & 1 & 3.67532 & 3.67532 & 0.5898 & 0.4443 \\ \text { Error } & 103 & 641.89430 & 6.23198 & & \\ \text { C. Total } & 104 & 645.56962 & & \end{array}$

Means for Oneway Anova

$\begin{array}{lrrrrr}\text { Level } & \text { Number } & \text { Mean } & \text { Std Error } & \text { Lower 95\% } & \text { Upper95\% } \\ \text { CONTROL } & 59 & 3.08610 & 0.32500 & 2.4415 & 3.7307 \\ \text { MOP } & 46 & 2.70902 & 0.36807 & 1.9790 & 3.4390\end{array}$

Std Error uses a pooled estimate of error variance 
Oneway Analysis of Data By Group parameter $=\Delta V$, Tooth $=\# 23$

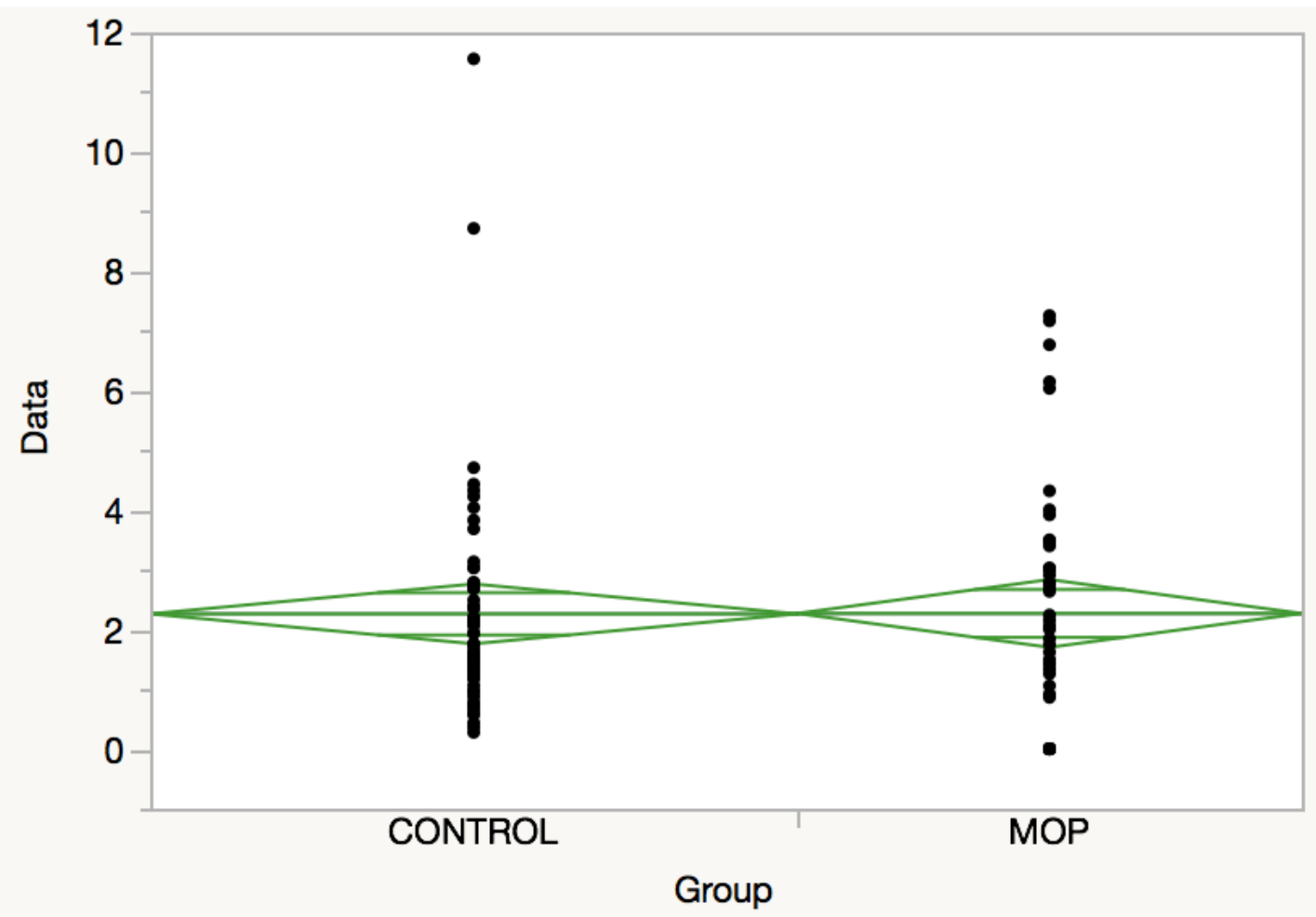

Oneway Anova

Summary of Fit

Rsquare

Adj Rsquare

Root Mean Square Error

Mean of Response

Observations (or Sum Wgts)
$3.848 \mathrm{e}-6$

$-0.0097$

1.942134

2.26439

105

\section{t Test}

MOP-CONTROL

Assuming equal variances

Difference $\quad 0.00760$ t Ratio $\quad 0.019907$ 
Std Err Dif

Upper CL Dif

Lower CL Dif

Confidence
$0.38200 \mathrm{DF}$

0.76522 Prob $>|t|$

-0.75001 Prob > t

0.95 Prob $<\mathrm{t}$
103

0.9842

0.4921

0.5079

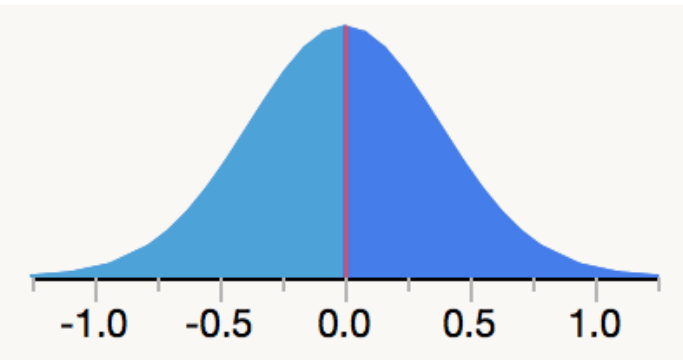

Analysis of Variance

\begin{tabular}{|c|c|c|c|c|c|}
\hline Source & DF & Sum of Squares & Mean Square & F Ratio & Prob $>$ F \\
\hline Group & 1 & 0.00149 & 0.00149 & 0.0004 & 0.9842 \\
\hline Error & 103 & 388.50406 & 3.77188 & & \\
\hline C. Total & 104 & 388.50555 & & & \\
\hline
\end{tabular}

Means for Oneway Anova

$\begin{array}{lrrrrr}\text { Level } & \text { Number } & \text { Mean } & \text { Std Error } & \text { Lower 95\% } & \text { Upper95\% } \\ \text { CONTROL } & 59 & 2.26106 & 0.25284 & 1.7596 & 2.7625 \\ \text { MOP } & 46 & 2.26866 & 0.28635 & 1.7008 & 2.8366\end{array}$

Std Error uses a pooled estimate of error variance 
Oneway Analysis of Data By Group parameter $=\Delta V$, Tooth $=\# 24$

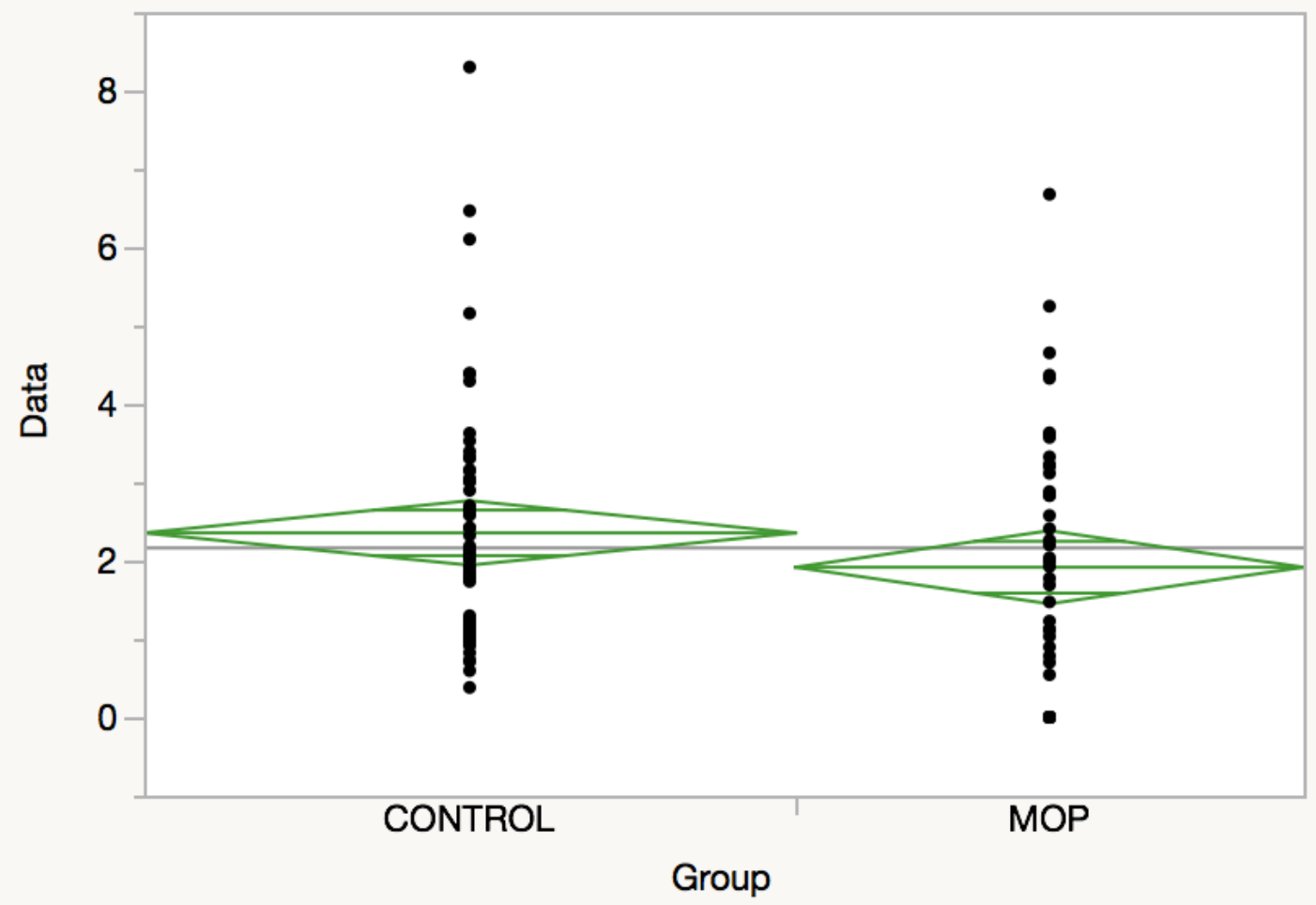

Oneway Anova

Summary of Fit

Rsquare

0.018593

Adj Rsquare

0.009065

Root Mean Square Error

1.595756

Mean of Response

2.160208

Observations (or Sum Wgts)

105

\section{t Test}

MOP-CONTROL

Assuming equal variances

Difference

-0.4385 t Ratio

$-1.3969$ 
Std Err Dif

Upper CL Dif

Lower CL Dif

Confidence
$0.3139 \mathrm{DF}$

0.1840 Prob $>|t|$

-1.0609 Prob > t

0.95 Prob $<\mathrm{t}$

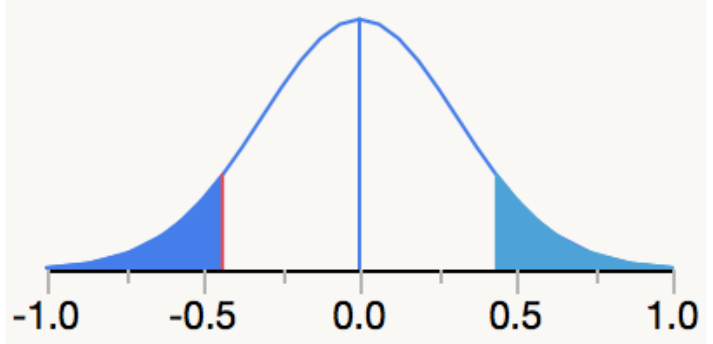

103

0.1654

0.9173

0.0827

Analysis of Variance

\begin{tabular}{|c|c|c|c|c|c|}
\hline Source & DF & Sum of Squares & Mean Square & F Ratio & Prob $>$ F \\
\hline Group & 1 & 4.96897 & 4.96897 & 1.9513 & 0.1654 \\
\hline Error & 103 & 262.28312 & 2.54644 & & \\
\hline C. Total & 104 & 267.25209 & & & \\
\hline
\end{tabular}

Means for Oneway Anova

$\begin{array}{lrrrrr}\text { Level } & \text { Number } & \text { Mean } & \text { Std Error } & \text { Lower 95\% } & \text { Upper 95\% } \\ \text { CONTROL } & 59 & 2.35229 & 0.20775 & 1.9403 & 2.7643 \\ \text { MOP } & 46 & 1.91384 & 0.23528 & 1.4472 & 2.3805\end{array}$

Std Error uses a pooled estimate of error variance 
Oneway Analysis of Data By Group parameter $=\Delta V$, Tooth $=\# 25$

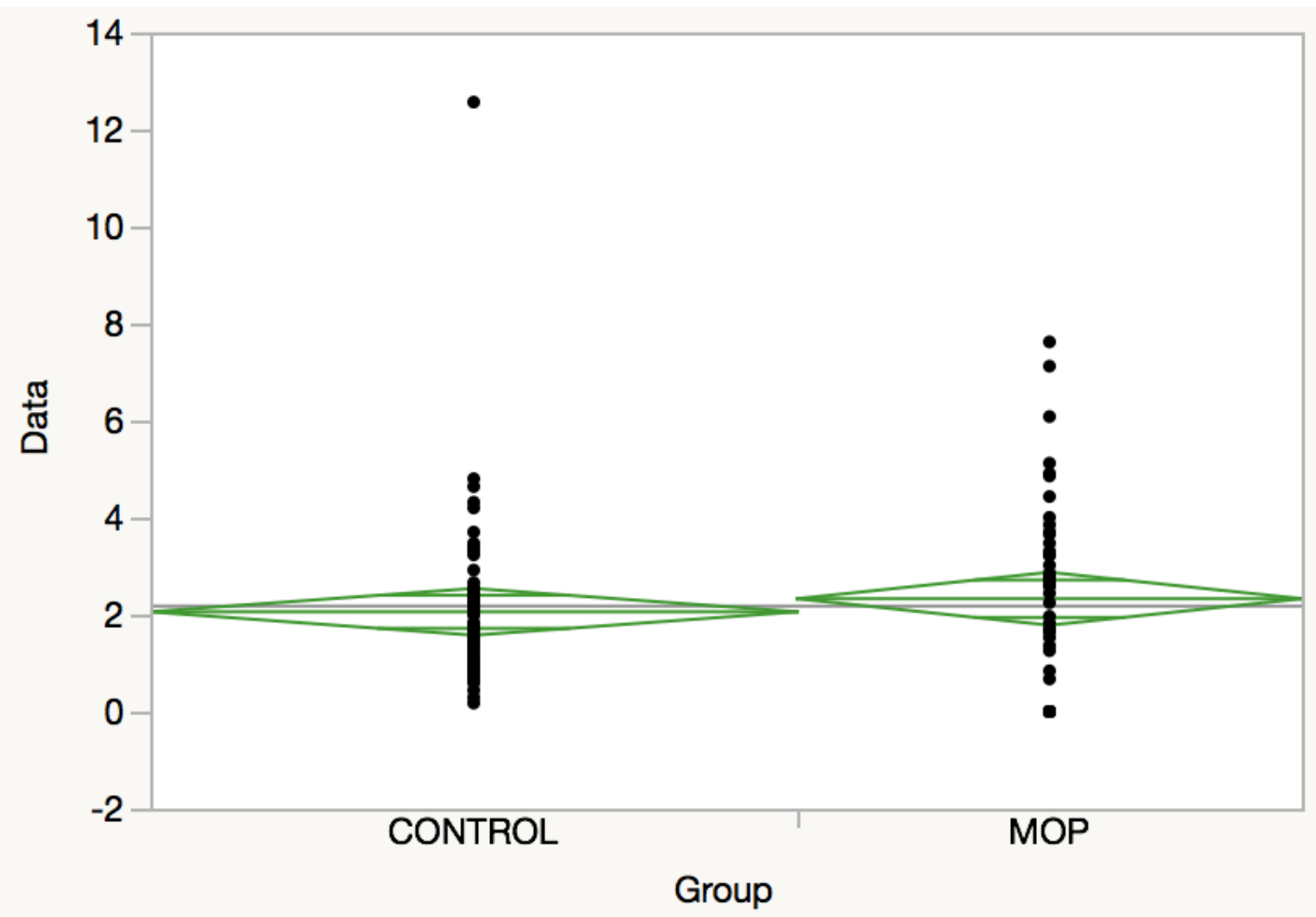

Oneway Anova

Summary of Fit

Rsquare

Adj Rsquare

Root Mean Square Error

Mean of Response

Observations (or Sum Wgts)
0.005206

$-0.00445$

1.869503

2.174375

105

\section{t Test}

MOP-CONTROL

Assuming equal variances

Difference

0.26997 t Ratio

0.734181 
Std Err Dif

Upper CL Dif

Lower CL Dif

Confidence
$0.36772 \mathrm{DF}$

$$
0.99926 \text { Prob }>|t|
$$

-0.45931 Prob > t

0.95 Prob $<\mathrm{t}$
103

0.4645

0.2323

0.7677

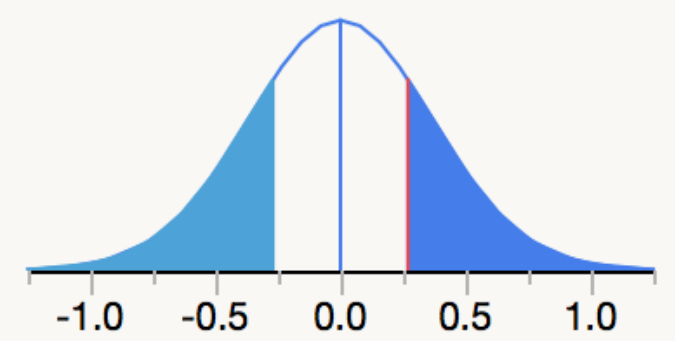

Analysis of Variance

\begin{tabular}{|c|c|c|c|c|c|}
\hline Source & DF & Sum of Squares & Mean Square & F Ratio & Prob $>$ F \\
\hline Group & 1 & 1.88391 & 1.88391 & 0.5390 & 0.4645 \\
\hline Error & 103 & 359.98931 & 3.49504 & & \\
\hline C. Total & 104 & 361.87322 & & & \\
\hline
\end{tabular}

Means for Oneway Anova

$\begin{array}{lrrrrr}\text { Level } & \text { Number } & \text { Mean } & \text { Std Error } & \text { Lower 95\% } & \text { Upper 95\% } \\ \text { CONTROL } & 59 & 2.05610 & 0.24339 & 1.5734 & 2.5388 \\ \text { MOP } & 46 & 2.32607 & 0.27564 & 1.7794 & 2.8727\end{array}$

Std Error uses a pooled estimate of error variance 
Oneway Analysis of Data By Group parameter $=\Delta V$, Tooth $=\# 26$

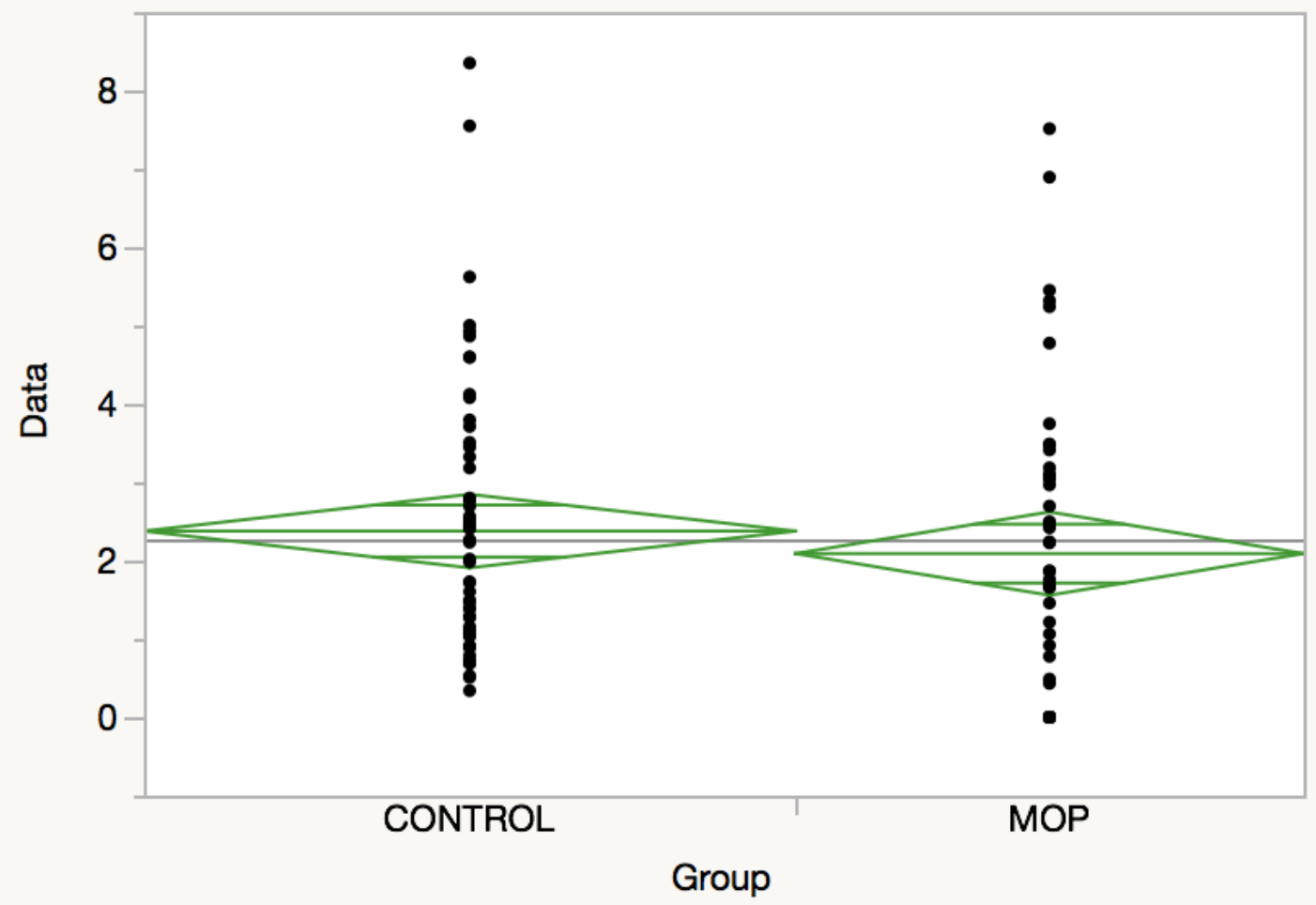

Oneway Anova

Summary of Fit

Rsquare

Adj Rsquare

Root Mean Square Error

Mean of Response

Observations (or Sum Wgts)

t Test

MOP-CONTROL

Assuming equal variances

Difference

-0.28741 t Ratio

$-0.80347$ 
Std Err Dif

Upper CL Dif

Lower CL Dif

Confidence
$0.35771 \mathrm{DF}$

0.42202 Prob $>|t|$

-0.99684 Prob > t

0.95 Prob $<\mathrm{t}$
103

0.4236

0.7882

0.2118

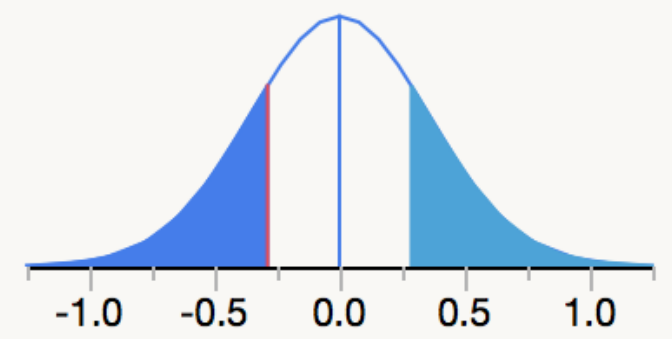

Analysis of Variance

\begin{tabular}{|c|c|c|c|c|c|}
\hline Source & DF & Sum of Squares & Mean Square & F Ratio & Prob $>$ F \\
\hline Group & 1 & 2.13508 & 2.13508 & 0.6456 & 0.4236 \\
\hline Error & 103 & 340.65415 & 3.30732 & & \\
\hline C. Total & 104 & 342.78923 & & & \\
\hline
\end{tabular}

Means for Oneway Anova

$\begin{array}{lrrrrr}\text { Level } & \text { Number } & \text { Mean } & \text { Std Error } & \text { Lower 95\% } & \text { Upper95\% } \\ \text { CONTROL } & 59 & 2.37588 & 0.23676 & 1.9063 & 2.8454 \\ \text { MOP } & 46 & 2.08848 & 0.26814 & 1.5567 & 2.6203\end{array}$

Std Error uses a pooled estimate of error variance 
Oneway Analysis of Data By Group parameter $=\Delta V$, Tooth $=\# 27$

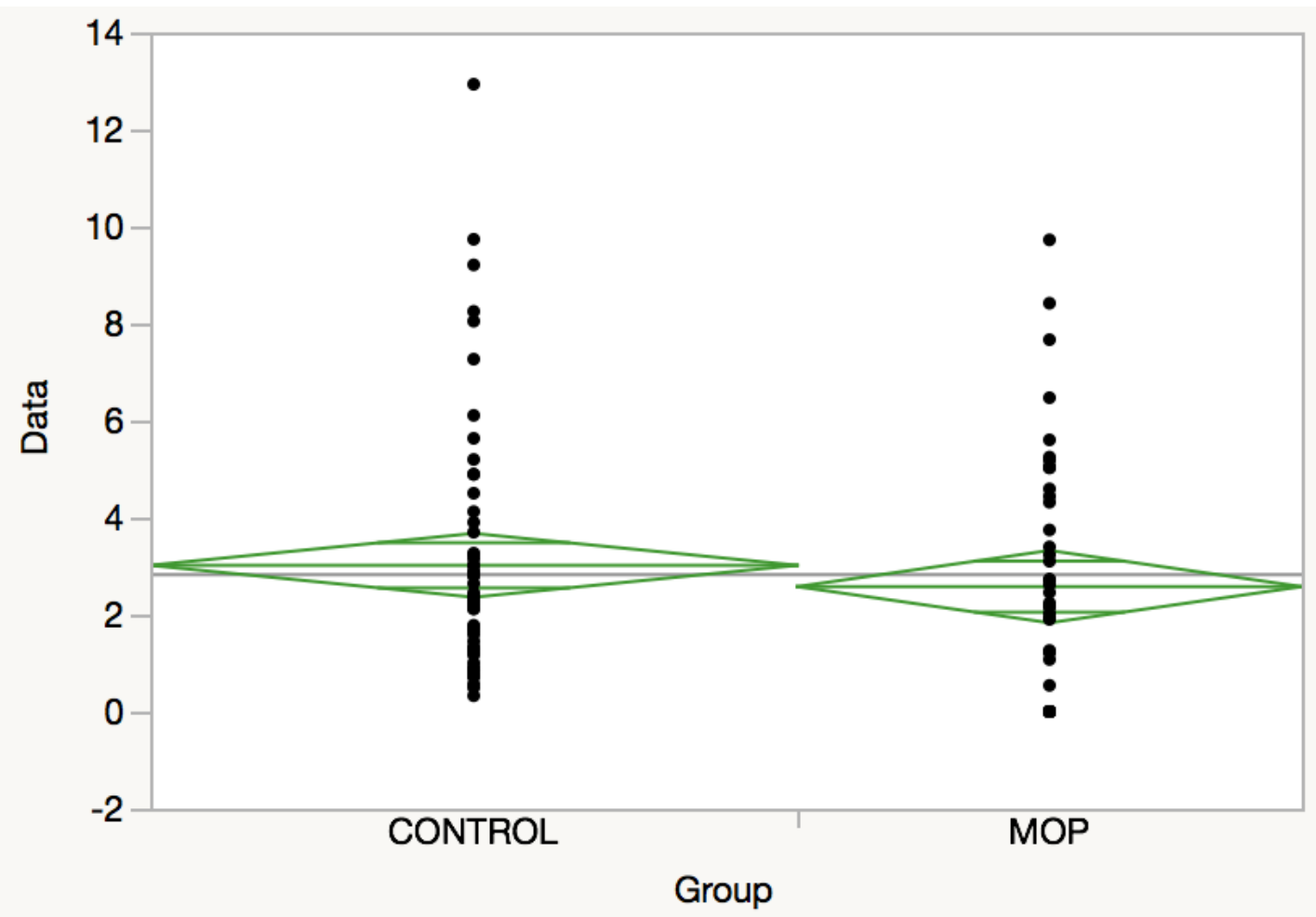

Oneway Anova

Summary of Fit

Rsquare

Adj Rsquare

Root Mean Square Error

Mean of Response

Observations (or Sum Wgts)
0.007413

$-0.00222$

2.549331

2.822233

105

\section{t Test}

MOP-CONTROL

Assuming equal variances

Difference

-0.4398 t Ratio

$-0.87709$ 
Std Err Dif

Upper CL Dif

Lower CL Dif

Confidence

$$
0.5014 \mathrm{DF}
$$

0.5547 Prob $>|t|$

-1.4343 Prob $>\mathrm{t}$

0.95 Prob $<\mathrm{t}$
103

0.3825

0.8088

0.1912

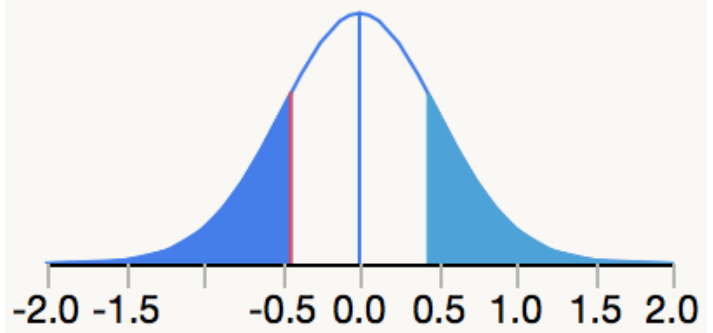

Analysis of Variance

$\begin{array}{lrrrrr}\text { Source } & \text { DF } & \text { Sum of Squares } & \text { Mean Square } & \text { F Ratio } & \text { Prob > F } \\ \text { Group } & 1 & 4.99965 & 4.99965 & 0.7693 & 0.3825 \\ \text { Error } & 103 & 669.40618 & 6.49909 & & \\ \text { C. Total } & 104 & 674.40583 & & \end{array}$

Means for Oneway Anova

$\begin{array}{lrrrrr}\text { Level } & \text { Number } & \text { Mean } & \text { Std Error } & \text { Lower 95\% } & \text { Upper95\% } \\ \text { CONTROL } & 59 & 3.01491 & 0.33189 & 2.3567 & 3.6731 \\ \text { MOP } & 46 & 2.57511 & 0.37588 & 1.8296 & 3.3206\end{array}$

Std Error uses a pooled estimate of error variance 
Oneway Analysis of Data By Group parameter $=\Delta V$, Tooth $=\# 6$

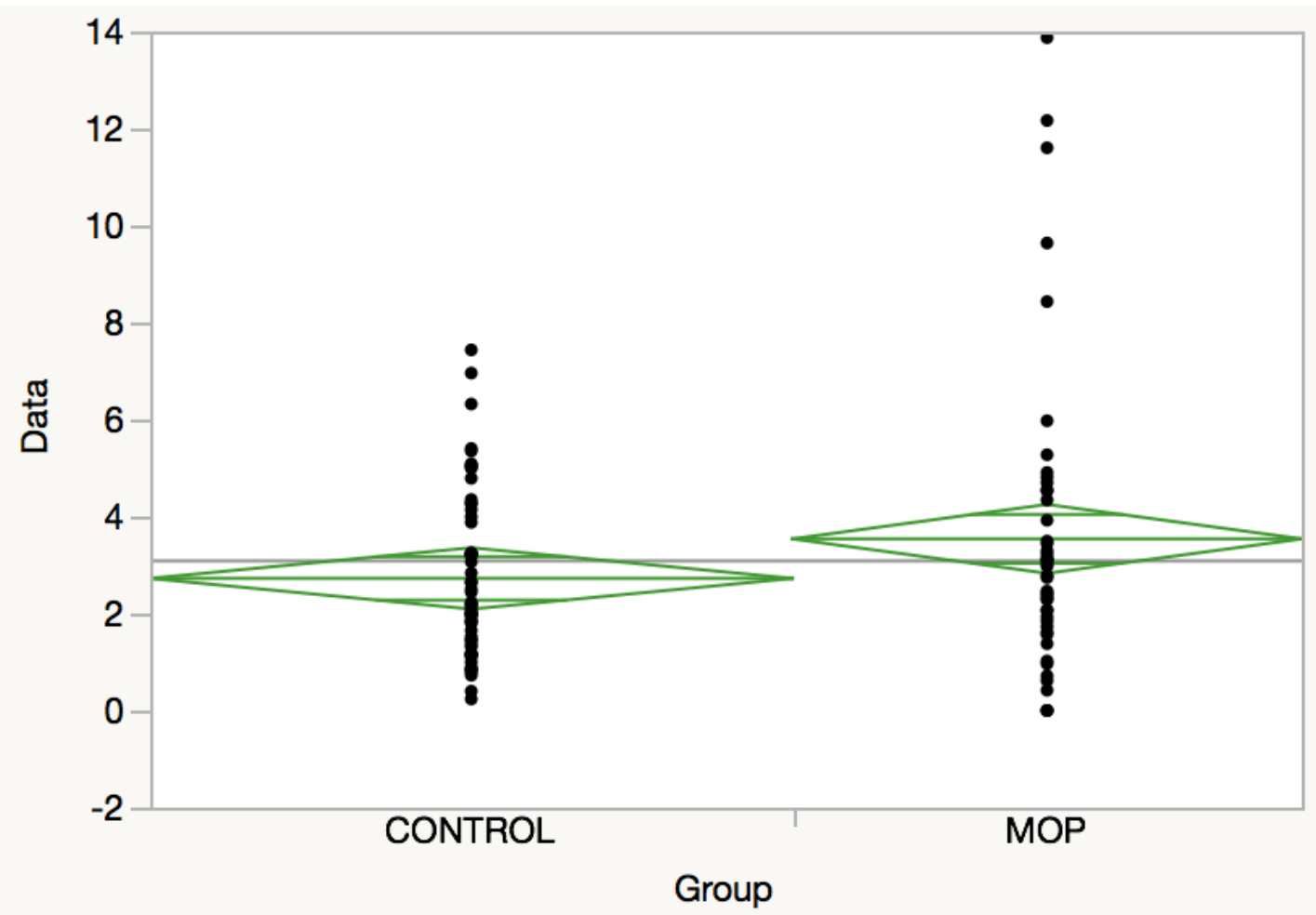

Missing Rows 1

Oneway Anova

Summary of Fit

Rsquare

0.027486

Adj Rsquare

0.017951

Root Mean Square Error

2.43156

Mean of Response

3.084696

Observations (or Sum Wgts)

104

\section{t Test}

MOP-CONTROL

Assuming equal variances

Difference $\quad 0.8151$ t Ratio $\quad 1.697871$ 
Std Err Dif

Upper CL Dif

Lower CL Dif

Confidence
$0.4801 \mathrm{DF}$

1.7673 Prob $>|t|$

-0.1371 Prob $>\mathrm{t}$

0.95 Prob $<\mathrm{t}$
102

0.0926

$0.0463^{*}$

0.9537

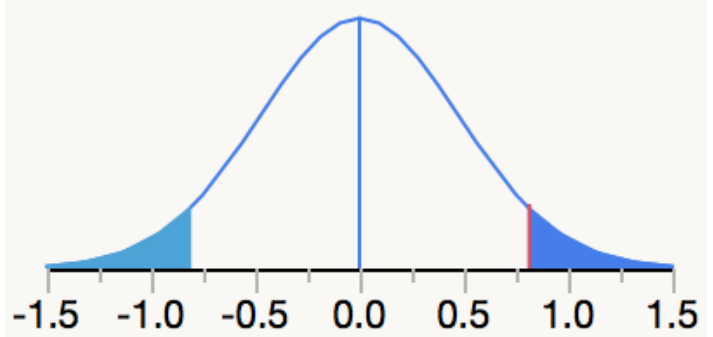

Analysis of Variance

\begin{tabular}{|c|c|c|c|c|c|}
\hline Source & DF & Sum of Squares & Mean Square & F Ratio & Prob $>$ F \\
\hline Group & 1 & 17.04430 & 17.0443 & 2.8828 & 0.0926 \\
\hline Error & 102 & 603.07323 & 5.9125 & & \\
\hline C. Total & 103 & 620.11754 & & & \\
\hline
\end{tabular}

Means for Oneway Anova

$\begin{array}{lrrrrr}\text { Level } & \text { Number } & \text { Mean } & \text { Std Error } & \text { Lower 95\% } & \text { Upper 95\% } \\ \text { CONTROL } & 58 & 2.72417 & 0.31928 & 2.0909 & 3.3575 \\ \text { MOP } & 46 & 3.53927 & 0.35851 & 2.8282 & 4.2504\end{array}$

Std Error uses a pooled estimate of error variance 
Oneway Analysis of Data By Group parameter $=\Delta V$, Tooth $=\# 7$

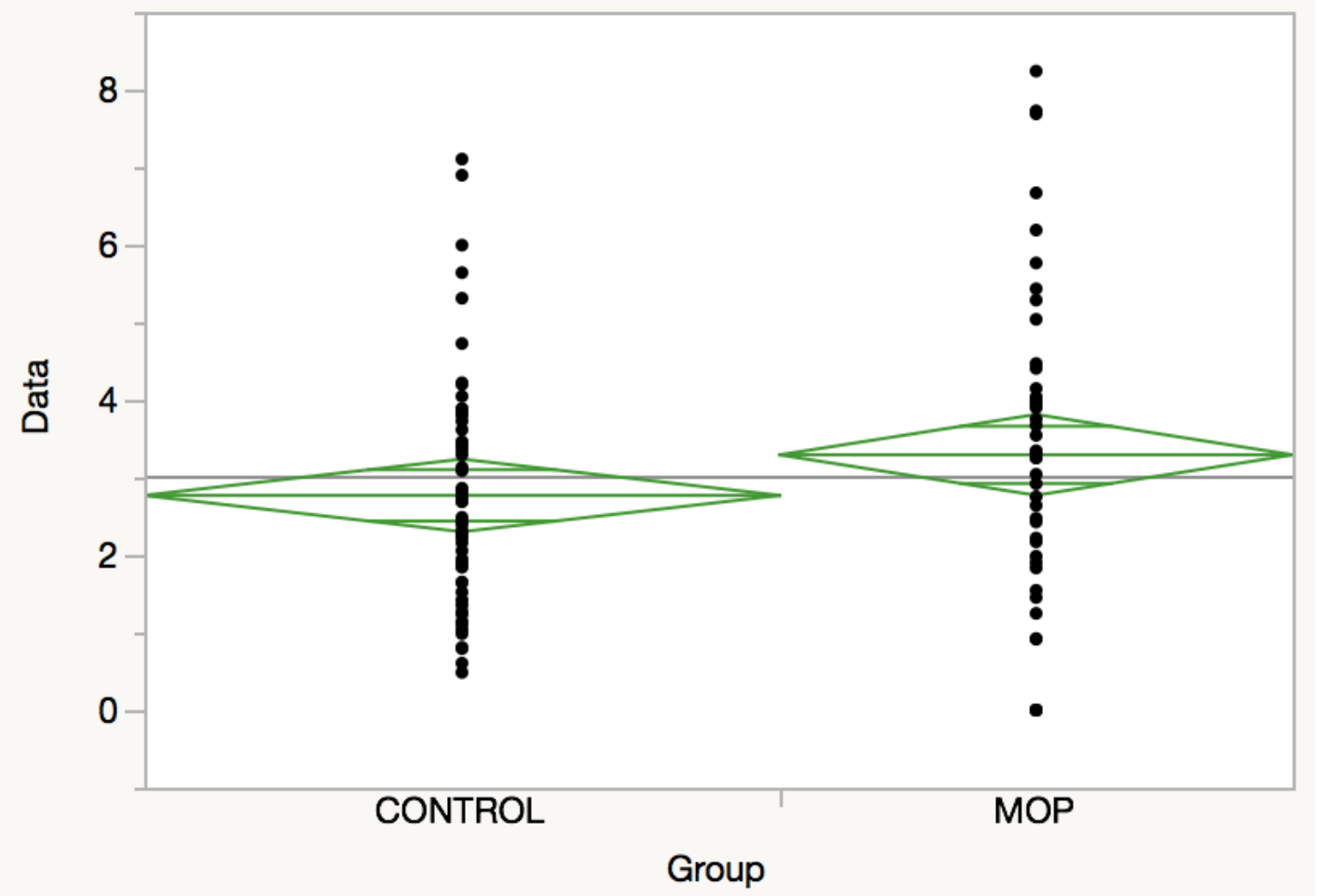

Missing Rows 2

Oneway Anova

Summary of Fit

Rsquare

0.021237

Adj Rsquare

0.011546

Root Mean Square Error

1.782519

Mean of Response

3.000757

Observations (or Sum Wgts)

103

\section{t Test}

MOP-CONTROL

Assuming equal variances

Difference $\quad 0.5230$ t Ratio $\quad 1.480352$ 
Std Err Dif

Upper CL Dif

Lower CL Dif

Confidence
$0.3533 \mathrm{DF}$

1.2238 Prob $>|\mathrm{t}|$

-0.1778 Prob $>\mathrm{t}$

0.95 Prob $<\mathrm{t}$

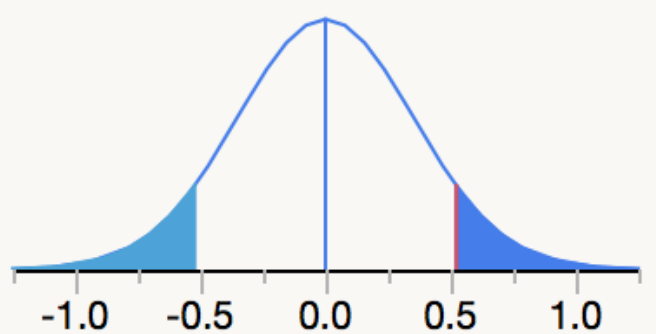

101

0.1419

0.0709

0.9291

Analysis of Variance

$\begin{array}{lrrrrr}\text { Source } & \text { DF } & \text { Sum of Squares } & \text { Mean Square } & \text { F Ratio } & \text { Prob > F } \\ \text { Group } & 1 & 6.96303 & 6.96303 & 2.1914 & 0.1419 \\ \text { Error } & 101 & 320.91480 & 3.17737 & & \\ \text { C. Total } & 102 & 327.87782 & & \end{array}$

Means for Oneway Anova

$\begin{array}{lrrrrr}\text { Level } & \text { Number } & \text { Mean } & \text { Std Error } & \text { Lower 95\% } & \text { Upper95\% } \\ \text { CONTROL } & 57 & 2.76718 & 0.23610 & 2.2988 & 3.2355 \\ \text { MOP } & 46 & 3.29018 & 0.26282 & 2.7688 & 3.8115\end{array}$

Std Error uses a pooled estimate of error variance 
Oneway Analysis of Data By Group parameter $=\Delta V$, Tooth $=\# 8$

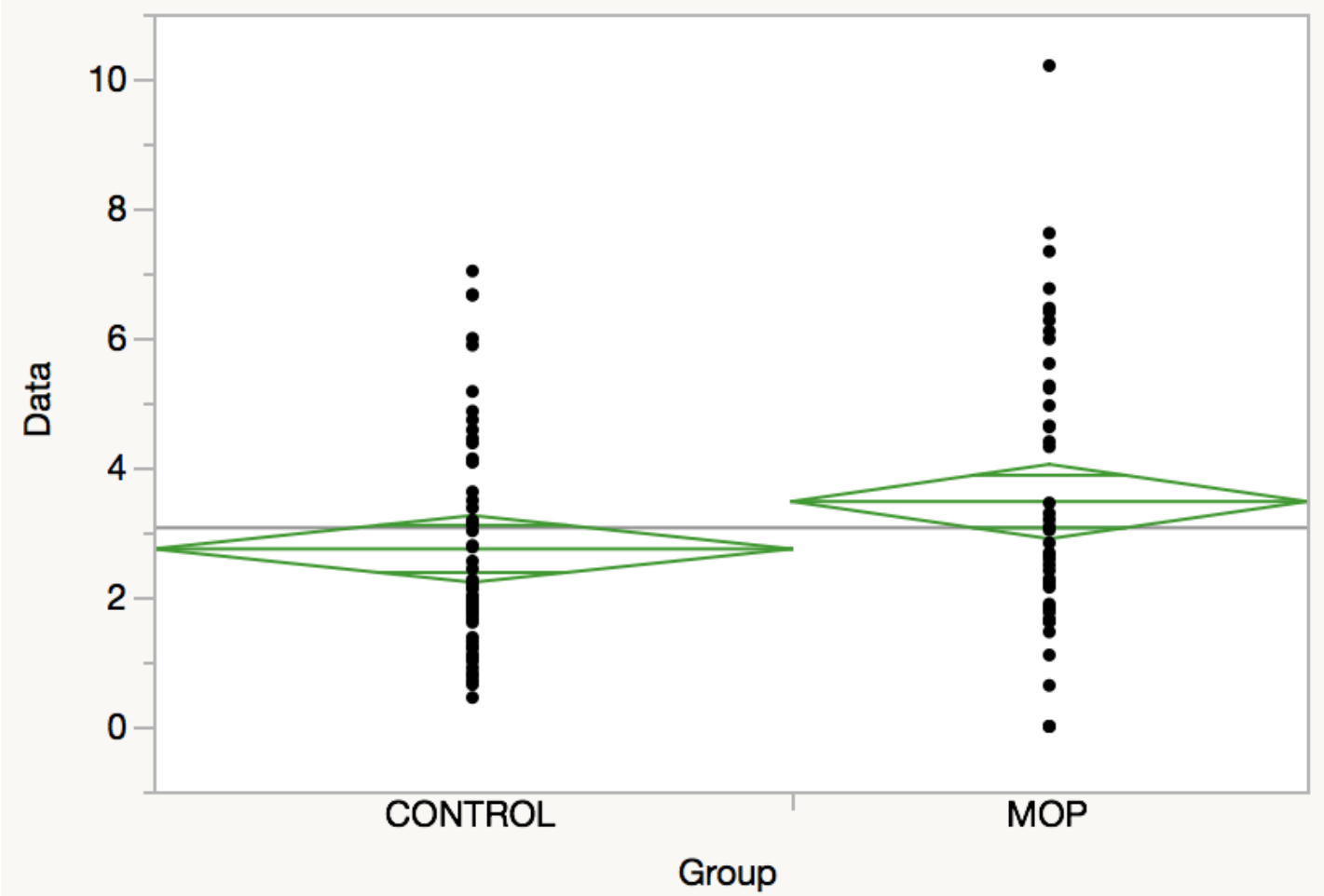

Missing Rows 2

Oneway Anova

Summary of Fit

Rsquare

0.033774

Adj Rsquare

0.024207

Root Mean Square Error

1.964156

Mean of Response

3.066161

Observations (or Sum Wgts)

103

\section{t Test}

MOP-CONTROL

Assuming equal variances

Difference $\quad 0.7315$ t Ratio $\quad 1.87894$ 
Std Err Dif

Upper CL Dif

Lower CL Dif

Confidence
$0.3893 \mathrm{DF}$

1.5037 Prob > $|\mathrm{t}|$

-0.0408 Prob $>\mathrm{t}$

0.95 Prob $<\mathrm{t}$

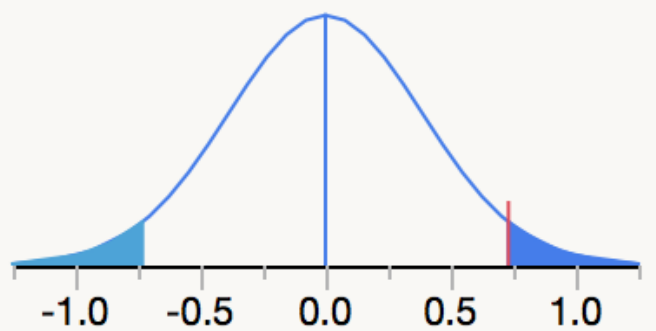

101

0.0631

$0.0316^{*}$

0.9684

Analysis of Variance

$\begin{array}{lrrrrr}\text { Source } & \text { DF } & \text { Sum of Squares } & \text { Mean Square } & \text { F Ratio } & \text { Prob > F } \\ \text { Group } & 1 & 13.62002 & 13.6200 & 3.5304 & 0.0631 \\ \text { Error } & 101 & 389.64879 & 3.8579 & & \\ \text { C. Total } & 102 & 403.26882 & & \end{array}$

Means for Oneway Anova

$\begin{array}{lrrrrr}\text { Level } & \text { Number } & \text { Mean } & \text { Std Error } & \text { Lower 95\% } & \text { Upper 95\% } \\ \text { CONTROL } & 57 & 2.73949 & 0.26016 & 2.2234 & 3.2556 \\ \text { MOP } & 46 & 3.47095 & 0.28960 & 2.8965 & 4.0454\end{array}$

Std Error uses a pooled estimate of error variance 
Oneway Analysis of Data By Group parameter $=\Delta V$, Tooth $=\# 9$

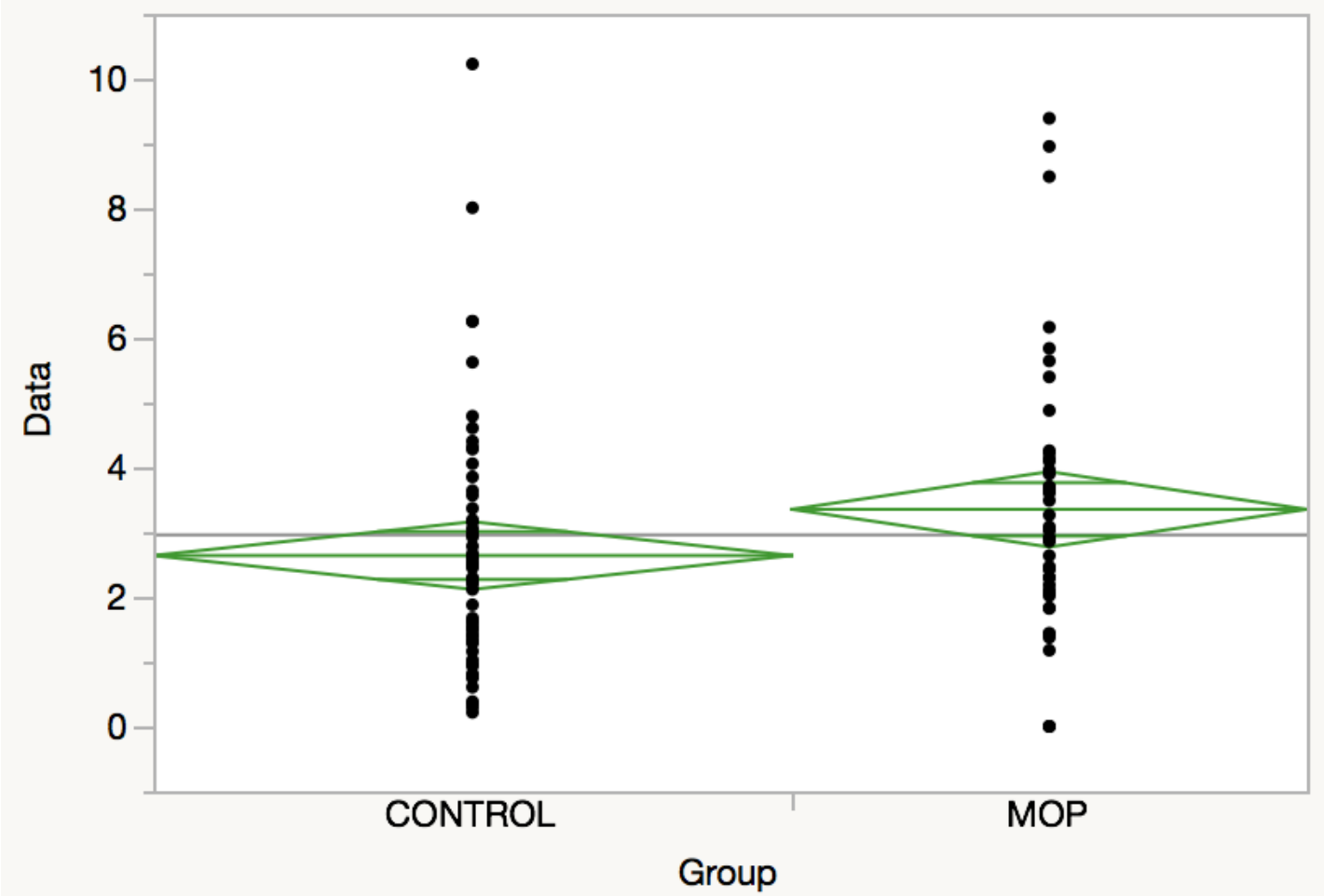

Missing Rows 2

Oneway Anova

Summary of Fit

Rsquare

0.031402

Adj Rsquare

0.021812

Root Mean Square Error

1.989245

Mean of Response

2.955904

Observations (or Sum Wgts)

103

\section{t Test}

MOP-CONTROL

Assuming equal variances

Difference $\quad 0.7134$ t Ratio $\quad 1.809526$ 
Std Err Dif

Upper CL Dif

Lower CL Dif

Confidence
$0.3943 \mathrm{DF}$

1.4956 Prob $>|\mathrm{t}|$

-0.0687 Prob $>\mathrm{t}$

0.95 Prob $<\mathrm{t}$
101

0.0733

$0.0367^{*}$

0.9633

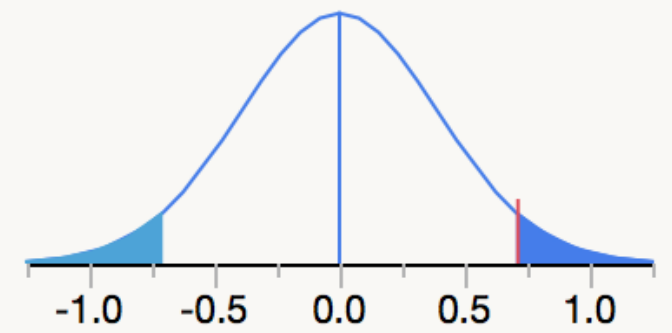

Analysis of Variance

$\begin{array}{lrrrrr}\text { Source } & \text { DF } & \text { Sum of Squares } & \text { Mean Square } & \text { F Ratio } & \text { Prob > F } \\ \text { Group } & 1 & 12.95705 & 12.9571 & 3.2744 & 0.0733 \\ \text { Error } & 101 & 399.66653 & 3.9571 & & \\ \text { C. Total } & 102 & 412.62358 & & \end{array}$

Means for Oneway Anova

$\begin{array}{lrrrrr}\text { Level } & \text { Number } & \text { Mean } & \text { Std Error } & \text { Lower 95\% } & \text { Upper95\% } \\ \text { CONTROL } & 57 & 2.63728 & 0.26348 & 2.1146 & 3.1600 \\ \text { MOP } & 46 & 3.35072 & 0.29330 & 2.7689 & 3.9325\end{array}$

Std Error uses a pooled estimate of error variance 
Oneway Analysis of Data By Group parameter $=\Delta x^{\circ}$, Tooth $=\# 10$

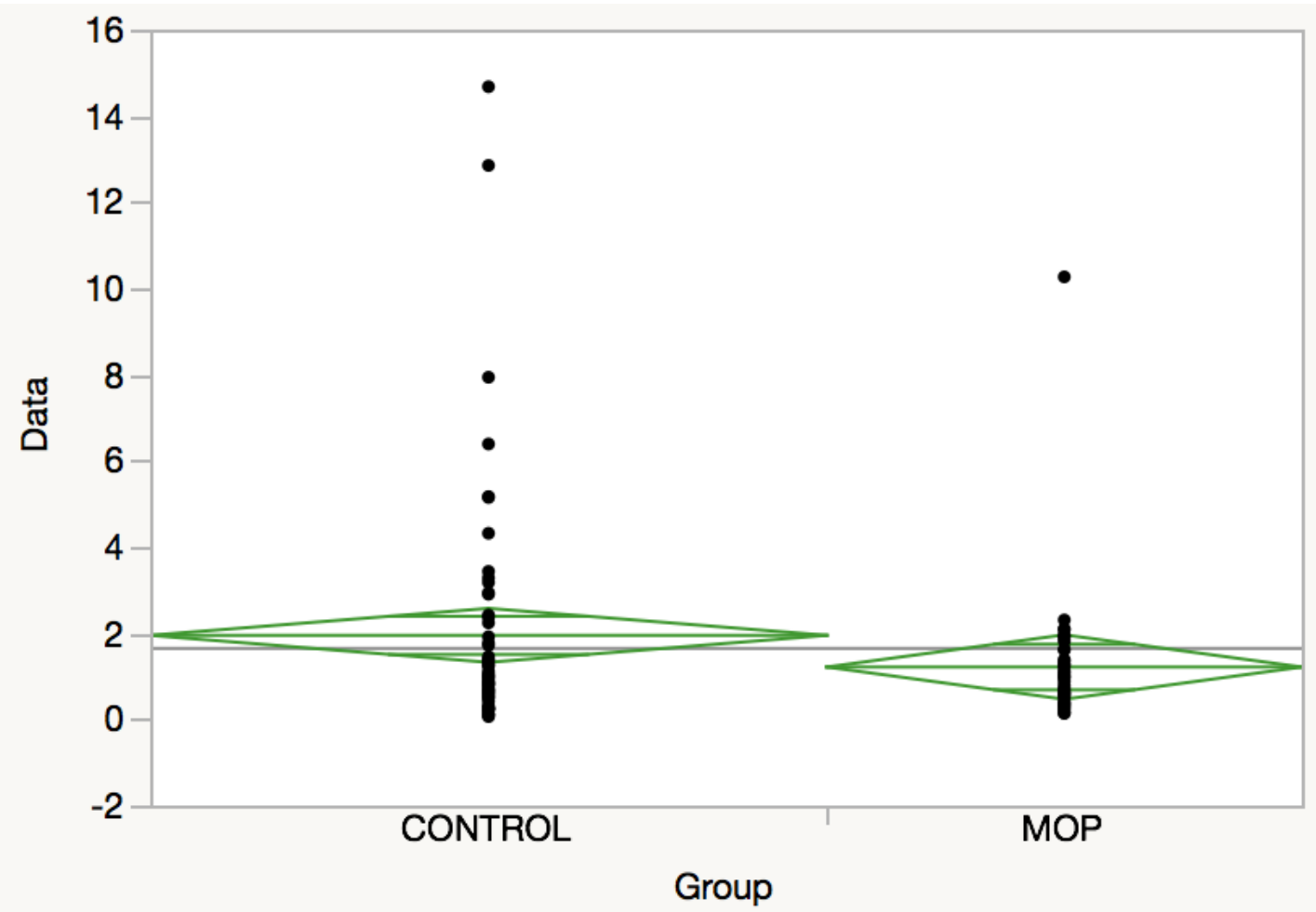

Missing Rows 8

Oneway Anova

Summary of Fit

Rsquare

Adj Rsquare

Root Mean Square Error

Mean of Response

Observations (or Sum Wgts)
0.023005

0.01272

2.381894

1.64392

97

\section{t Test}

MOP-CONTROL

Assuming equal variances

Difference

-0.7348 t Ratio

$-1.49563$ 
Std Err Dif

Upper CL Dif

Lower CL Dif

Confidence
$0.4913 \mathrm{DF}$

0.2405 Prob $>|t|$

-1.7101 Prob $>\mathrm{t}$

0.95 Prob $<\mathrm{t}$

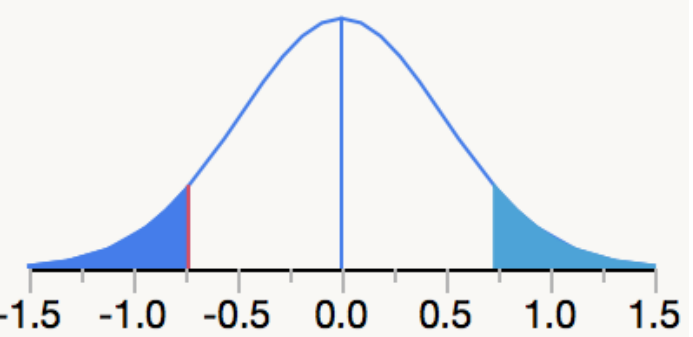

95

0.1381

0.9310

0.0690

Analysis of Variance

\begin{tabular}{|c|c|c|c|c|c|}
\hline Source & DF & Sum of Squares & Mean Square & F Ratio & Prob $>$ F \\
\hline Group & 1 & 12.69087 & 12.6909 & 2.2369 & 0.1381 \\
\hline Error & 95 & 538.97462 & 5.6734 & & \\
\hline C. Total & 96 & 551.66550 & & & \\
\hline
\end{tabular}

Means for Oneway Anova

$\begin{array}{lrrrrr}\text { Level } & \text { Number } & \text { Mean } & \text { Std Error } & \text { Lower 95\% } & \text { Upper 95\% } \\ \text { CONTROL } & 57 & 1.94693 & 0.31549 & 1.3206 & 2.5733 \\ \text { MOP } & 40 & 1.21214 & 0.37661 & 0.4645 & 1.9598\end{array}$

Std Error uses a pooled estimate of error variance 
Oneway Analysis of Data By Group parameter $=\Delta x^{\circ}$, Tooth $=\# 11$

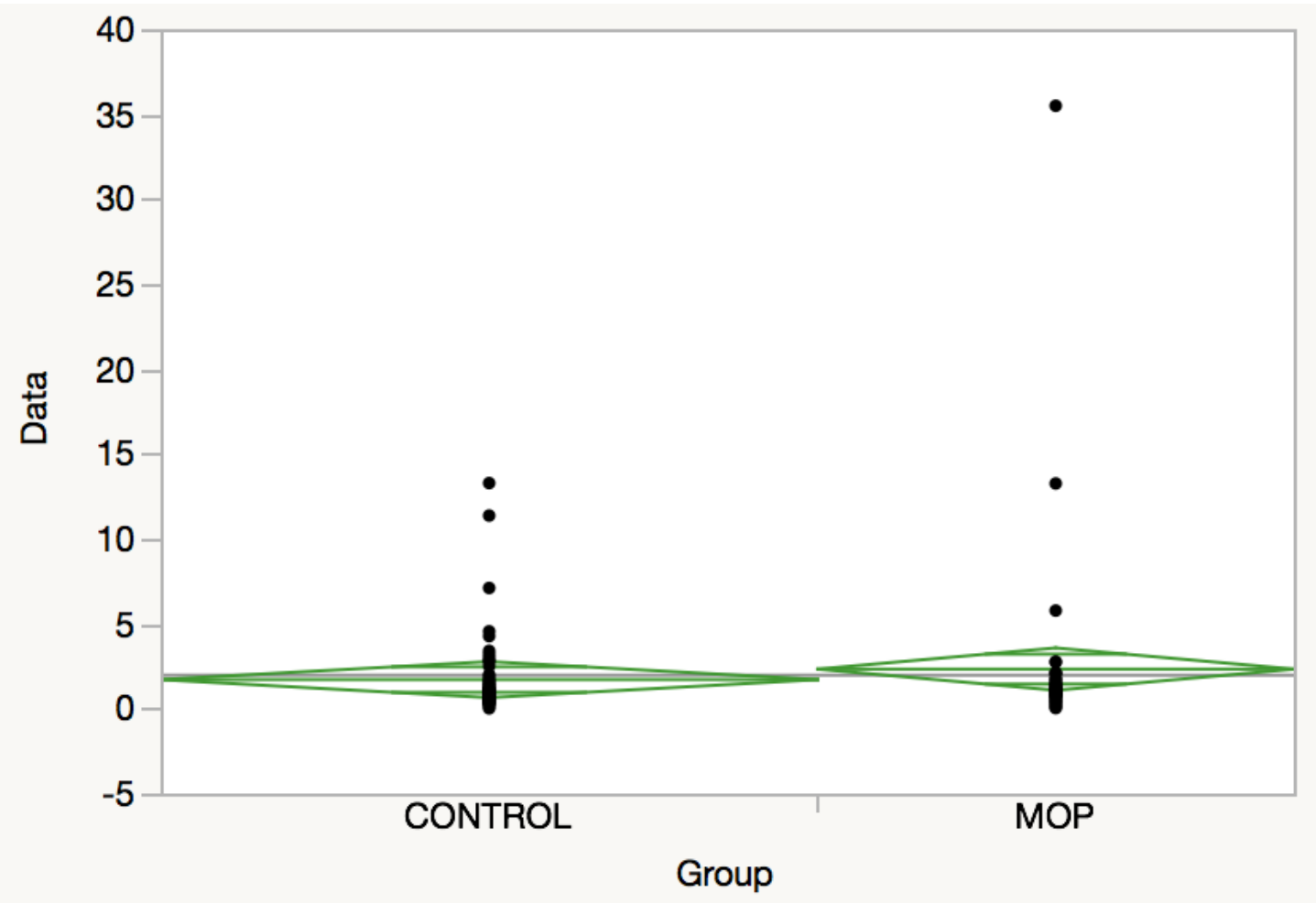

Missing Rows 5

Oneway Anova

Summary of Fit

Rsquare

Adj Rsquare

Root Mean Square Error

Mean of Response

Observations (or Sum Wgts)
0.005671

$-0.00448$

4.076782

1.965403

100

\section{t Test}

MOP-CONTROL

Assuming equal variances

Difference

0.6175 t Ratio

0.74759 
Std Err Dif

Upper CL Dif

Lower CL Dif

Confidence
$0.8260 \mathrm{DF}$

2.2567 Prob $>|t|$

-1.0217 Prob $>\mathrm{t}$

0.95 Prob $<\mathrm{t}$

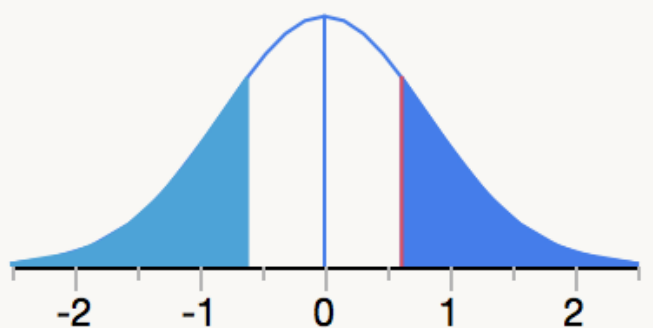

98

0.4565

0.2282

0.7718

Analysis of Variance

\begin{tabular}{|c|c|c|c|c|c|}
\hline Source & DF & Sum of Squares & Mean Square & F Ratio & Prob $>$ F \\
\hline Group & 1 & 9.2889 & 9.2889 & 0.5589 & 0.4565 \\
\hline Error & 98 & 1628.7752 & 16.6202 & & \\
\hline C. Total & 99 & 1638.0640 & & & \\
\hline
\end{tabular}

Means for Oneway Anova

$\begin{array}{lrrrrr}\text { Level } & \text { Number } & \text { Mean } & \text { Std Error } & \text { Lower 95\% } & \text { Upper 95\% } \\ \text { CONTROL } & 58 & 1.70605 & 0.53531 & 0.6437 & 2.7684 \\ \text { MOP } & 42 & 2.32356 & 0.62906 & 1.0752 & 3.5719\end{array}$

Std Error uses a pooled estimate of error variance 
Oneway Analysis of Data By Group parameter $=\Delta x^{\circ}$, Tooth $=\# 22$

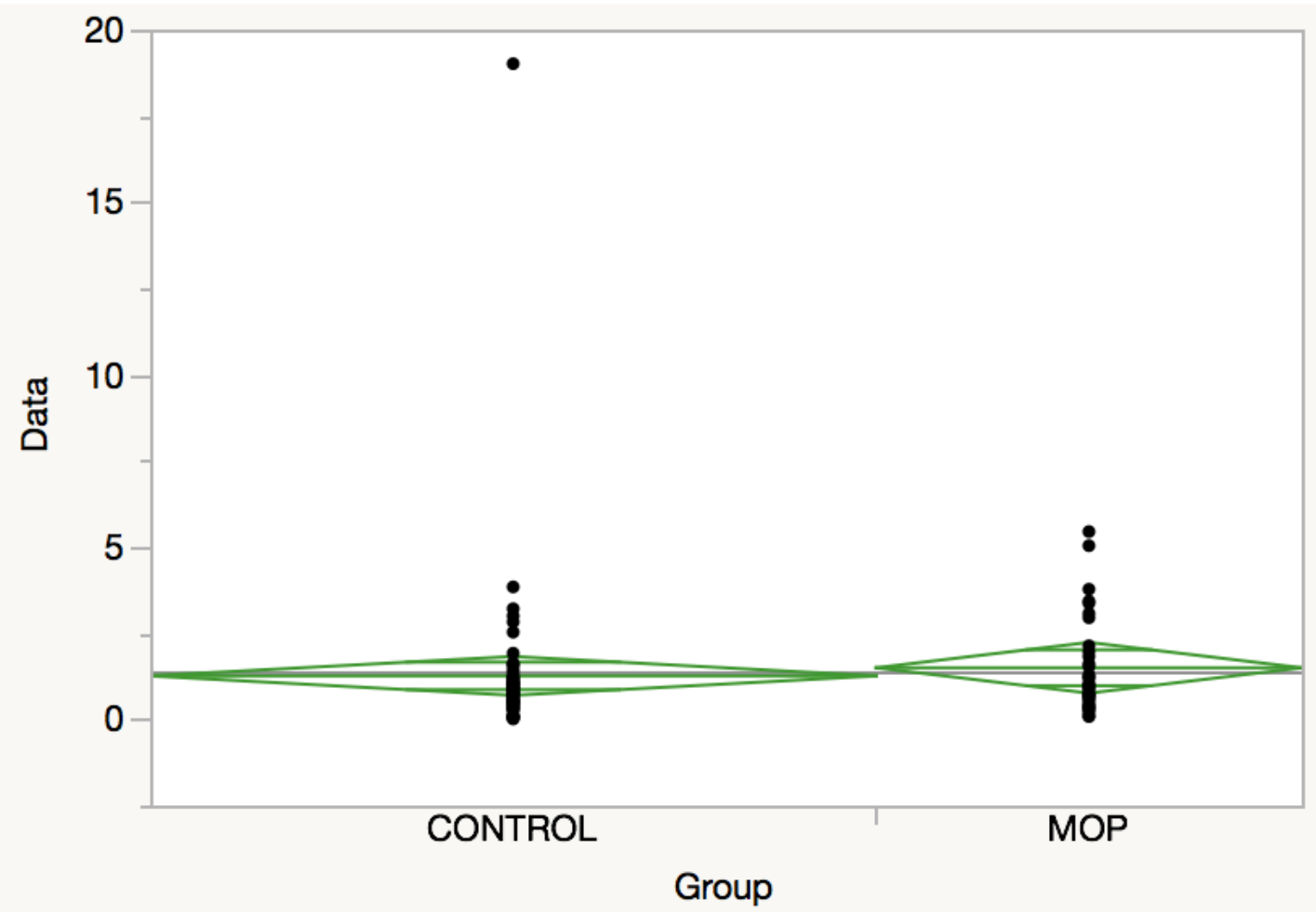

Missing Rows 13

Oneway Anova

Summary of Fit

Rsquare

0.002809

Adj Rsquare

$-0.00827$

Root Mean Square Error

2.162552

Mean of Response

1.345241

Observations (or Sum Wgts)

92

\section{t Test}

MOP-CONTROL

Assuming equal variances

Difference $\quad 0.2352$ t Ratio $\quad 0.503515$ 
Std Err Dif

Upper CL Dif

Lower CL Dif

Confidence
$0.4671 \mathrm{DF}$

1.1632 Prob $>|t|$

-0.6928 Prob $>t$

0.95 Prob $<\mathrm{t}$

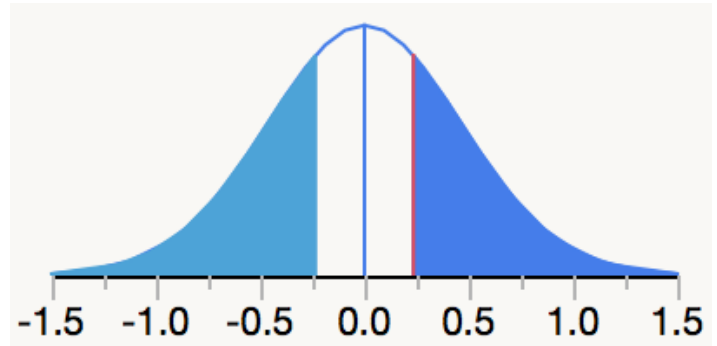

90

0.6158

0.3079

0.6921

Analysis of Variance

\begin{tabular}{|c|c|c|c|c|c|}
\hline Source & DF & Sum of Squares & Mean Square & F Ratio & Prob $>$ F \\
\hline Group & 1 & 1.18565 & 1.18565 & 0.2535 & 0.6158 \\
\hline Error & 90 & 420.89692 & 4.67663 & & \\
\hline C. Total & 91 & 422.08258 & & & \\
\hline
\end{tabular}

Means for Oneway Anova

$\begin{array}{lrrrrr}\text { Level } & \text { Number } & \text { Mean } & \text { Std Error } & \text { Lower 95\% } & \text { Upper 95\% } \\ \text { CONTROL } & 58 & 1.25832 & 0.28396 & 0.69419 & 1.8225 \\ \text { MOP } & 34 & 1.49351 & 0.37087 & 0.75671 & 2.2303\end{array}$

Std Error uses a pooled estimate of error variance 
Oneway Analysis of Data By Group parameter $=\Delta x^{\circ}$, Tooth $=\# 23$

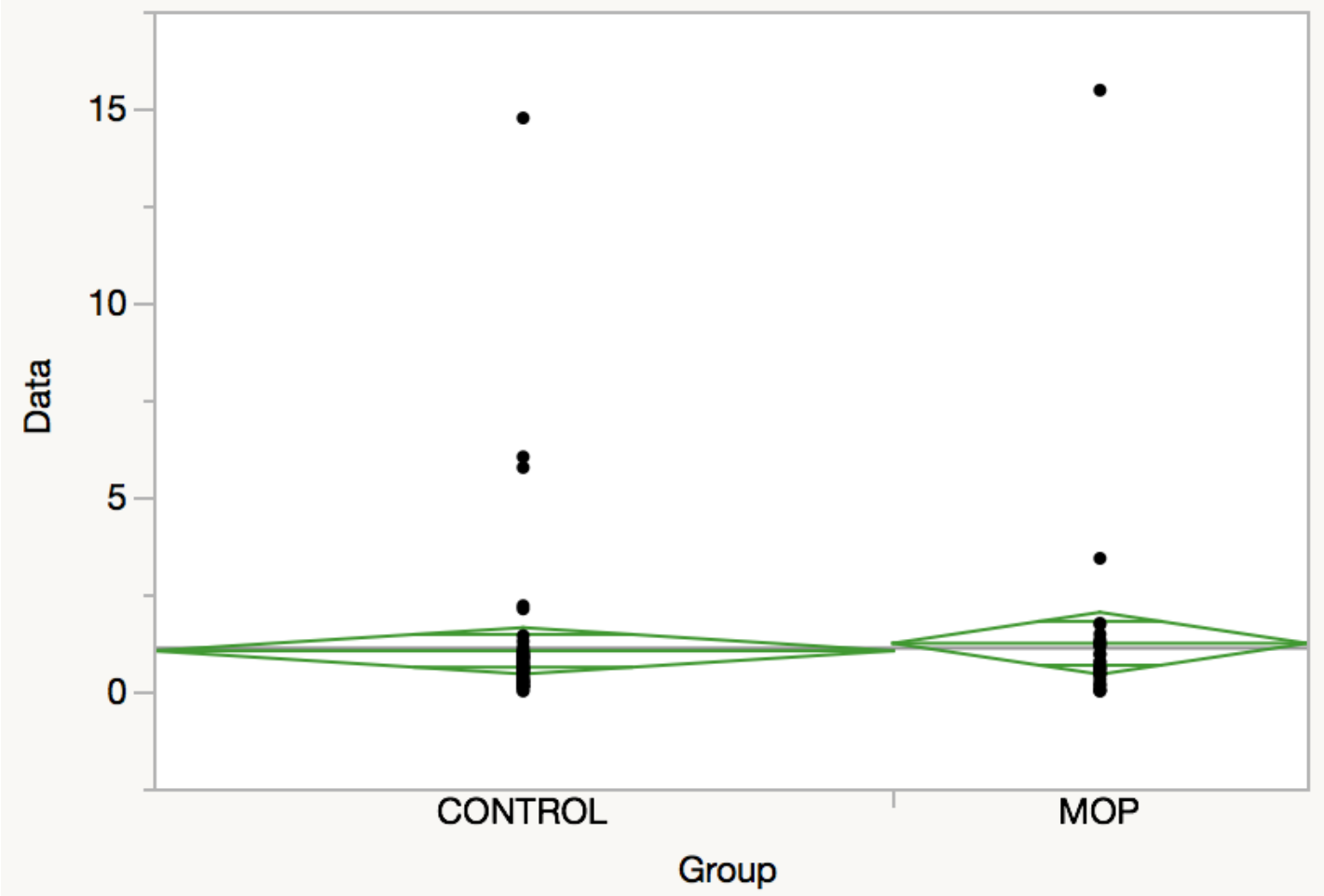

Missing Rows 13

Oneway Anova

Summary of Fit

Rsquare

Adj Rsquare

Root Mean Square Error

Mean of Response

Observations (or Sum Wgts)
0.001646

$-0.00945$

2.308971

1.107978

92

\section{t Test}

MOP-CONTROL

Assuming equal variances

Difference $\quad 0.1933$ t Ratio $\quad 0.385216$ 
Std Err Dif

Upper CL Dif

Lower CL Dif

Confidence
$0.5019 \mathrm{DF}$

1.1905 Prob $>|t|$

-0.8038 Prob $>\mathrm{t}$

0.95 Prob $<\mathrm{t}$
90

0.7010

0.3505

0.6495

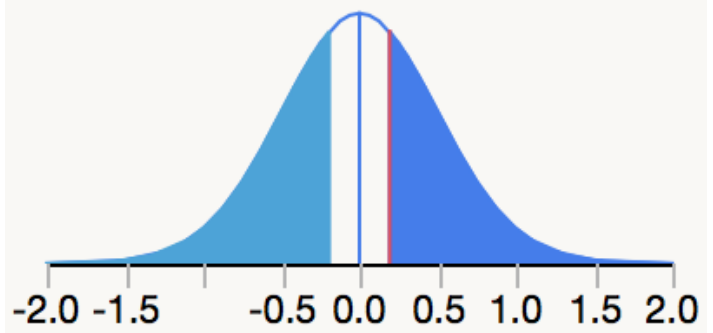

Analysis of Variance

\begin{tabular}{|c|c|c|c|c|c|}
\hline Source & DF & Sum of Squares & Mean Square & F Ratio & Prob $>$ F \\
\hline Group & 1 & 0.79112 & 0.79112 & 0.1484 & 0.7010 \\
\hline Error & 90 & 479.82103 & 5.33134 & & \\
\hline C. Total & 91 & 480.61216 & & & \\
\hline
\end{tabular}

Means for Oneway Anova

$\begin{array}{lrrrrr}\text { Level } & \text { Number } & \text { Mean } & \text { Std Error } & \text { Lower 95\% } & \text { Upper95\% } \\ \text { CONTROL } & 59 & 1.03863 & 0.30060 & 0.44143 & 1.6358 \\ \text { MOP } & 33 & 1.23197 & 0.40194 & 0.43345 & 2.0305\end{array}$

Std Error uses a pooled estimate of error variance 
Oneway Analysis of Data By Group parameter $=\Delta x^{\circ}$, Tooth $=\# 24$

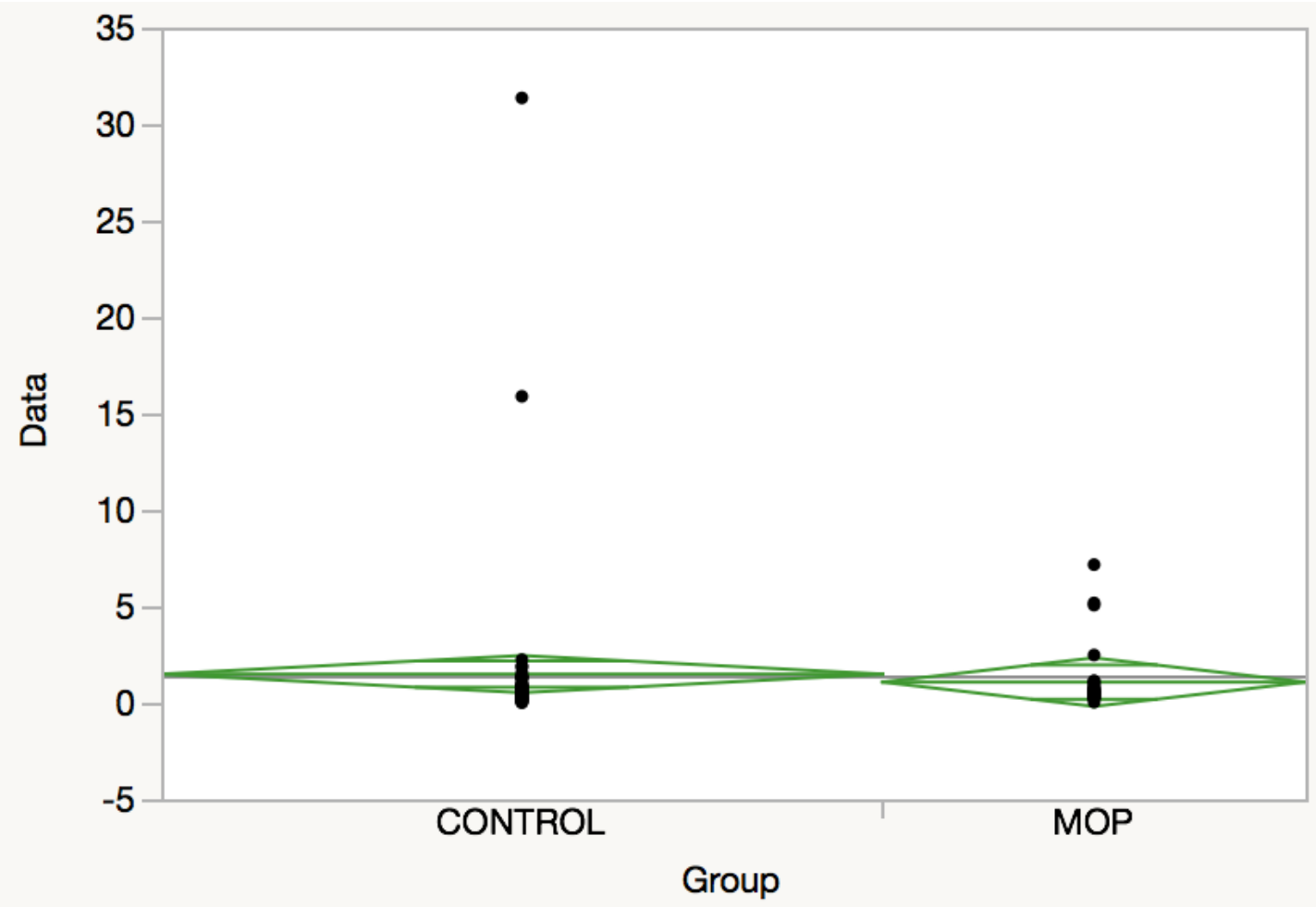

Missing Rows 13

Oneway Anova

Summary of Fit

Rsquare

Adj Rsquare

Root Mean Square Error

Mean of Response

Observations (or Sum Wgts)
0.002992

$-0.00809$

3.696739

1.332075

92

\section{t Test}

MOP-CONTROL

Assuming equal variances

Difference

-0.4149 t Ratio

$-0.51968$ 
Std Err Dif

Upper CL Dif

Lower CL Dif

Confidence
$0.7985 \mathrm{DF}$

$$
1.1714 \text { Prob }>|t|
$$

-2.0013 Prob $>\mathrm{t}$

0.95 Prob $<\mathrm{t}$

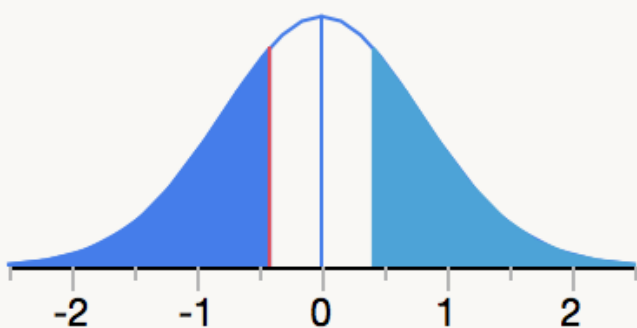

90

0.6046

0.6977

0.3023

Analysis of Variance

\begin{tabular}{|c|c|c|c|c|c|}
\hline Source & DF & Sum of Squares & Mean Square & F Ratio & Prob $>$ F \\
\hline Group & 1 & 3.6907 & 3.6907 & 0.2701 & 0.6046 \\
\hline Error & 90 & 1229.9293 & 13.6659 & & \\
\hline C. Total & 91 & 1233.6200 & & & \\
\hline
\end{tabular}

Means for Oneway Anova

$\begin{array}{lrrrrr}\text { Level } & \text { Number } & \text { Mean } & \text { Std Error } & \text { Lower 95\% } & \text { Upper 95\% } \\ \text { CONTROL } & 58 & 1.48543 & 0.48541 & 0.5211 & 2.4498 \\ \text { MOP } & 34 & 1.07048 & 0.63399 & -0.1890 & 2.3300\end{array}$

Std Error uses a pooled estimate of error variance 
Oneway Analysis of Data By Group parameter $=\Delta x^{\circ}$, Tooth $=\# 25$

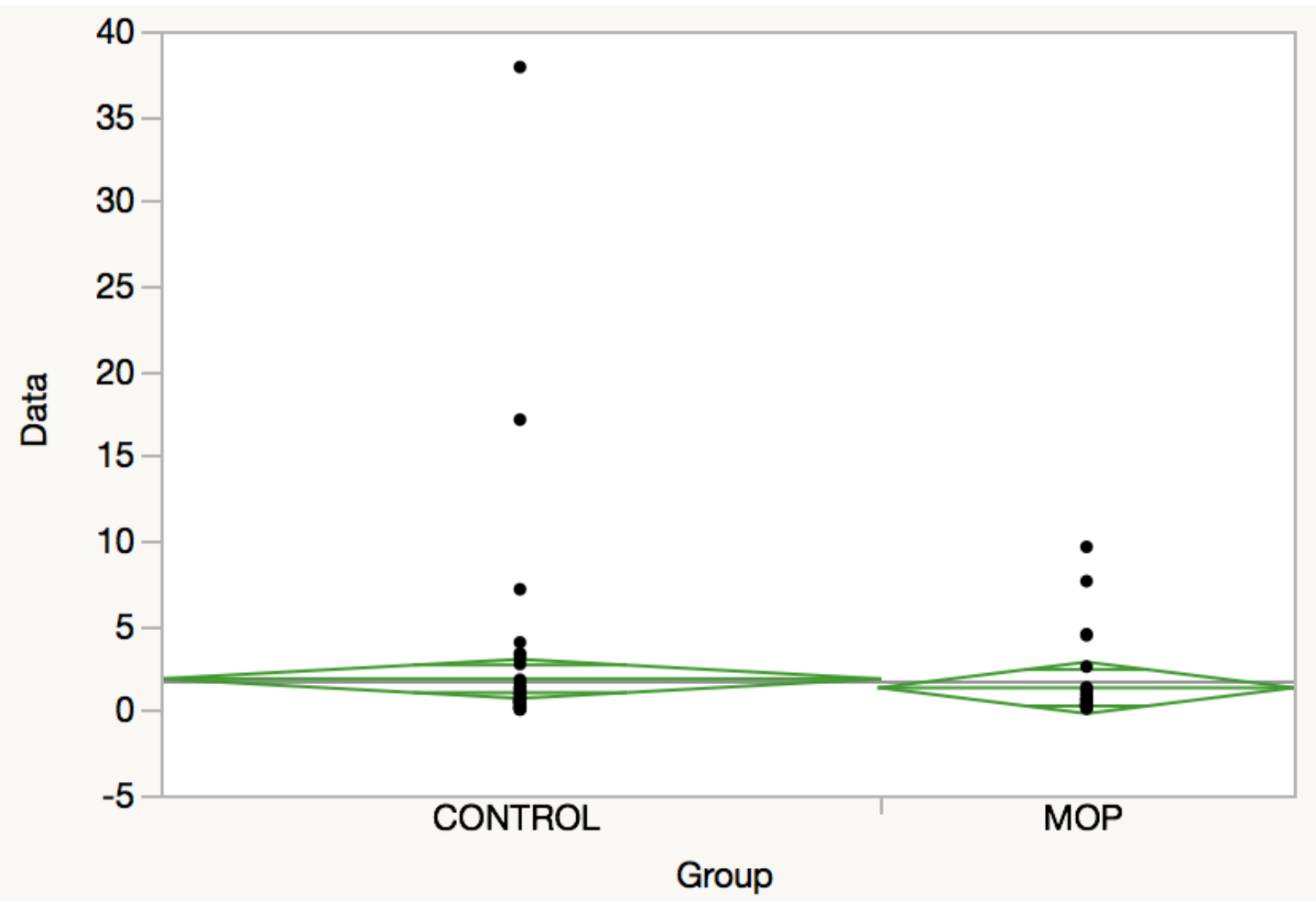

Missing Rows 12

Oneway Anova

Summary of Fit

Rsquare

Adj Rsquare

Root Mean Square Error

Mean of Response

Observations (or Sum Wgts)
0.003316

$-0.00764$

4.456897

1.659316

93

\section{t Test}

MOP-CONTROL

Assuming equal variances

Difference

-0.5280 t Ratio

$-0.5502$ 
Std Err Dif

Upper CL Dif

Lower CL Dif

Confidence
$0.9596 \mathrm{DF}$

1.3782 Prob $>|t|$

-2.4342 Prob $>\mathrm{t}$

0.95 Prob $<\mathrm{t}$

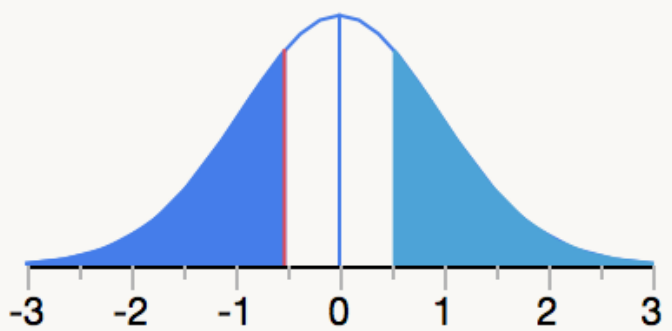

91

0.5835

0.7082

0.2918

Analysis of Variance

\begin{tabular}{|c|c|c|c|c|c|}
\hline Source & DF & Sum of Squares & Mean Square & F Ratio & Prob $>$ F \\
\hline Group & 1 & 6.0132 & 6.0132 & 0.3027 & 0.5835 \\
\hline Error & 91 & 1807.6175 & 19.8639 & & \\
\hline C. Total & 92 & 1813.6307 & & & \\
\hline
\end{tabular}

Means for Oneway Anova

$\begin{array}{lrrrrr}\text { Level } & \text { Number } & \text { Mean } & \text { Std Error } & \text { Lower 95\% } & \text { Upper95\% } \\ \text { CONTROL } & 59 & 1.85235 & 0.58024 & 0.6998 & 3.0049 \\ \text { MOP } & 34 & 1.32435 & 0.76435 & -0.1939 & 2.8426\end{array}$

Std Error uses a pooled estimate of error variance 
Oneway Analysis of Data By Group parameter $=\Delta x^{\circ}$, Tooth $=\# 26$

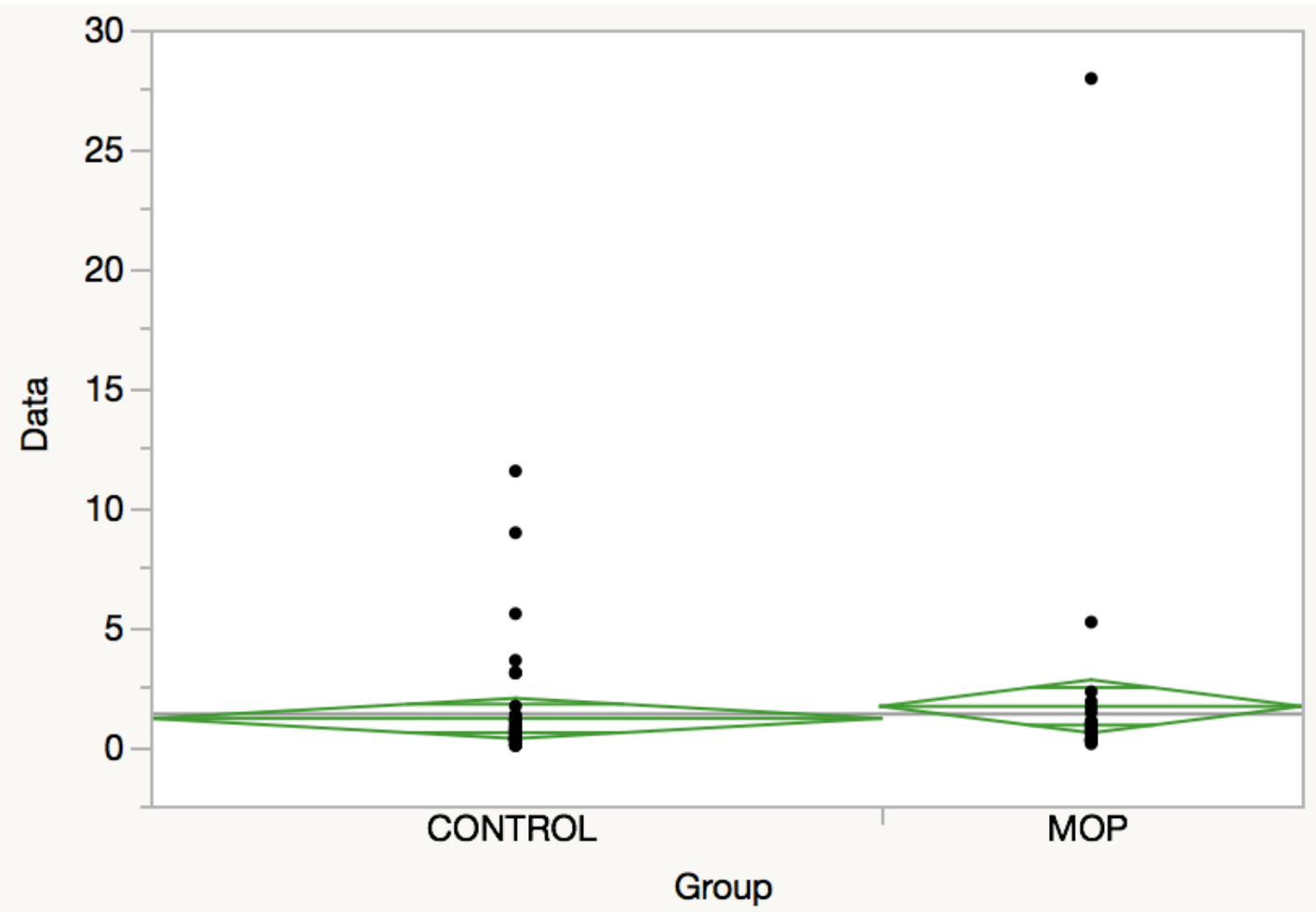

Missing Rows 12

Oneway Anova

Summary of Fit

Rsquare

Adj Rsquare

Root Mean Square Error

Mean of Response

Observations (or Sum Wgts)
0.005665

$-0.00526$

3.26395

1.332288

93

\section{t Test}

MOP-CONTROL

Assuming equal variances

Difference

0.5060 t Ratio

0.720008 
Std Err Dif

Upper CL Dif

Lower CL Dif

Confidence
$0.7028 \mathrm{DF}$

1.9020 Prob $>|t|$

-0.8900 Prob $>\mathrm{t}$

0.95 Prob $<\mathrm{t}$
91

0.4734

0.2367

0.7633

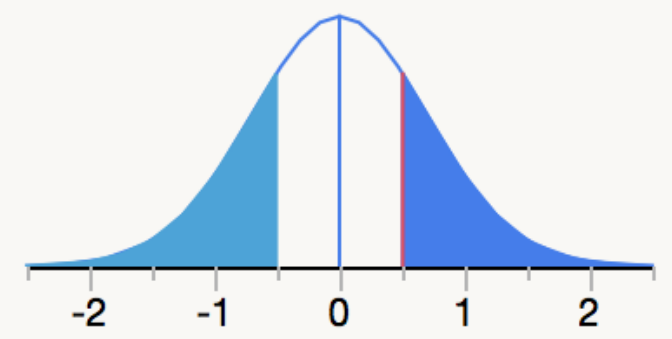

Analysis of Variance

\begin{tabular}{|c|c|c|c|c|c|}
\hline Source & DF & Sum of Squares & Mean Square & F Ratio & Prob $>$ F \\
\hline Group & 1 & 5.52284 & 5.5228 & 0.5184 & 0.4734 \\
\hline Error & 91 & 969.45678 & 10.6534 & & \\
\hline C. Total & 92 & 974.97962 & & & \\
\hline
\end{tabular}

Means for Oneway Anova

$\begin{array}{lrrrrr}\text { Level } & \text { Number } & \text { Mean } & \text { Std Error } & \text { Lower 95\% } & \text { Upper 95\% } \\ \text { CONTROL } & 59 & 1.14730 & 0.42493 & 0.30322 & 1.9914 \\ \text { MOP } & 34 & 1.65330 & 0.55976 & 0.54140 & 2.7652\end{array}$

Std Error uses a pooled estimate of error variance 
Oneway Analysis of Data By Group parameter $=\Delta x^{\circ}$, Tooth $=\# 27$

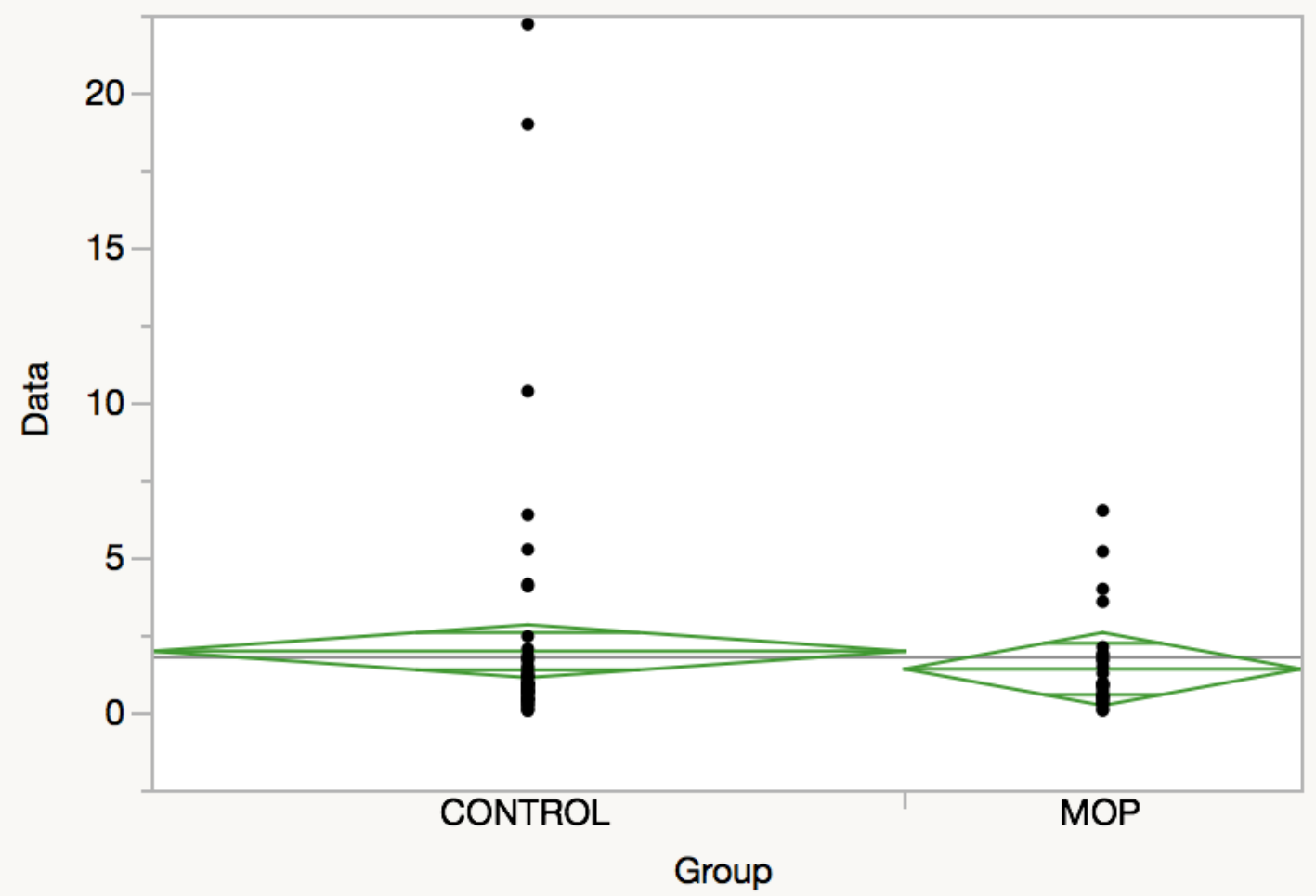

Missing Rows 15

Oneway Anova

Summary of Fit

Rsquare

Adj Rsquare

Root Mean Square Error

Mean of Response

Observations (or Sum Wgts)
0.006971

$-0.00431$

3.29266

1.76792

90

\section{t Test}

MOP-CONTROL

Assuming equal variances

Difference

-0.5741 t Ratio

$-0.78596$ 
Std Err Dif

Upper CL Dif

Lower CL Dif

Confidence
$0.7304 \mathrm{DF}$

$$
0.8775 \text { Prob }>|t|
$$$$
-2.0256 \text { Prob >t }
$$

0.95 Prob $<\mathrm{t}$

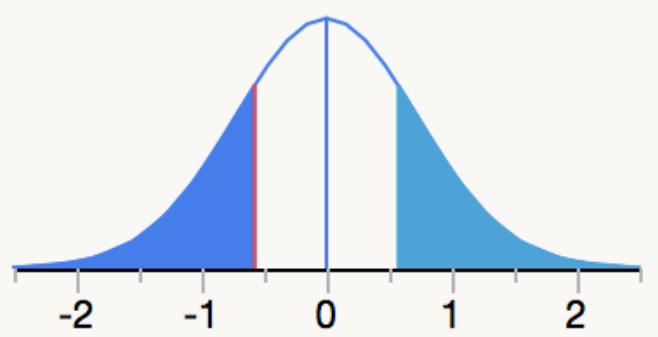

88

0.4340

0.7830

0.2170

Analysis of Variance

\begin{tabular}{|c|c|c|c|c|c|}
\hline Source & DF & Sum of Squares & Mean Square & F Ratio & Prob $>$ F \\
\hline Group & 1 & 6.69716 & 6.6972 & 0.6177 & 0.4340 \\
\hline Error & 88 & 954.06143 & 10.8416 & & \\
\hline C. Total & 89 & 960.75859 & & & \\
\hline
\end{tabular}

Means for Oneway Anova

$\begin{array}{lrrrrr}\text { Level } & \text { Number } & \text { Mean } & \text { Std Error } & \text { Lower 95\% } & \text { Upper95\% } \\ \text { CONTROL } & 59 & 1.96565 & 0.42867 & 1.1138 & 2.8175 \\ \text { MOP } & 31 & 1.39159 & 0.59138 & 0.2163 & 2.5668\end{array}$

Std Error uses a pooled estimate of error variance 
Oneway Analysis of Data By Group parameter $=\Delta x^{\circ}$, Tooth $=\# 6$

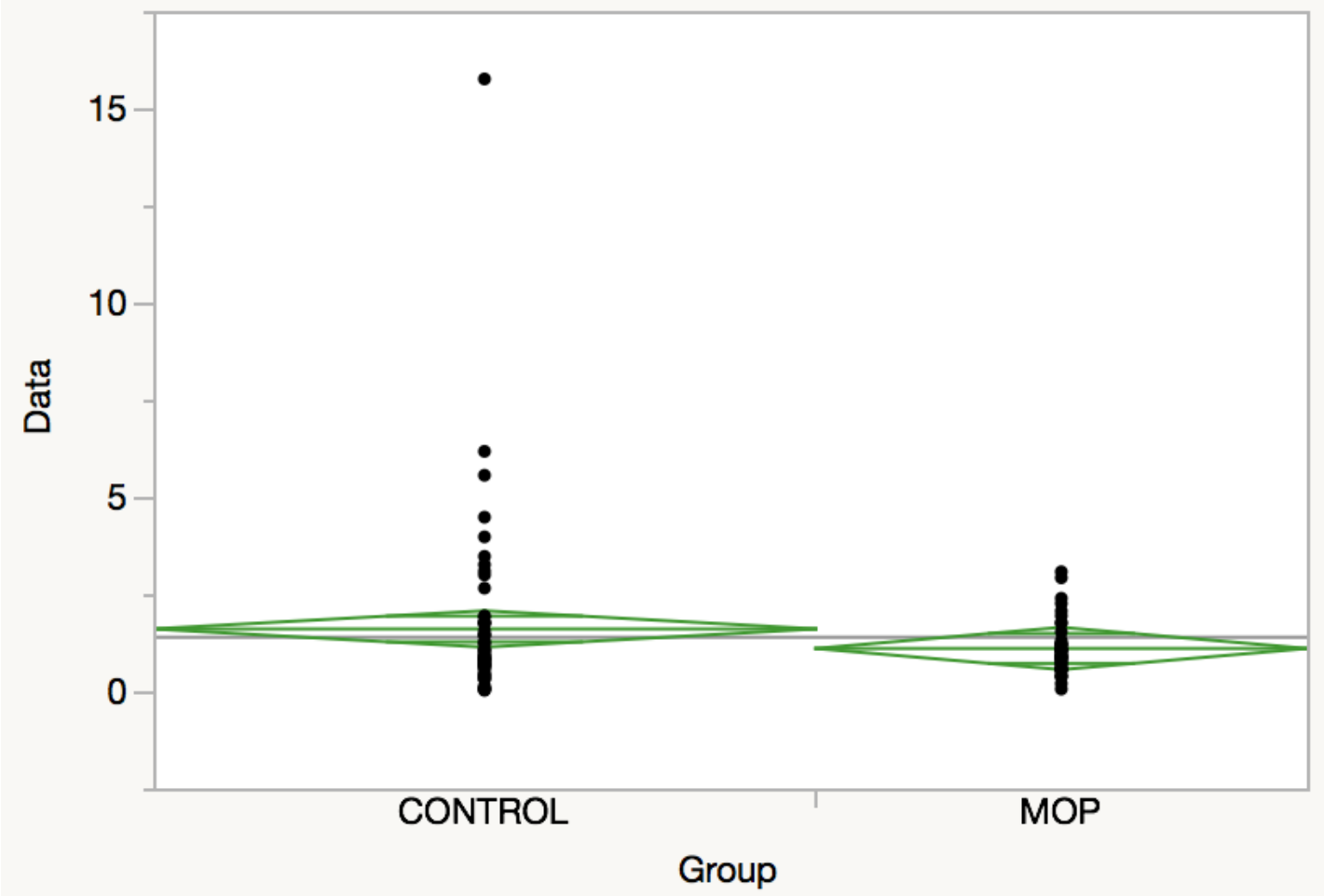

Missing Rows 4

Oneway Anova

Summary of Fit

Rsquare

0.019109

Adj Rsquare

0.009201

Root Mean Square Error

1.798827

Mean of Response

1.387514

Observations (or Sum Wgts)

101

\section{t Test}

MOP-CONTROL

Assuming equal variances

Difference

-0.5027 t Ratio

$-1.38875$ 
Std Err Dif

Upper CL Dif

Lower CL Dif

Confidence
$0.3620 \mathrm{DF}$

0.2156 Prob $>|t|$

-1.2210 Prob >t

0.95 Prob $<\mathrm{t}$
99

0.1680

0.9160

0.0840

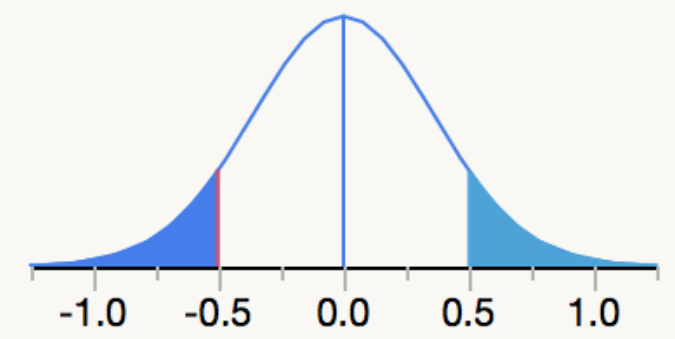

Analysis of Variance

\begin{tabular}{|c|c|c|c|c|c|}
\hline Source & DF & Sum of Squares & Mean Square & F Ratio & Prob $>$ F \\
\hline Group & 1 & 6.24058 & 6.24058 & 1.9286 & 0.1680 \\
\hline Error & 99 & 320.34214 & 3.23578 & & \\
\hline C. Total & 100 & 326.58272 & & & \\
\hline
\end{tabular}

Means for Oneway Anova

$\begin{array}{lrrrrr}\text { Level } & \text { Number } & \text { Mean } & \text { Std Error } & \text { Lower 95\% } & \text { Upper95\% } \\ \text { CONTROL } & 58 & 1.60154 & 0.23620 & 1.1329 & 2.0702 \\ \text { MOP } & 43 & 1.09882 & 0.27432 & 0.5545 & 1.6431\end{array}$

Std Error uses a pooled estimate of error variance 
Oneway Analysis of Data By Group parameter $=\Delta x^{\circ}$, Tooth $=\# 7$

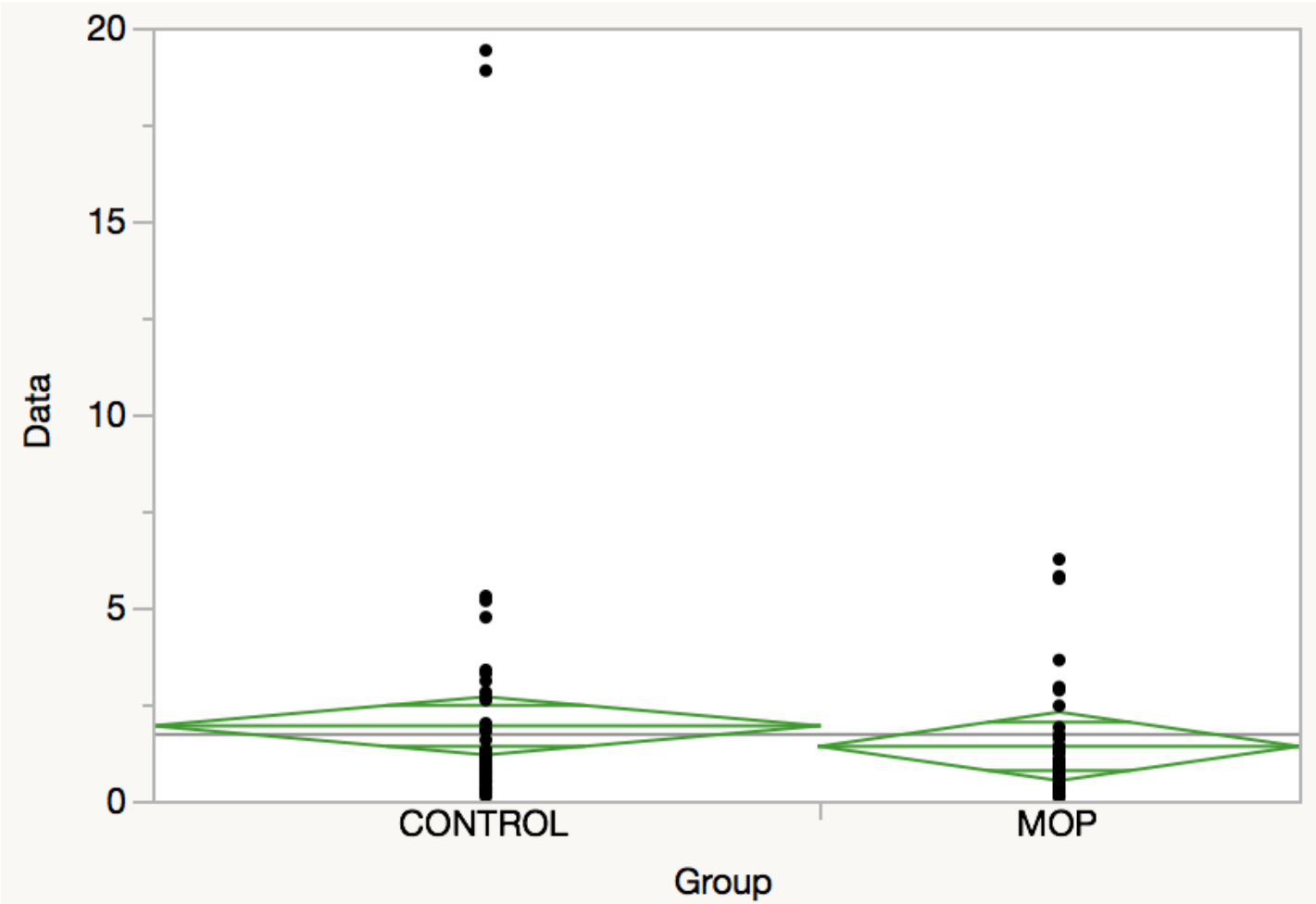

Missing Rows 7

Oneway Anova

Summary of Fit

Rsquare

Adj Rsquare

Root Mean Square Error

Mean of Response

Observations (or Sum Wgts)
0.00852

$-0.00181$

2.859625

1.713536

98

\section{t Test}

MOP-CONTROL

Assuming equal variances

Difference

-0.5319 t Ratio

$-0.90828$ 
Std Err Dif

Upper CL Dif

Lower CL Dif

Confidence
$0.5856 \mathrm{DF}$

0.6305 Prob $>|\mathrm{t}|$

-1.6943 Prob $>t$

0.95 Prob $<\mathrm{t}$
96

0.3660

0.8170

0.1830

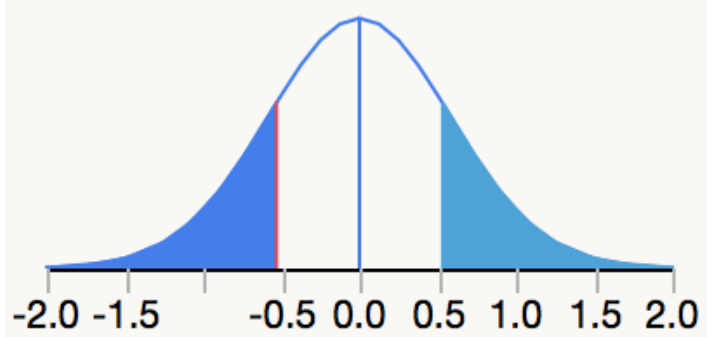

Analysis of Variance

\begin{tabular}{|c|c|c|c|c|c|}
\hline Source & DF & Sum of Squares & Mean Square & F Ratio & Prob $>$ F \\
\hline Group & 1 & 6.74617 & 6.74617 & 0.8250 & 0.3660 \\
\hline Error & 96 & 785.03587 & 8.17746 & & \\
\hline C. Total & 97 & 791.78203 & & & \\
\hline
\end{tabular}

Means for Oneway Anova

$\begin{array}{lrrrrr}\text { Level } & \text { Number } & \text { Mean } & \text { Std Error } & \text { Lower 95\% } & \text { Upper 95\% } \\ \text { CONTROL } & 57 & 1.93606 & 0.37877 & 1.1842 & 2.6879 \\ \text { MOP } & 41 & 1.40418 & 0.44660 & 0.5177 & 2.2907\end{array}$

Std Error uses a pooled estimate of error variance 
Oneway Analysis of Data By Group parameter $=\Delta x^{\circ}$, Tooth $=\# 8$

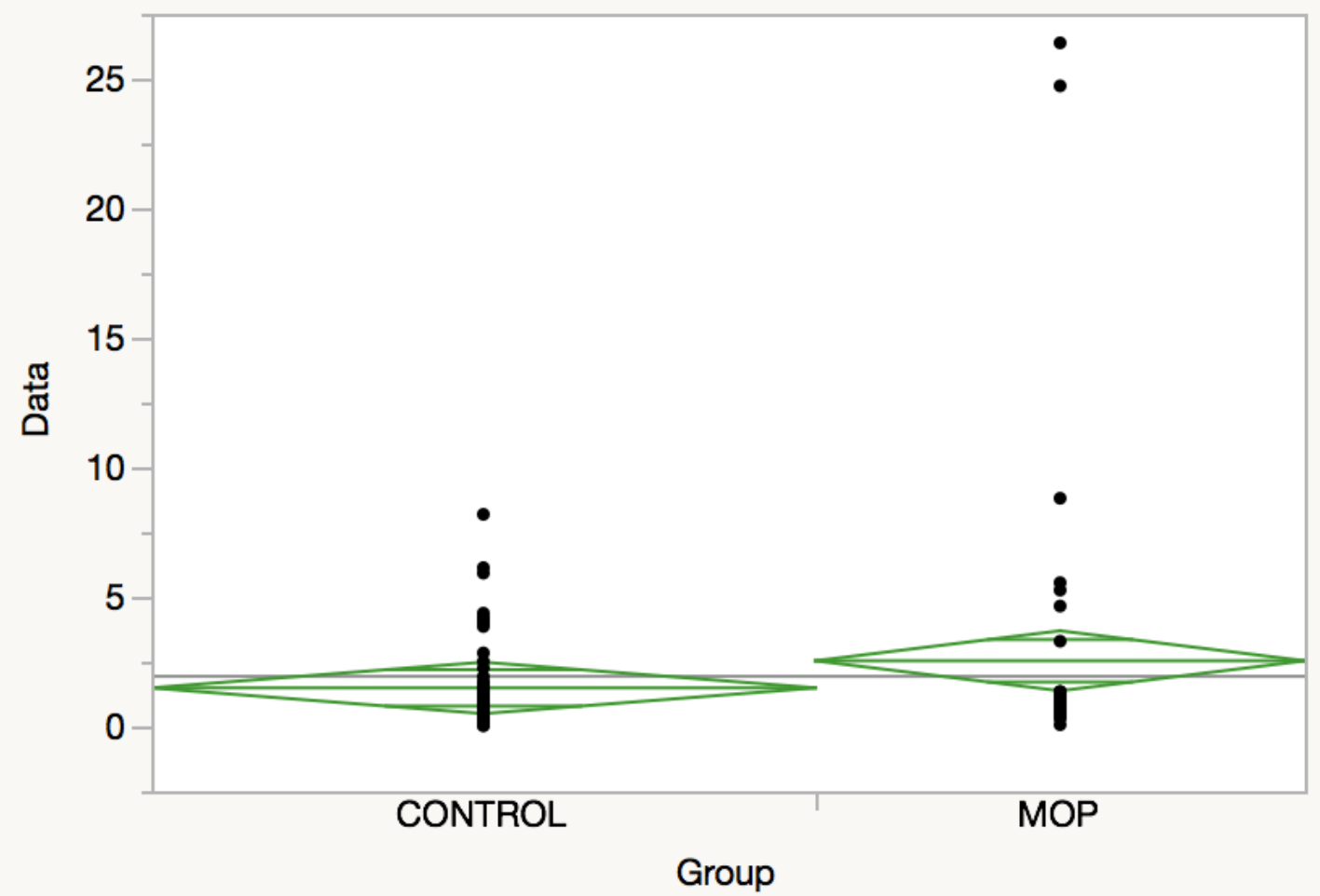

Missing Rows 6

Oneway Anova

Summary of Fit

Rsquare

Adj Rsquare

Root Mean Square Error

Mean of Response

Observations (or Sum Wgts)
0.018684

0.008567

3.782214

1.929723

99

\section{t Test}

MOP-CONTROL

Assuming equal variances

Difference

1.0452 t Ratio

1.358979 
Std Err Dif

Upper CL Dif

Lower CL Dif

Confidence
$0.7691 \mathrm{DF}$

2.5718 Prob $>|t|$

-0.4813 Prob $>\mathrm{t}$

0.95 Prob $<\mathrm{t}$
97

0.1773

0.0887

0.9113

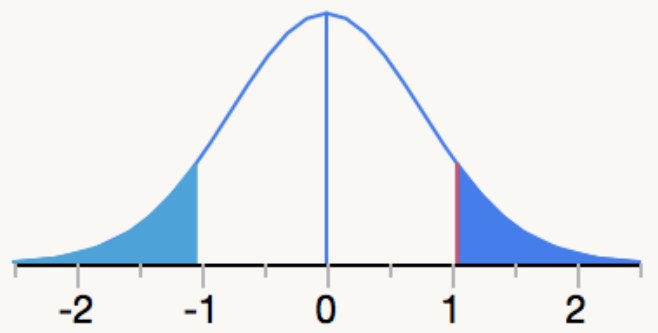

Analysis of Variance

$\begin{array}{lrrrrr}\text { Source } & \text { DF } & \text { Sum of Squares } & \text { Mean Square } & \text { F Ratio } & \text { Prob > F } \\ \text { Group } & 1 & 26.4191 & 26.4191 & 1.8468 & 0.1773 \\ \text { Error } & 97 & 1387.5989 & 14.3051 & & \\ \text { C. Total } & 98 & 1414.0180 & & \end{array}$

Means for Oneway Anova

$\begin{array}{lrrrrr}\text { Level } & \text { Number } & \text { Mean } & \text { Std Error } & \text { Lower 95\% } & \text { Upper 95\% } \\ \text { CONTROL } & 57 & 1.48629 & 0.50097 & 0.4920 & 2.4806 \\ \text { MOP } & 42 & 2.53153 & 0.58361 & 1.3732 & 3.6898\end{array}$

Std Error uses a pooled estimate of error variance 
Oneway Analysis of Data By Group parameter $=\Delta x^{\circ}$, Tooth $=\# 9$

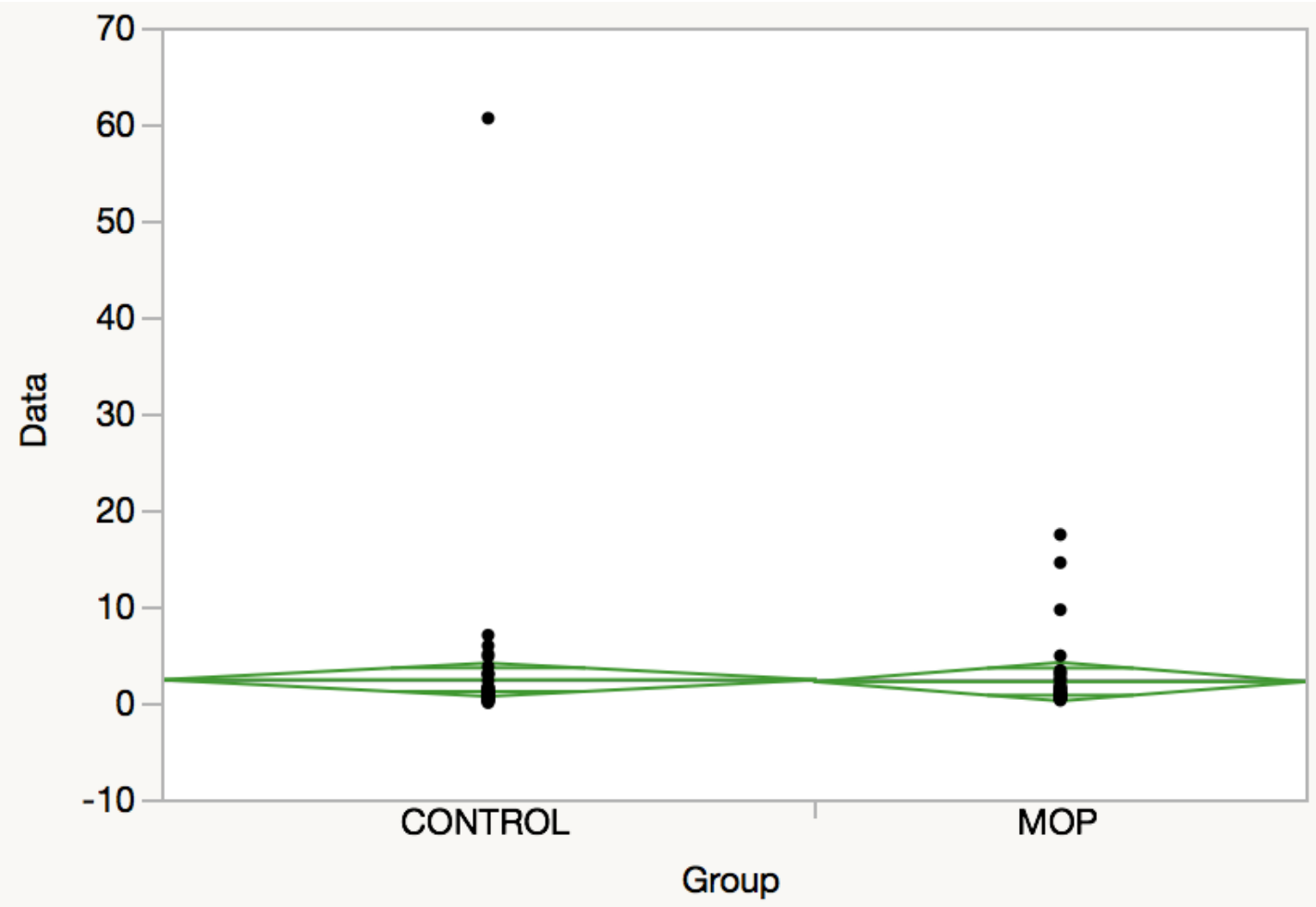

Missing Rows 7

Oneway Anova

Summary of Fit

Rsquare

0.00025

Adj Rsquare

$-0.01016$

Root Mean Square Error

6.516316

Mean of Response

2.303482

Observations (or Sum Wgts)

98

\section{t Test}

MOP-CONTROL

Assuming equal variances

Difference

-0.2061 t Ratio

$-0.15497$ 


$\begin{array}{lrr}\text { Std Err Dif } & 1.3301 \text { DF } & 96 \\ \text { Upper CL Dif } & 2.4342 \text { Prob }>|t| & 0.8772 \\ \text { Lower CL Dif } & -2.8464 \text { Prob }>\mathrm{t} & 0.5614 \\ \text { Confidence } & 0.95 \text { Prob }<\mathrm{t} & 0.4386\end{array}$

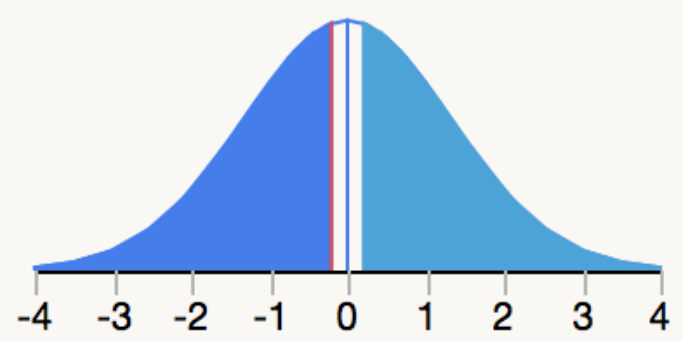

Analysis of Variance

\begin{tabular}{|c|c|c|c|c|c|}
\hline Source & DF & Sum of Squares & Mean Square & F Ratio & Prob $>$ F \\
\hline Group & 1 & 1.0198 & 1.0198 & 0.0240 & 0.8772 \\
\hline Error & 96 & 4076.3885 & 42.4624 & & \\
\hline C. Total & 97 & 4077.4083 & & & \\
\hline
\end{tabular}

Means for Oneway Anova

$\begin{array}{lrrrrr}\text { Level } & \text { Number } & \text { Mean } & \text { Std Error } & \text { Lower 95\% } & \text { Upper 95\% } \\ \text { CONTROL } & 56 & 2.39183 & 0.8708 & 0.66334 & 4.1203 \\ \text { MOP } & 42 & 2.18569 & 1.0055 & 0.18981 & 4.1816\end{array}$

Std Error uses a pooled estimate of error variance 
Oneway Analysis of Data By Group parameter $=\Delta y^{\circ}$, Tooth $=\# 10$

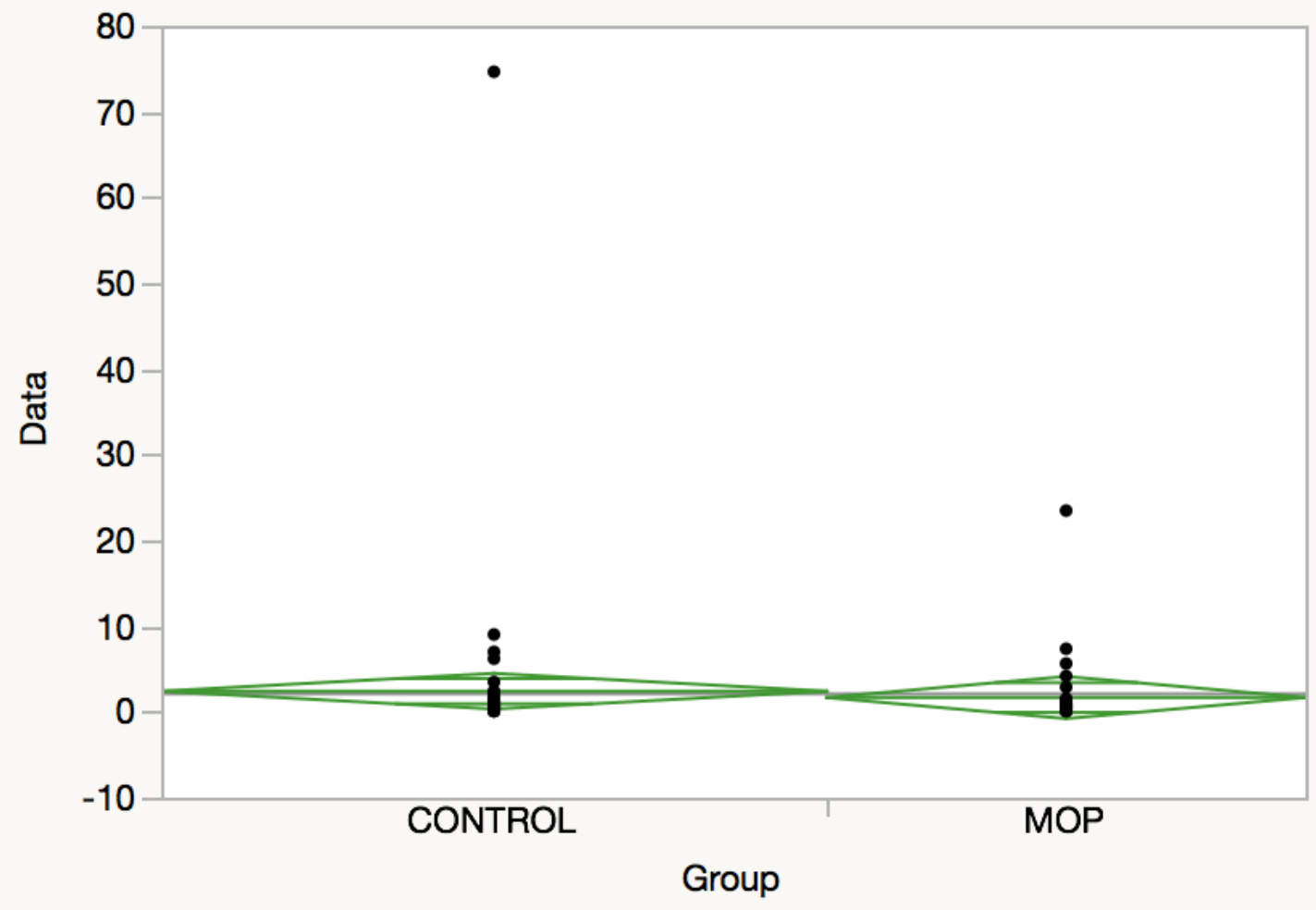

Missing Rows 7

Oneway Anova

Summary of Fit

Rsquare

Adj Rsquare

Root Mean Square Error

Mean of Response

Observations (or Sum Wgts)
0.002162

$-0.00823$

7.926351

2.095082

98

\section{t Test}

MOP-CONTROL

Assuming equal variances

Difference

-0.7403 t Ratio

$-0.45609$ 
Std Err Dif

Upper CL Dif

Lower CL Dif

Confidence
$1.6231 \mathrm{DF}$

2.4816 Prob $>|t|$

-3.9622 Prob $>\mathrm{t}$

0.95 Prob $<\mathrm{t}$
96

0.6494

0.6753

0.3247

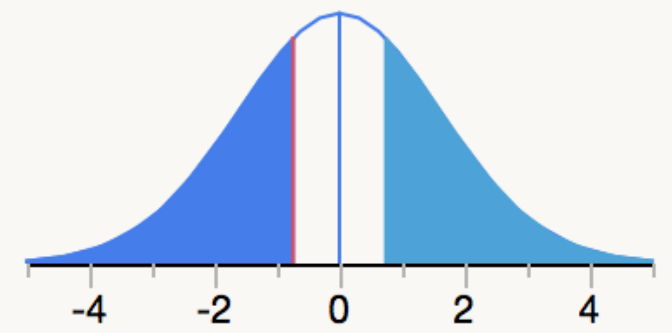

Analysis of Variance

\begin{tabular}{|c|c|c|c|c|c|}
\hline Source & DF & Sum of Squares & Mean Square & F Ratio & Prob $>$ F \\
\hline Group & 1 & 13.0692 & 13.0692 & 0.2080 & 0.6494 \\
\hline Error & 96 & 6031.3956 & 62.8270 & & \\
\hline C. Total & 97 & 6044.4648 & & & \\
\hline
\end{tabular}

Means for Oneway Anova

$\begin{array}{lrrrrr}\text { Level } & \text { Number } & \text { Mean } & \text { Std Error } & \text { Lower 95\% } & \text { Upper 95\% } \\ \text { CONTROL } & 57 & 2.40480 & 1.0499 & 0.3208 & 4.4888 \\ \text { MOP } & 41 & 1.66450 & 1.2379 & -0.7927 & 4.1217\end{array}$

Std Error uses a pooled estimate of error variance 
Oneway Analysis of Data By Group parameter $=\Delta y^{\circ}$, Tooth $=\# 11$

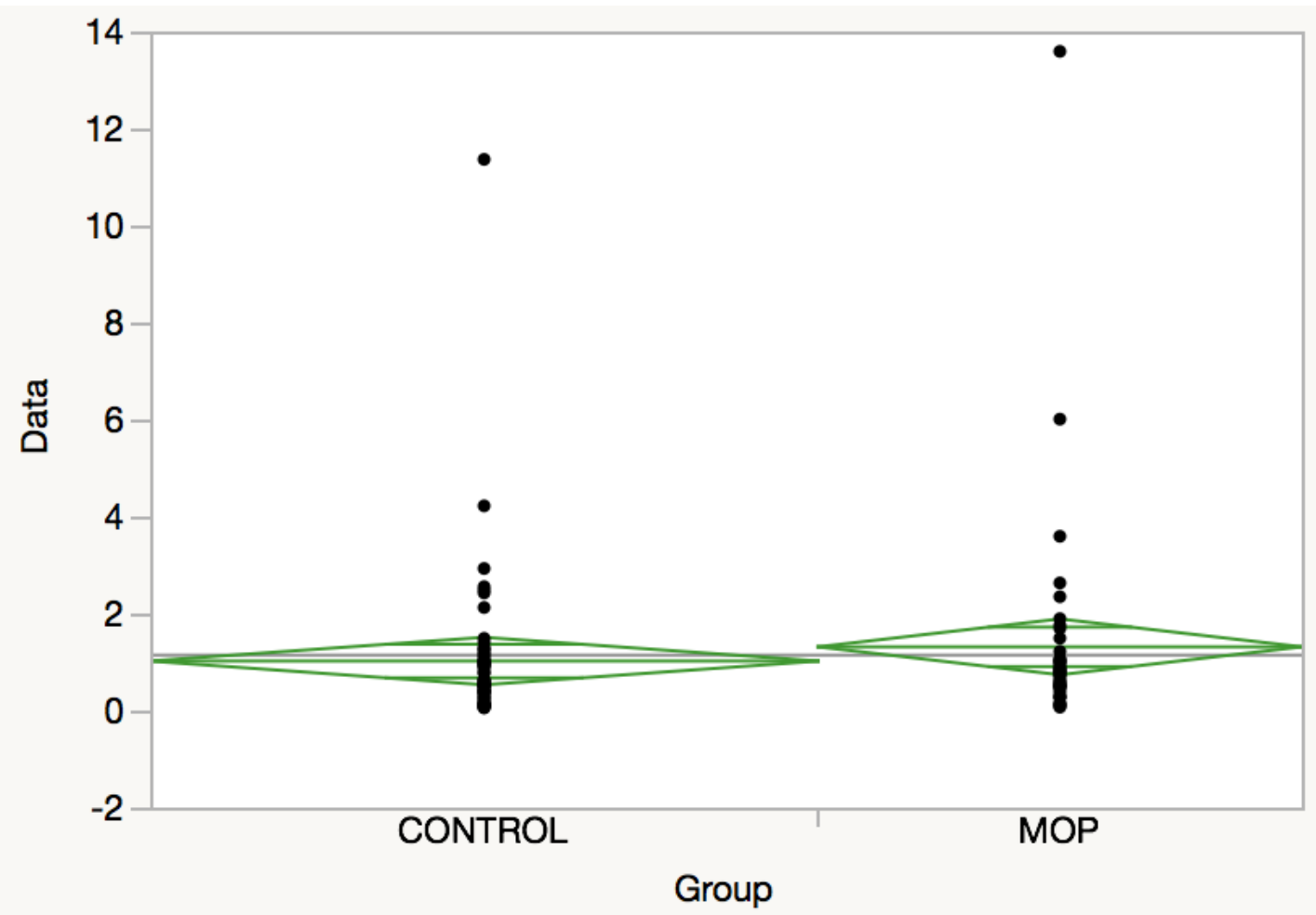

Missing Rows 5

Oneway Anova

Summary of Fit

Rsquare

Adj Rsquare

Root Mean Square Error

Mean of Response

Observations (or Sum Wgts)
0.005973

$-0.00417$

1.880265

1.142899

100

\section{t Test}

MOP-CONTROL

Assuming equal variances

Difference

0.2923 t Ratio

0.767397 
Std Err Dif

Upper CL Dif

Lower CL Dif

Confidence
$0.3810 \mathrm{DF}$

$1.0484 \operatorname{Prob}>|\mathrm{t}|$

-0.4637 Prob >t

0.95 Prob $<\mathrm{t}$
98

0.4447

0.2223

0.7777

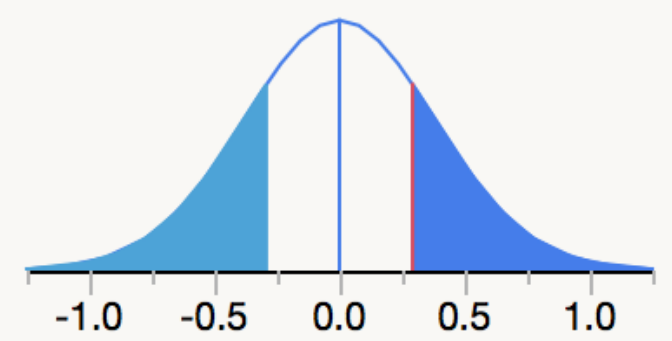

Analysis of Variance

\begin{tabular}{|c|c|c|c|c|c|}
\hline Source & DF & Sum of Squares & Mean Square & F Ratio & Prob $>$ F \\
\hline Group & 1 & 2.08199 & 2.08199 & 0.5889 & 0.4447 \\
\hline Error & 98 & 346.46879 & 3.53540 & & \\
\hline C. Total & 99 & 348.55078 & & & \\
\hline
\end{tabular}

Means for Oneway Anova

$\begin{array}{lrrrrr}\text { Level } & \text { Number } & \text { Mean } & \text { Std Error } & \text { Lower 95\% } & \text { Upper 95\% } \\ \text { CONTROL } & 58 & 1.02011 & 0.24689 & 0.53017 & 1.5101 \\ \text { MOP } & 42 & 1.31246 & 0.29013 & 0.73670 & 1.8882\end{array}$

Std Error uses a pooled estimate of error variance 
Oneway Analysis of Data By Group parameter $=\Delta y^{\circ}$, Tooth $=\# 22$

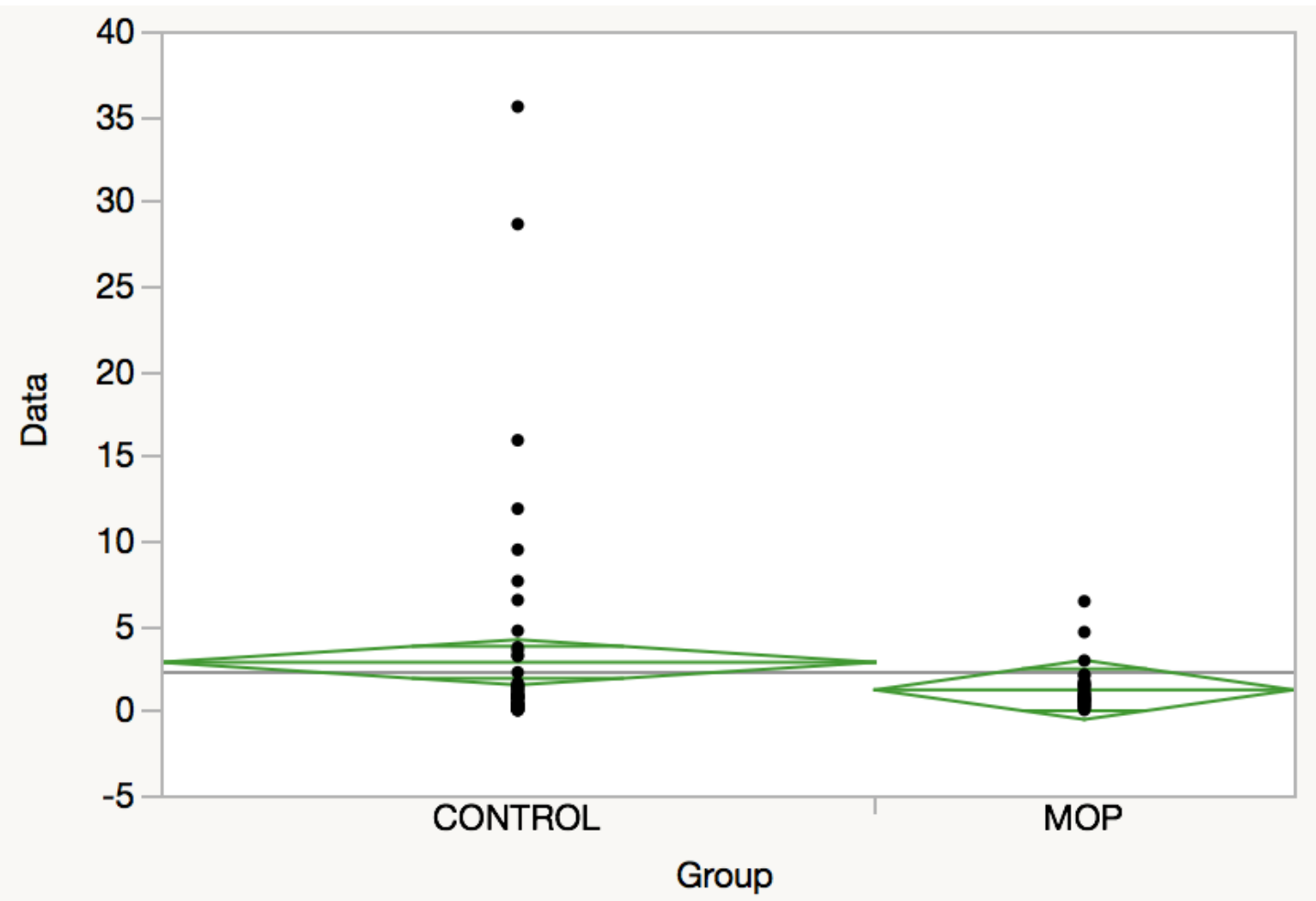

Missing Rows 13

Oneway Anova

Summary of Fit

Rsquare

Adj Rsquare

Root Mean Square Error

Mean of Response

Observations (or Sum Wgts)
0.023407

0.012556

5.118069

2.226

92

\section{t Test}

MOP-CONTROL

Assuming equal variances

Difference

-1.6236 t Ratio

$-1.4687$ 

Std Err Dif
$1.1055 \mathrm{DF}$
90
Upper CL Dif
0.5726 Prob $>|t|$
0.1454
Lower CL Dif
-3.8198 Prob $>\mathrm{t}$
0.9273
Confidence
0.95 Prob $<\mathrm{t}$
0.0727

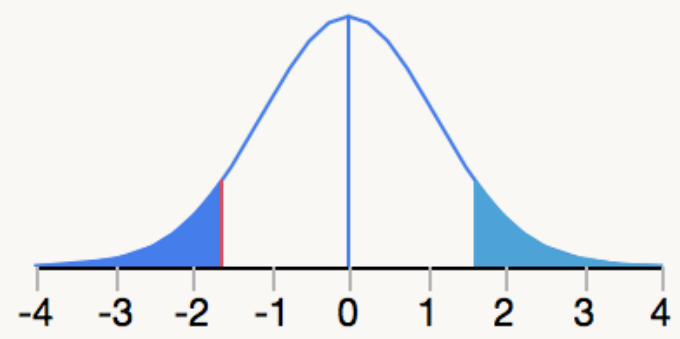

Analysis of Variance

\begin{tabular}{|c|c|c|c|c|c|}
\hline Source & DF & Sum of Squares & Mean Square & F Ratio & Prob $>$ F \\
\hline Group & 1 & 56.5039 & 56.5039 & 2.1571 & 0.1454 \\
\hline Error & 90 & 2357.5163 & 26.1946 & & \\
\hline C. Total & 91 & 2414.0202 & & & \\
\hline
\end{tabular}

Means for Oneway Anova

$\begin{array}{lrrrrr}\text { Level } & \text { Number } & \text { Mean } & \text { Std Error } & \text { Lower 95\% } & \text { Upper95\% } \\ \text { CONTROL } & 58 & 2.82603 & 0.67204 & 1.491 & 4.1611 \\ \text { MOP } & 34 & 1.20242 & 0.87774 & -0.541 & 2.9462\end{array}$

Std Error uses a pooled estimate of error variance 
Oneway Analysis of Data By Group parameter $=\Delta y^{\circ}$, Tooth $=\# 23$

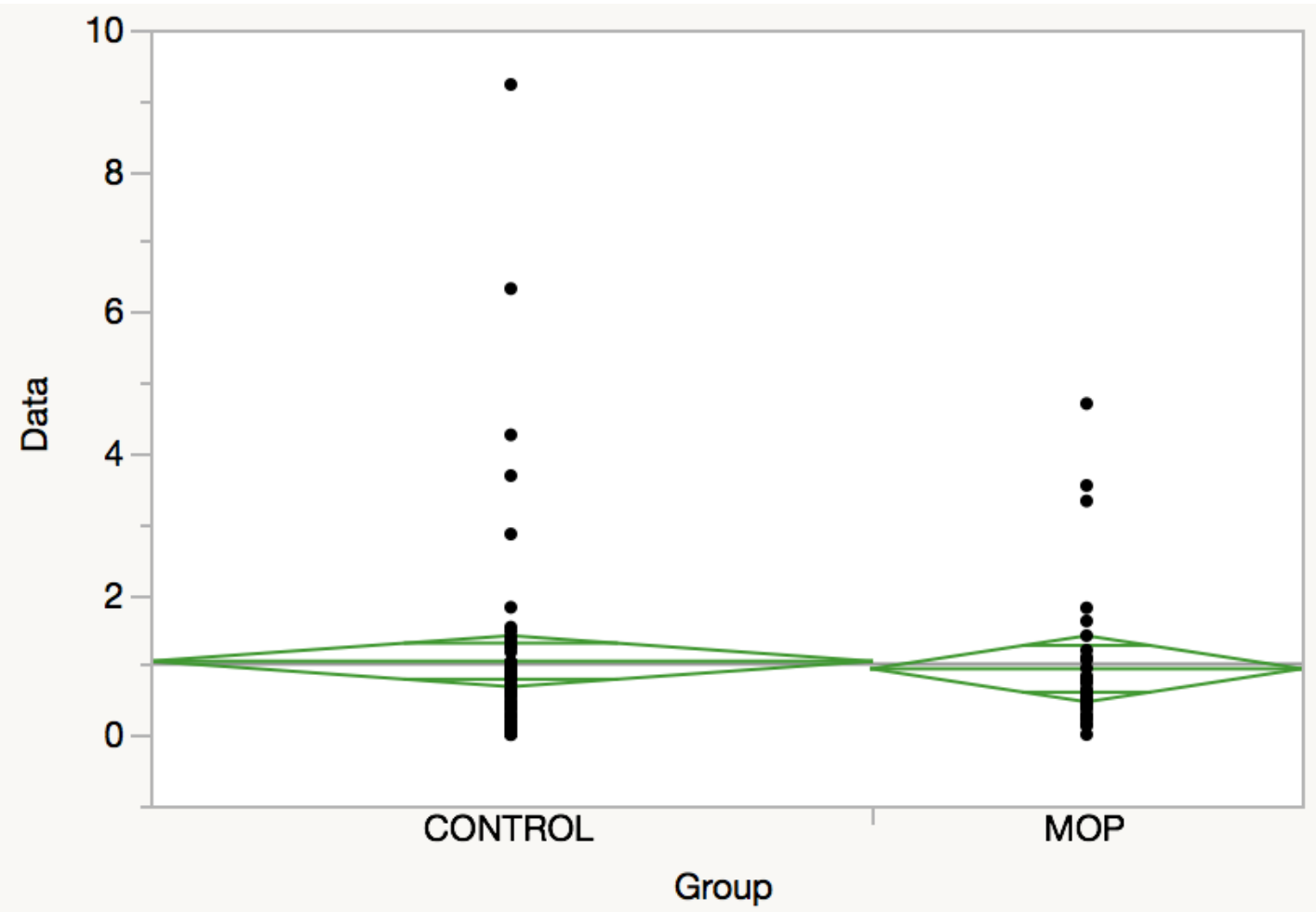

Missing Rows 14

Oneway Anova

Summary of Fit

Rsquare

Adj Rsquare

Root Mean Square Error

Mean of Response

Observations (or Sum Wgts)

t Test

MOP-CONTROL

Assuming equal variances

Difference

-0.10822 t Ratio

$-0.36247$ 
Std Err Dif

Upper CL Dif

Lower CL Dif

Confidence
$0.29856 \mathrm{DF}$

0.48501 Prob $>|t|$

-0.70145 Prob $>t$

0.95 Prob $<\mathrm{t}$
89

0.7179

0.6411

0.3589

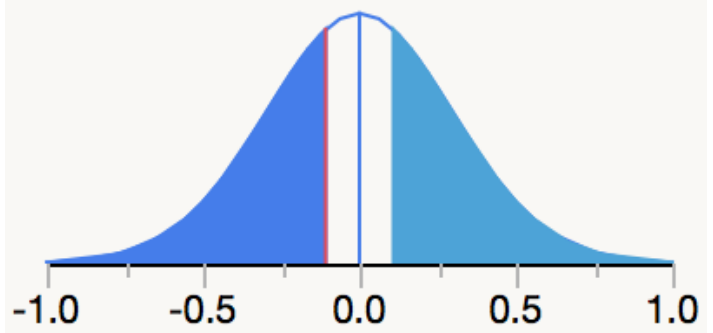

Analysis of Variance

$\begin{array}{lrrrrr}\text { Source } & \text { DF } & \text { Sum of Squares } & \text { Mean Square } & \text { F Ratio } & \text { Prob }>\text { F } \\ \text { Group } & 1 & 0.24941 & 0.24941 & 0.1314 & 0.7179 \\ \text { Error } & 89 & 168.95093 & 1.89833 & & \\ \text { C. Total } & 90 & 169.20034 & & & \end{array}$

Means for Oneway Anova

$\begin{array}{lrrrrr}\text { Level } & \text { Number } & \text { Mean } & \text { Std Error } & \text { Lower 95\% } & \text { Upper 95\% } \\ \text { CONTROL } & 57 & 1.04608 & 0.18249 & 0.68347 & 1.4087 \\ \text { MOP } & 34 & 0.93786 & 0.23629 & 0.46836 & 1.4074\end{array}$

Std Error uses a pooled estimate of error variance 
Oneway Analysis of Data By Group parameter $=\Delta y^{\circ}$, Tooth $=\# 24$

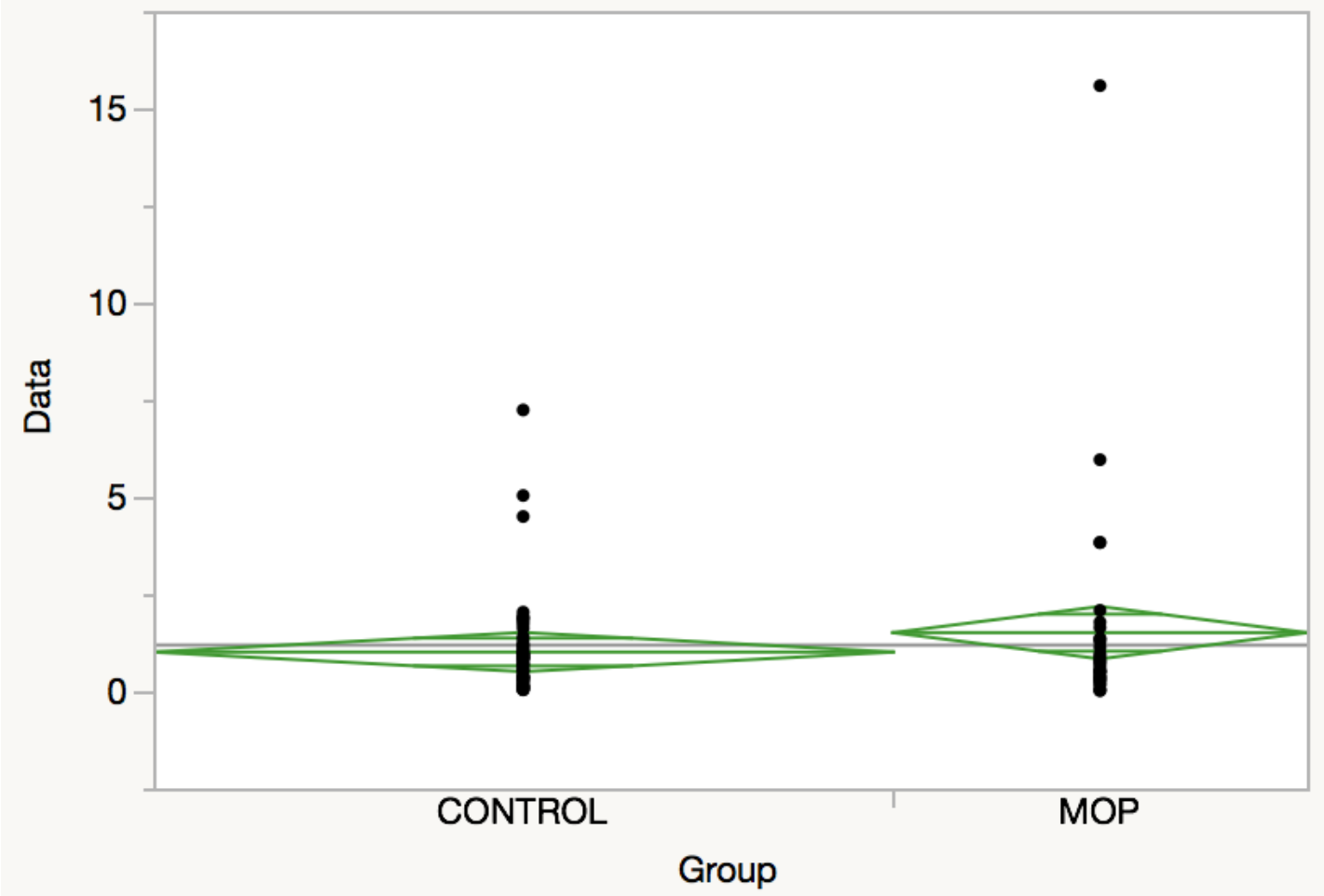

Missing Rows 13

Oneway Anova

Summary of Fit

Rsquare

Adj Rsquare

Root Mean Square Error

Mean of Response

Observations (or Sum Wgts)
0.015131

0.004188

1.951761

1.186068

92

\section{t Test}

MOP-CONTROL

Assuming equal variances

Difference

0.4989 t Ratio

1.175881 
Std Err Dif

Upper CL Dif

Lower CL Dif

Confidence
$0.4243 \mathrm{DF}$

1.3418 Prob $>|\mathrm{t}|$

-0.3440 Prob $>\mathrm{t}$

0.95 Prob $<\mathrm{t}$
90

0.2427

0.1214

0.8786

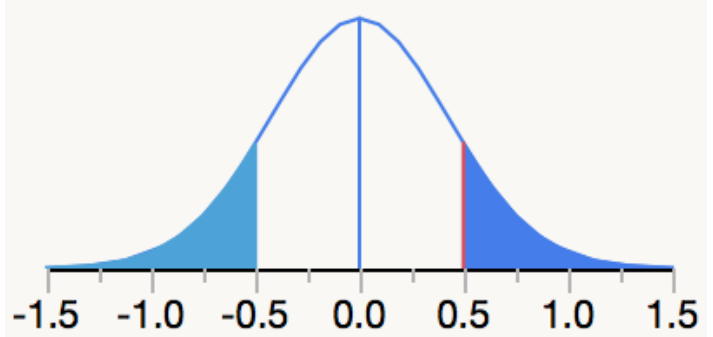

Analysis of Variance

\begin{tabular}{|c|c|c|c|c|c|}
\hline Source & DF & Sum of Squares & Mean Square & F Ratio & Prob $>$ F \\
\hline Group & 1 & 5.26721 & 5.26721 & 1.3827 & 0.2427 \\
\hline Error & 90 & 342.84332 & 3.80937 & & \\
\hline C. Total & 91 & 348.11053 & & & \\
\hline
\end{tabular}

Means for Oneway Anova

$\begin{array}{lrrrrr}\text { Level } & \text { Number } & \text { Mean } & \text { Std Error } & \text { Lower 95\% } & \text { Upper95\% } \\ \text { CONTROL } & 59 & 1.00712 & 0.25410 & 0.50231 & 1.5119 \\ \text { MOP } & 33 & 1.50601 & 0.33976 & 0.83102 & 2.1810\end{array}$

Std Error uses a pooled estimate of error variance 
Oneway Analysis of Data By Group parameter $=\Delta y^{\circ}$, Tooth $=\# 25$

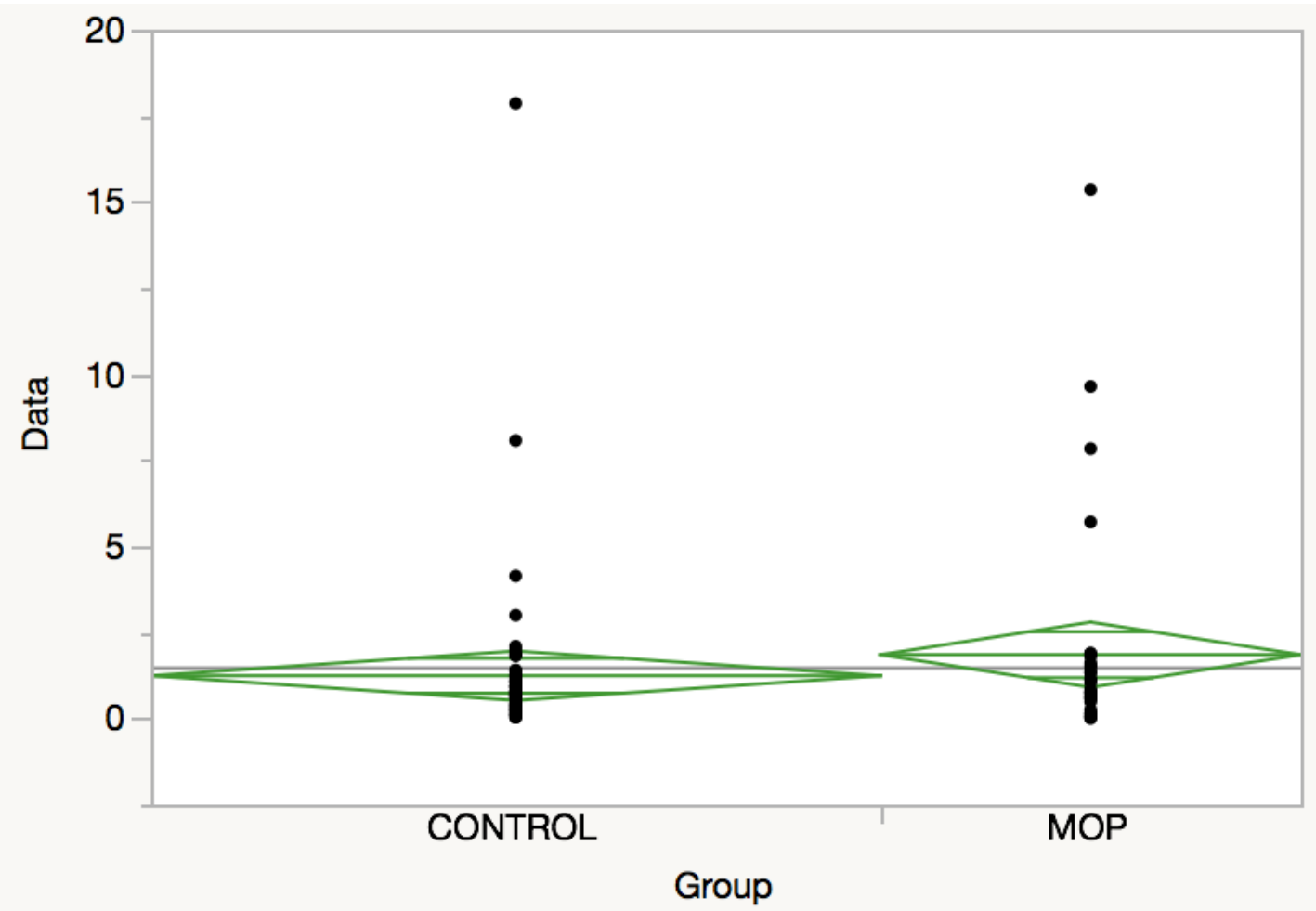

Missing Rows 12

Oneway Anova

Summary of Fit

Rsquare

Adj Rsquare

Root Mean Square Error

Mean of Response

Observations (or Sum Wgts)
0.011345

0.000481

2.773618

1.463713

93

\section{t Test}

MOP-CONTROL

Assuming equal variances

Difference

0.6103 t Ratio

1.021886 
Std Err Dif

Upper CL Dif

Lower CL Dif

Confidence
$0.5972 \mathrm{DF}$

1.7965 Prob $>|\mathrm{t}|$

-0.5760 Prob > t

0.95 Prob $<\mathrm{t}$
91

0.3095

0.1548

0.8452

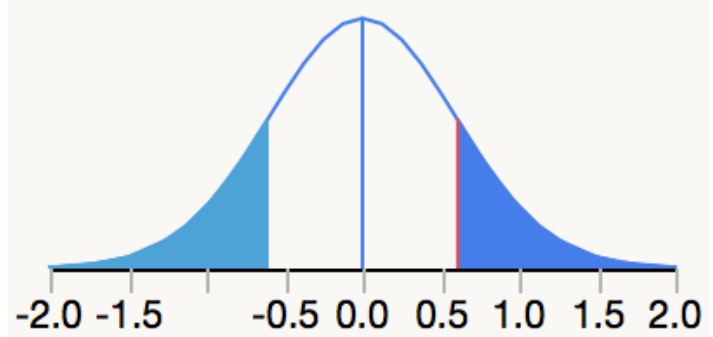

Analysis of Variance

\begin{tabular}{|c|c|c|c|c|c|}
\hline Source & DF & Sum of Squares & Mean Square & F Ratio & Prob > F \\
\hline Group & 1 & 8.03338 & 8.03338 & 1.0443 & 0.3095 \\
\hline Error & 91 & 700.05892 & 7.69296 & & \\
\hline C. Total & 92 & 708.09230 & & & \\
\hline
\end{tabular}

Means for Oneway Anova

$\begin{array}{lrrrrr}\text { Level } & \text { Number } & \text { Mean } & \text { Std Error } & \text { Lower 95\% } & \text { Upper 95\% } \\ \text { CONTROL } & 59 & 1.24060 & 0.36109 & 0.52333 & 1.9579 \\ \text { MOP } & 34 & 1.85088 & 0.47567 & 0.90601 & 2.7957\end{array}$

Std Error uses a pooled estimate of error variance 
Oneway Analysis of Data By Group parameter $=\Delta y^{\circ}$, Tooth $=\# 26$

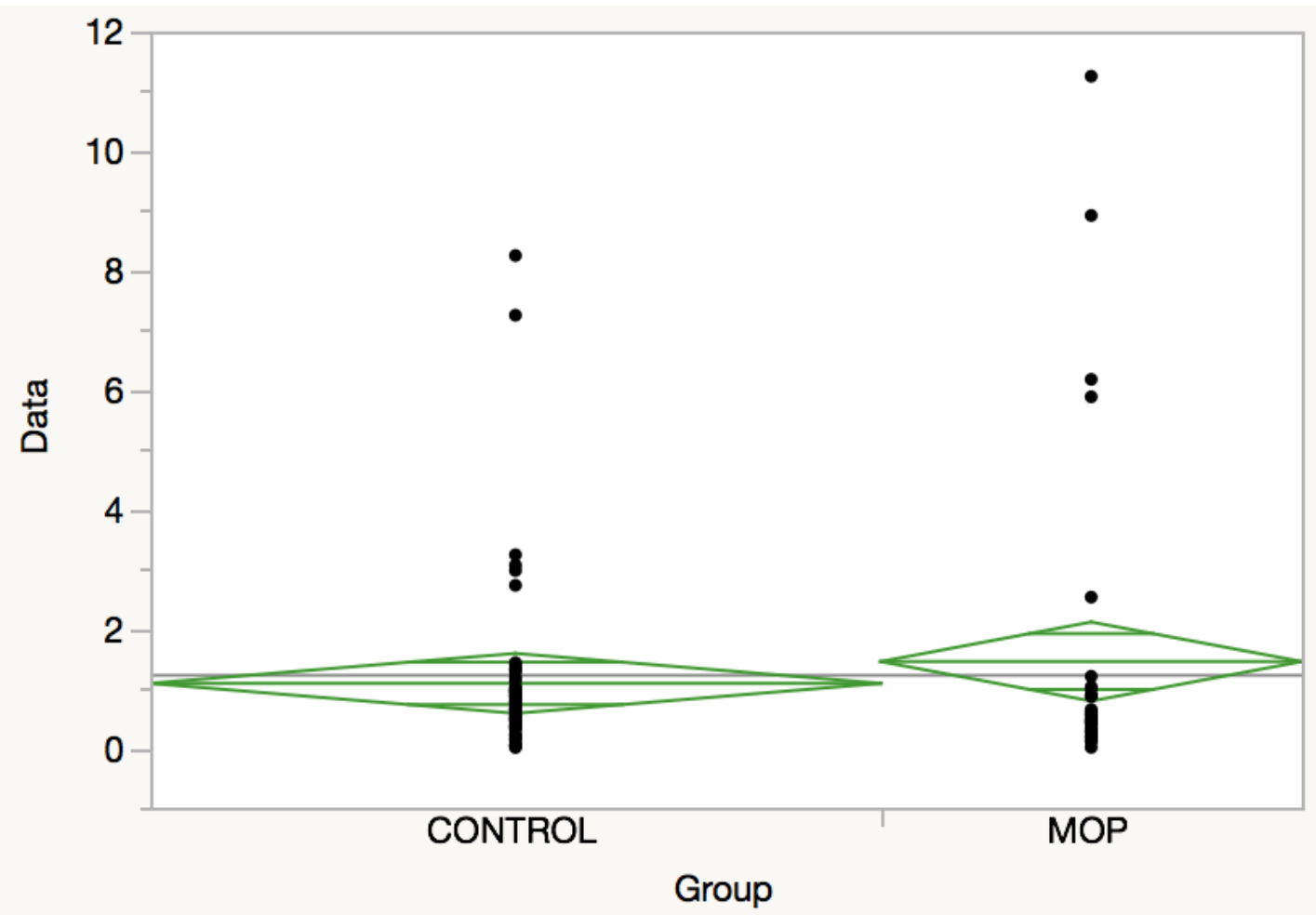

Missing Rows 12

Oneway Anova

Summary of Fit

Rsquare

Adj Rsquare

Root Mean Square Error

Mean of Response

Observations (or Sum Wgts)
0.008319

$-0.00258$

1.942789

1.213495

93

\section{t Test}

MOP-CONTROL

Assuming equal variances

Difference

0.3655 t Ratio

0.873714 
Std Err Dif

Upper CL Dif

Lower CL Dif

Confidence
$0.4183 \mathrm{DF}$

1.1964 Prob $>|t|$

-0.4654 Prob $>t$

0.95 Prob $<\mathrm{t}$
91

0.3846

0.1923

0.8077

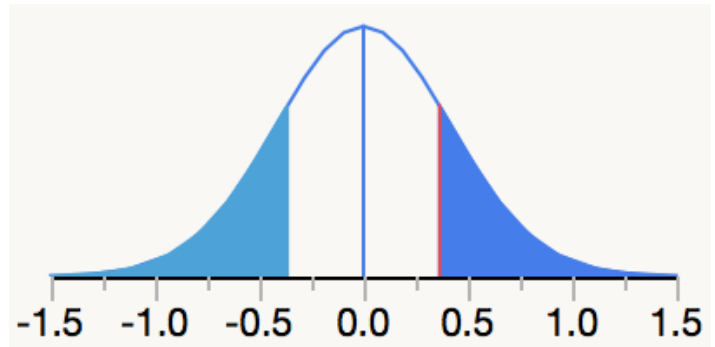

Analysis of Variance

$\begin{array}{lcccc}\text { Source } & \text { DF } & \text { Sum of Squares } & \text { Mean Square } & \text { F Ratio } \\ \text { Group } & 1 & 2.88131 & 2.88131 & 0.7634 \\ \text { Error } & 91 & 343.47318 & 3.77443 & 0.3846 \\ \text { C. Total } & 92 & 346.35449 & & \end{array}$

Means for Oneway Anova

$\begin{array}{lrrrrr}\text { Level } & \text { Number } & \text { Mean } & \text { Std Error } & \text { Lower 95\% } & \text { Upper 95\% } \\ \text { CONTROL } & 59 & 1.07988 & 0.25293 & 0.57746 & 1.5823 \\ \text { MOP } & 34 & 1.44536 & 0.33319 & 0.78353 & 2.1072\end{array}$

Std Error uses a pooled estimate of error variance 
Oneway Analysis of Data By Group parameter $=\Delta y^{\circ}$, Tooth $=\# 27$

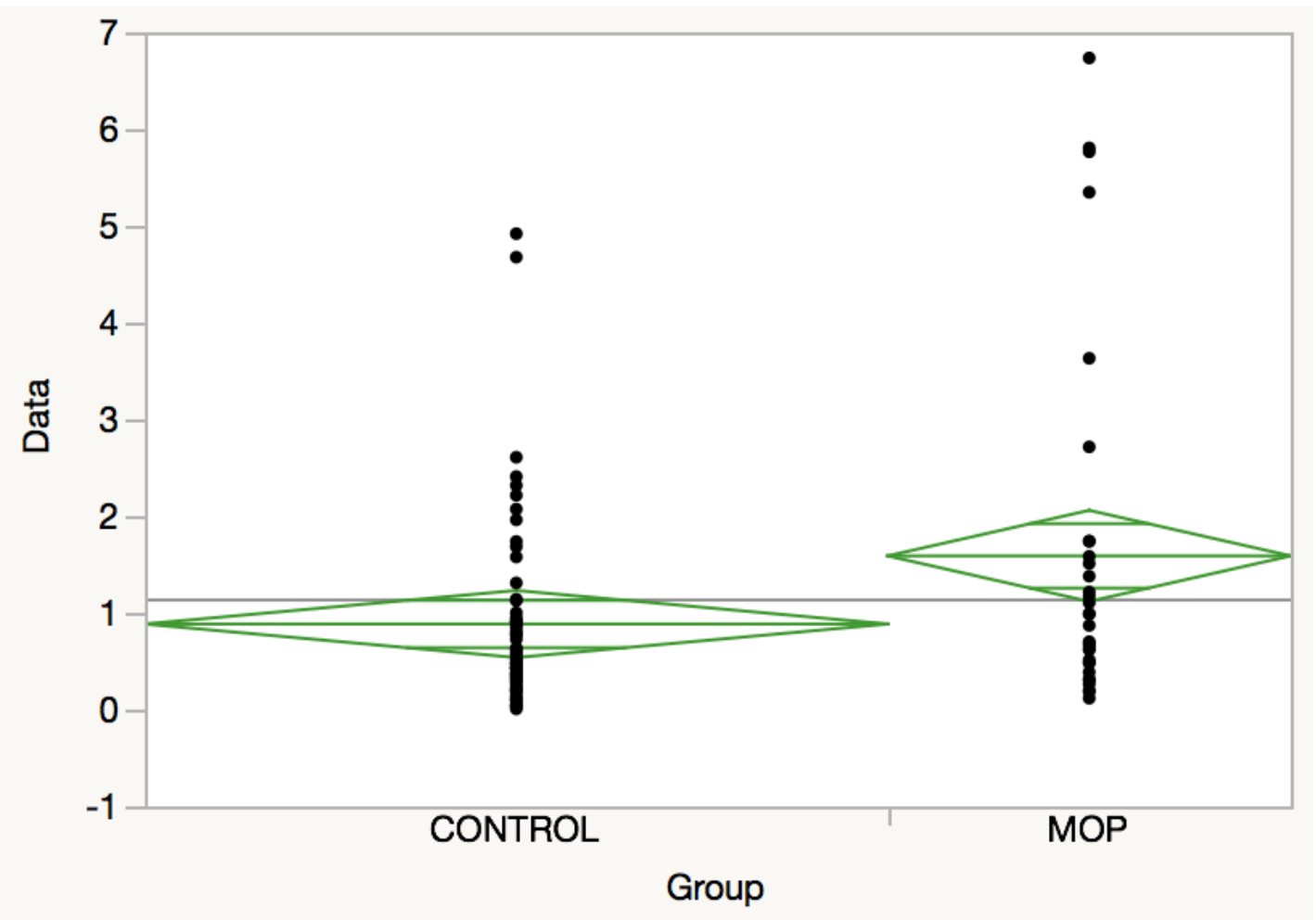

Missing Rows 14

Oneway Anova

Summary of Fit

Rsquare

0.060379

Adj Rsquare

0.049822

Root Mean Square Error

1.340998

Mean of Response

1.131988

Observations (or Sum Wgts)

91

\section{t Test}

MOP-CONTROL

Assuming equal variances

Difference

0.70406 t Ratio

2.391459 
Std Err Dif

Upper CL Dif

Lower CL Dif

Confidence
$0.29441 \mathrm{DF}$

1.28904 Prob $>|t|$

0.11908 Prob $>\mathrm{t}$

0.95 Prob $<\mathrm{t}$
89

$0.0189 *$

$0.0094^{*}$

0.9906

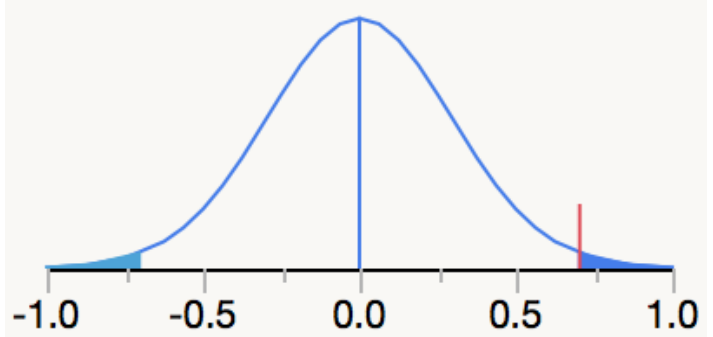

Analysis of Variance

\begin{tabular}{|c|c|c|c|c|c|}
\hline Source & DF & Sum of Squares & Mean Square & F Ratio & Prob $>$ F \\
\hline Group & 1 & 10.28447 & 10.2845 & 5.7191 & $0.0189 *$ \\
\hline Error & 89 & 160.04650 & 1.7983 & & \\
\hline C. Total & 90 & 170.33097 & & & \\
\hline
\end{tabular}

Means for Oneway Anova

$\begin{array}{lrrrrr}\text { Level } & \text { Number } & \text { Mean } & \text { Std Error } & \text { Lower 95\% } & \text { Upper95\% } \\ \text { CONTROL } & 59 & 0.88441 & 0.17458 & 0.5375 & 1.2313 \\ \text { MOP } & 32 & 1.58847 & 0.23706 & 1.1174 & 2.0595\end{array}$

Std Error uses a pooled estimate of error variance 
Oneway Analysis of Data By Group parameter $=\Delta y^{\circ}$, Tooth $=\# 6$

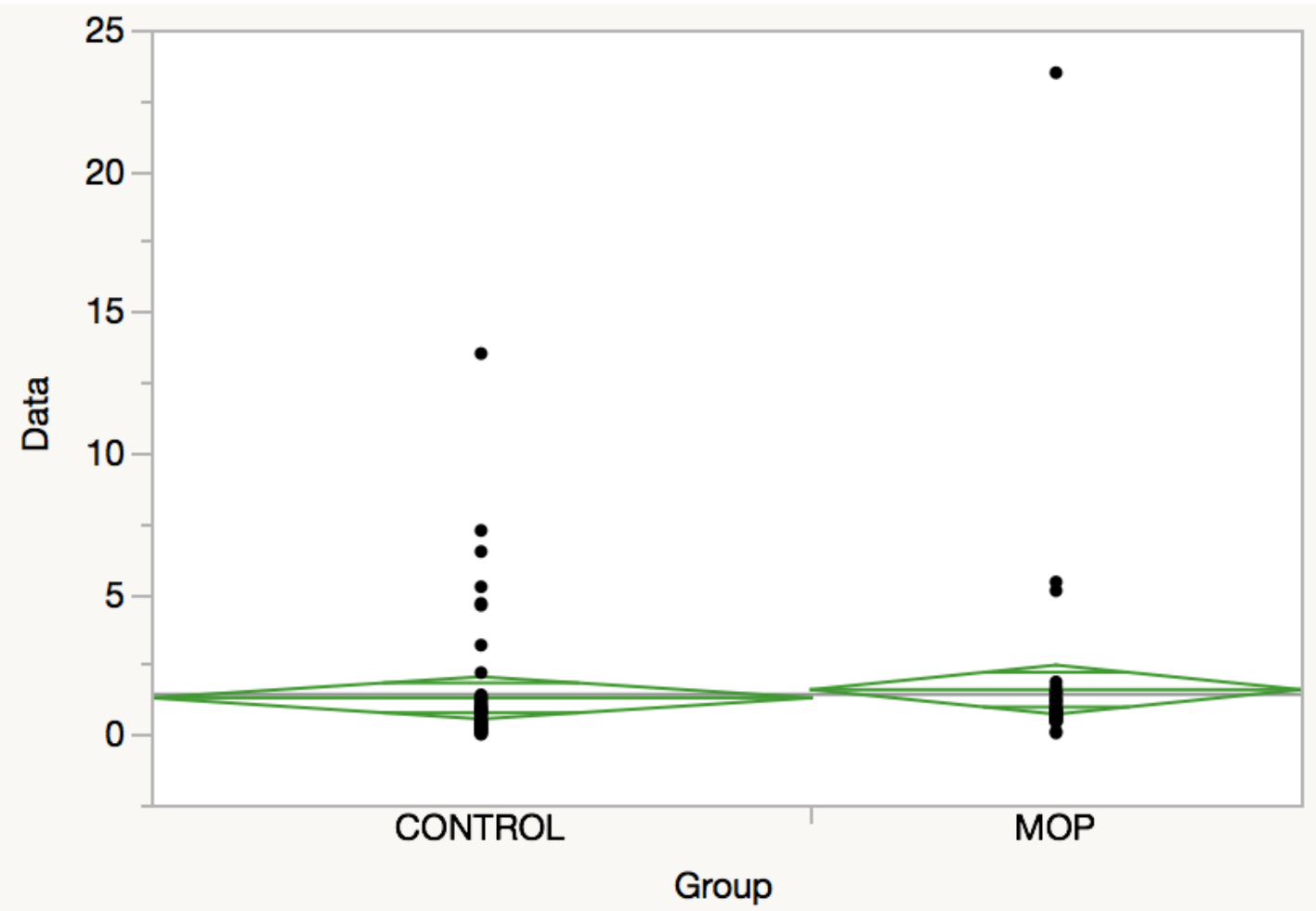

Missing Rows 4

Oneway Anova

Summary of Fit

Rsquare

Adj Rsquare

Root Mean Square Error

Mean of Response

Observations (or Sum Wgts)

\section{t Test}

MOP-CONTROL

Assuming equal variances

Difference

0.2910 t Ratio

0.50178 
Std Err Dif

Upper CL Dif

Lower CL Dif

Confidence
$0.5798 \mathrm{DF}$

1.4415 Prob $>|\mathrm{t}|$

-0.8596 Prob > t

0.95 Prob $<\mathrm{t}$
99

0.6169

0.3085

0.6915

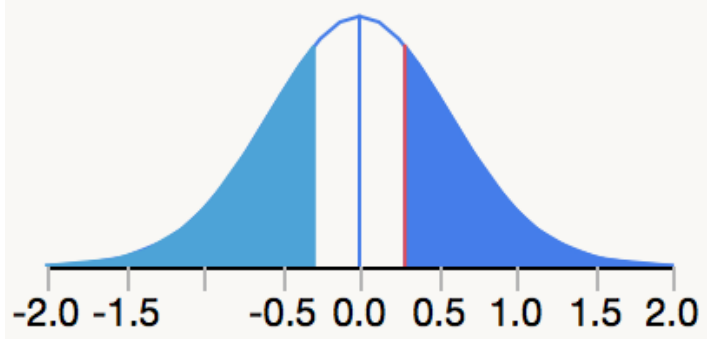

Analysis of Variance

$\begin{array}{lrrrrr}\text { Source } & \text { DF } & \text { Sum of Squares } & \text { Mean Square } & \text { F Ratio } & \text { Prob > F } \\ \text { Group } & 1 & 2.09037 & 2.09037 & 0.2518 & 0.6169 \\ \text { Error } & 99 & 821.92241 & 8.30225 & & \\ \text { C. Total } & 100 & 824.01278 & & \end{array}$

Means for Oneway Anova

$\begin{array}{lrrrrr}\text { Level } & \text { Number } & \text { Mean } & \text { Std Error } & \text { Lower 95\% } & \text { Upper 95\% } \\ \text { CONTROL } & 58 & 1.28809 & 0.37834 & 0.53738 & 2.0388 \\ \text { MOP } & 43 & 1.57904 & 0.43940 & 0.70717 & 2.4509\end{array}$

Std Error uses a pooled estimate of error variance 
Oneway Analysis of Data By Group parameter $=\Delta y^{\circ}$, Tooth $=\# 7$

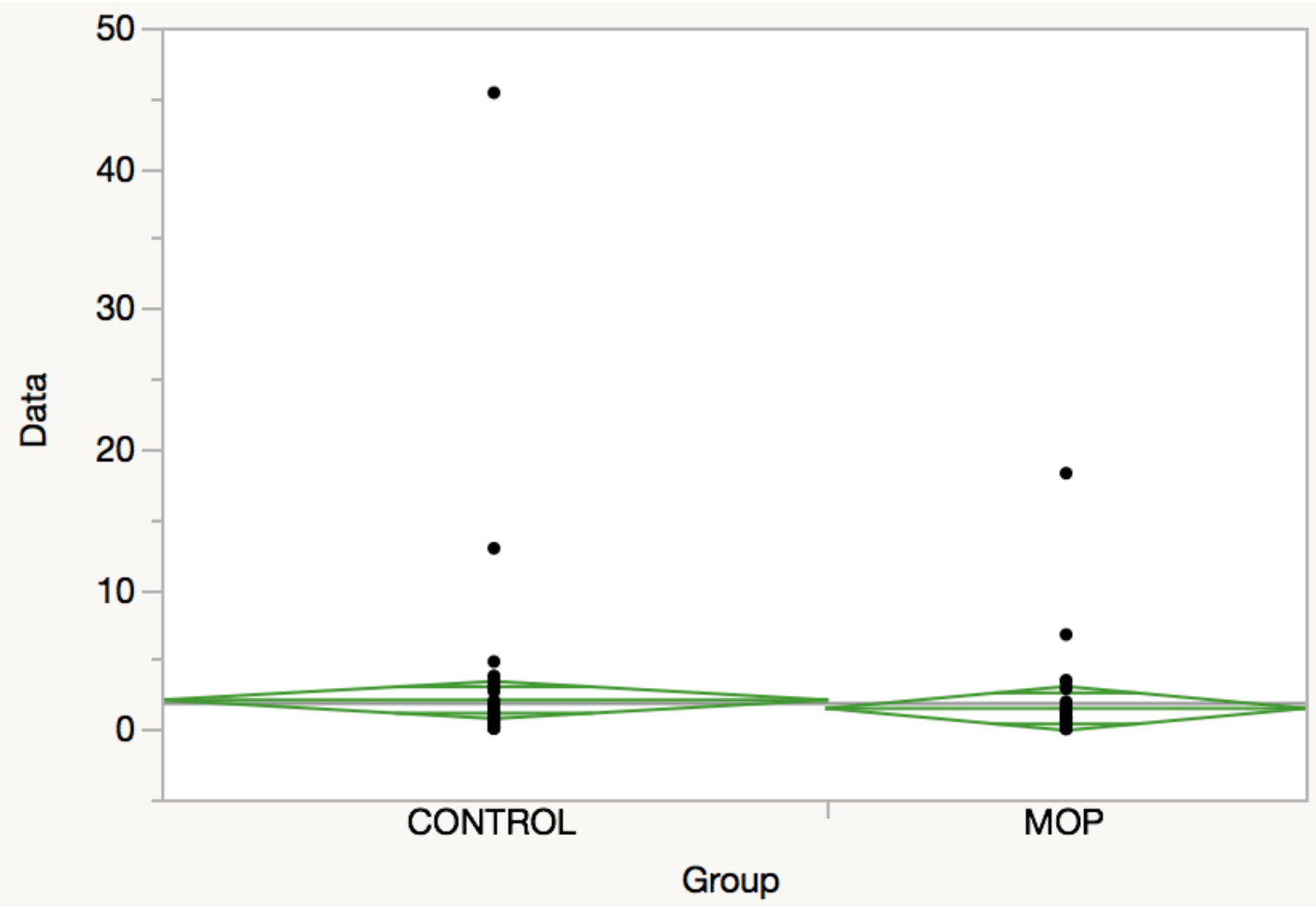

Missing Rows 7

Oneway Anova

Summary of Fit

Rsquare

Adj Rsquare

Root Mean Square Error

Mean of Response

Observations (or Sum Wgts)
0.003509

$-0.00687$

5.054236

1.82166

98

\section{t Test}

MOP-CONTROL

Assuming equal variances

Difference

-0.6018 t Ratio

$-0.58144$ 

Std Err Dif
$1.0350 \mathrm{DF}$
96
Upper CL Dif
1.4527 Prob $>|\mathrm{t}|$
0.5623
Lower CL Dif
-2.6562 Prob $>t$
0.7188
Confidence
0.95 Prob $<\mathrm{t}$
0.2812

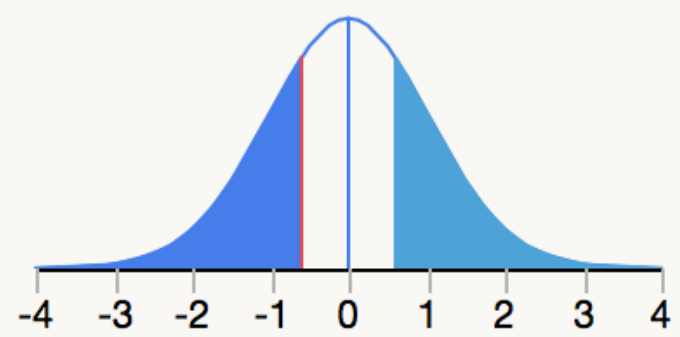

Analysis of Variance

\begin{tabular}{|c|c|c|c|c|c|}
\hline Source & DF & Sum of Squares & Mean Square & F Ratio & Prob $>$ F \\
\hline Group & 1 & 8.6361 & 8.6361 & 0.3381 & 0.5623 \\
\hline Error & 96 & 2452.3493 & 25.5453 & & \\
\hline C. Total & 97 & 2460.9854 & & & \\
\hline
\end{tabular}

Means for Oneway Anova

$\begin{array}{lrrrrr}\text { Level } & \text { Number } & \text { Mean } & \text { Std Error } & \text { Lower 95\% } & \text { Upper95\% } \\ \text { CONTROL } & 57 & 2.07343 & 0.66945 & 0.7446 & 3.4023 \\ \text { MOP } & 41 & 1.47164 & 0.78934 & -0.0952 & 3.0385\end{array}$

Std Error uses a pooled estimate of error variance 
Oneway Analysis of Data By Group parameter $=\Delta y^{\circ}$, Tooth $=\# 8$

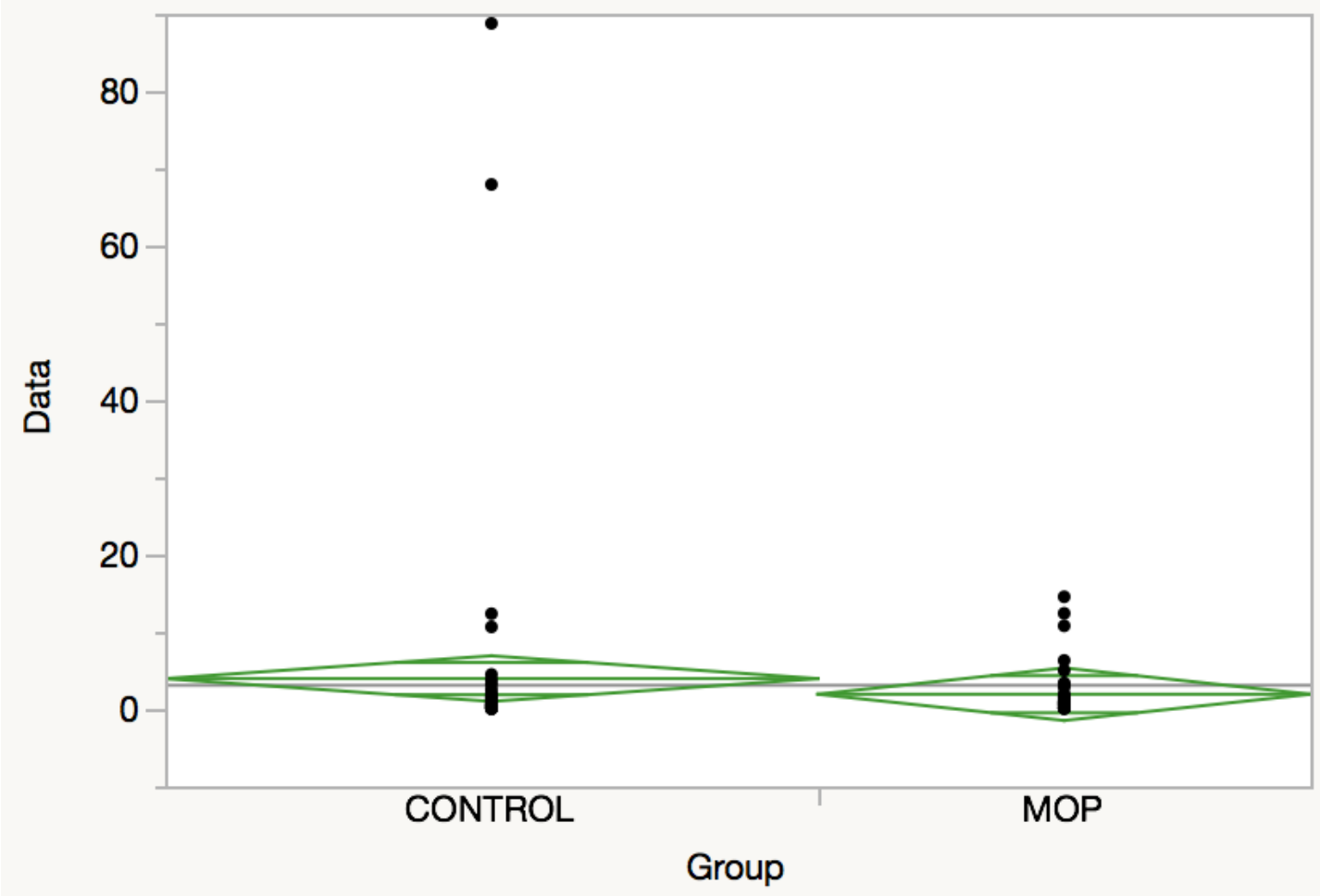

Missing Rows 5

Oneway Anova

Summary of Fit

Rsquare

Adj Rsquare

Root Mean Square Error

Mean of Response

Observations (or Sum Wgts)
0.008014

$-0.00211$

11.24598

3.063489

100

\section{t Test}

MOP-CONTROL

Assuming equal variances

Difference

-2.0212 t Ratio

$-0.88976$ 
Std Err Dif

Upper CL Dif

Lower CL Dif

Confidence
$2.2716 \mathrm{DF}$

2.4867 Prob $>|t|$

-6.5290 Prob $>\mathrm{t}$

0.95 Prob $<\mathrm{t}$
98

0.3758

0.8121

0.1879

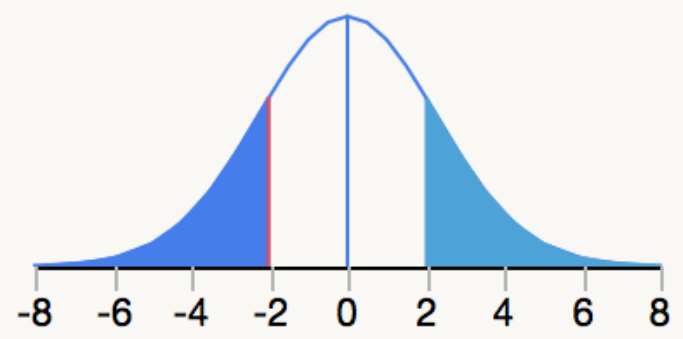

Analysis of Variance

\begin{tabular}{|c|c|c|c|c|c|}
\hline Source & DF & Sum of Squares & Mean Square & F Ratio & Prob $>$ F \\
\hline Group & 1 & 100.125 & 100.125 & 0.7917 & 0.3758 \\
\hline Error & 98 & 12394.258 & 126.472 & & \\
\hline C. Total & 99 & 12494.383 & & & \\
\hline
\end{tabular}

Means for Oneway Anova

$\begin{array}{lrrrrr}\text { Level } & \text { Number } & \text { Mean } & \text { Std Error } & \text { Lower 95\% } & \text { Upper 95\% } \\ \text { CONTROL } & 57 & 3.93258 & 1.4896 & 0.977 & 6.8886 \\ \text { MOP } & 43 & 1.91143 & 1.7150 & -1.492 & 5.3148\end{array}$

Std Error uses a pooled estimate of error variance 
Oneway Analysis of Data By Group parameter $=\Delta y^{\circ}$, Tooth $=\# 9$

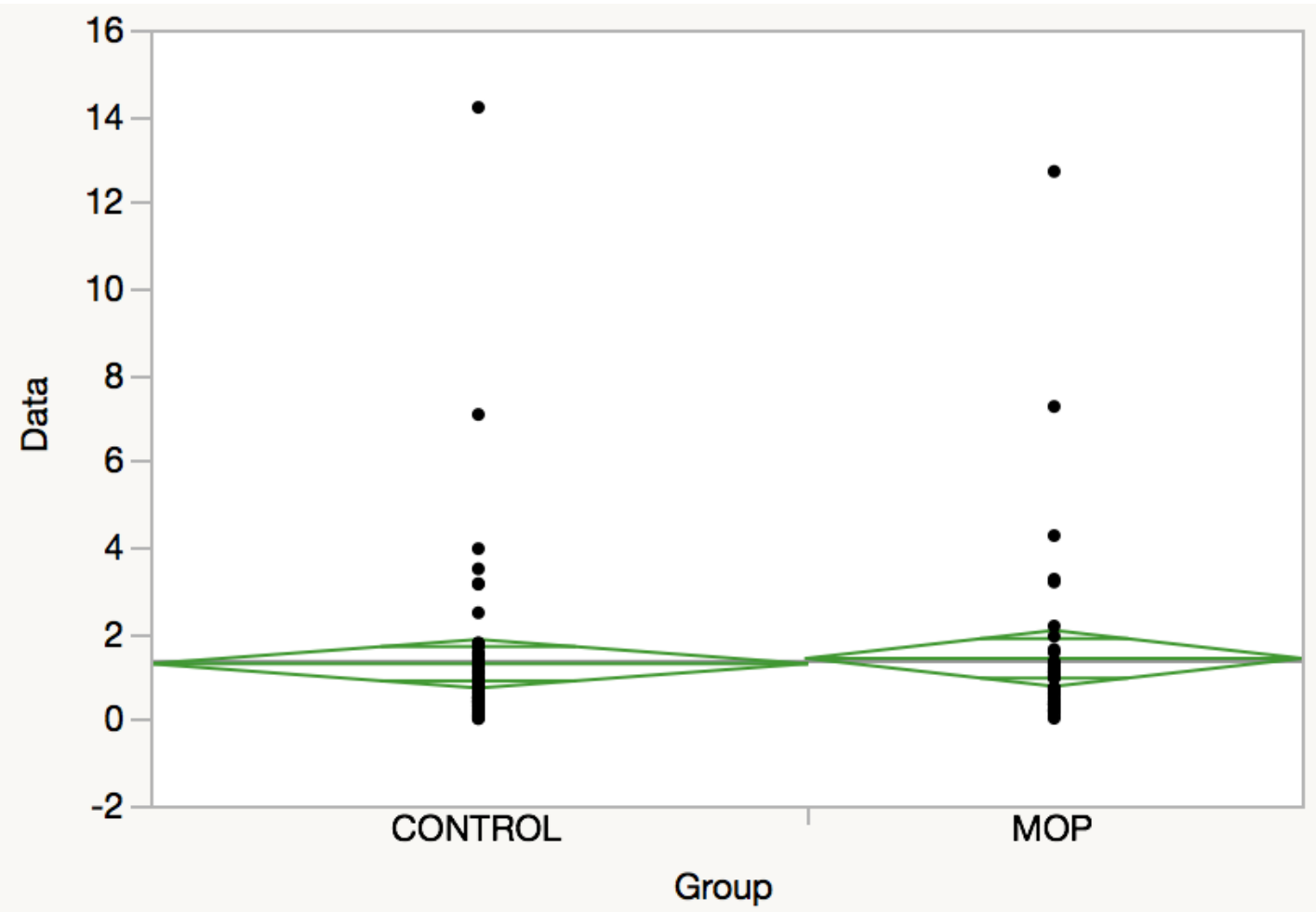

Missing Rows 5

Oneway Anova

Summary of Fit

Rsquare

Adj Rsquare

Root Mean Square Error

Mean of Response

Observations (or Sum Wgts)

t Test

MOP-CONTROL

Assuming equal variances

Difference

0.12413 t Ratio

0.286507 
Std Err Dif

Upper CL Dif

Lower CL Dif

Confidence
$0.43325 \mathrm{DF}$

0.98391 Prob $>|t|$

-0.73565 Prob $>\mathrm{t}$

0.95 Prob $<\mathrm{t}$

0.7751

0.3875

0.6125

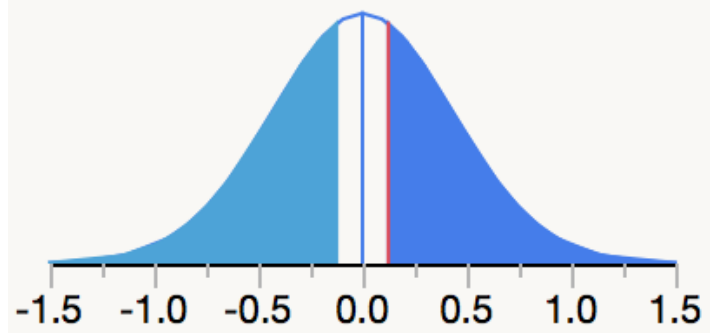

Analysis of Variance

\begin{tabular}{|c|c|c|c|c|c|}
\hline Source & DF & Sum of Squares & Mean Square & F Ratio & Prob $>$ F \\
\hline Group & 1 & 0.37766 & 0.37766 & 0.0821 & 0.7751 \\
\hline Error & 98 & 450.87192 & 4.60073 & & \\
\hline C. Total & 99 & 451.24958 & & & \\
\hline
\end{tabular}

Means for Oneway Anova

$\begin{array}{lrrrrr}\text { Level } & \text { Number } & \text { Mean } & \text { Std Error } & \text { Lower 95\% } & \text { Upper 95\% } \\ \text { CONTROL } & 57 & 1.28861 & 0.28410 & 0.72482 & 1.8524 \\ \text { MOP } & 43 & 1.41274 & 0.32710 & 0.76362 & 2.0619\end{array}$

Std Error uses a pooled estimate of error variance 
Oneway Analysis of Data By Group parameter $=\Delta z^{\circ}$, Tooth $=\# 10$

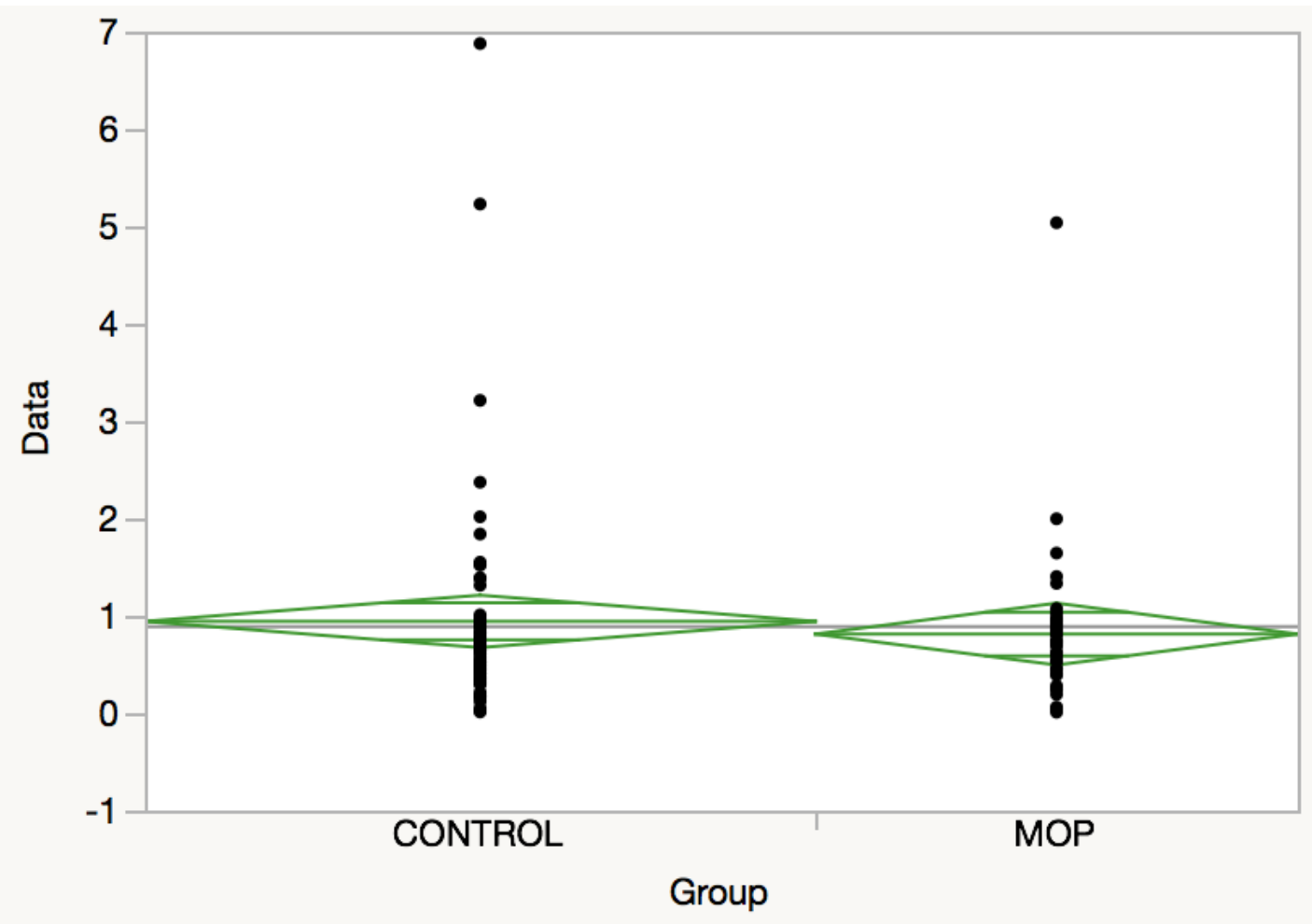

Missing Rows 7

Oneway Anova

Summary of Fit

Rsquare

Adj Rsquare

Root Mean Square Error

Mean of Response

Observations (or Sum Wgts)

t Test

MOP-CONTROL

Assuming equal variances

Difference

-0.13060 t Ratio

$-0.62214$ 
Std Err Dif

Upper CL Dif

Lower CL Dif

Confidence
$0.20991 \mathrm{DF}$

0.28608 Prob $>|t|$

-0.54727 Prob $>t$

0.95 Prob $<\mathrm{t}$

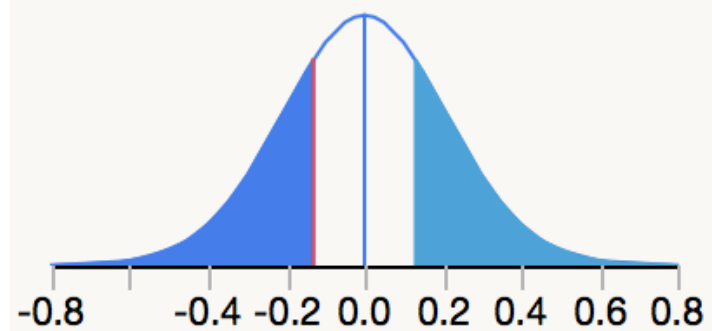

96

0.5353

0.7323

0.2677

Analysis of Variance

\begin{tabular}{|c|c|c|c|c|c|}
\hline Source & DF & Sum of Squares & Mean Square & F Ratio & Prob $>$ F \\
\hline Group & 1 & 0.40672 & 0.40672 & 0.3871 & 0.5353 \\
\hline Error & 96 & 100.87596 & 1.05079 & & \\
\hline C. Total & 97 & 101.28268 & & & \\
\hline
\end{tabular}

Means for Oneway Anova

$\begin{array}{lrrrrr}\text { Level } & \text { Number } & \text { Mean } & \text { Std Error } & \text { Lower 95\% } & \text { Upper95\% } \\ \text { CONTROL } & 57 & 0.942981 & 0.13578 & 0.67347 & 1.2125 \\ \text { MOP } & 41 & 0.812385 & 0.16009 & 0.49461 & 1.1302\end{array}$

Std Error uses a pooled estimate of error variance 
Oneway Analysis of Data By Group parameter $=\Delta z^{\circ}$, Tooth $=\# 11$

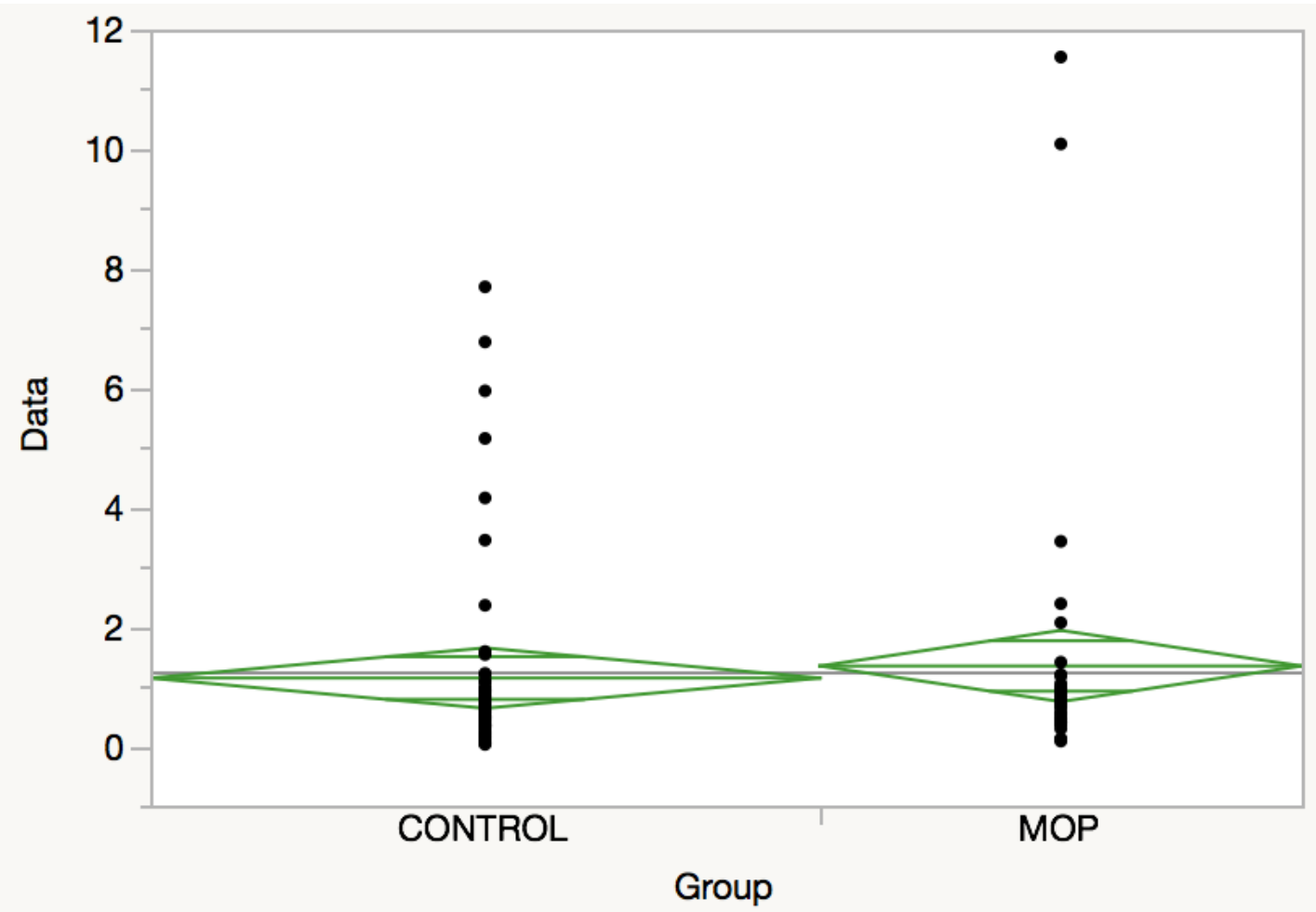

Missing Rows 7

Oneway Anova

Summary of Fit

Rsquare

Adj Rsquare

Root Mean Square Error

Mean of Response

Observations (or Sum Wgts)
0.002723

$-0.00767$

1.926672

1.219765

98

\section{t Test}

MOP-CONTROL

Assuming equal variances

Difference $\quad 0.20198$ t Ratio $\quad 0.511947$ 
Std Err Dif

Upper CL Dif

Lower CL Dif

Confidence
$0.39454 \mathrm{DF}$

0.98514 Prob $>|t|$

-0.58117 Prob > t

0.95 Prob $<\mathrm{t}$
96

0.6099

0.3049

0.6951

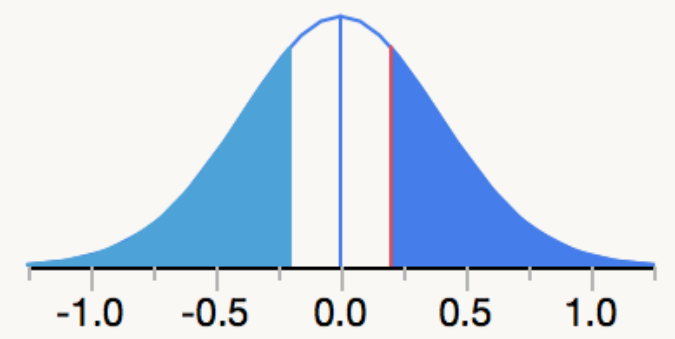

Analysis of Variance

\begin{tabular}{|c|c|c|c|c|c|}
\hline Source & DF & Sum of Squares & Mean Square & F Ratio & Prob $>$ F \\
\hline Group & 1 & 0.97289 & 0.97289 & 0.2621 & 0.6099 \\
\hline Error & 96 & 356.35807 & 3.71206 & & \\
\hline C. Total & 97 & 357.33096 & & & \\
\hline
\end{tabular}

Means for Oneway Anova

$\begin{array}{lrrrrr}\text { Level } & \text { Number } & \text { Mean } & \text { Std Error } & \text { Lower 95\% } & \text { Upper 95\% } \\ \text { CONTROL } & 57 & 1.13526 & 0.25519 & 0.62871 & 1.6418 \\ \text { MOP } & 41 & 1.33725 & 0.30090 & 0.73997 & 1.9345\end{array}$

Std Error uses a pooled estimate of error variance 
Oneway Analysis of Data By Group parameter $=\Delta z^{\circ}$, Tooth $=\# 22$

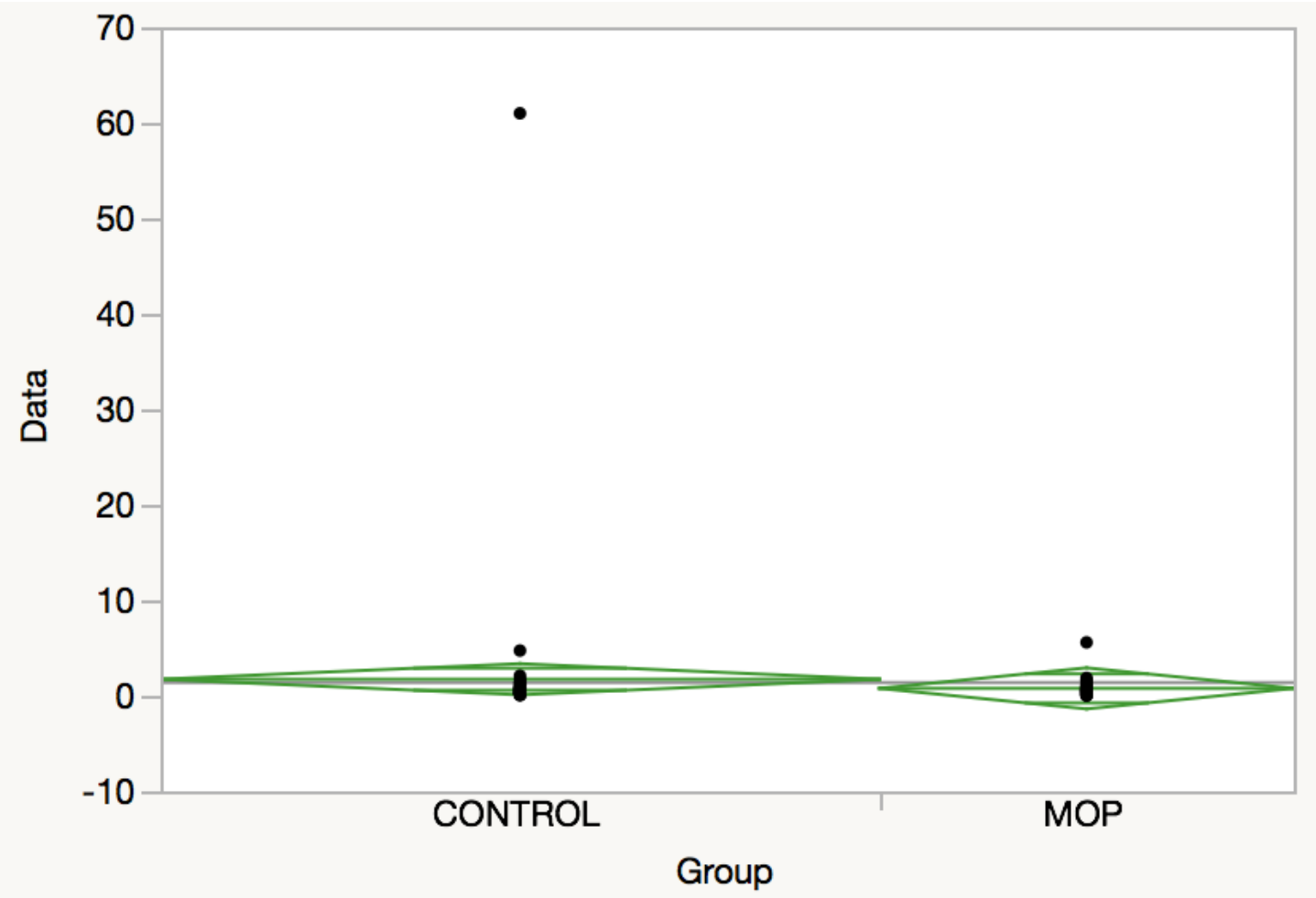

Missing Rows 12

Oneway Anova

Summary of Fit

Rsquare

Adj Rsquare

Root Mean Square Error

Mean of Response

Observations (or Sum Wgts)
0.005462

$-0.00547$

6.315376

1.385628

93

\section{t Test}

MOP-CONTROL

Assuming equal variances

Difference

-0.9613 t Ratio

$-0.70693$ 


$\begin{array}{lrr}\text { Std Err Dif } & 1.3598 \text { DF } & 91 \\ \text { Upper CL Dif } & 1.7398 \text { Prob }>|t| & 0.4814 \\ \text { Lower CL Dif } & -3.6624 \text { Prob }>\mathrm{t} & 0.7593 \\ \text { Confidence } & 0.95 \text { Prob }<\mathrm{t} & 0.2407\end{array}$

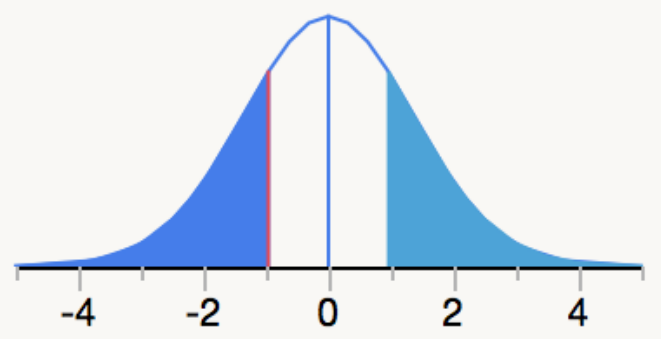

Analysis of Variance

\begin{tabular}{|c|c|c|c|c|c|}
\hline Source & DF & Sum of Squares & Mean Square & F Ratio & Prob $>$ F \\
\hline Group & 1 & 19.9323 & 19.9323 & 0.4998 & 0.4814 \\
\hline Error & 91 & 3629.4421 & 39.8840 & & \\
\hline C. Total & 92 & 3649.3744 & & & \\
\hline
\end{tabular}

Means for Oneway Anova

$\begin{array}{lrrrrr}\text { Level } & \text { Number } & \text { Mean } & \text { Std Error } & \text { Lower 95\% } & \text { Upper95\% } \\ \text { CONTROL } & 59 & 1.73707 & 0.8222 & 0.104 & 3.3703 \\ \text { MOP } & 34 & 0.77578 & 1.0831 & -1.376 & 2.9272\end{array}$

Std Error uses a pooled estimate of error variance 
Oneway Analysis of Data By Group parameter $=\Delta z^{\circ}$, Tooth $=\# 23$

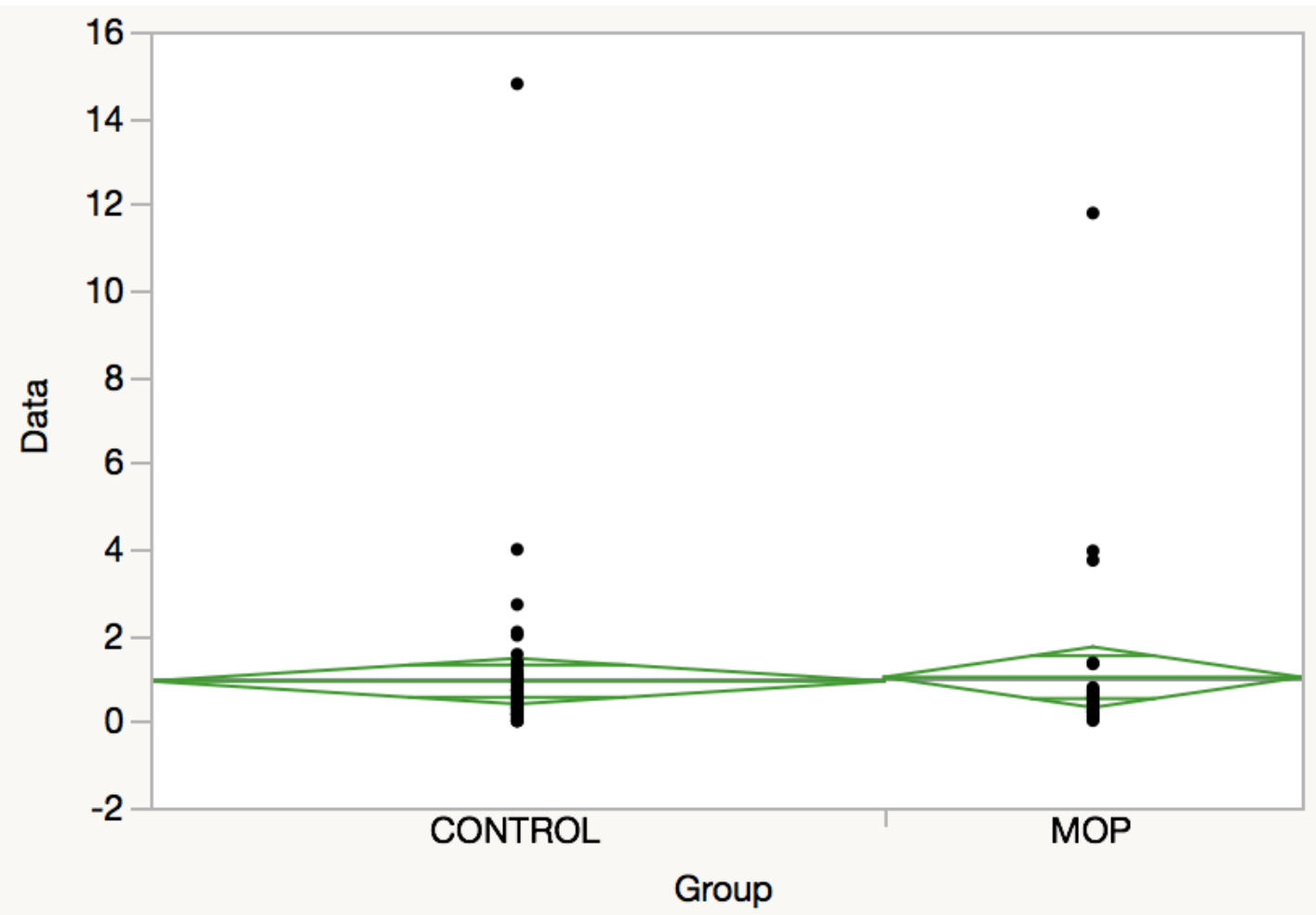

Missing Rows 14

Oneway Anova

Summary of Fit

Rsquare

Adj Rsquare

Root Mean Square Error

Mean of Response

Observations (or Sum Wgts)

t Test

MOP-CONTROL

Assuming equal variances

Difference

0.09174 t Ratio

0.207073 
Std Err Dif

Upper CL Dif

Lower CL Dif

Confidence
$0.44303 \mathrm{DF}$

0.97203 Prob $>|t|$

-0.78855 Prob >t

0.95 Prob $<\mathrm{t}$
89

0.8364

0.4182

0.5818

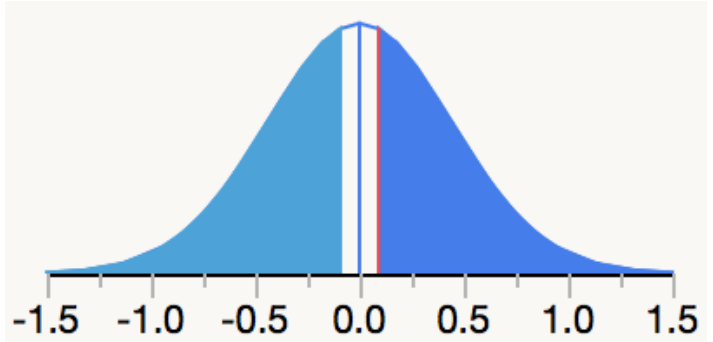

Analysis of Variance

\begin{tabular}{|c|c|c|c|c|c|}
\hline Source & DF & Sum of Squares & Mean Square & F Ratio & Prob $>$ F \\
\hline Group & 1 & 0.17702 & 0.17702 & 0.0429 & 0.8364 \\
\hline Error & 89 & 367.41124 & 4.12822 & & \\
\hline C. Total & 90 & 367.58826 & & & \\
\hline
\end{tabular}

Means for Oneway Anova

$\begin{array}{lrrrrr}\text { Level } & \text { Number } & \text { Mean } & \text { Std Error } & \text { Lower 95\% } & \text { Upper95\% } \\ \text { CONTROL } & 58 & 0.93151 & 0.26679 & 0.40141 & 1.4616 \\ \text { MOP } & 33 & 1.02325 & 0.35369 & 0.32048 & 1.7260\end{array}$

Std Error uses a pooled estimate of error variance 
Oneway Analysis of Data By Group parameter $=\Delta z^{\circ}$, Tooth $=\# 24$

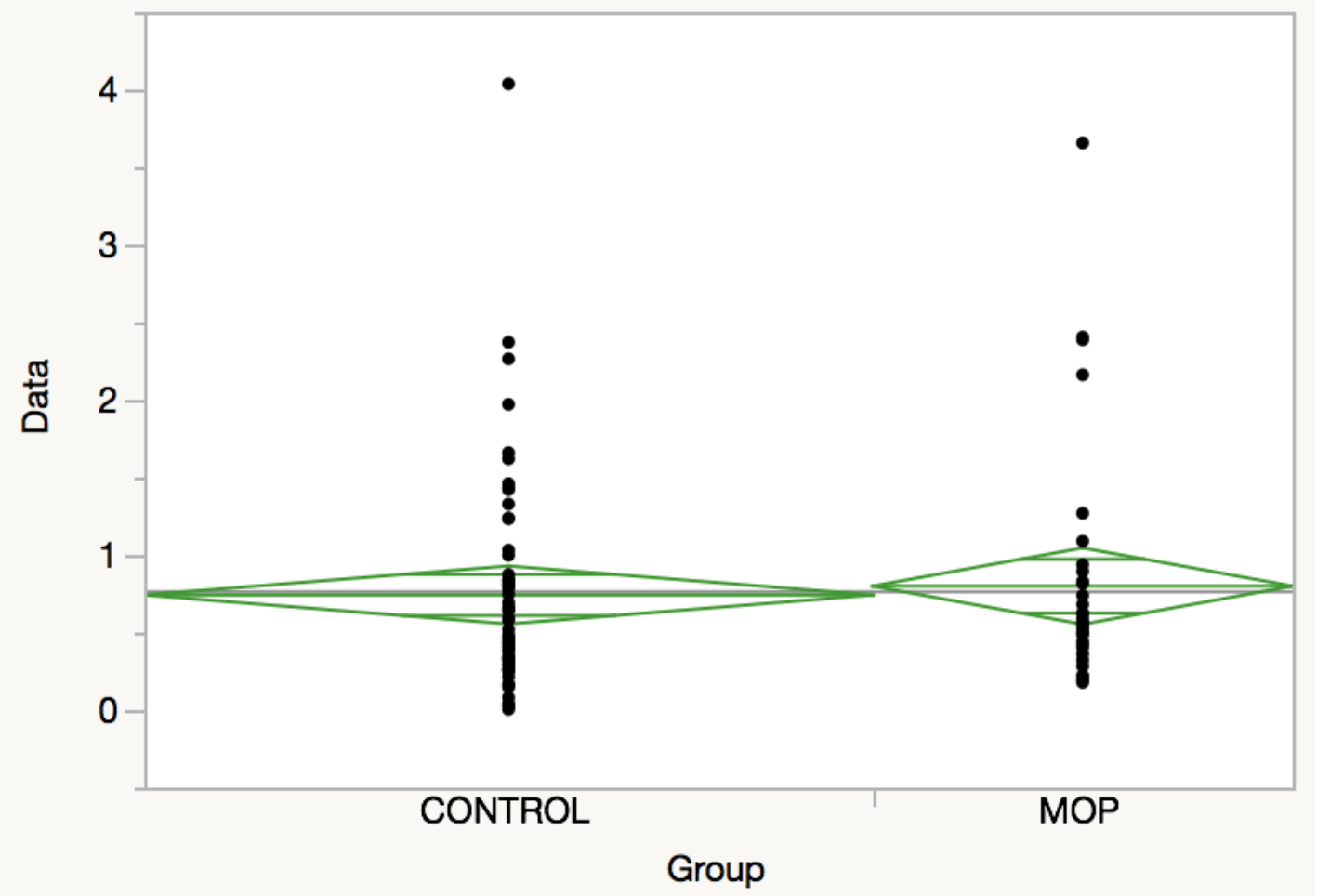

Missing Rows 12

Oneway Anova

Summary of Fit

Rsquare

0.001489

Adj Rsquare

$-0.00948$

Root Mean Square Error

0.722255

Mean of Response

0.762737

Observations (or Sum Wgts)

93

\section{t Test}

MOP-CONTROL

Assuming equal variances

Difference $\quad 0.05728$ t Ratio $\quad 0.368332$ 
Std Err Dif

Upper CL Dif

Lower CL Dif

Confidence
$0.15551 \mathrm{DF}$

0.36619 Prob $>|t|$

-0.25163 Prob >t

0.95 Prob $<\mathrm{t}$
91

0.7135

0.3567

0.6433

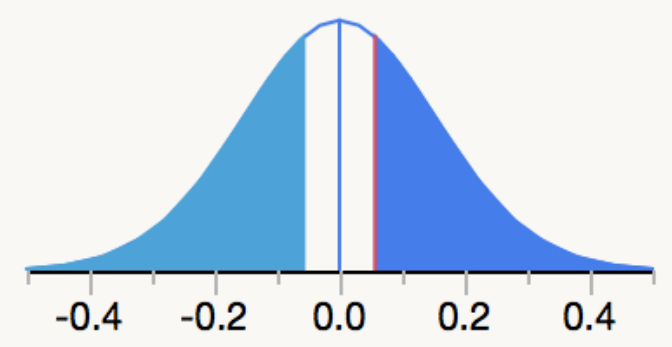

Analysis of Variance

\begin{tabular}{|c|c|c|c|c|c|}
\hline Source & DF & Sum of Squares & Mean Square & F Ratio & Prob $>$ F \\
\hline Group & 1 & 0.070772 & 0.070772 & 0.1357 & 0.7135 \\
\hline Error & 91 & 47.470333 & 0.521652 & & \\
\hline C. Total & 92 & 47.541104 & & & \\
\hline
\end{tabular}

Means for Oneway Anova

$\begin{array}{lrrrrr}\text { Level } & \text { Number } & \text { Mean } & \text { Std Error } & \text { Lower 95\% } & \text { Upper 95\% } \\ \text { CONTROL } & 59 & 0.741796 & 0.09403 & 0.55502 & 0.9286 \\ \text { MOP } & 34 & 0.799076 & 0.12387 & 0.55303 & 1.0451\end{array}$

Std Error uses a pooled estimate of error variance 
Oneway Analysis of Data By Group parameter $=\Delta z^{\circ}$, Tooth $=\# 25$

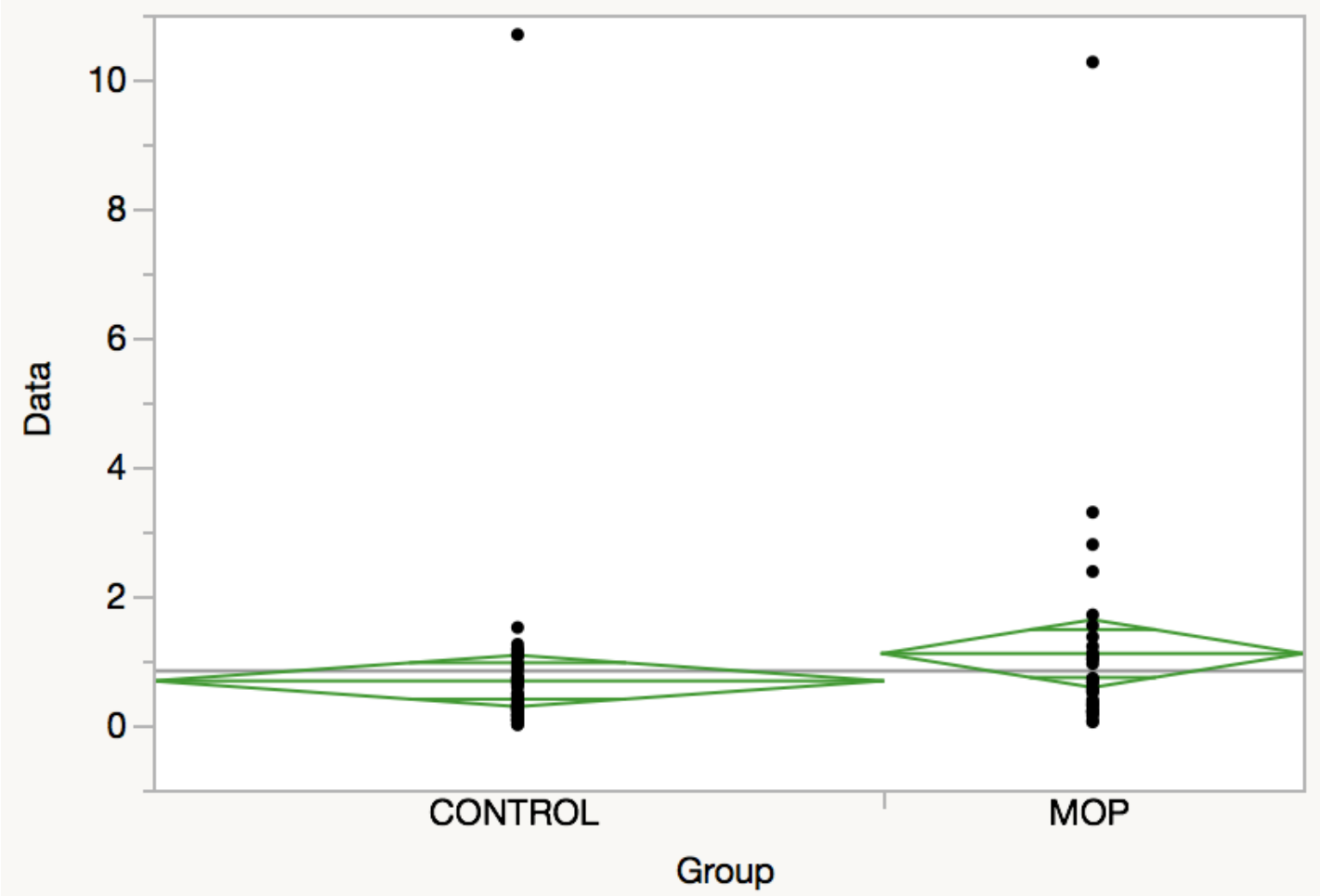

Missing Rows 12

Oneway Anova

Summary of Fit

Rsquare

Adj Rsquare

Root Mean Square Error

Mean of Response

Observations (or Sum Wgts)
0.017638

0.006842

1.540877

0.838081

93

\section{t Test}

MOP-CONTROL

Assuming equal variances

Difference

0.4241 t Ratio

1.278217 
Std Err Dif

Upper CL Dif

Lower CL Dif

Confidence
$0.3318 \mathrm{DF}$

1.0831 Prob $>|t|$

-0.2349 Prob > t

0.95 Prob $<\mathrm{t}$
91

0.2044

0.1022

0.8978

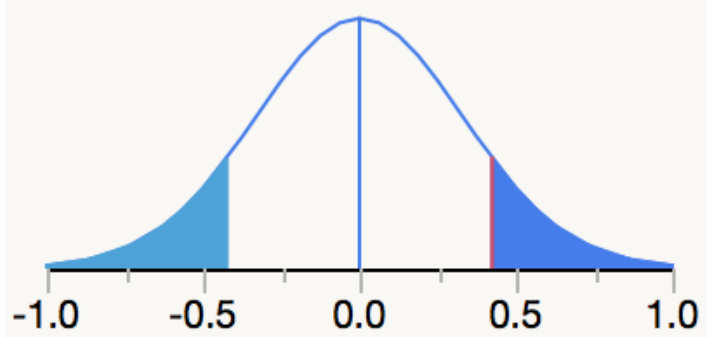

Analysis of Variance

$\begin{array}{lrrrrr}\text { Source } & \text { DF } & \text { Sum of Squares } & \text { Mean Square } & \text { F Ratio } & \text { Prob > F } \\ \text { Group } & 1 & 3.87923 & 3.87923 & 1.6338 & 0.2044 \\ \text { Error } & 91 & 216.06152 & 2.37430 \\ \text { C. Total } & 92 & 219.94075 & & & \end{array}$

Means for Oneway Anova

$\begin{array}{lrrrrr}\text { Level } & \text { Number } & \text { Mean } & \text { Std Error } & \text { Lower 95\% } & \text { Upper95\% } \\ \text { CONTROL } & 59 & 0.68304 & 0.20061 & 0.28456 & 1.0815 \\ \text { MOP } & 34 & 1.10712 & 0.26426 & 0.58220 & 1.6320\end{array}$

Std Error uses a pooled estimate of error variance 
Oneway Analysis of Data By Group parameter $=\Delta z^{\circ}$, Tooth $=\# 26$

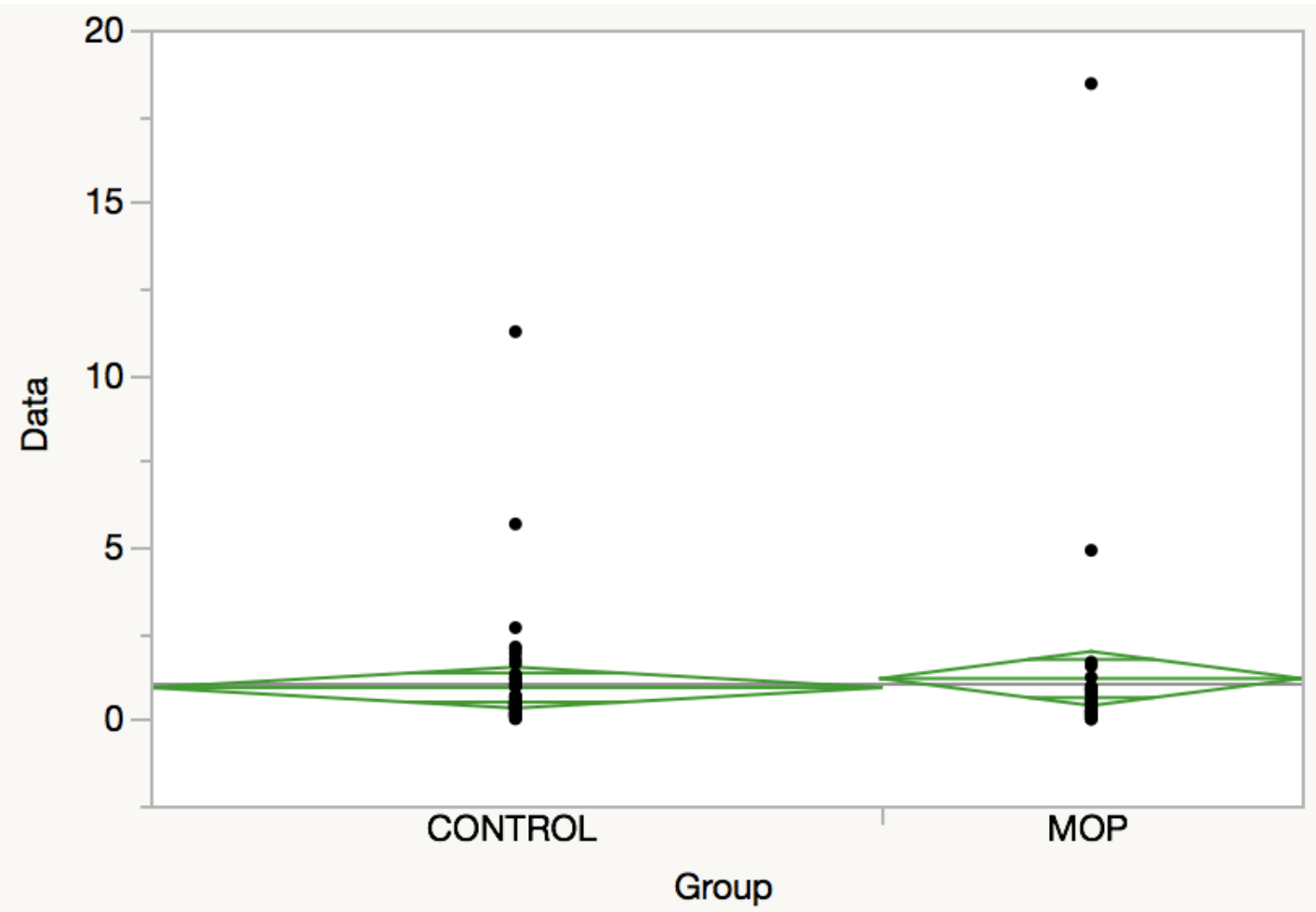

Missing Rows 12

Oneway Anova

Summary of Fit

Rsquare

Adj Rsquare

Root Mean Square Error

Mean of Response

Observations (or Sum Wgts)
0.003071

$-0.00788$

2.304466

1.014933

93

\section{t Test}

MOP-CONTROL

Assuming equal variances

Difference

0.2627 t Ratio

0.529425 
Std Err Dif

Upper CL Dif

Lower CL Dif

Confidence
$0.4962 \mathrm{DF}$

1.2483 Prob $>|t|$

-0.7229 Prob $>\mathrm{t}$

0.95 Prob $<\mathrm{t}$
91

0.5978

0.2989

0.7011

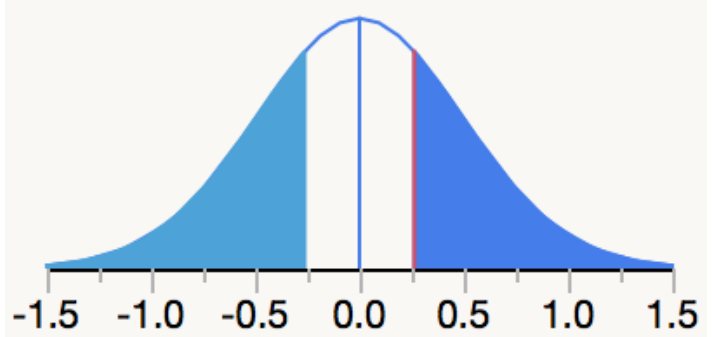

Analysis of Variance

\begin{tabular}{|c|c|c|c|c|c|}
\hline Source & DF & Sum of Squares & Mean Square & F Ratio & Prob $>$ F \\
\hline Group & 1 & 1.48850 & 1.48850 & 0.2803 & 0.5978 \\
\hline Error & 91 & 483.26112 & 5.31056 & & \\
\hline C. Total & 92 & 484.74962 & & & \\
\hline
\end{tabular}

Means for Oneway Anova

$\begin{array}{lrrrrr}\text { Level } & \text { Number } & \text { Mean } & \text { Std Error } & \text { Lower 95\% } & \text { Upper95\% } \\ \text { CONTROL } & 59 & 0.91889 & 0.30002 & 0.32295 & 1.5148 \\ \text { MOP } & 34 & 1.18159 & 0.39521 & 0.39655 & 1.9666\end{array}$

Std Error uses a pooled estimate of error variance 
Oneway Analysis of Data By Group parameter $=\Delta z^{\circ}$, Tooth $=\# 27$

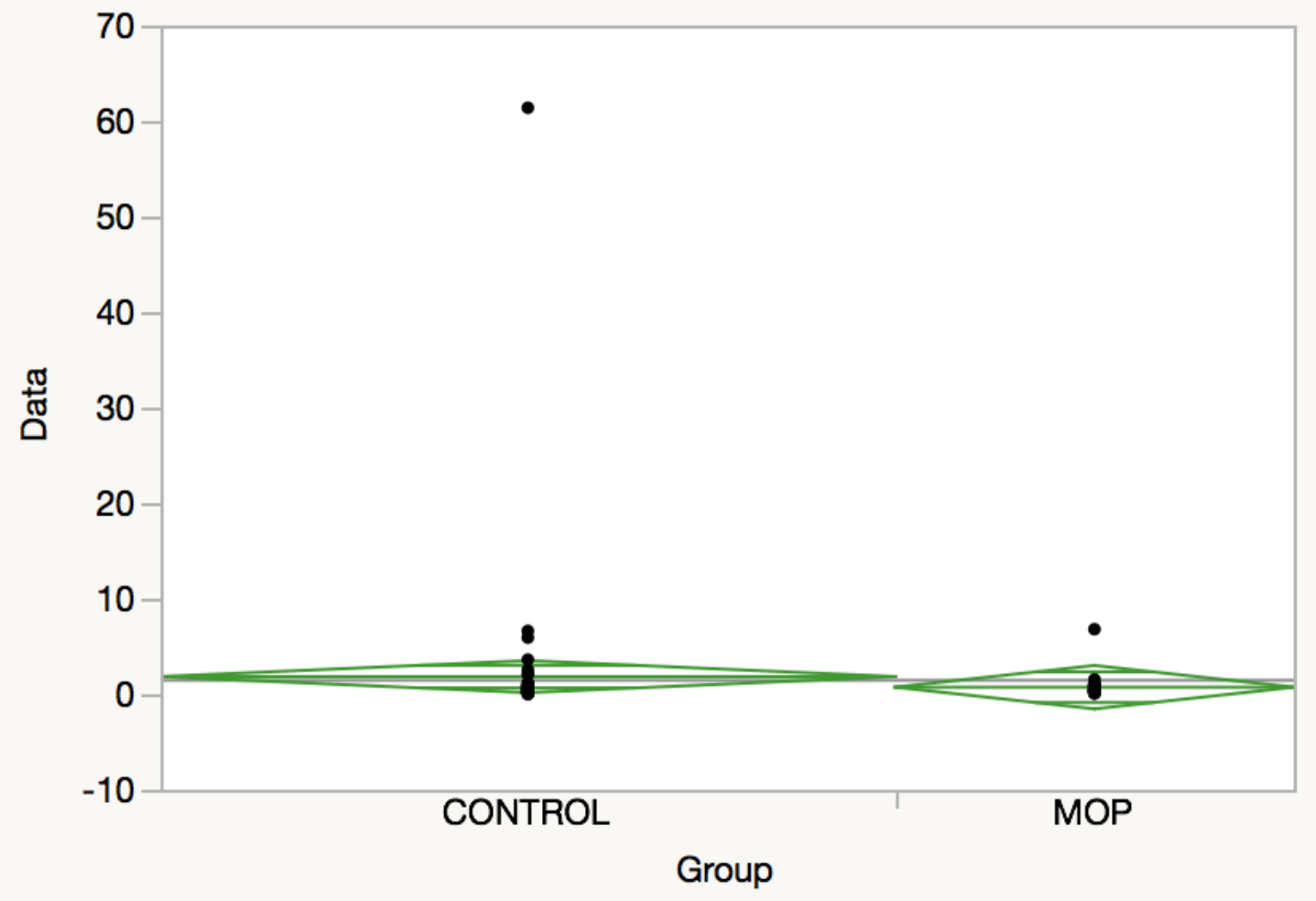

Missing Rows 14

Oneway Anova

Summary of Fit

Rsquare

Adj Rsquare

Root Mean Square Error

Mean of Response

Observations (or Sum Wgts)
0.006762

$-0.0044$

6.477066

1.448077

91

\section{t Test}

MOP-CONTROL

Assuming equal variances

Difference

-1.1069 t Ratio

$-0.77843$ 
Std Err Dif

Upper CL Dif

Lower CL Dif

Confidence
$1.4220 \mathrm{DF}$

1.7186 Prob $>|t|$

-3.9324 Prob $>\mathrm{t}$

0.95 Prob $<\mathrm{t}$
89

0.4384

0.7808

0.2192

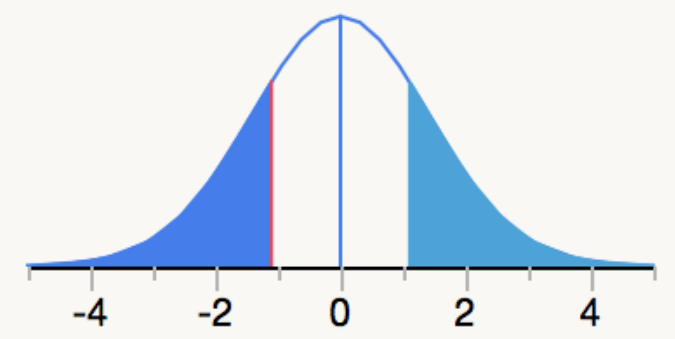

Analysis of Variance

\begin{tabular}{|c|c|c|c|c|c|}
\hline Source & DF & Sum of Squares & Mean Square & F Ratio & Prob > F \\
\hline Group & 1 & 25.4209 & 25.4209 & 0.6059 & 0.4384 \\
\hline Error & 89 & 3733.7625 & 41.9524 & & \\
\hline C. Total & 90 & 3759.1834 & & & \\
\hline
\end{tabular}

Means for Oneway Anova

$\begin{array}{lrrcrr}\text { Level } & \text { Number } & \text { Mean } & \text { Std Error } & \text { Lower 95\% } & \text { Upper95\% } \\ \text { CONTROL } & 59 & 1.83732 & 0.8432 & 0.162 & 3.5128 \\ \text { MOP } & 32 & 0.73040 & 1.1450 & -1.545 & 3.0055\end{array}$

Std Error uses a pooled estimate of error variance 
Oneway Analysis of Data By Group parameter $=\Delta z^{\circ}$, Tooth $=\# 6$

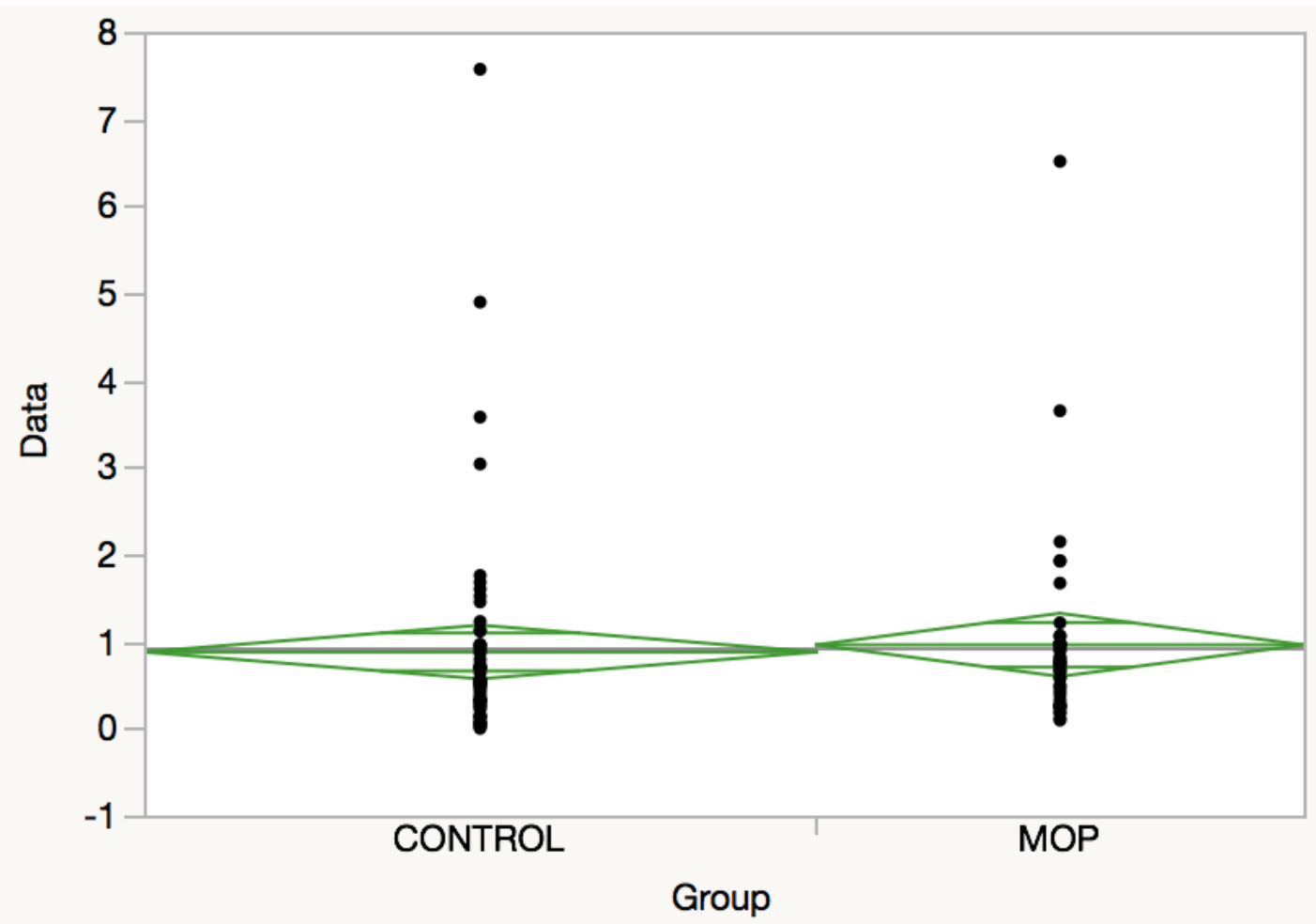

Missing Rows 5

Oneway Anova

Summary of Fit

Rsquare

Adj Rsquare

Root Mean Square Error

Mean of Response

Observations (or Sum Wgts)

t Test

MOP-CONTROL

Assuming equal variances

Difference

0.08200 t Ratio

0.341666 
Std Err Dif

Upper CL Dif

Lower CL Dif

Confidence
$0.24000 \mathrm{DF}$

$$
0.55826 \text { Prob }>|t|
$$

-0.39427 Prob >t

0.95 Prob $<\mathrm{t}$
98

0.7333

0.3667

0.6333

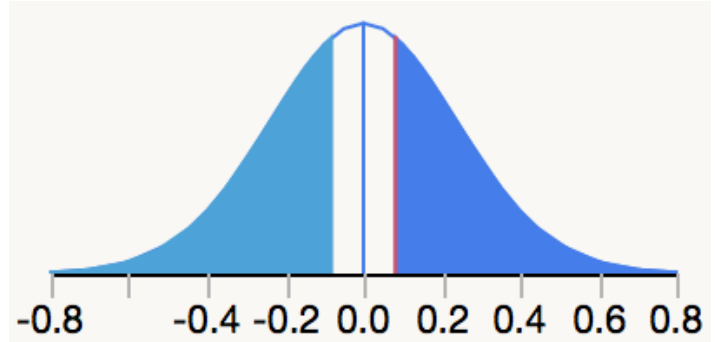

Analysis of Variance

\begin{tabular}{|c|c|c|c|c|c|}
\hline Source & DF & Sum of Squares & Mean Square & F Ratio & Prob $>$ F \\
\hline Group & 1 & 0.16379 & 0.16379 & 0.1167 & 0.7333 \\
\hline Error & 98 & 137.50318 & 1.40309 & & \\
\hline C. Total & 99 & 137.66697 & & & \\
\hline
\end{tabular}

Means for Oneway Anova

$\begin{array}{lrrrrr}\text { Level } & \text { Number } & \text { Mean } & \text { Std Error } & \text { Lower 95\% } & \text { Upper 95\% } \\ \text { CONTROL } & 58 & 0.877441 & 0.15554 & 0.56879 & 1.1861 \\ \text { MOP } & 42 & 0.959440 & 0.18278 & 0.59673 & 1.3222\end{array}$

Std Error uses a pooled estimate of error variance 
Oneway Analysis of Data By Group parameter $=\Delta z^{\circ}$, Tooth $=\# 7$

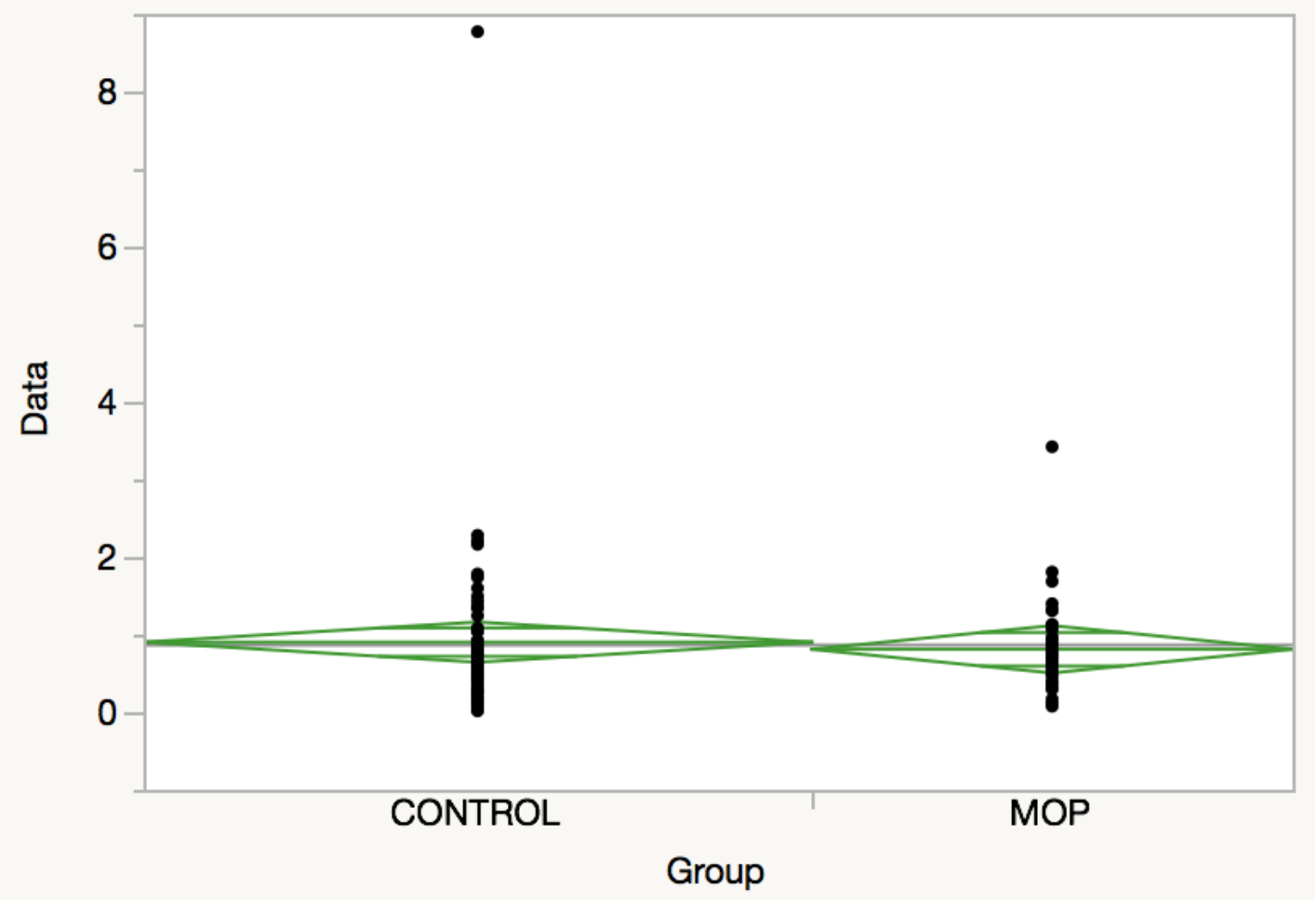

Missing Rows 7

Oneway Anova

Summary of Fit

Rsquare

Adj Rsquare

Root Mean Square Error

Mean of Response

Observations (or Sum Wgts)

t Test

MOP-CONTROL

Assuming equal variances

Difference

-0.09209 t Ratio

$-0.45592$ 
Std Err Dif

Upper CL Dif

Lower CL Dif

Confidence
$0.20200 \mathrm{DF}$

0.30887 Prob $>|t|$

-0.49305 Prob > t

0.95 Prob $<\mathrm{t}$
96

0.6495

0.6753

0.3247

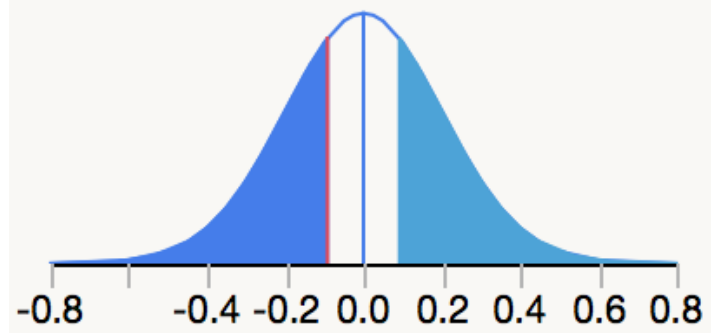

Analysis of Variance

\begin{tabular}{|c|c|c|c|c|c|}
\hline Source & DF & Sum of Squares & Mean Square & F Ratio & Prob $>$ F \\
\hline Group & 1 & 0.202251 & 0.202251 & 0.2079 & 0.6495 \\
\hline Error & 96 & 93.409576 & 0.973016 & & \\
\hline C. Total & 97 & 93.611827 & & & \\
\hline
\end{tabular}

Means for Oneway Anova

$\begin{array}{lrrrrr}\text { Level } & \text { Number } & \text { Mean } & \text { Std Error } & \text { Lower 95\% } & \text { Upper95\% } \\ \text { CONTROL } & 57 & 0.902495 & 0.13065 & 0.64315 & 1.1618 \\ \text { MOP } & 41 & 0.810401 & 0.15405 & 0.50461 & 1.1162\end{array}$

Std Error uses a pooled estimate of error variance 
Oneway Analysis of Data By Group parameter $=\Delta z^{\circ}$, Tooth $=\# 8$

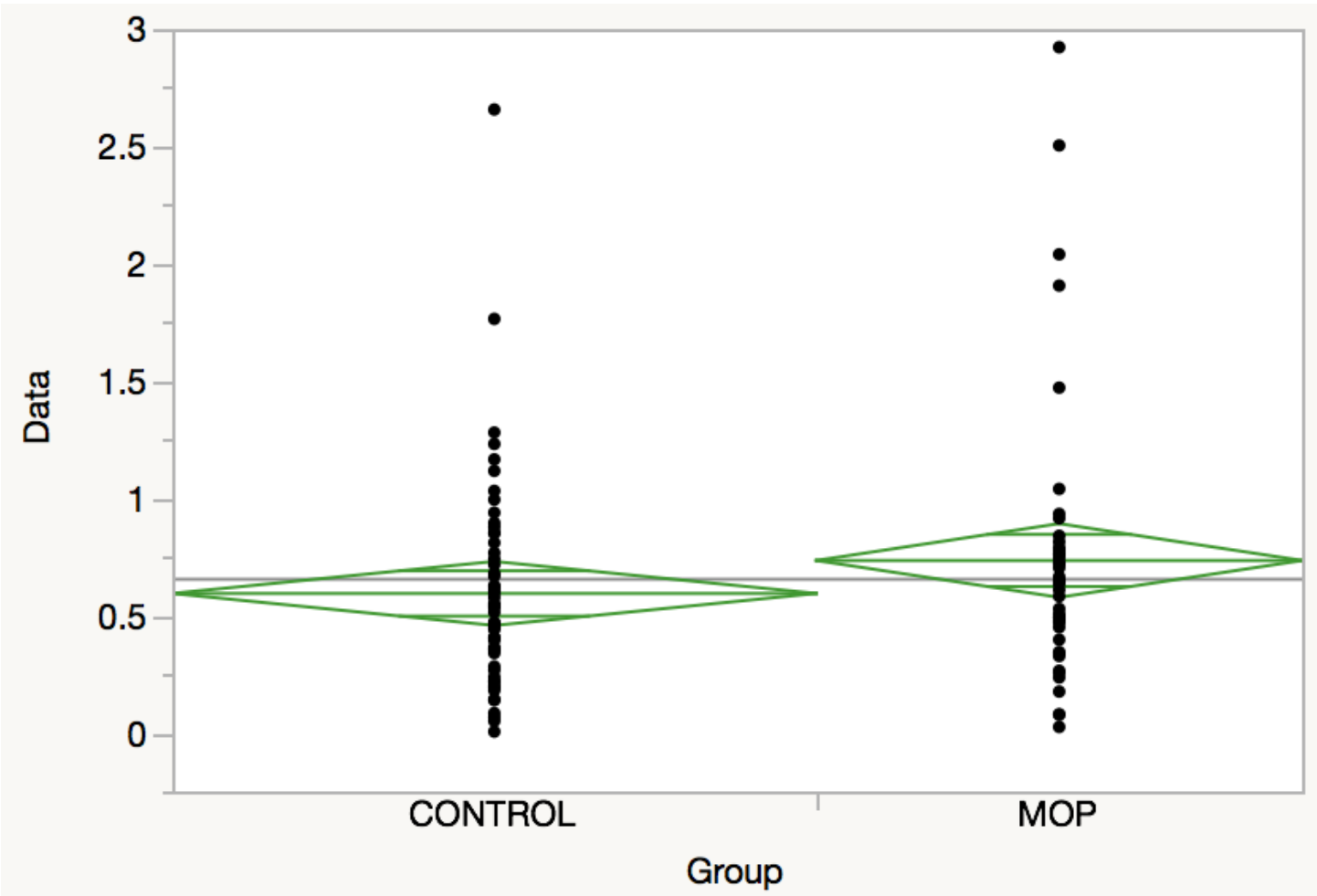

Missing Rows 5

Oneway Anova

Summary of Fit

Rsquare

0.017977

Adj Rsquare

0.007956

Root Mean Square Error

0.519418

Mean of Response

0.654179

Observations (or Sum Wgts)

100

\section{t Test}

MOP-CONTROL

Assuming equal variances

Difference $\quad 0.14053$ t Ratio $\quad 1.339407$ 
Std Err Dif

Upper CL Dif

Lower CL Dif

Confidence
$0.10492 \mathrm{DF}$

0.34873 Prob $>|t|$

-0.06768 Prob $>\mathrm{t}$

0.95 Prob $<\mathrm{t}$
98

0.1835

0.0918

0.9082

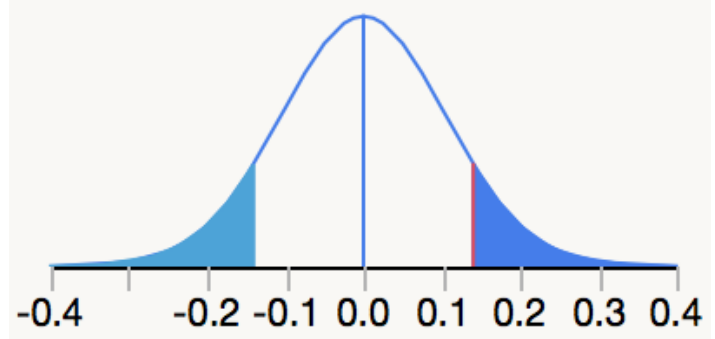

Analysis of Variance

\begin{tabular}{|c|c|c|c|c|c|}
\hline Source & DF & Sum of Squares & Mean Square & F Ratio & Prob $>$ F \\
\hline Group & 1 & 0.484016 & 0.484016 & 1.7940 & 0.1835 \\
\hline Error & 98 & 26.439965 & 0.269796 & & \\
\hline C. Total & 99 & 26.923981 & & & \\
\hline
\end{tabular}

Means for Oneway Anova

$\begin{array}{lrrrrr}\text { Level } & \text { Number } & \text { Mean } & \text { Std Error } & \text { Lower 95\% } & \text { Upper95\% } \\ \text { CONTROL } & 57 & 0.593753 & 0.06880 & 0.45722 & 0.73028 \\ \text { MOP } & 43 & 0.734279 & 0.07921 & 0.57709 & 0.89147\end{array}$

Std Error uses a pooled estimate of error variance 
Oneway Analysis of Data By Group parameter $=\Delta z^{\circ}$, Tooth $=\# 9$

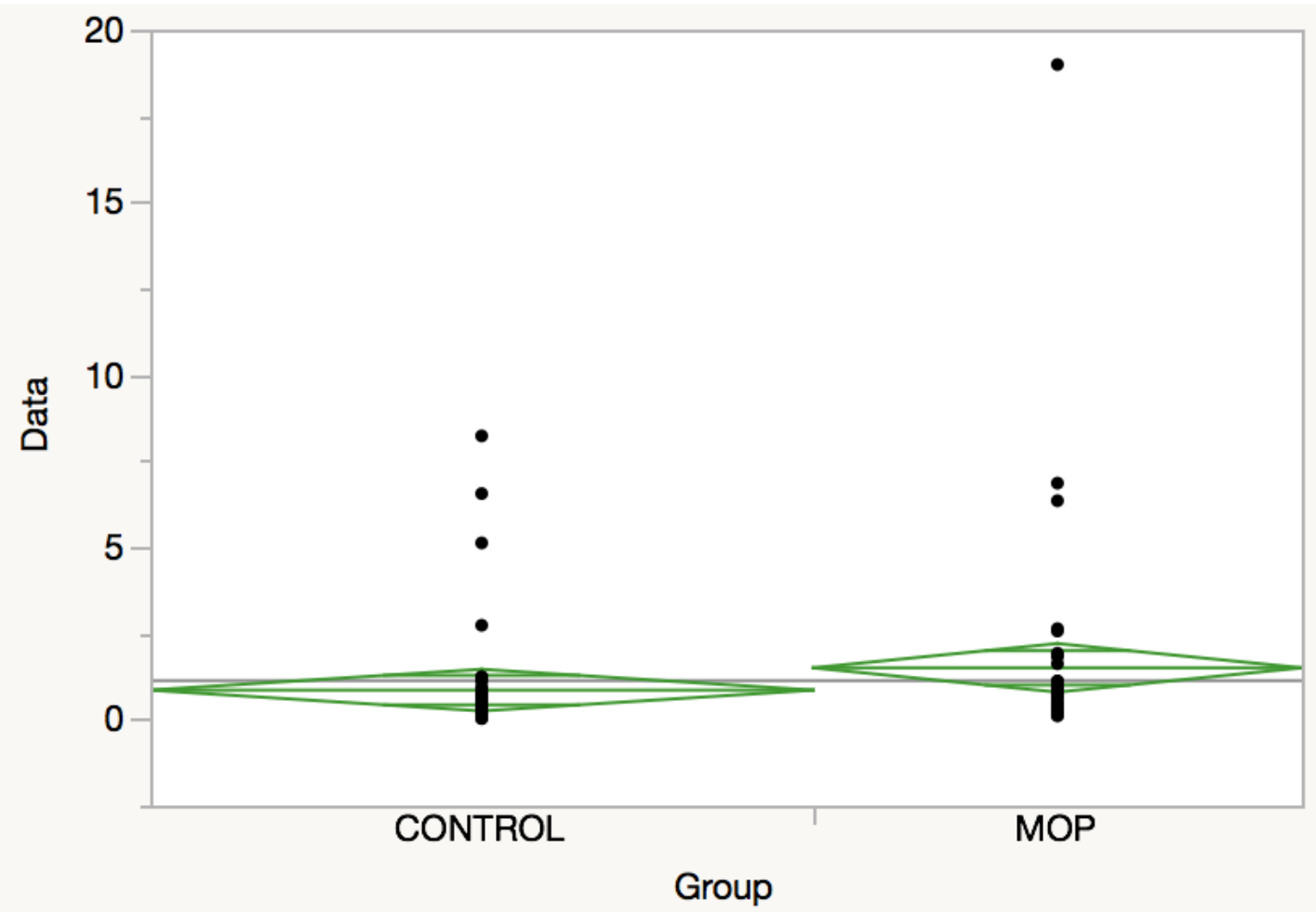

Missing Rows 6

Oneway Anova

Summary of Fit

Rsquare

0.019298

Adj Rsquare

0.009188

Root Mean Square Error

2.300853

Mean of Response

1.12015

Observations (or Sum Wgts)

99

\section{t Test}

MOP-CONTROL

Assuming equal variances

Difference

0.6464 t Ratio

1.381583 
Std Err Dif

Upper CL Dif

Lower CL Dif

Confidence
$0.4679 \mathrm{DF}$

1.5751 Prob $>|t|$

-0.2822 Prob > t

0.95 Prob $<\mathrm{t}$

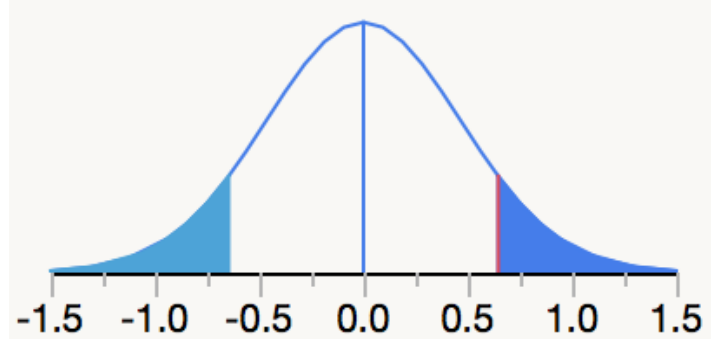

97

0.1703

0.0851

0.9149

Analysis of Variance

\begin{tabular}{|c|c|c|c|c|c|}
\hline Source & DF & Sum of Squares & Mean Square & F Ratio & Prob $>$ F \\
\hline Group & 1 & 10.10490 & 10.1049 & 1.9088 & 0.1703 \\
\hline Error & 97 & 513.51063 & 5.2939 & & \\
\hline C. Total & 98 & 523.61553 & & & \\
\hline
\end{tabular}

Means for Oneway Anova

$\begin{array}{lrrrrr}\text { Level } & \text { Number } & \text { Mean } & \text { Std Error } & \text { Lower 95\% } & \text { Upper95\% } \\ \text { CONTROL } & 57 & 0.84591 & 0.30476 & 0.24105 & 1.4508 \\ \text { MOP } & 42 & 1.49234 & 0.35503 & 0.78770 & 2.1970\end{array}$




\section{DISCREPANCY BY ARCH}

Oneway Analysis of Data By Group parameter $=\Delta V, \operatorname{Arch}=$ Lower

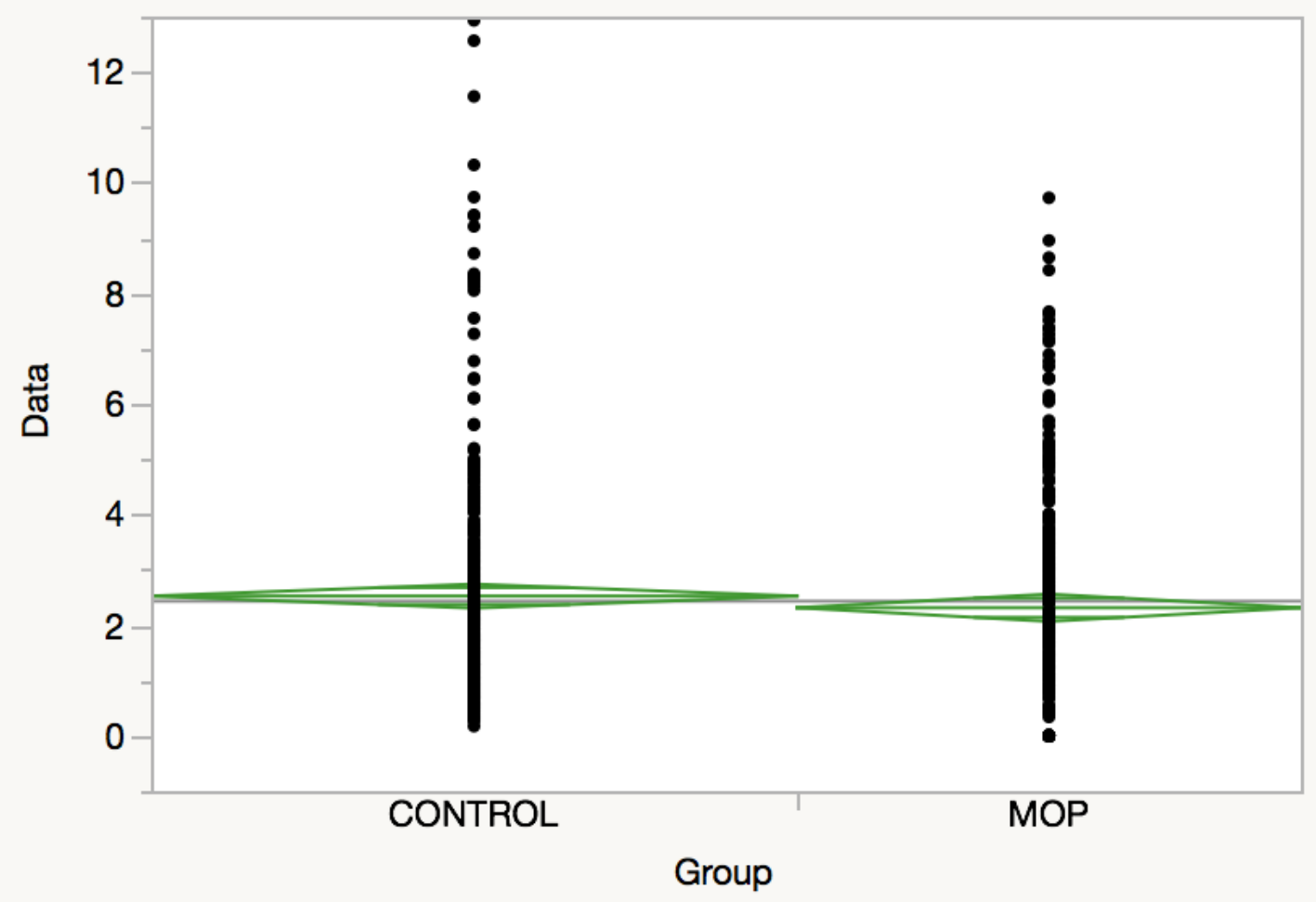

Oneway Anova

Summary of Fit

Rsquare

0.002514

Adj Rsquare

0.000926

Root Mean Square Error

2.087169

Mean of Response

2.432013

Observations (or Sum Wgts)

630

t Test

MOP-CONTROL

Assuming equal variances 


$\begin{array}{llr}\text { Difference } & -0.21086 \text { t Ratio } & -1.25813 \\ \text { Std Err Dif } & 0.16760 \text { DF } & 628 \\ \text { Upper CL Dif } & 0.11826 \text { Prob }>|\mathrm{t}| & 0.2088 \\ \text { Lower CL Dif } & -0.53998 \text { Prob }>\mathrm{t} & 0.8956 \\ \text { Confidence } & 0.95 \text { Prob }<\mathrm{t} & 0.1044\end{array}$

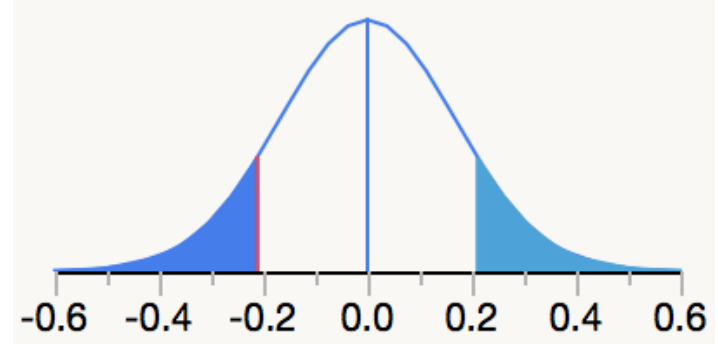

Analysis of Variance

\begin{tabular}{|c|c|c|c|c|c|}
\hline Source & DF & Sum of Squares & Mean Square & F Ratio & Prob $>$ F \\
\hline Group & 1 & 6.8955 & 6.89552 & 1.5829 & 0.2088 \\
\hline Error & 628 & 2735.7415 & 4.35628 & & \\
\hline C. Total & 629 & 2742.6370 & & & \\
\hline
\end{tabular}

Means for Oneway Anova

$\begin{array}{lrrrrr}\text { Level } & \text { Number } & \text { Mean } & \text { Std Error } & \text { Lower 95\% } & \text { Upper95\% } \\ \text { CONTROL } & 354 & 2.52439 & 0.11093 & 2.3065 & 2.7422 \\ \text { MOP } & 276 & 2.31353 & 0.12563 & 2.0668 & 2.5602\end{array}$

Std Error uses a pooled estimate of error variance 
Oneway Analysis of Data By Group parameter $=\Delta V$, Arch $=$ Upper

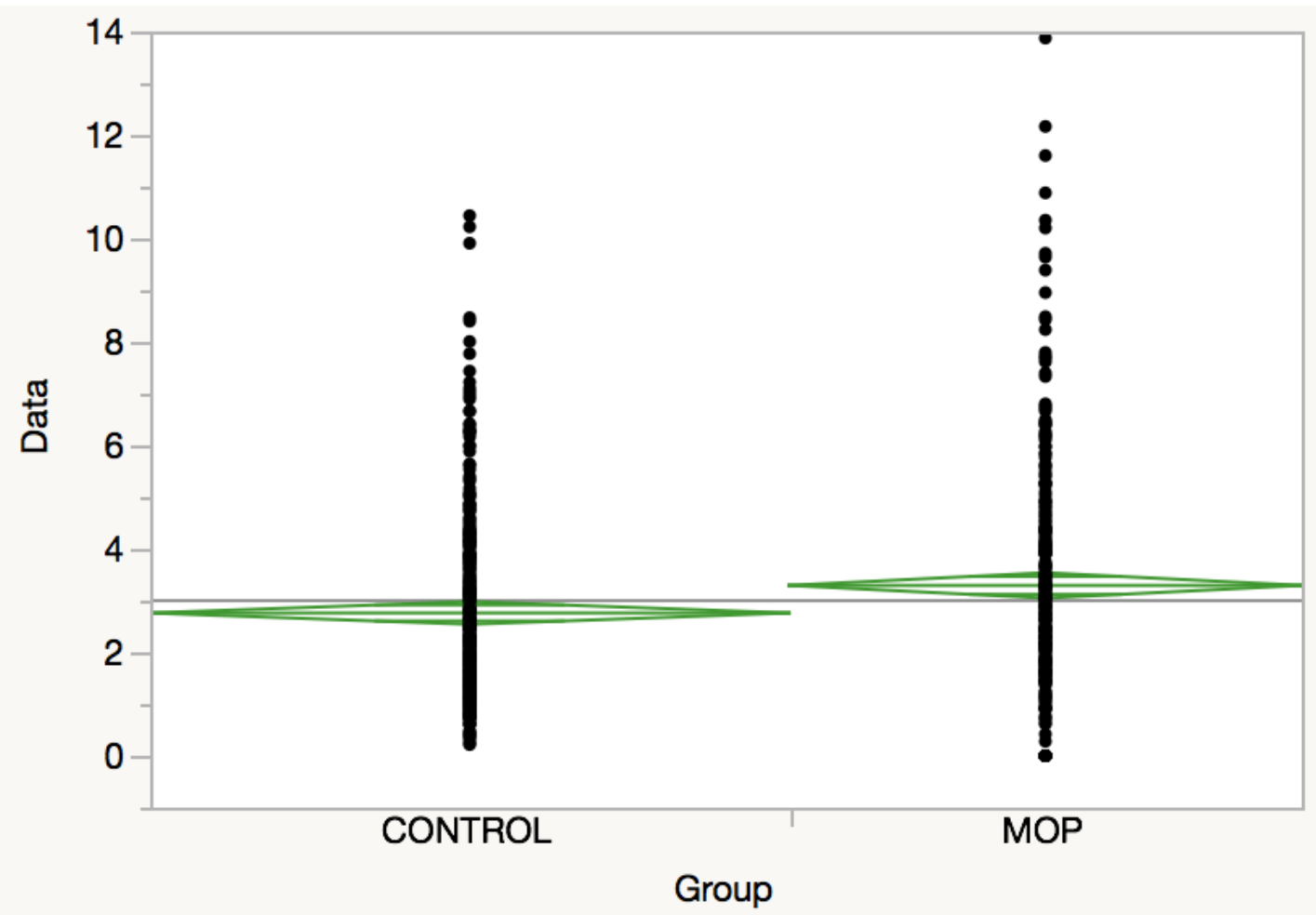

Missing Rows 10

Oneway Anova

Summary of Fit

Rsquare

0.016103

Adj Rsquare

0.014511

Root Mean Square Error

2.071772

Mean of Response

2.99776

Observations (or Sum Wgts)

620

\section{t Test}

MOP-CONTROL

Assuming equal variances

Difference $\quad 0.532451$ t Ratio $\quad 3.180353$ 
Std Err Dif

Upper CL Dif

Lower CL Dif

Confidence
$0.167419 \mathrm{DF}$

0.861229 Prob $>|\mathrm{t}|$

0.203672 Prob >t

0.95 Prob $<\mathrm{t}$
618

$0.0015 *$

$0.0008 *$

0.9992

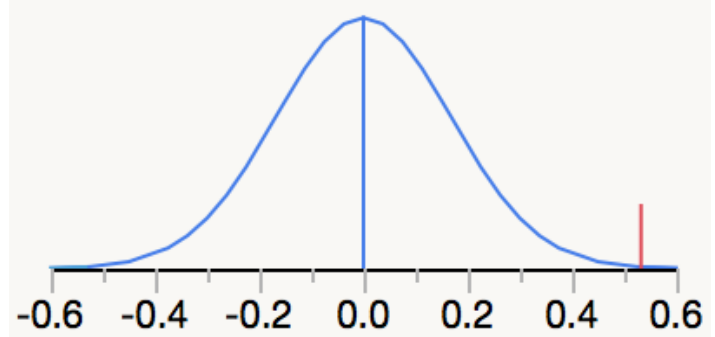

Analysis of Variance

\begin{tabular}{|c|c|c|c|c|c|}
\hline Source & DF & Sum of Squares & Mean Square & F Ratio & Prob $>$ F \\
\hline Group & 1 & 43.4145 & 43.4145 & 10.1146 & $0.0015 *$ \\
\hline Error & 618 & 2652.6036 & 4.2922 & & \\
\hline C. Total & 619 & 2696.0181 & & & \\
\hline
\end{tabular}

Means for Oneway Anova

$\begin{array}{lrrrrr}\text { Level } & \text { Number } & \text { Mean } & \text { Std Error } & \text { Lower 95\% } & \text { Upper95\% } \\ \text { CONTROL } & 344 & 2.76073 & 0.11170 & 2.5414 & 2.9801 \\ \text { MOP } & 276 & 3.29318 & 0.12471 & 3.0483 & 3.5381\end{array}$

Std Error uses a pooled estimate of error variance 
Oneway Analysis of Data By Group parameter $=\Delta x^{\circ}, \operatorname{Arch}=$ Lower

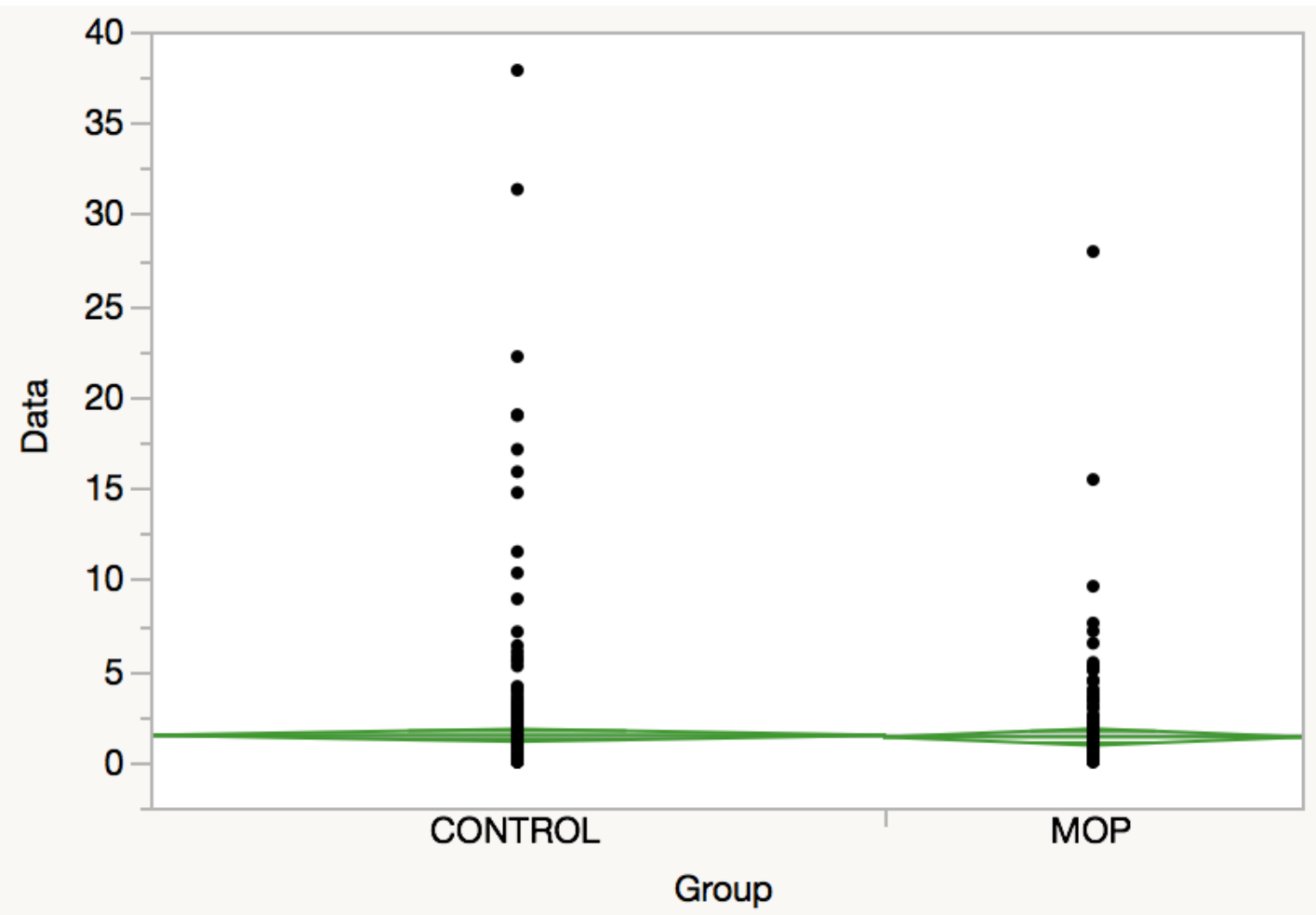

Missing Rows 78

Oneway Anova

Summary of Fit

Rsquare

Adj Rsquare

Root Mean Square Error

Mean of Response

Observations (or Sum Wgts)
0.000205

$-0.00161$

3.278466

1.42315

552

\section{t Test}

MOP-CONTROL

Assuming equal variances

Difference

-0.09738 t Ratio

$-0.33545$ 
Std Err Dif

Upper CL Dif

Lower CL Dif

Confidence
$0.29030 \mathrm{DF}$

0.47286 Prob $>|t|$

-0.66762 Prob >t

0.95 Prob $<\mathrm{t}$
550

0.7374

0.6313

0.3687

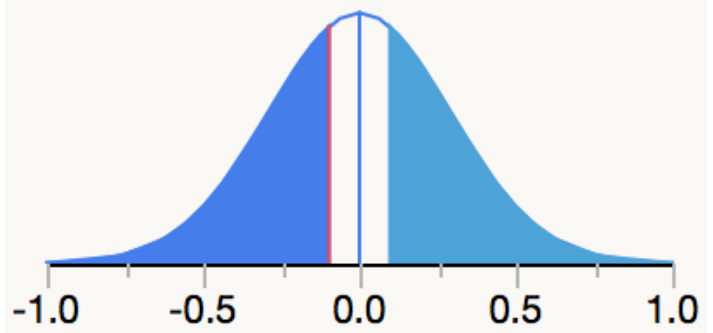

Analysis of Variance

\begin{tabular}{|c|c|c|c|c|c|}
\hline Source & DF & Sum of Squares & Mean Square & F Ratio & Prob $>$ F \\
\hline Group & 1 & 1.2095 & 1.2095 & 0.1125 & 0.7374 \\
\hline Error & 550 & 5911.5872 & 10.7483 & & \\
\hline C. Total & 551 & 5912.7967 & & & \\
\hline
\end{tabular}

Means for Oneway Anova

$\begin{array}{lrrrrr}\text { Level } & \text { Number } & \text { Mean } & \text { Std Error } & \text { Lower 95\% } & \text { Upper95\% } \\ \text { CONTROL } & 352 & 1.45843 & 0.17474 & 1.1152 & 1.8017 \\ \text { MOP } & 200 & 1.36105 & 0.23182 & 0.9057 & 1.8164\end{array}$

Std Error uses a pooled estimate of error variance 
Oneway Analysis of Data By Group parameter $=\Delta x^{\circ}, \operatorname{Arch}=$ Upper

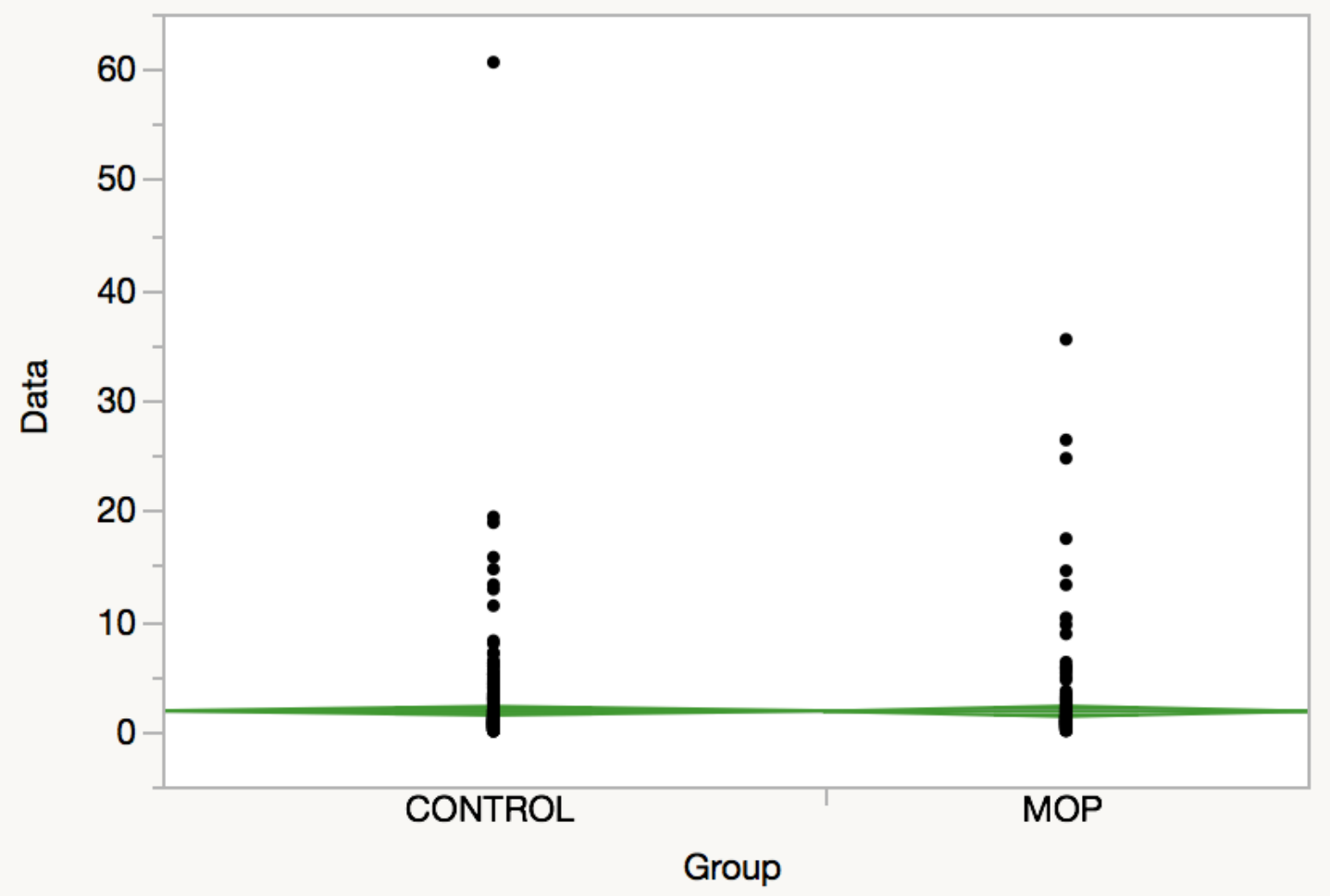

Missing Rows 37

Oneway Anova

Summary of Fit

Rsquare

Adj Rsquare

Root Mean Square Error

Mean of Response

Observations (or Sum Wgts)

t Test

MOP-CONTROL

Assuming equal variances

Difference

-0.04600 t Ratio

$-0.14295$ 
Std Err Dif

Upper CL Dif

Lower CL Dif

Confidence
$0.32177 \mathrm{DF}$

0.58596 Prob $>|t|$

-0.67796 Prob >t

0.95 Prob $<\mathrm{t}$
591

0.8864

0.5568

0.4432

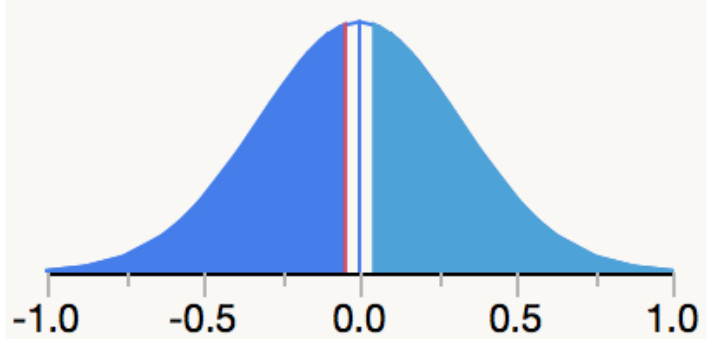

Analysis of Variance

\begin{tabular}{|c|c|c|c|c|c|}
\hline Source & DF & Sum of Squares & Mean Square & F Ratio & Prob $>$ F \\
\hline Group & 1 & 0.3060 & 0.3060 & 0.0204 & 0.8864 \\
\hline Error & 591 & 8848.4340 & 14.9720 & & \\
\hline C. Total & 592 & 8848.7400 & & & \\
\hline
\end{tabular}

Means for Oneway Anova

$\begin{array}{lrrrrr}\text { Level } & \text { Number } & \text { Mean } & \text { Std Error } & \text { Lower 95\% } & \text { Upper95\% } \\ \text { CONTROL } & 343 & 1.84207 & 0.20893 & 1.4317 & 2.2524 \\ \text { MOP } & 250 & 1.79607 & 0.24472 & 1.3154 & 2.2767\end{array}$

Std Error uses a pooled estimate of error variance 
Oneway Analysis of Data By Group parameter $=\Delta y^{\circ}, \operatorname{Arch}=$ Lower

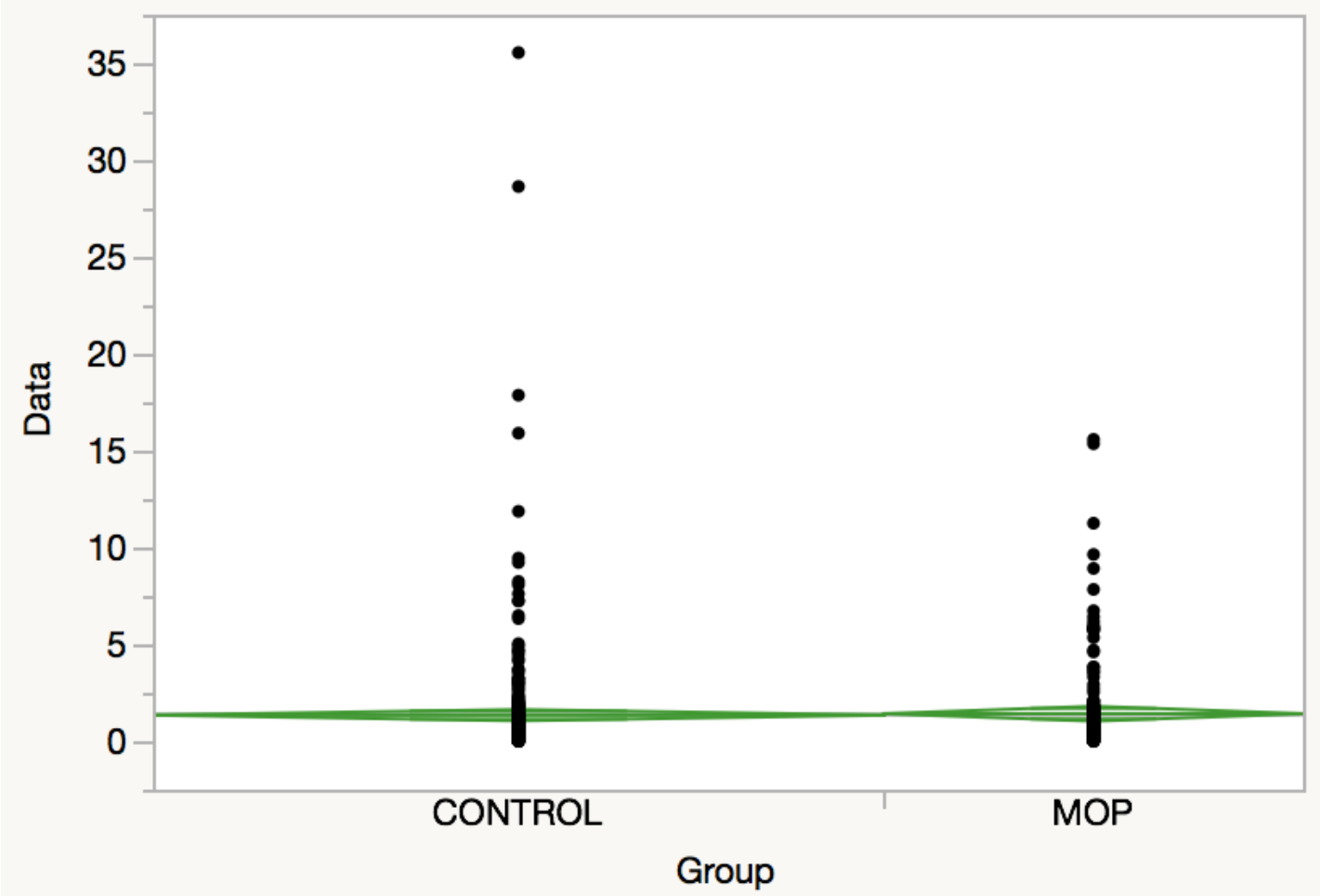

Missing Rows 78

Oneway Anova

Summary of Fit

Rsquare

Adj Rsquare

Root Mean Square Error

Mean of Response

Observations (or Sum Wgts)

t Test

MOP-CONTROL

Assuming equal variances

Difference

0.07490 t Ratio

0.30475 
Std Err Dif

Upper CL Dif

Lower CL Dif

Confidence
$0.24578 \mathrm{DF}$

0.55767 Prob $>|t|$

-0.40787 Prob > t

0.95 Prob $<\mathrm{t}$
550

0.7607

0.3803

0.6197

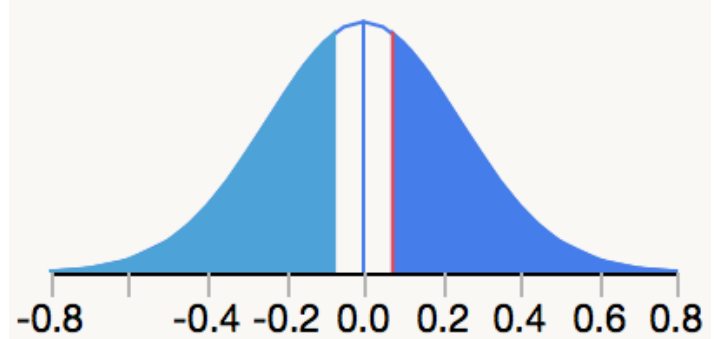

Analysis of Variance

$\begin{array}{lrrrrr}\text { Source } & \text { DF } & \text { Sum of Squares } & \text { Mean Square } & \text { F Ratio } & \text { Prob > F } \\ \text { Group } & 1 & 0.7170 & 0.71702 & 0.0929 & 0.7607 \\ \text { Error } & 550 & 4246.2439 & 7.72044 & & \\ \text { C. Total } & 551 & 4246.9609 & & \end{array}$

Means for Oneway Anova

$\begin{array}{lrrrrr}\text { Level } & \text { Number } & \text { Mean } & \text { Std Error } & \text { Lower 95\% } & \text { Upper95\% } \\ \text { CONTROL } & 351 & 1.34486 & 0.14831 & 1.0535 & 1.6362 \\ \text { MOP } & 201 & 1.41976 & 0.19599 & 1.0348 & 1.8047\end{array}$

Std Error uses a pooled estimate of error variance 
Oneway Analysis of Data By Group parameter $=\Delta y^{\circ}, \operatorname{Arch}=$ Upper

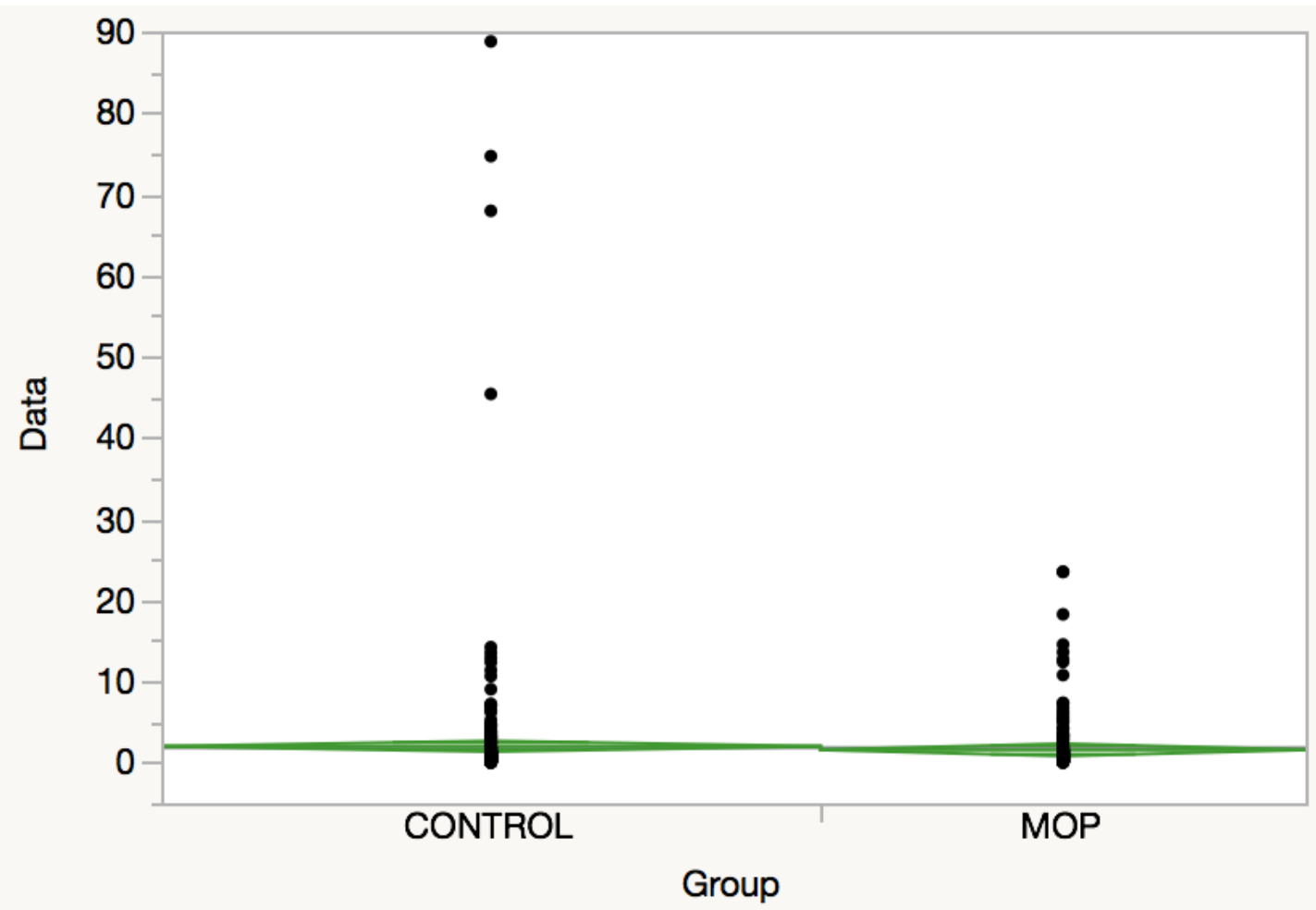

Missing Rows 33

Oneway Anova

Summary of Fit

Rsquare

Adj Rsquare

Root Mean Square Error

Mean of Response

Observations (or Sum Wgts)
0.001217

$-0.00046$

6.19614

1.8112

597

\section{t Test}

MOP-CONTROL

Assuming equal variances

Difference

-0.4369 t Ratio

$-0.85133$ 
Std Err Dif

Upper CL Dif

Lower CL Dif

Confidence
$0.5132 \mathrm{DF}$

0.5710 Prob $>|t|$

-1.4447 Prob $>\mathrm{t}$

0.95 Prob $<\mathrm{t}$
595

0.3949

0.8025

0.1975

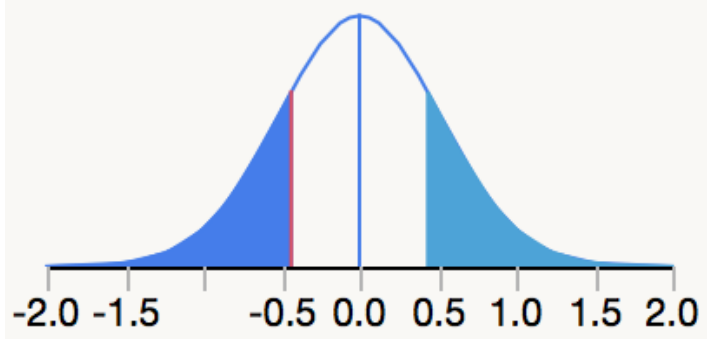

Analysis of Variance

$\begin{array}{lrrrrr}\text { Source } & \text { DF } & \text { Sum of Squares } & \text { Mean Square } & \text { F Ratio } & \text { Prob > F } \\ \text { Group } & 1 & 27.825 & 27.8253 & 0.7248 & 0.3949 \\ \text { Error } & 595 & 22843.329 & 38.3921 & & \\ \text { C. Total } & 596 & 22871.154 & & \end{array}$

Means for Oneway Anova

$\begin{array}{lrrrrr}\text { Level } & \text { Number } & \text { Mean } & \text { Std Error } & \text { Lower 95\% } & \text { Upper 95\% } \\ \text { CONTROL } & 344 & 1.99635 & 0.33407 & 1.3402 & 2.6525 \\ \text { MOP } & 253 & 1.55946 & 0.38955 & 0.7944 & 2.3245\end{array}$

Std Error uses a pooled estimate of error variance 
Oneway Analysis of Data By Group parameter $=\Delta z^{\circ}, \operatorname{Arch}=$ Lower

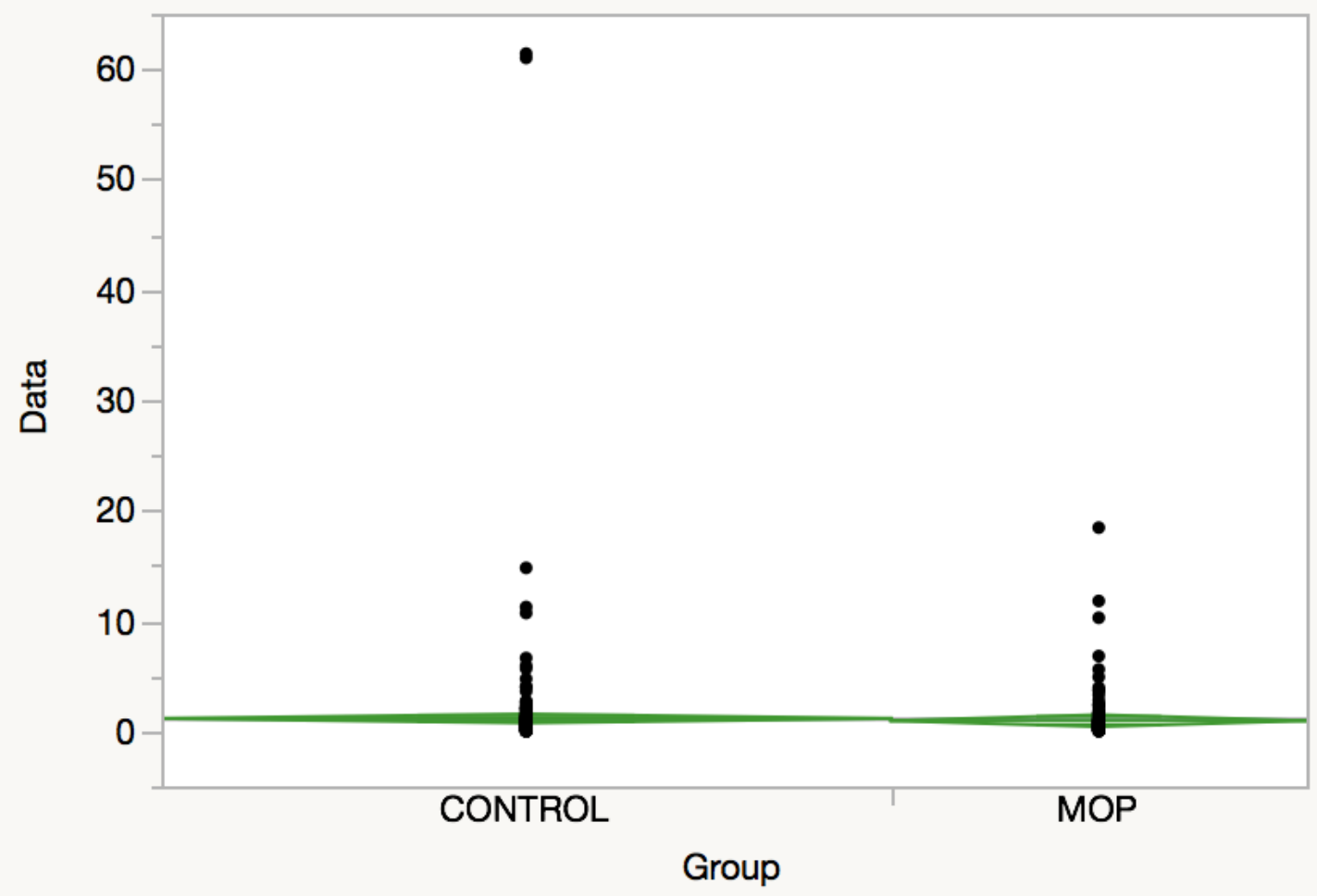

Missing Rows 76

Oneway Anova

Summary of Fit

Rsquare

Adj Rsquare

Root Mean Square Error

Mean of Response

Observations (or Sum Wgts)

t Test

MOP-CONTROL

Assuming equal variances

Difference

-0.20438 t Ratio
0.000625

$-0.00119$

3.938009

1.068048

554 
Std Err Dif

Upper CL Dif

Lower CL Dif

Confidence
$0.34797 \mathrm{DF}$

0.47913 Prob $>|t|$

-0.88790 Prob $>\mathrm{t}$

0.95 Prob $<\mathrm{t}$

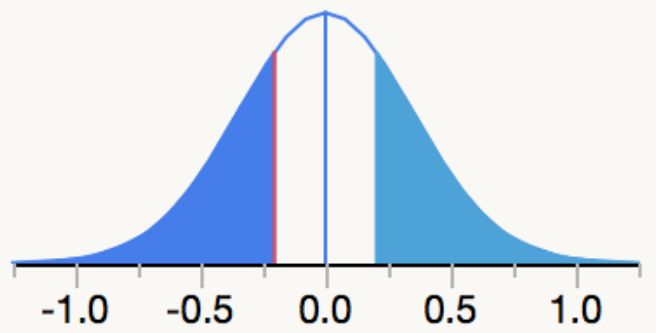

552

0.5572

0.7214

0.2786

Analysis of Variance

\begin{tabular}{|c|c|c|c|c|c|}
\hline Source & DF & Sum of Squares & Mean Square & F Ratio & Prob $>$ F \\
\hline Group & 1 & 5.3499 & 5.3499 & 0.3450 & 0.5572 \\
\hline Error & 552 & 8560.3697 & 15.5079 & & \\
\hline C. Total & 553 & 8565.7197 & & & \\
\hline
\end{tabular}

Means for Oneway Anova

$\begin{array}{lrrrrr}\text { Level } & \text { Number } & \text { Mean } & \text { Std Error } & \text { Lower 95\% } & \text { Upper95\% } \\ \text { CONTROL } & 353 & 1.14220 & 0.20960 & 0.73049 & 1.5539 \\ \text { MOP } & 201 & 0.93782 & 0.27777 & 0.39221 & 1.4834\end{array}$

Std Error uses a pooled estimate of error variance 
Oneway Analysis of Data By Group parameter $=\Delta z^{\circ}, \operatorname{Arch}=$ Upper

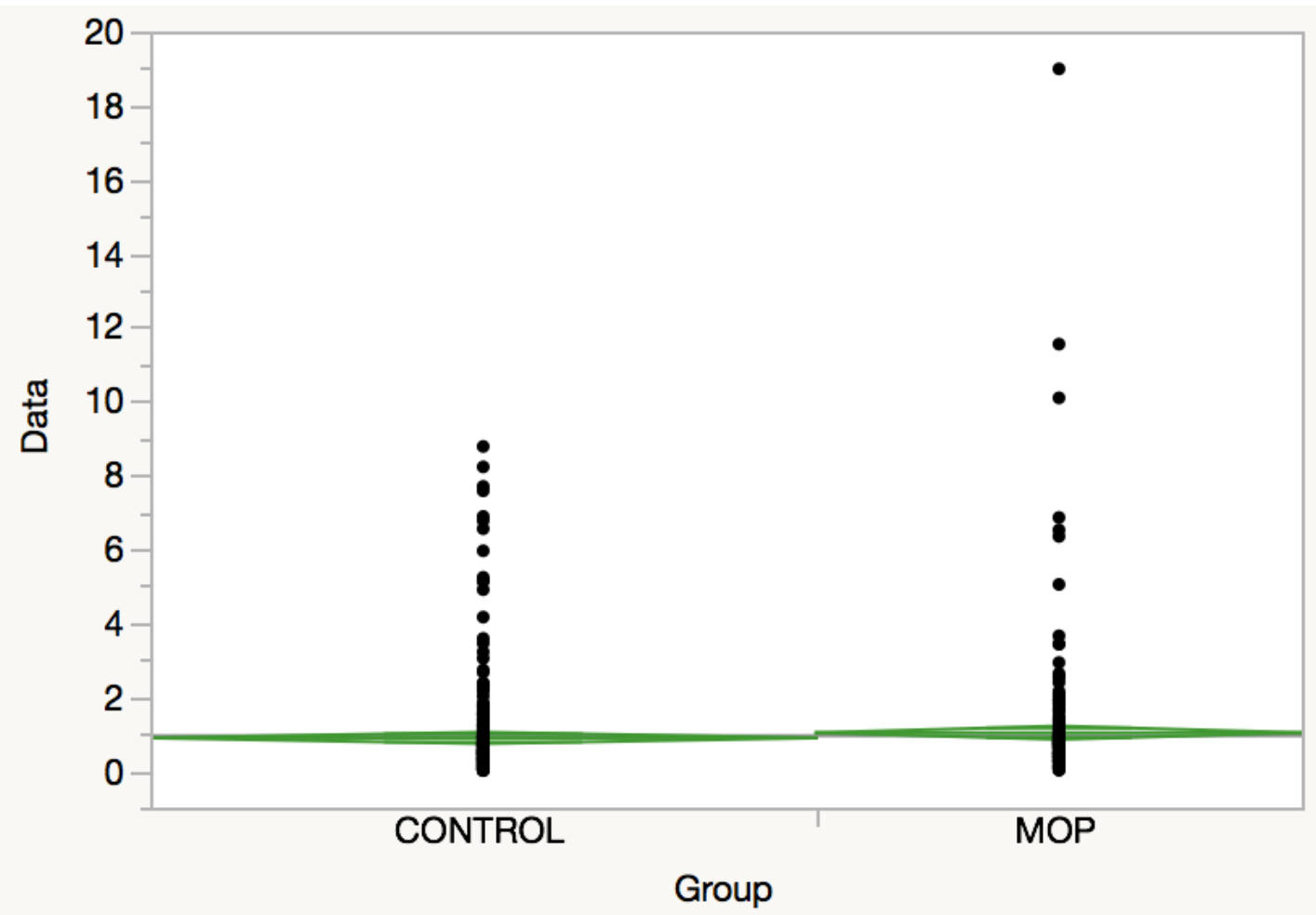

Missing Rows 37

Oneway Anova

Summary of Fit

Rsquare

Adj Rsquare

Root Mean Square Error

Mean of Response

Observations (or Sum Wgts)

t Test

MOP-CONTROL

Assuming equal variances

Difference

0.14068 t Ratio

1.159753 
Std Err Dif

Upper CL Dif

Lower CL Dif

Confidence
$0.12130 \mathrm{DF}$

0.37892 Prob $>|t|$

-0.09756 Prob >t

0.95 Prob $<\mathrm{t}$
591

0.2466

0.1233

0.8767

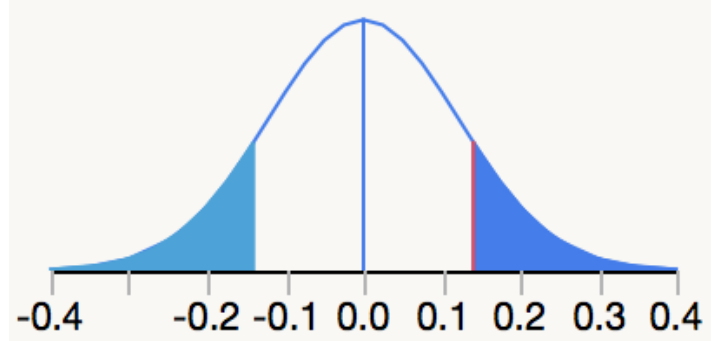

Analysis of Variance

$\begin{array}{lrrrrr}\text { Source } & \text { DF } & \text { Sum of Squares } & \text { Mean Square } & \text { F Ratio } & \text { Prob > F } \\ \text { Group } & 1 & 2.8619 & 2.86194 & 1.3450 & 0.2466 \\ \text { Error } & 591 & 1257.5267 & 2.12779 & & \\ \text { C. Total } & 592 & 1260.3886 & & \end{array}$

Means for Oneway Anova

$\begin{array}{lrrrrr}\text { Level } & \text { Number } & \text { Mean } & \text { Std Error } & \text { Lower 95\% } & \text { Upper 95\% } \\ \text { CONTROL } & 343 & 0.88296 & 0.07876 & 0.72827 & 1.0376 \\ \text { MOP } & 250 & 1.02364 & 0.09226 & 0.84245 & 1.2048\end{array}$

Std Error uses a pooled estimate of error variance 


\section{GENDER}

Response Data parameter $=\Delta V$

Analysis of Variance

\begin{tabular}{lrrrr} 
Source & DF & Sum of Squares & Mean Square & F Ratio \\
\hline Model & 3 & 62.6285 & 20.8762 & 4.7501 \\
\hline Error & 1246 & 5476.0418 & 4.3949 & Prob > F \\
C. Total & 1249 & 5538.6703 & & $0.0027 * 6$
\end{tabular}

Parameter Estimates

\begin{tabular}{|c|c|c|c|c|}
\hline Term & Estimate & Std Error & t Ratio & $\operatorname{Prob}>|\mathbf{t}|$ \\
\hline In tercept & 2.8031036 & 0.064155 & 43.69 & $<.0001 *$ \\
\hline Gender $[F]$ & -0.225228 & 0.064155 & -3.51 & $0.0005 *$ \\
\hline Group [CONTROL] & -0.124465 & 0.064155 & -1.94 & 0.0526 \\
\hline Gender $[\mathrm{F}] *$ Group [CONTROL] & 0.0604603 & 0.064155 & 0.94 & 0.3462 \\
\hline
\end{tabular}

Effect Details

Gender

Least Squares Means Table

\begin{tabular}{lrrr} 
Level & Least Sq Mean & Std Error & Mean \\
\hline F & 2.5778754 & 0.07304577 & 2.57532 \\
M & 3.0283317 & 0.10548735 & 2.97916
\end{tabular}


LS Means Plot

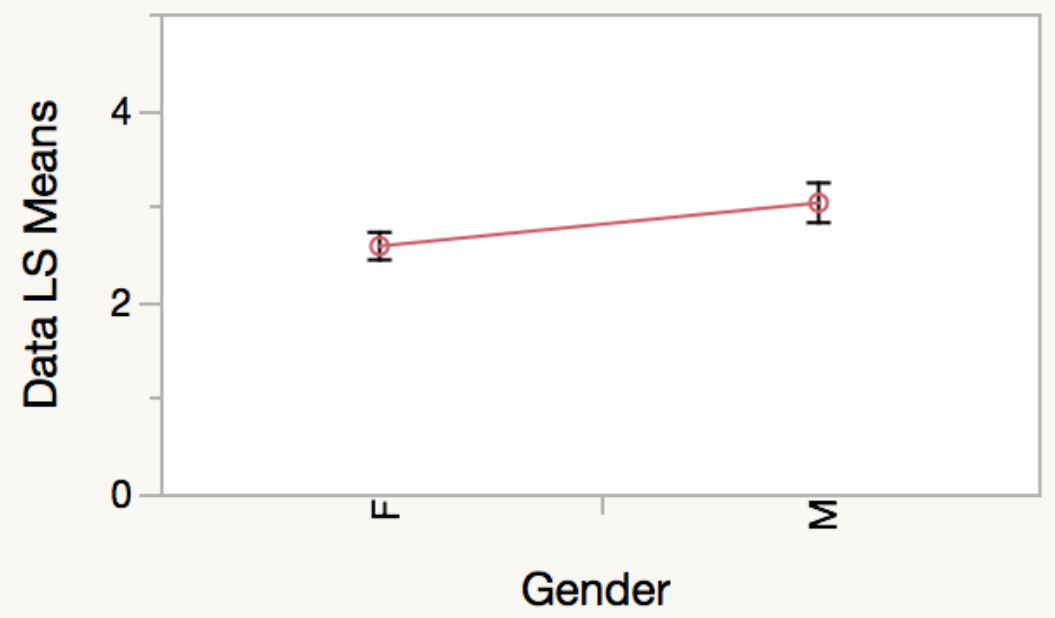

Group

Least Squares Means Table

$\begin{array}{lrrr}\text { Level } & \text { Least Sq Mean } & \text { Std Error } & \text { Mean } \\ \text { CONTROL } & 2.6786382 & 0.08152058 & 2.64087 \\ \text { MOP } & 2.9275689 & 0.09908411 & 2.80336\end{array}$

LS Means Plot

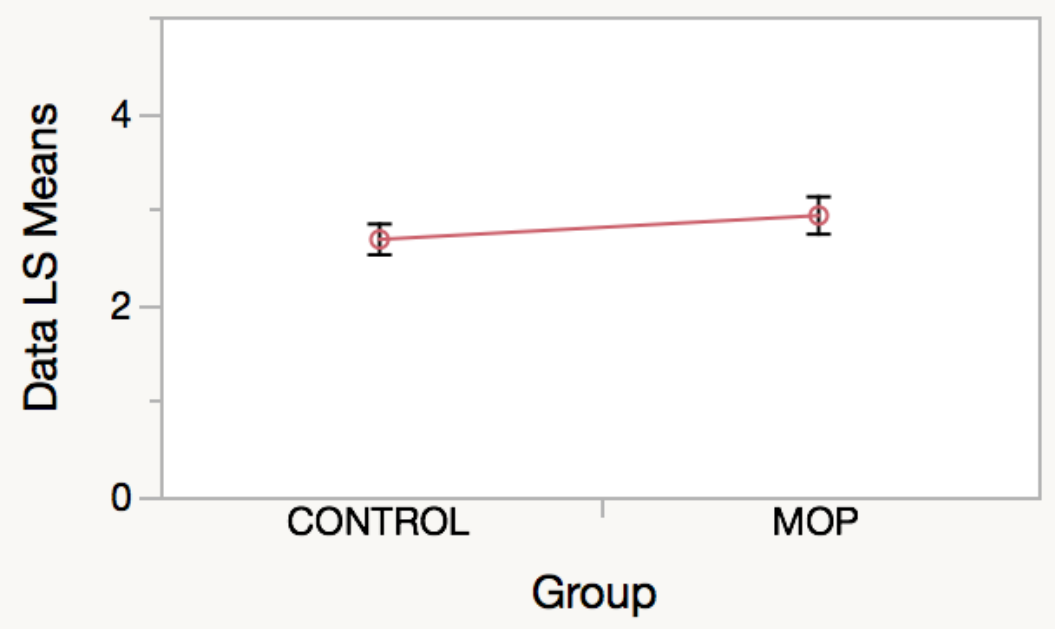


Gender*Group

Least Squares Means Table

\begin{tabular}{lrr} 
Level & Least Sq Mean & Std Error \\
\hline F,CONTROL & 2.5138704 & 0.10121519 \\
F,MOP & 2.6418804 & 0.10534811 \\
M,CONTROL & 2.8434061 & 0.12781982 \\
M,MOP & 3.2132574 & 0.16784641
\end{tabular}

LS Means Plot

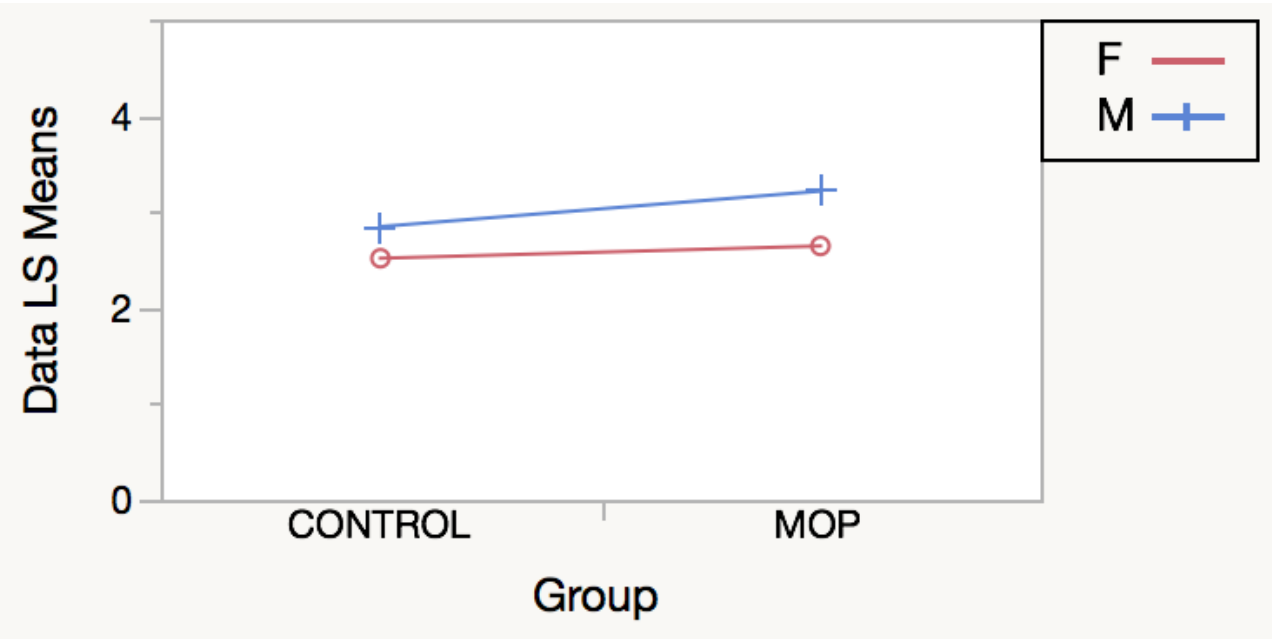

Response Data parameter $=\Delta x^{\circ}$

Analysis of Variance

\begin{tabular}{lrrrr} 
Source & DF & Sum of Squares & Mean Square & F Ratio \\
\hline Model & 3 & 28.039 & 9.3463 & 0.7216 \\
\hline Error & 1141 & 14779.132 & 12.9528 & Prob > F \\
\hline C. Total & 1144 & 14807.171 & & 0.5392
\end{tabular}


Parameter Estimates

$\begin{array}{lcccc}\text { Term } & \text { Estimate } & \text { Std Error } & \text { t Ratio } & \text { Prob>|t| } \\ \text { Intercept } & 1.5845063 & 0.115811 & 13.68 & <.0001 * \\ \text { Gender[F] } & 0.143712 & 0.115811 & 1.24 & 0.2149 \\ \text { Group [CONTROL] } & 0.0196779 & 0.115811 & 0.17 & 0.8651 \\ \text { Gender[F]*Group [CONTROL] } & 0.0468023 & 0.115811 & 0.40 & 0.6862\end{array}$

Effect Details

Gender

Least Squares Means Table

$\begin{array}{lrrr}\text { Level } & \text { Least Sq Mean } & \text { Std Error } & \text { Mean } \\ \text { F } & 1.7282183 & 0.13390025 & 1.73846 \\ \text { M } & 1.4407943 & 0.18899550 & 1.43202\end{array}$

LS Means Plot

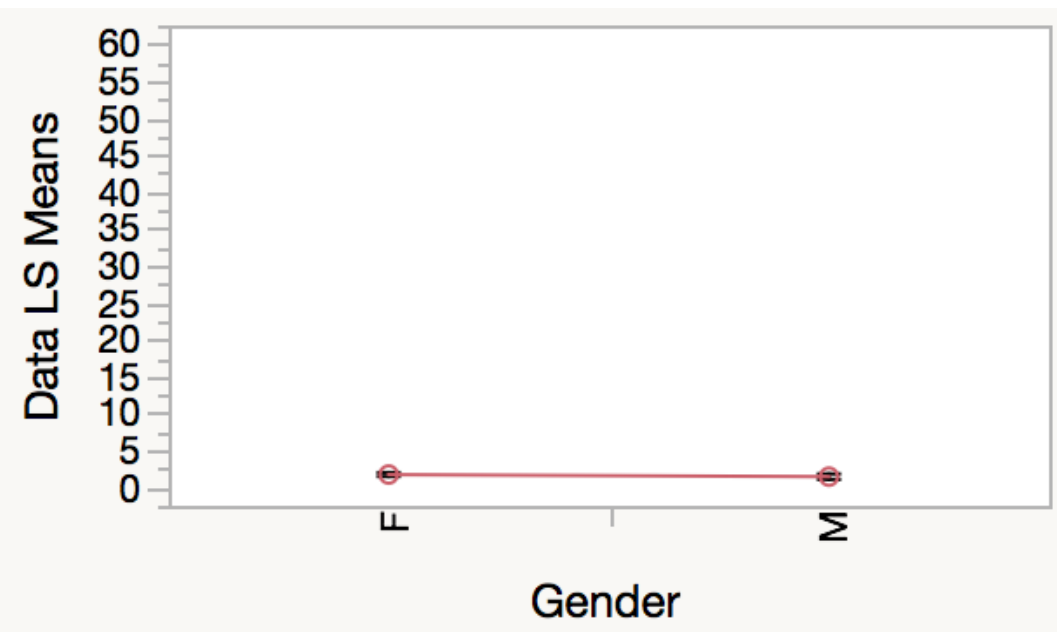

\section{Group}

Least Squares Means Table

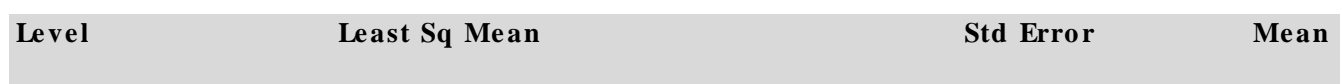




$\begin{array}{lrrr}\text { Level } & \text { Least Sq Mean } & \text { Std Error } & \text { Mean } \\ \text { CONTROL } & 1.6041843 & 0.14023703 & 1.64777 \\ \text { MOP } & 1.5648284 & 0.18434249 & 1.60273\end{array}$

LS Means Plot

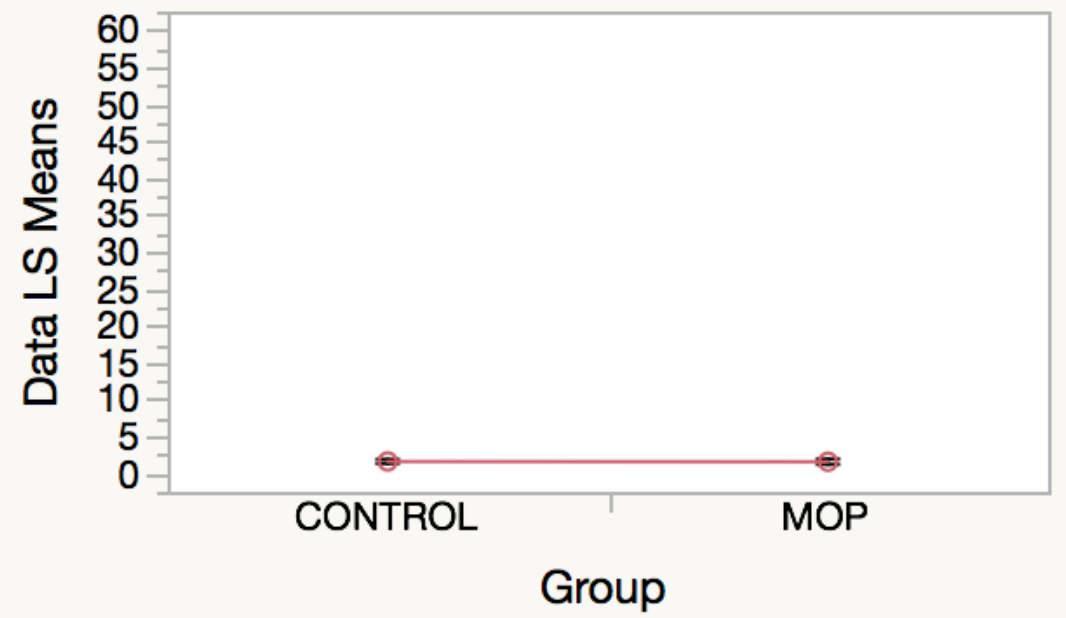

Gender*Group

Least Squares Means Table

$\begin{array}{lrr}\text { Level } & \text { Least Sq Mean } & \text { Std Error } \\ \text { F,CONTROL } & 1.7946985 & 0.17416773 \\ \text { F,MOP } & 1.6617381 & 0.20342741 \\ \text { M,CONTROL } & 1.4136700 & 0.21984381 \\ \text { M,MOP } & 1.4679186 & 0.30748317\end{array}$


LS Means Plot

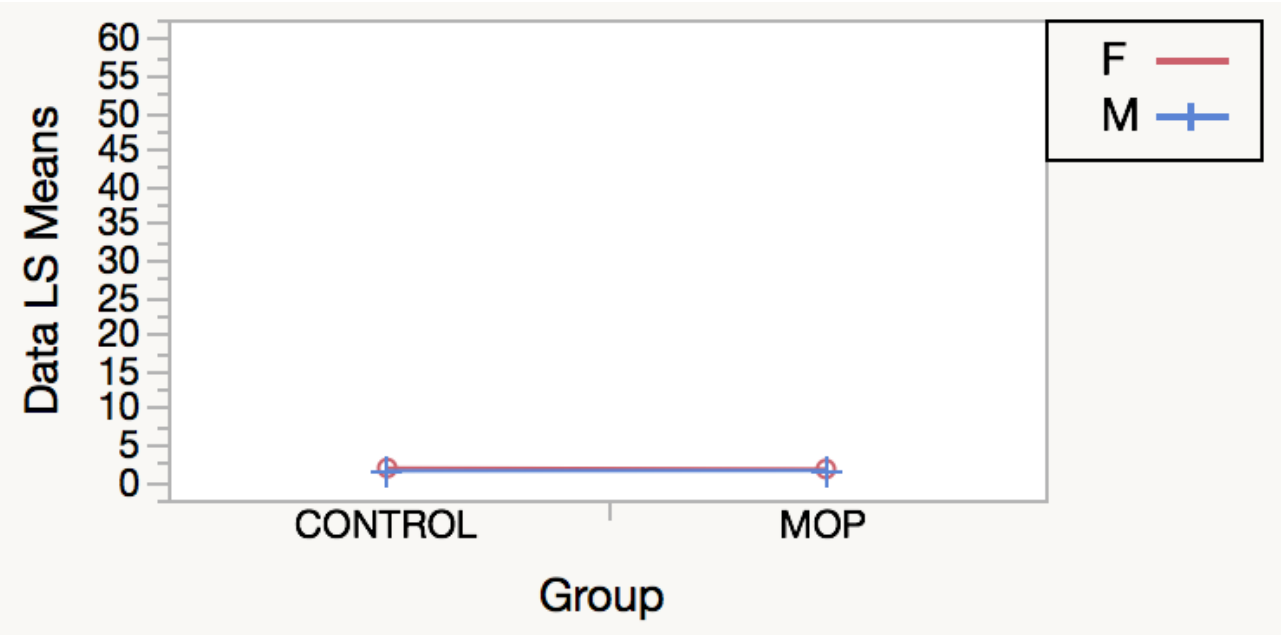

Response Data paramete $r=\Delta y^{\circ}$

Analysis of Variance

\begin{tabular}{lrrrr} 
Source & DF & Sum of Squares & Mean Square & F Ratio \\
\hline Model & 3 & 17.446 & 5.8155 & 0.2452 \\
Error & 1145 & 27155.961 & 23.7170 & Prob > F \\
C. Total & 1148 & 27173.407 & & 0.8648
\end{tabular}

Parameter Estimates

$\begin{array}{lcccr}\text { Term } & \text { Estimate } & \text { Std Error } & \text { t Ratio } & \text { Prob }>|\mathbf{t}| \\ \text { Intercept } & 1.5937065 & 0.156198 & 10.20 & <.0001 * \\ \text { Gender[F] } & -0.012004 & 0.156198 & -0.08 & 0.9388 \\ \text { Group [CONTROL] } & 0.0534302 & 0.156198 & 0.34 & 0.7324 \\ \text { Gender[F]*Group [CONTROL] } & 0.0980597 & 0.156198 & 0.63 & 0.5303\end{array}$


Effect Details

Gender

Least Squares Means Table

$\begin{array}{lrrr}\text { Level } & \text { Least Sq Mean } & \text { Std Error } & \text { Mean } \\ \text { F } & 1.5817030 & 0.18067680 & 1.60492 \\ \text { M } & 1.6057100 & 0.25484677 & 1.59172\end{array}$

LS Means Plot

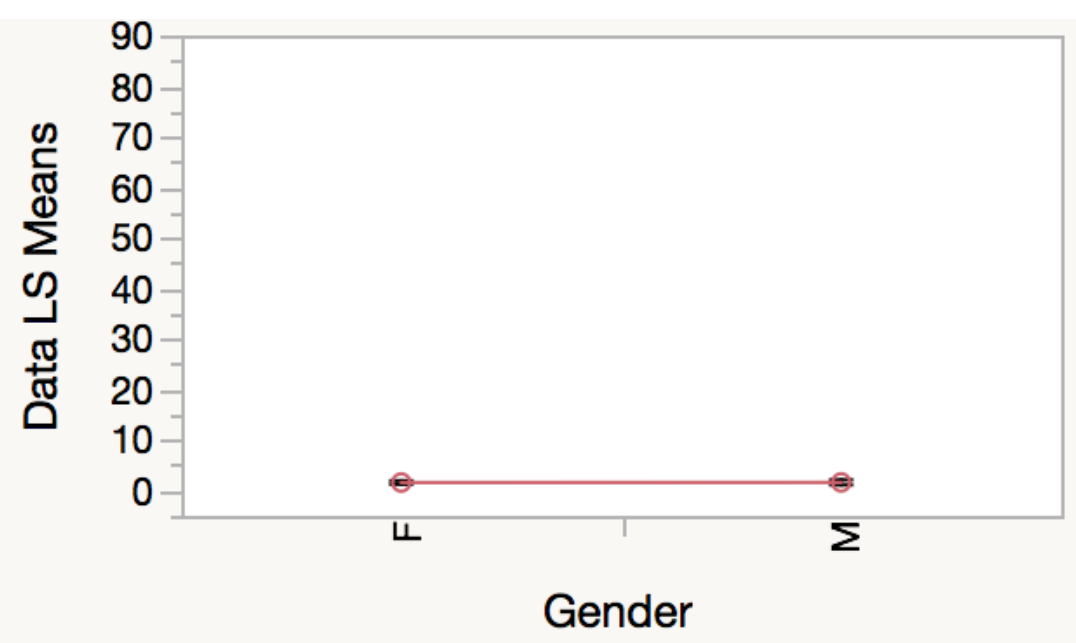

Group

Least Squares Means Table

$\begin{array}{lrrr}\text { Level } & \text { Least Sq Mean } & \text { Std Error } & \text { Mean } \\ \text { CONTROL } & 1.6471367 & 0.19003027 & 1.66732 \\ \text { MOP } & 1.5402763 & 0.24795056 & 1.49761\end{array}$


LS Means Plot

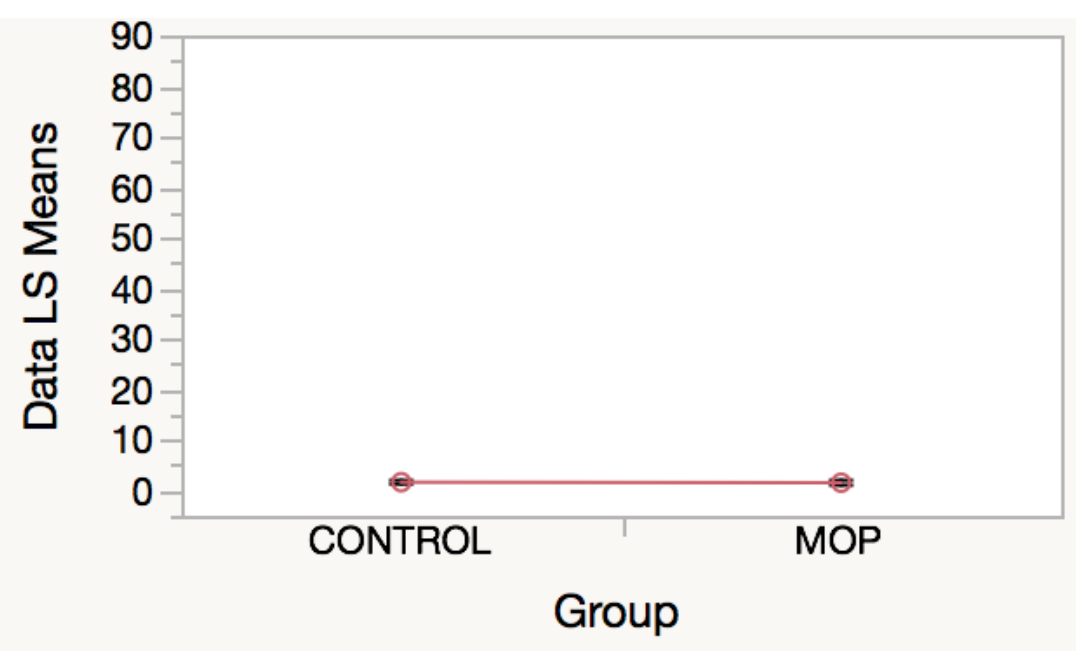

Gender*Group

Least Squares Means Table

$\begin{array}{lrr}\text { Level } & \text { Least Sq Mean } & \text { Std Error } \\ \text { F,CONTROL } & 1.7331929 & 0.23512629 \\ \text { F,MOP } & 1.4302130 & 0.27439397 \\ \text { M,CONTROL } & 1.5610805 & 0.29859947 \\ \text { M,MOP } & 1.6503395 & 0.41306885\end{array}$

LS Means Plot

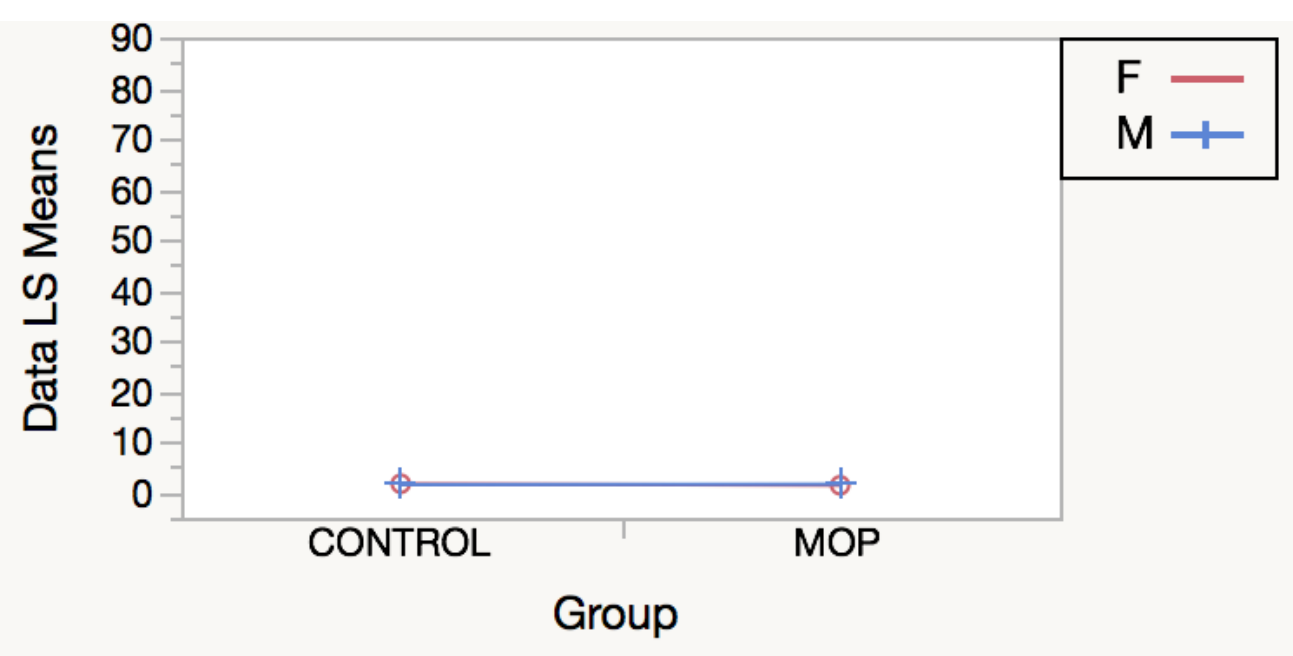


Response Data paramete $r=\Delta z^{\circ}$

Analysis of Variance

\begin{tabular}{lrrrr} 
Source & DF & Sum of Squares & Mean Square & F Ratio \\
\hline Model & 3 & 3.3260 & 1.10867 & 0.1289 \\
Error & 1143 & 9827.3137 & 8.59782 & Prob > F \\
C. Total & 1146 & 9830.6397 & 0.9429
\end{tabular}

Parameter Estimates

\begin{tabular}{|c|c|c|c|c|}
\hline Term & Estim ate & Std Error & t Ratio & Prob $>|t|$ \\
\hline In tercept & 1.0038667 & 0.094212 & 10.66 & $<.0001 *$ \\
\hline Gender $[F]$ & -0.023564 & 0.094212 & -0.25 & 0.8025 \\
\hline Gender $[\mathrm{F}]^{*}$ Group [CONTROL] & -0.043327 & 0.094212 & -0.46 & 0.6457 \\
\hline
\end{tabular}

Effect Details

Gender

Least Squares Means Table

\begin{tabular}{lrrr} 
Level & Least Sq Mean & Std Error & Mean \\
\hline F & 0.9803026 & 0.10898468 & 0.97762 \\
M & 1.0274308 & 0.15370806 & 1.04956
\end{tabular}


LS Means Plot

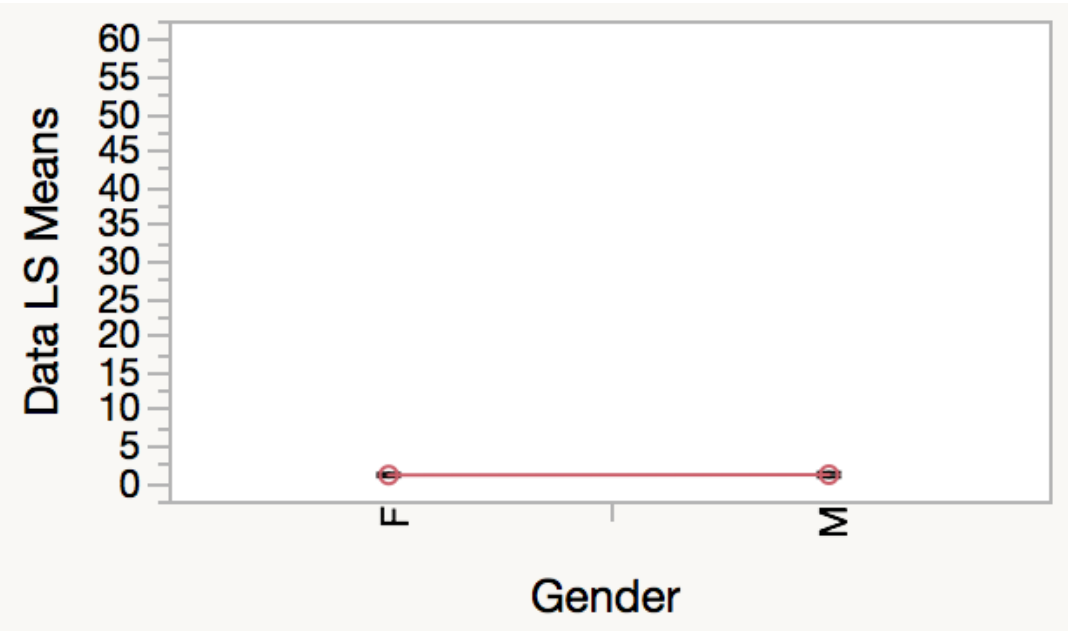

Group

Least Squares Means Table

$\begin{array}{lrrr}\text { Level } & \text { Least Sq Mean } & \text { Std Error } & \text { Mean } \\ \text { CONTROL } & 1.0300107 & 0.11428379 & 1.01444 \\ \text { MOP } & 0.9777227 & 0.14981002 & 0.98539\end{array}$

LS Means Plot

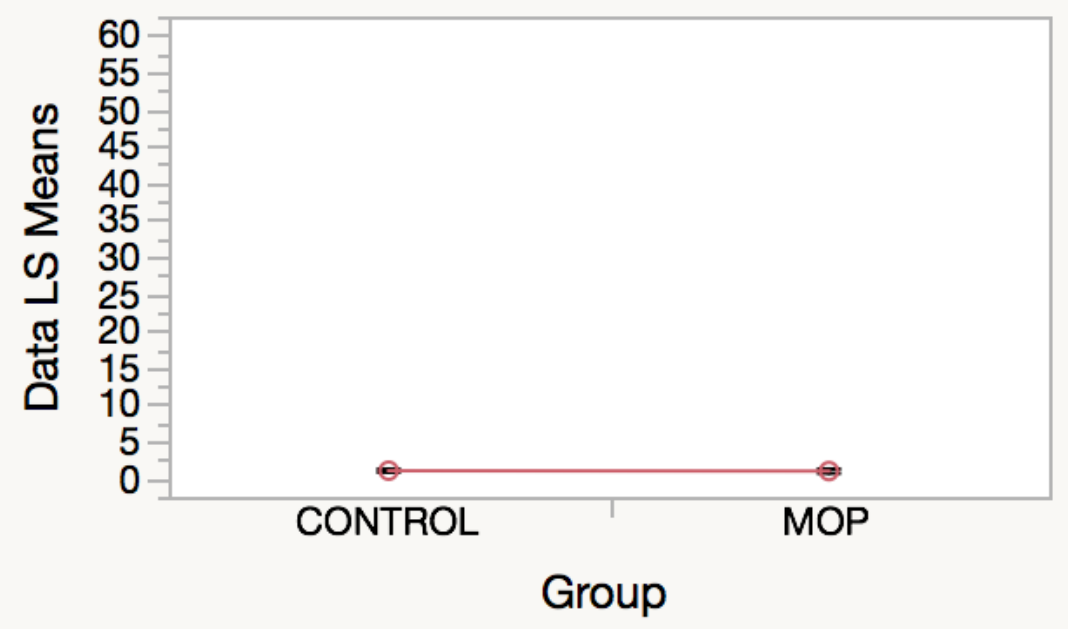


Gender*Group

Least Squares Means Table

\begin{tabular}{lrr} 
Level & Least Sq Mean & Std Error \\
\hline F,CONTROL & 0.9631201 & 0.14156818 \\
F,MOP & 0.9974851 & 0.16573801 \\
M,CONTROL & 1.0969014 & 0.17944802 \\
M,MOP & 0.9579603 & 0.24960584
\end{tabular}

LS Means Plot

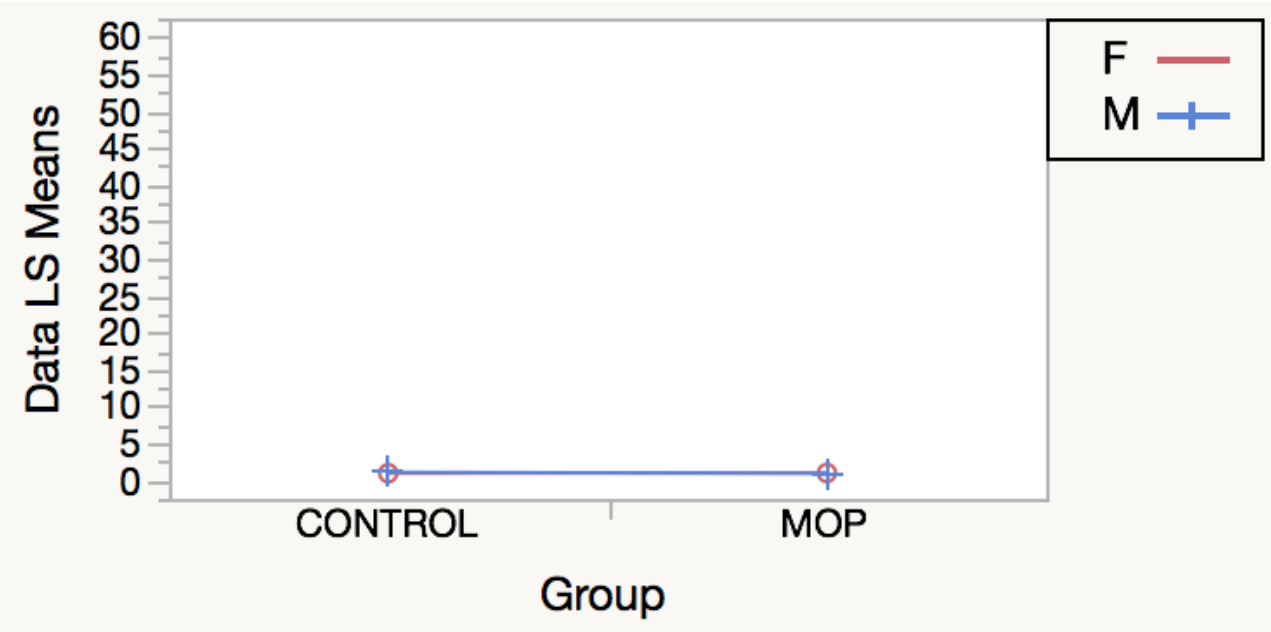

\section{$\underline{\text { AGE }}$}

Response Data parameter $=\Delta V$ 
Regression Plot

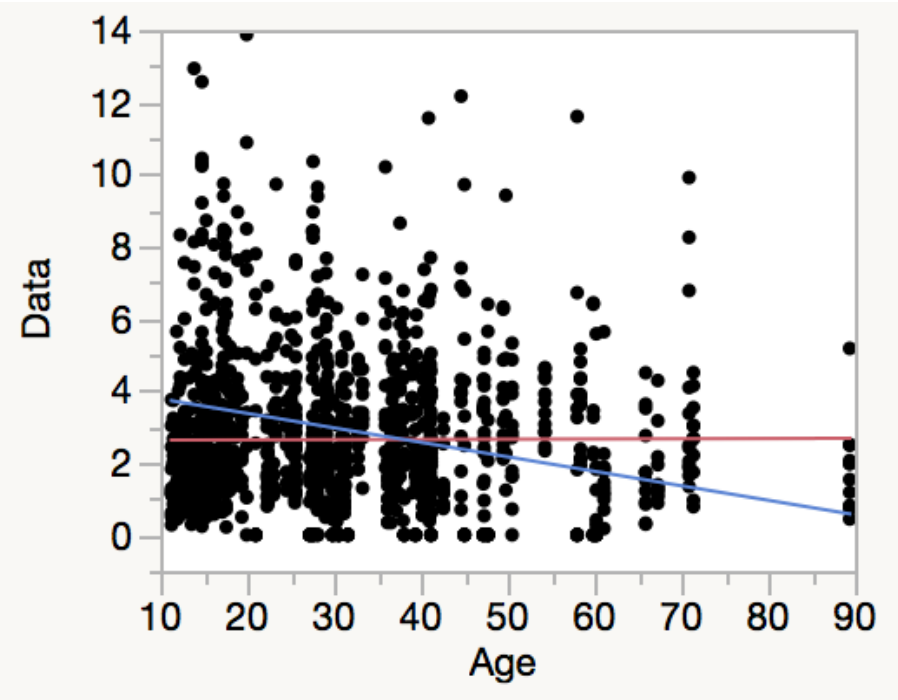

Summary of Fit

RSquare

RSquare Adj

Root Mean Square Error

Mean of Response

Observations (or Sum Wgts)
0.019423

0.017062

2.08778

2.712624

1250

Analysis of Variance

$\begin{array}{lrrrr}\text { Source } & \text { DF } & \text { Sum of Squares } & \text { Mean Square } & \text { F Ratio } \\ \text { Model } & 3 & 107.5750 & 35.8583 & 8.2266 \\ \text { Error } & 1246 & 5431.0953 & 4.3588 & \text { Prob > F } \\ \text { C. Total } & 1249 & 5538.6703 & & <.0001 *\end{array}$

Lack Of Fit

\begin{tabular}{|rrrrr|}
\hline Source & DF & Sum of Squares & Mean Square & F Ratio \\
\hline Lack Of Fit & 94 & 1208.0278 & 12.8514 & 3.5057 \\
\hline Pure Error & 1152 & 4223.0675 & 3.6659 & Prob > F
\end{tabular}




\begin{tabular}{|c|c|c|c|c|}
\hline Source & DF & Sum of Squares & Mean Square & F Ratio \\
\hline Total Error & 1246 & 5431.0953 & & $<.0001 *$ \\
\hline & & & & Max RSq \\
\hline
\end{tabular}

Parameter Estimates

$\begin{array}{lcccc}\text { Term } & \text { Estimate } & \text { Std Error } & \text { t Ratio } & \text { Prob }>|\mathbf{t}| \\ \text { In tercept } & 3.399233 & 0.166633 & 20.40 & <.0001 * \\ \text { Age } & -0.019779 & 0.004696 & -4.21 & <.0001 * \\ \text { Group [CONTROL] } & -0.141622 & 0.061028 & -2.32 & 0.0205 * \\ \text { (Age-31.103)*Group [CONTROL] } & 0.0204225 & 0.004696 & 4.35 & <.0001 *\end{array}$

Response Data parameter $=\Delta x^{\circ}$

Regression Plot

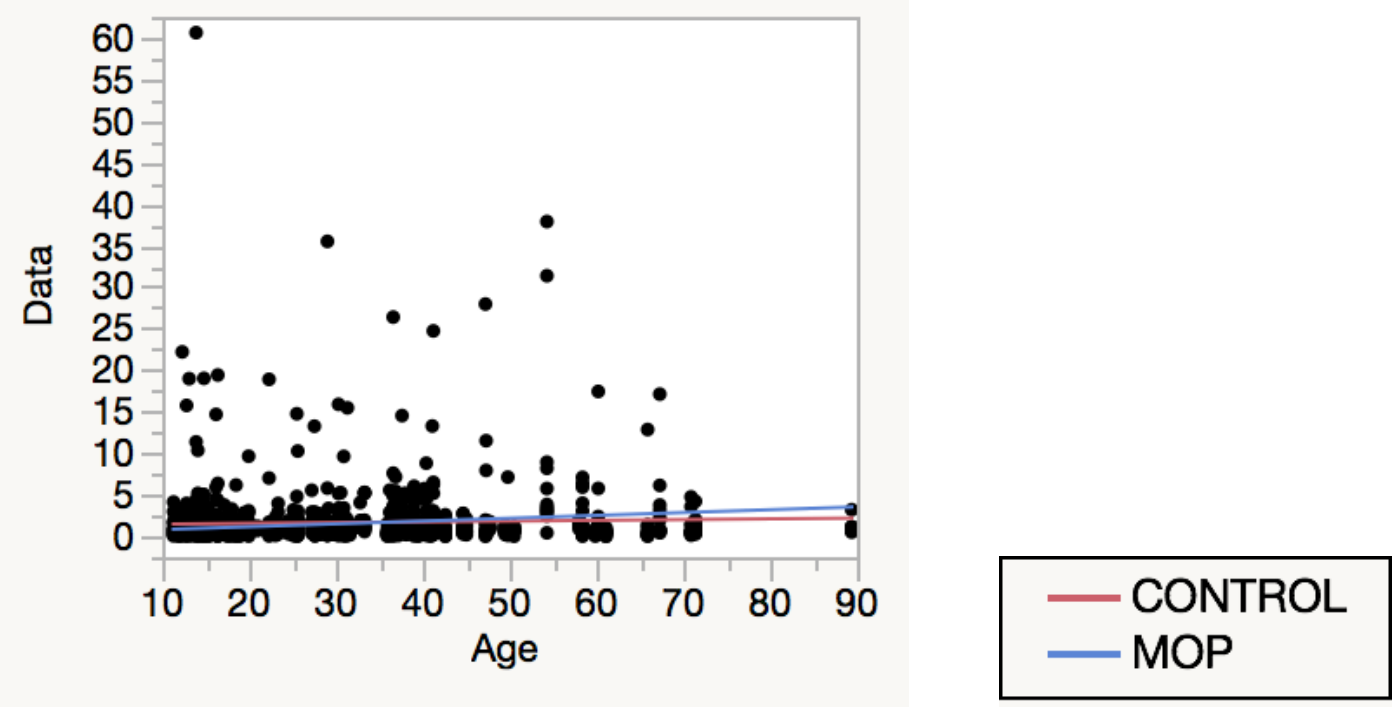


Summary of Fit

RSquare

RSquare Adj

Root Mean Square Error

Mean of Response

Observations (or Sum Wgts)
0.004856

0.002239

3.593654

1.630069

1145

Analysis of Variance

\begin{tabular}{lrrrr} 
Source & DF & Sum of Squares & Mean Square & F Ratio \\
\hline Model & 3 & 71.901 & 23.9669 & 1.8558 \\
\hline Error & 1141 & 14735.270 & 12.9143 & Prob > F \\
\hline C. Total & 1144 & 14807.171 & & 0.1353
\end{tabular}

Lack Of Fit

\begin{tabular}{|c|c|c|c|c|}
\hline Source & DF & Sum of Squares & Mean Square & F Ratio \\
\hline Lack Of Fit & 94 & 1694.837 & 18.0302 & 1.4476 \\
\hline Pure Error & 1047 & 13040.433 & 12.4550 & Prob > F \\
\hline \multirow[t]{3}{*}{ Total Error } & 1141 & 14735.270 & & $0.0047 *$ \\
\hline & & & & $\operatorname{Max}$ RSq \\
\hline & & & & 0.1193 \\
\hline
\end{tabular}

Parameter Estimates

\begin{tabular}{|c|c|c|c|c|}
\hline Term & Estim ate & Std Error & t Ratio & Prob $>|t|$ \\
\hline In tercept & 0.9318393 & 0.321624 & 2.90 & $0.0038 *$ \\
\hline Age & 0.0216664 & 0.009369 & 2.31 & $0.0209 *$ \\
\hline Group [CONTROL] & 0.0737516 & 0.111104 & 0.66 & 0.5069 \\
\hline$($ Age -30.3344$) *$ Group [CONTROL] & -0.01256 & 0.009369 & -1.34 & 0.1803 \\
\hline
\end{tabular}


Response Data paramete $r=\Delta y^{\circ}$

Regression Plot

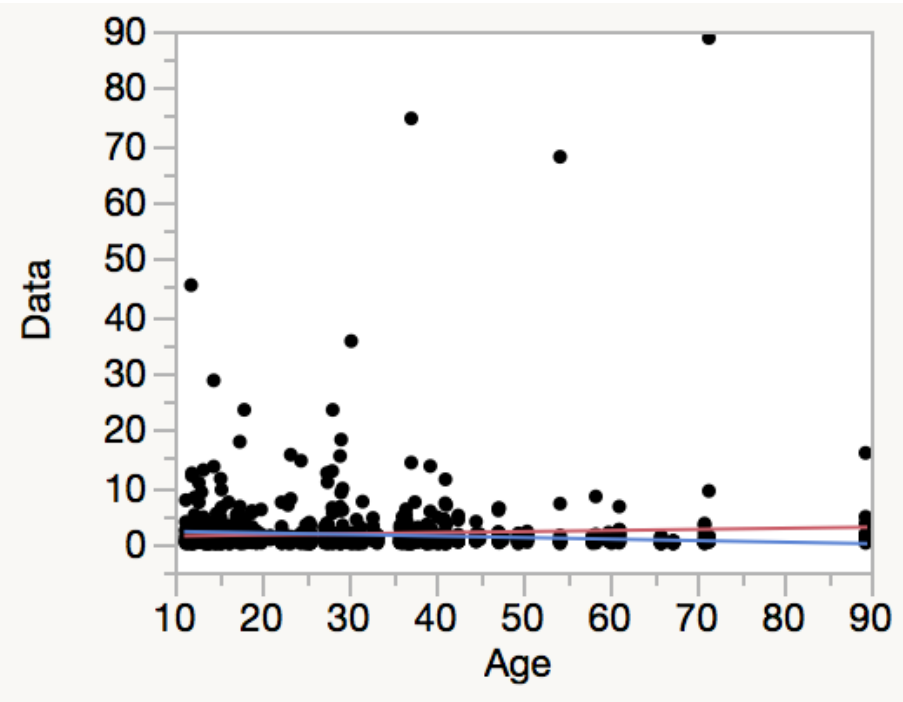

Summary of Fit

RSquare

RSquare Adj

Root Mean Square Error

Mean of Response

Observations (or Sum Wgts)
0.004954

0.002347

4.859493

1.600262

1149

Analysis of Variance

\begin{tabular}{lrrrr} 
Source & DF & Sum of Squares & Mean Square & F Ratio \\
\hline Model & 3 & 134.609 & 44.8697 & 1.9001 \\
Error & 1145 & 27038.798 & 23.6147 & Prob > F \\
C. Total & 1148 & 27173.407 & & 0.1278
\end{tabular}


Lack Of Fit

\begin{tabular}{lrrrr|} 
Source & DF & Sum of Squares & Mean Square & F Ratio \\
\hline Lack Of Fit & 94 & 2157.556 & 22.9527 & 0.9695 \\
Pure Error & 1051 & 24881.242 & 23.6739 & Prob > F \\
Total Error & 1145 & 27038.798 & & 0.5634 \\
& & & Max RSq \\
& & & 0.0844
\end{tabular}

Parameter Estimates

$\begin{array}{lrrrr}\text { Term } & \text { Estimate } & \text { Std Error } & \text { t Ratio } & \text { Prob }>|\mathbf{t}| \\ \text { Intercept } & 1.7456962 & 0.434782 & 4.02 & <.0001 * \\ \text { Age } & -0.003735 & 0.012665 & -0.29 & 0.7681 \\ \text { Group [CONTROL] } & 0.0670169 & 0.149743 & 0.45 & 0.6546 \\ \text { (Age-30.3823)*Group [CONTROL] } & 0.0232065 & 0.012665 & 1.83 & 0.0672\end{array}$

Response Data paramete $r=\Delta z^{\circ}$ 
Regression Plot
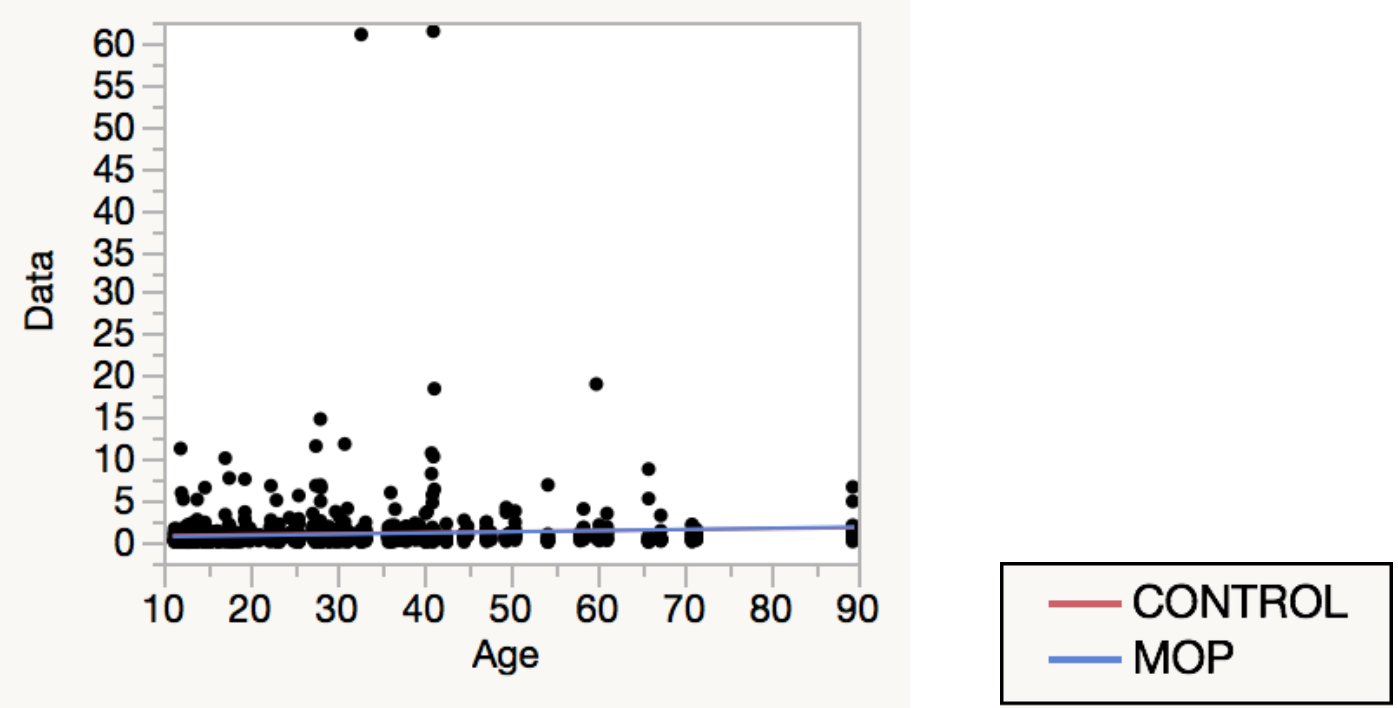

Summary of Fit

RSquare

RSquare Adj

Root Mean Square Error

Mean of Response

Observations (or Sum Wgts)
0.004628

0.002016

2.925906

1.003019

1147

Analysis of Variance

\begin{tabular}{lrrrr} 
Source & DF & Sum of Squares & Mean Square & F Ratio \\
\hline Model & 3 & 45.4992 & 15.1664 & 1.7716 \\
Error & 1143 & 9785.1405 & 8.5609 & Prob > F \\
C. Total & 1146 & 9830.6397 & & 0.1508
\end{tabular}

Lack Of Fit

\begin{tabular}{lrrrr|}
\hline Source & DF & Sum of Squares & Mean Square & F Ratio \\
\hline Lack Of Fit & 94 & 777.0652 & 8.26665 & 0.9627 \\
\hline Pure Error & 1049 & 9008.0753 & 8.58730 & Prob > F \\
\hline
\end{tabular}




\begin{tabular}{|c|c|c|c|c|}
\hline Source & DF & Sum of Squares & Mean Square & F Ratio \\
\hline Total Error & 1143 & 9785.1405 & & 0.5816 \\
\hline
\end{tabular}

$\operatorname{Max} \mathbf{R S q}$

0.0837

Parameter Estimates

\begin{tabular}{|c|c|c|c|c|}
\hline Term & Estim ate & Std Error & t Ratio & Prob $>|t|$ \\
\hline In tercept & 0.5805838 & 0.264223 & 2.20 & $0.0282 *$ \\
\hline Age & 0.0134782 & 0.007677 & 1.76 & 0.0794 \\
\hline Group [CONTROL] & 0.0443676 & 0.090508 & 0.49 & 0.6241 \\
\hline$($ Age -30.3968$) *$ Group [CONTROL] & -0.001583 & 0.007677 & -0.21 & 0.8366 \\
\hline
\end{tabular}

\section{SEVERITY OF MAL-ALIGNMENT}

Response Data Upper or Lower?=Lower, Parameters $=\Delta V$

Effect Sum mary

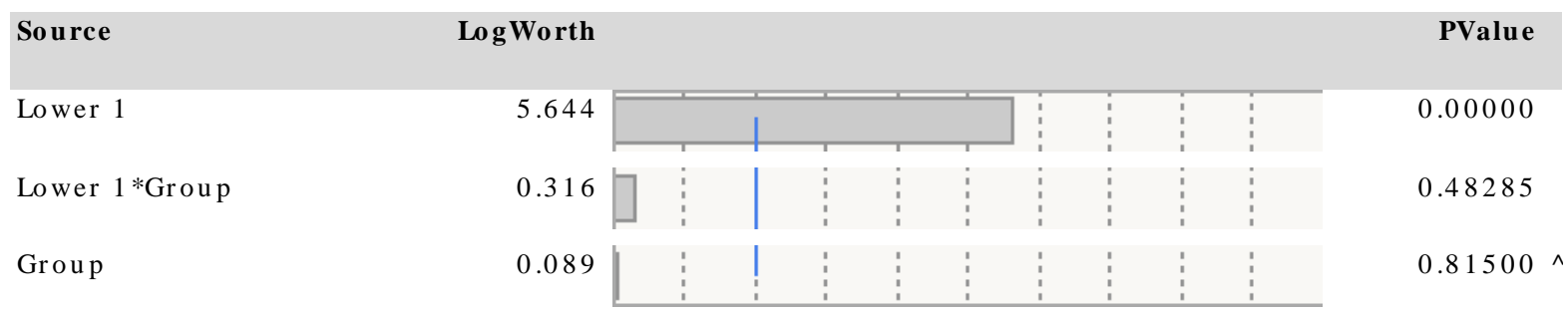


Regression Plot
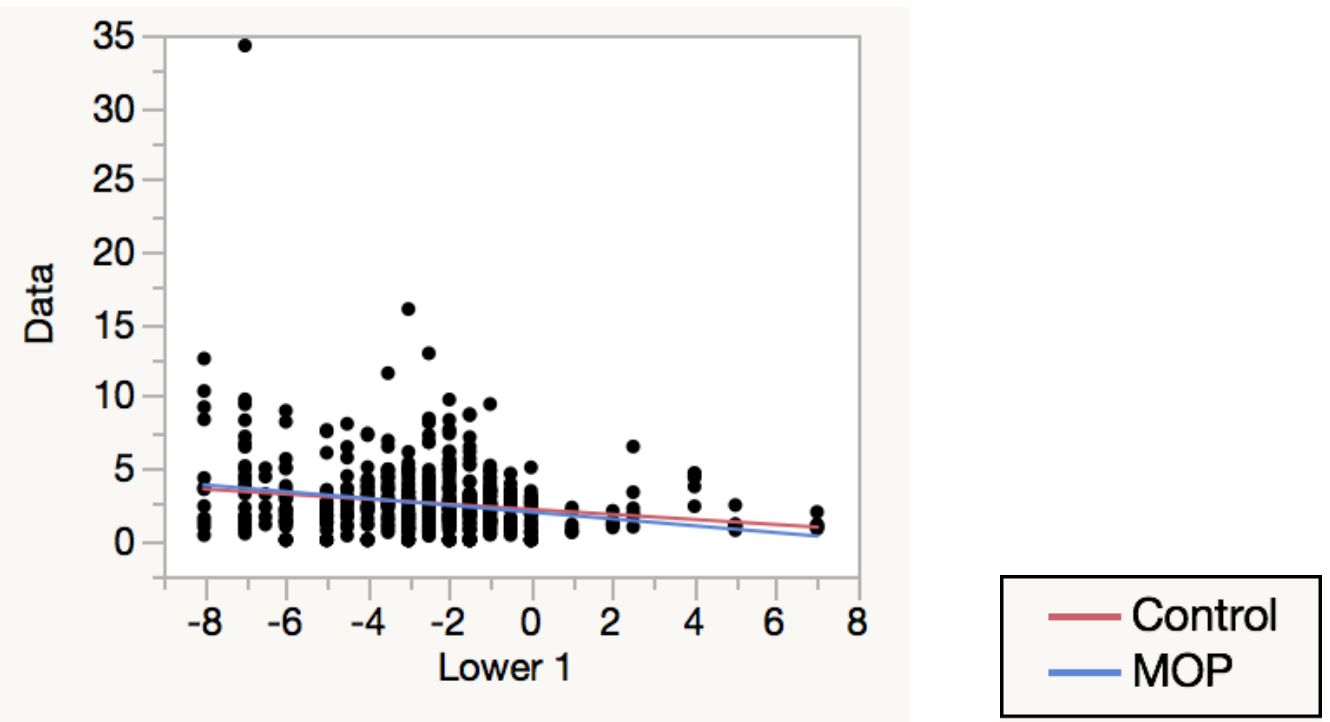

Sum mary of Fit

RSquare

RSquare Adj

Root Mean Square Error

Mean of Response

Observations (or Sum Wgts)
0.037277

0.032618

2.456496

2.535953

624

Analysis of Variance

\begin{tabular}{lrrrr} 
Source & DF & Sum of Squares & Mean Square & F Ratio \\
\hline Model & 3 & 144.8641 & 48.2880 & 8.0022 \\
Error & 620 & 3741.3110 & 6.0344 & Prob > F \\
C. Total & 623 & 3886.1751 & & $<.0001^{*}$
\end{tabular}

Lack Of Fit

\begin{tabular}{|lrrrr|}
\hline Source & DF & Sum of Squares & Mean Square & F Ratio \\
\hline Lack Of Fit & 30 & 297.5388 & 9.91796 & 1.6992 \\
\hline Pure Error & 590 & 3443.7723 & 5.83690 & Prob > F \\
\hline
\end{tabular}




\begin{tabular}{|c|c|c|c|c|}
\hline Source & DF & Sum of Squares & Mean Square & F Ratio \\
\hline Total Error & 620 & 3741.3110 & & $0.0123 *$ \\
\hline
\end{tabular}

$\operatorname{Max}$ RSq

0.1138

Parameter Estimates

\begin{tabular}{|c|c|c|c|c|}
\hline Term & Estim ate & Std Error & t Ratio & $\operatorname{Prob}>|\mathbf{t}|$ \\
\hline Intercept & 2.0217398 & 0.148121 & 13.65 & $<.0001 *$ \\
\hline Lower 1 & -0.206726 & 0.043314 & -4.77 & $<.0001 *$ \\
\hline Group [Control] & 0.0233045 & 0.09956 & 0.23 & 0.8150 \\
\hline$($ Lower $1+2.44712) *$ Group [Control] & 0.0304126 & 0.043314 & 0.70 & 0.4829 \\
\hline
\end{tabular}

Response Data Upper or Lower?=Lower, Parameters $=\Delta x^{\circ}$

Effect Sum mary

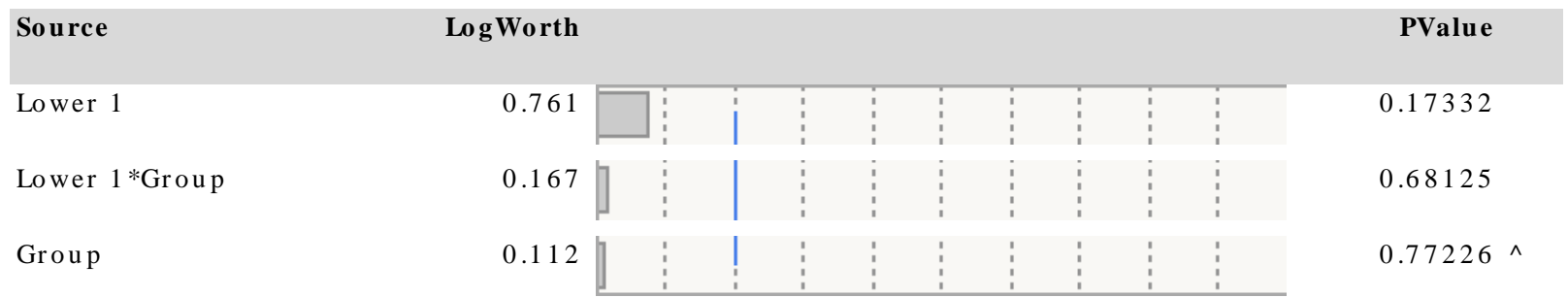


Regression Plot

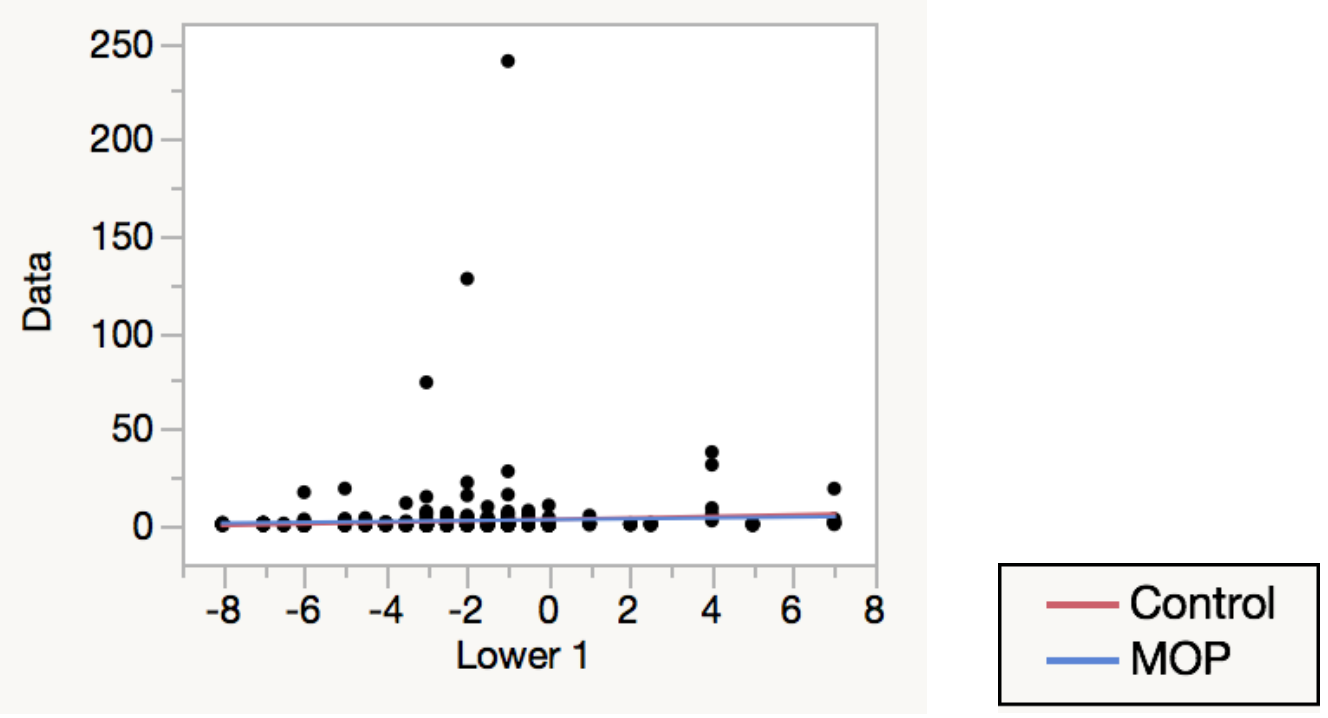

Summary of Fit

RSquare

RSquare Adj

Root Mean Square Error

Mean of Response

Observations (or Sum Wgts)
0.005737

0.000353

12.26496

2.20346

558

Analysis of Variance

\begin{tabular}{lrrrr} 
Source & DF & Sum of Squares & Mean Square & F Ratio \\
\hline Model & 3 & 480.854 & 160.285 & 1.0655 \\
Error & 554 & 83337.799 & 150.429 & Prob > F \\
C. Total & 557 & 83818.653 & & 0.3632
\end{tabular}

\section{Lack Of Fit}

\begin{tabular}{lrrrr|} 
Source & DF & Sum of Squares & Mean Square & F Ratio \\
\hline Lack Of Fit & 30 & 2429.828 & 80.994 & 0.5246 \\
\hline Pure Error & 524 & 80907.971 & 154.405 & Prob > F \\
\hline
\end{tabular}




\begin{tabular}{|lrrrr} 
Source & DF & Sum of Squares & Mean Square & F Ratio \\
\hline Total Error & 554 & 83337.799 & & 0.9834
\end{tabular}

\section{$\operatorname{Max}$ RSq}

0.0347

Parameter Estimates

\begin{tabular}{|c|c|c|c|c|}
\hline Term & Estim ate & Std Error & t Ratio & $\operatorname{Prob}>|t|$ \\
\hline Intercept & 3.0002921 & 0.805692 & 3.72 & $0.0002 *$ \\
\hline Lower 1 & 0.3167809 & 0.232353 & 1.36 & 0.1733 \\
\hline Group [Control] & -0.156776 & 0.541425 & -0.29 & 0.7723 \\
\hline (Lower $1+2.43548) *$ Group [Control] & 0.0954925 & 0.232353 & 0.41 & 0.6812 \\
\hline
\end{tabular}

Response Data Upper or Lower?=Lower, Parameters $=\Delta y^{\circ}$

\section{Effect Su m mary}

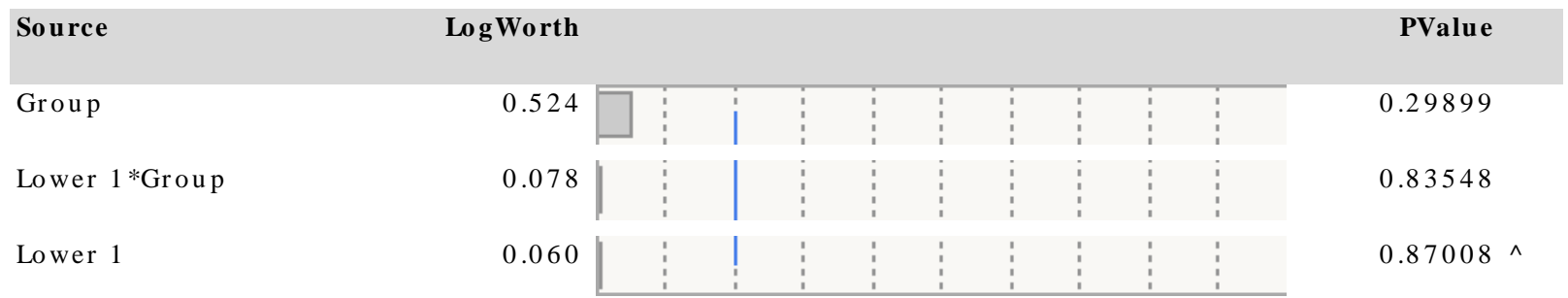


Regression Plot

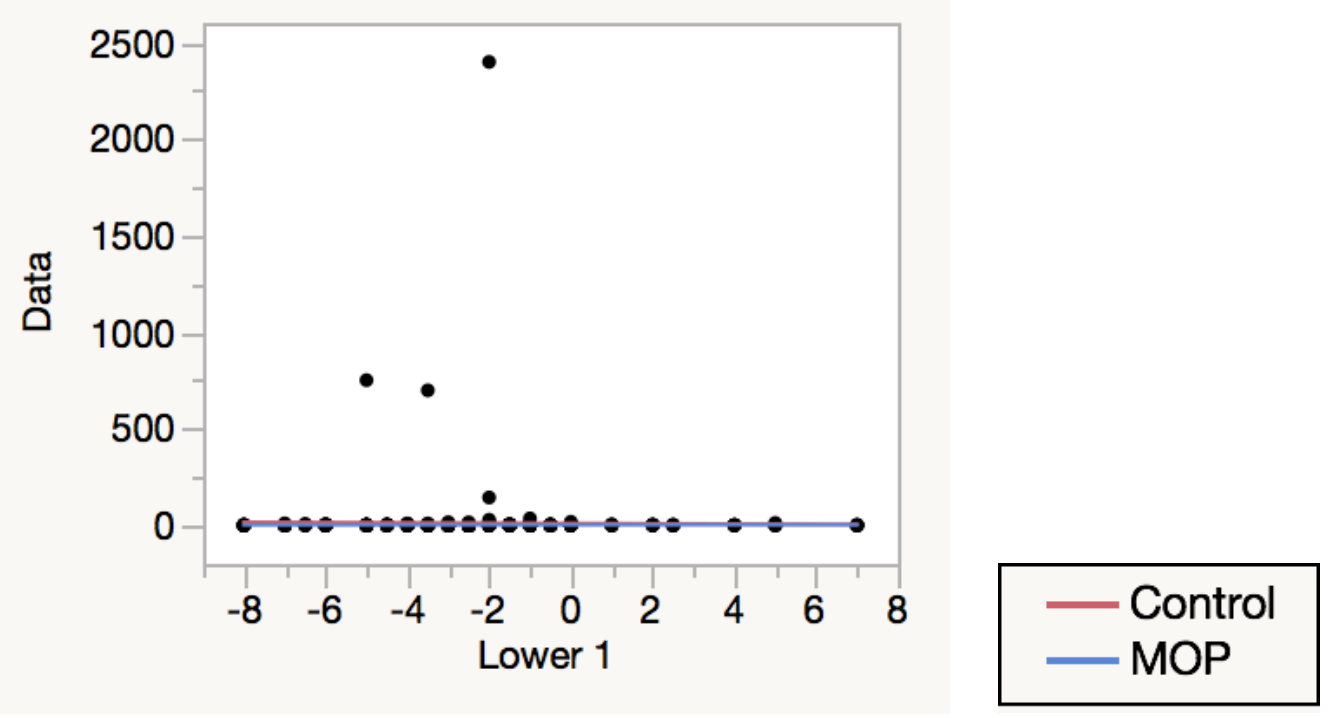

Summary of Fit

RSquare

RSquare Adj

Root Mean Square Error

Mean of Response

Observations (or Sum Wgts)
0.002161

$-0.00325$

110.6776

8.525555

557

Analysis of Variance

\begin{tabular}{lrrrr} 
Source & DF & Sum of Squares & Mean Square & F Ratio \\
\hline Model & 3 & 14668.2 & 4889.4 & 0.3991 \\
Error & 553 & 6773988.5 & 12249.5 & Prob > F \\
C. Total & 556 & 6788656.7 & & 0.7537
\end{tabular}

\section{Lack Of Fit}

\begin{tabular}{lrrrr|}
\hline Source & DF & Sum of Squares & Mean Square & F Ratio \\
\hline Lack Of Fit & 30 & 203422.5 & 6780.7 & 0.5397 \\
\hline Pure Error & 523 & 6570566.0 & 12563.2 & Prob > F \\
\hline
\end{tabular}




\begin{tabular}{|lccrr}
\hline Source & DF & Sum of Squares & Mean Square & F Ratio \\
\hline Total Error & 553 & 6773988.5 & 0.9794
\end{tabular}

\section{$\operatorname{Max} \mathbf{R S q}$}

0.0321

Parameter Estimates

\begin{tabular}{|c|c|c|c|c|}
\hline Term & Estim ate & Std Error & t Ratio & Prob $>|t|$ \\
\hline In tercept & 6.38774 & 7.276625 & 0.88 & 0.3804 \\
\hline Lower 1 & -0.343087 & 2.096753 & -0.16 & 0.8701 \\
\hline Group [Control] & 5.0871797 & 4.893473 & 1.04 & 0.2990 \\
\hline$($ Lower $1+2.43537) *$ Group [Control] & -0.435651 & 2.096753 & -0.21 & 0.8355 \\
\hline
\end{tabular}

Response Data Upper or Lower $?=$ Lower, Parameters $=\Delta z^{\circ}$

Effect Sum mary

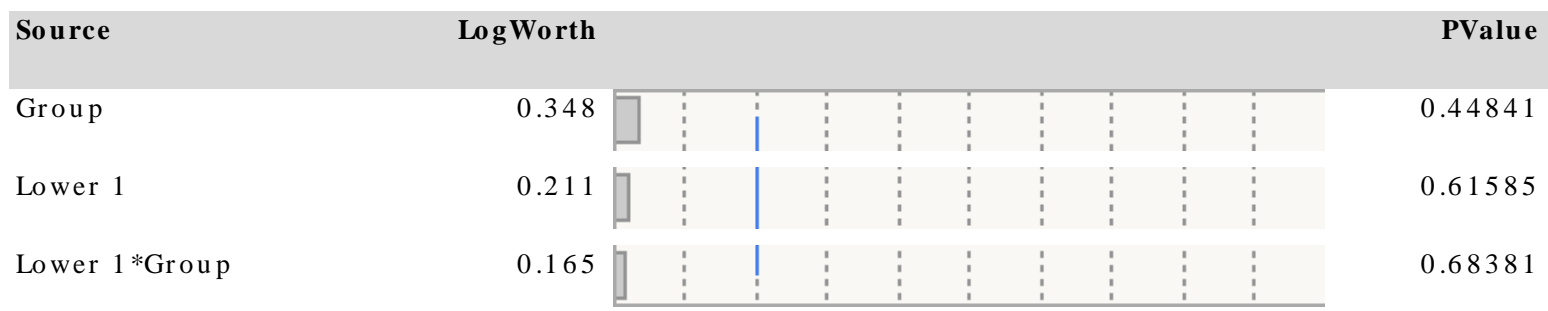

Summary of Fit

RSquare

0.002312

RSquare Adj

$-0.00309$

Root Mean Square Error

18.01167

Mean of Response

1.884385 


\section{Analysis of Variance}

\begin{tabular}{lrrrr} 
Source & DF & Sum of Squares & Mean Square & F Ratio \\
\hline Model & 3 & 416.54 & 138.847 & 0.4280 \\
Error & 554 & 179728.77 & 324.420 & Prob > F \\
C. Total & 557 & 180145.32 & & 0.7330
\end{tabular}

Lack Of Fit

\begin{tabular}{lrrrr|} 
Source & DF & Sum of Squares & Mean Square & F Ratio \\
\hline Lack Of Fit & 30 & 8688.71 & 289.624 & 0.8873 \\
\hline Pure Error & 524 & 171040.06 & 326.412 & Prob > F \\
\hline Total Error & 554 & 179728.77 & & 0.6415
\end{tabular}

179728.77

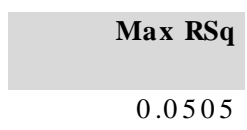

Parameter Estimates

\begin{tabular}{|c|c|c|c|c|}
\hline Term & Estim ate & Std Error & t Ratio & Prob $>|t|$ \\
\hline In tercept & 1.3295364 & 1.183197 & 1.12 & 0.2616 \\
\hline Lower 1 & -0.171302 & 0.341221 & -0.50 & 0.6158 \\
\hline Group [Control] & 0.6031815 & 0.795109 & 0.76 & 0.4484 \\
\hline$($ Lower $1+2.43548) *$ Group [Control] & -0.139042 & 0.341221 & -0.41 & 0.6838 \\
\hline
\end{tabular}


Response Data Upper or Lower?=Upper, Parameters $=\Delta V$

Regression Plot
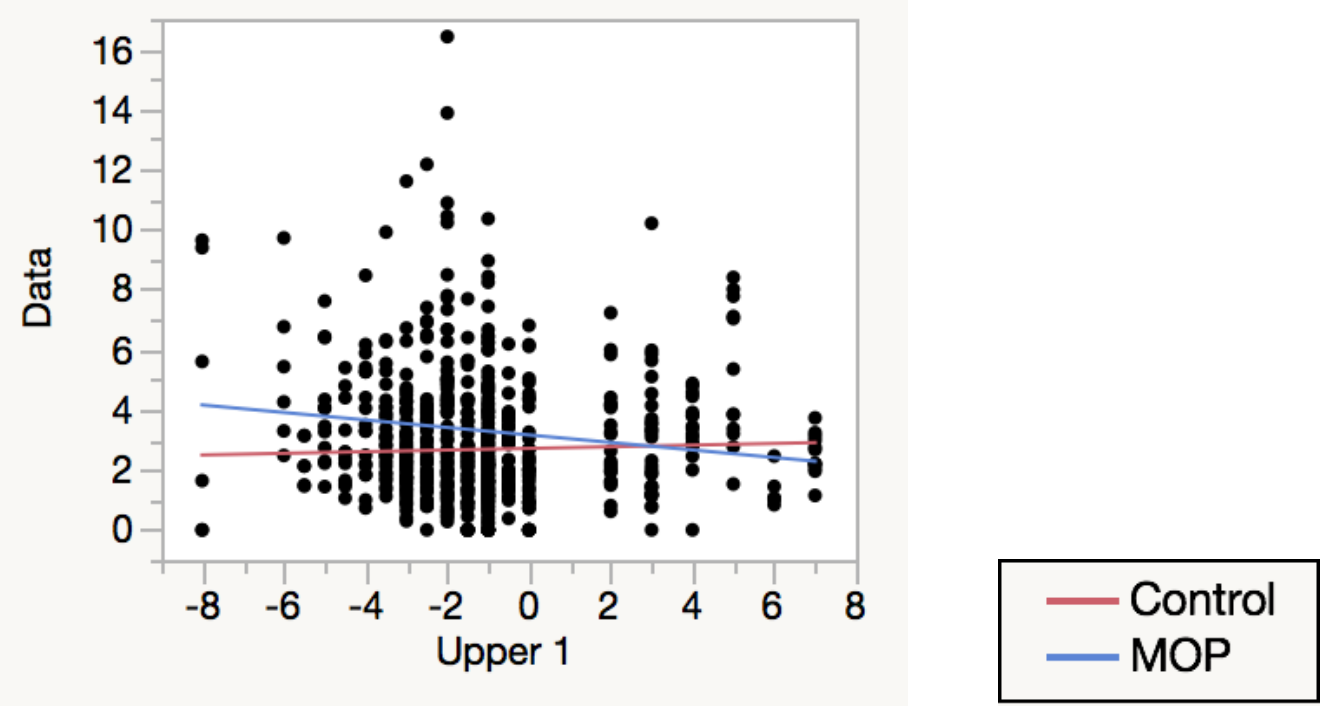

Summary of Fit

RSquare

RSquare Adj

Root Mean Square Error

Mean of Response

Observations (or Sum Wgts)
0.032431

0.027794

2.134533

2.980339

630

Analysis of Variance

\begin{tabular}{lrrrr} 
Source & DF & Sum of Squares & Mean Square & F Ratio \\
\hline Model & 3 & 95.5993 & 31.8664 & 6.9940 \\
Error & 626 & 2852.2013 & 4.5562 & Prob > F \\
C. Total & 629 & 2947.8007 & & $0.0001 *$
\end{tabular}

Lack Of Fit

Source 


\begin{tabular}{lrrrr} 
Source & DF & Sum of Squares & Mean Square & F Ratio \\
\hline Lack Of Fit & 29 & 367.9473 & 12.6878 & 3.0491 \\
\hline Pure Error & 597 & 2484.2541 & 4.1612 & Prob > F \\
\hline Total Error & 626 & 2852.2013 & & $<.0001 *$
\end{tabular}

Max RSq

0.1573

Parameter Estimates

\begin{tabular}{|c|c|c|c|c|}
\hline Term & Estim ate & Std Error & t Ratio & $\operatorname{Prob}>|t|$ \\
\hline In tercept & 2.9351191 & 0.096403 & 30.45 & $<.0001 *$ \\
\hline Upper 1 & -0.048711 & 0.033546 & -1.45 & 0.1470 \\
\hline Group [Con trol] & -0.309013 & 0.08673 & -3.56 & $0.0004 *$ \\
\hline$($ Upper $1+1.12381) *$ Group [Control] & 0.0761774 & 0.033546 & 2.27 & $0.0235 *$ \\
\hline
\end{tabular}

Response Data Upper or Lower?=Upper, Parameters $=\Delta x^{\circ}$

Effect Sum mary

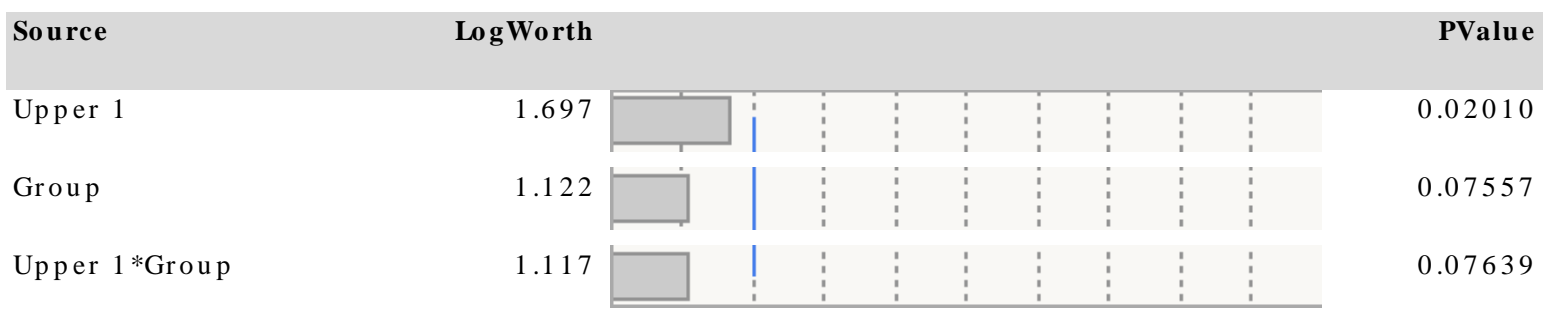


Regression Plot
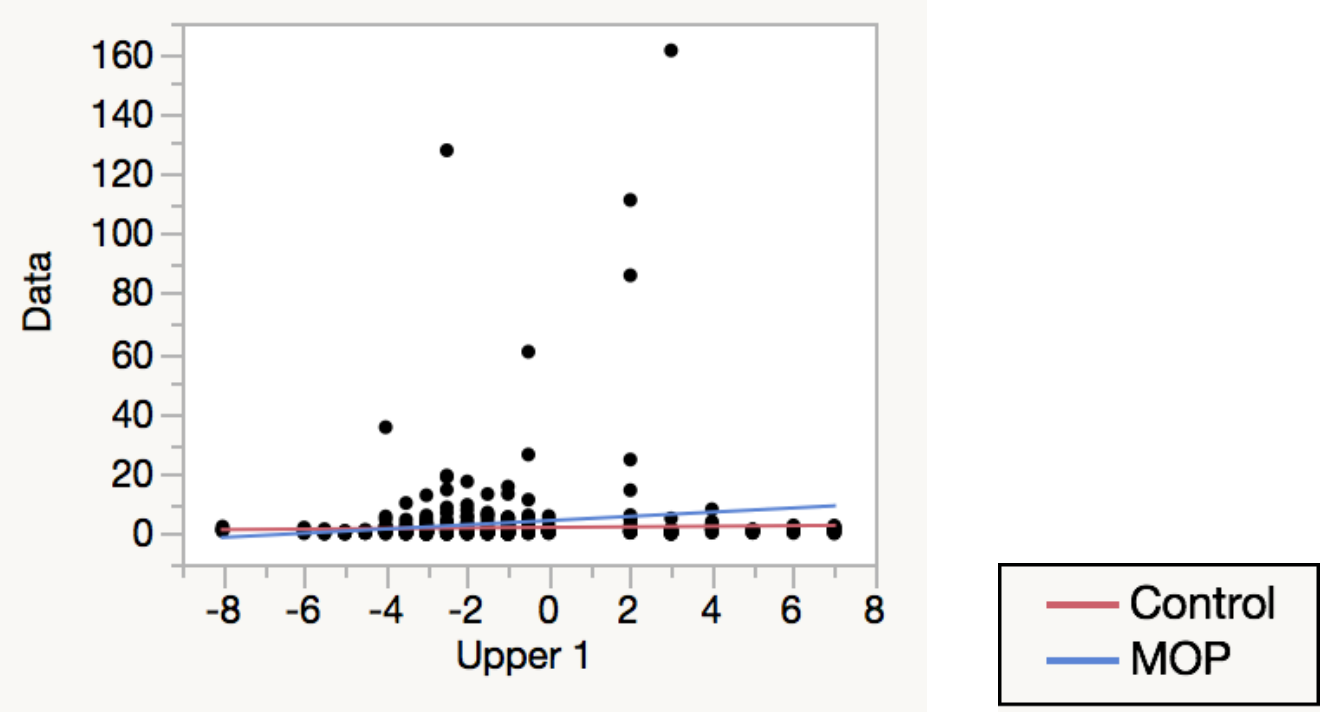

Summary of Fit

RSquare

RSquare Adj

Root Mean Square Error

Mean of Response

Observations (or Sum Wgts)
0.014769

0.009801

10.65926

2.62509

599

Analysis of Variance

\begin{tabular}{lrrrr} 
Source & DF & Sum of Squares & Mean Square & F Ratio \\
\hline Model & 3 & 1013.393 & 337.798 & 2.9730 \\
Error & 595 & 67603.849 & 113.620 & Prob > F \\
C. Total & 598 & 68617.242 & & $0.0312 *$
\end{tabular}

Lack Of Fit

\begin{tabular}{lrrrr|} 
Source & DF & Sum of Squares & Mean Square & F Ratio \\
\hline Lack Of Fit & 29 & 4166.568 & 143.675 & 1.2819 \\
\hline Pure Error & 566 & 63437.281 & 112.080 & Prob > F \\
\hline
\end{tabular}




\begin{tabular}{|c|c|c|c|c|}
\hline Source & DF & Sum of Squares & Mean Square & F Ratio \\
\hline Total Error & 595 & 67603.849 & & 0.1500 \\
\hline
\end{tabular}

\section{Max RSq}

0.0755

Parameter Estimates

\begin{tabular}{|c|c|c|c|c|}
\hline Term & Estim ate & Std Error & t Ratio & Prob $>|t|$ \\
\hline In tercept & 3.305485 & 0.495891 & 6.67 & $<.0001 *$ \\
\hline Upper 1 & 0.3993148 & 0.171325 & 2.33 & $0.0201 *$ \\
\hline Group [Control] & -0.79355 & 0.445783 & -1.78 & 0.0756 \\
\hline (Upper $1+1.1227)^{*}$ Group [Control] & -0.304117 & 0.171325 & -1.78 & 0.0764 \\
\hline
\end{tabular}

Response Data Upper or Lower? $=$ Upper, Parameters $=\Delta y^{\circ}$

Effect Sum mary

Sog Worth
Soulue


Regression Plot
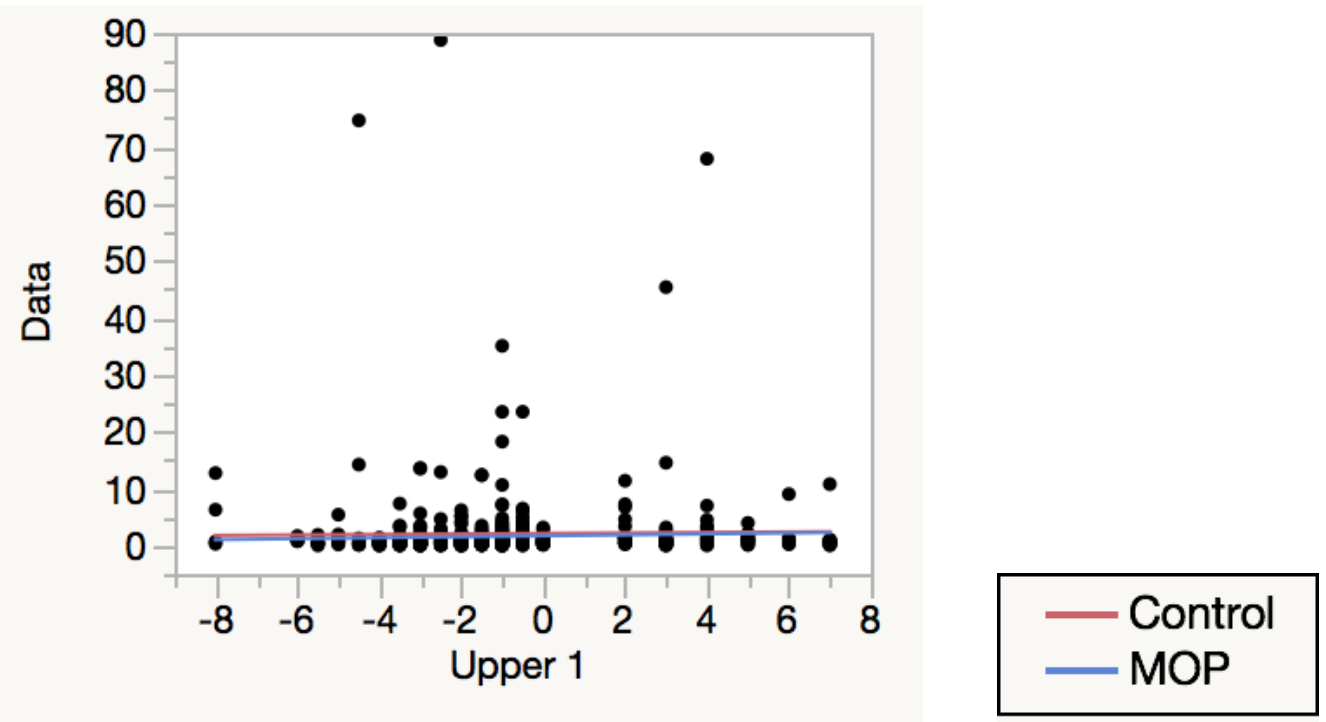

Summary of Fit

RSquare

RSquare Adj

Root Mean Square Error

Mean of Response

Observations (or Sum Wgts)

\begin{abstract}
0.00241
\end{abstract}
$-0.00262$

6.340136

1.864955

599

Analysis of Variance

\begin{tabular}{lrrrr} 
Source & DF & Sum of Squares & Mean Square & F Ratio \\
\hline Model & 3 & 57.774 & 19.2579 & 0.4791 \\
Error & 595 & 23917.412 & 40.1973 & Prob > F \\
C. Total & 598 & 23975.185 & & 0.6969
\end{tabular}

Lack Of Fit

\begin{tabular}{|lrrrr|} 
Source & DF & Sum of Squares & Mean Square & F Ratio \\
\hline Lack Of Fit & 29 & 1789.519 & 61.7076 & 1.5784 \\
\hline Pure Error & 566 & 22127.892 & 39.0952 & Prob > F \\
\hline
\end{tabular}




\begin{tabular}{|c|c|c|c|c|}
\hline Source & DF & Sum of Squares & Mean Square & F Ratio \\
\hline \multirow[t]{2}{*}{ Total Error } & 595 & 23917.412 & & 0.0291 * \\
\hline & & & & Max RSq \\
\hline
\end{tabular}

Parameter Estimates

\begin{tabular}{|c|c|c|c|c|}
\hline Term & Estim ate & Std Error & t Ratio & $\operatorname{Pro} b>|t|$ \\
\hline Intercept & 1.9067661 & 0.294956 & 6.46 & $<.0001 *$ \\
\hline Upper 1 & 0.0637803 & 0.101904 & 0.63 & 0.5316 \\
\hline Group [Control] & 0.2428441 & 0.265152 & 0.92 & 0.3601 \\
\hline$(\text { Upper } 1+1.1227)^{*}$ Group [Control] & -0.019353 & 0.101904 & -0.19 & 0.8494 \\
\hline
\end{tabular}

Response Data Upper or Lower?=Upper, Parameters $=\Delta z^{\circ}$

Effect Sum mary

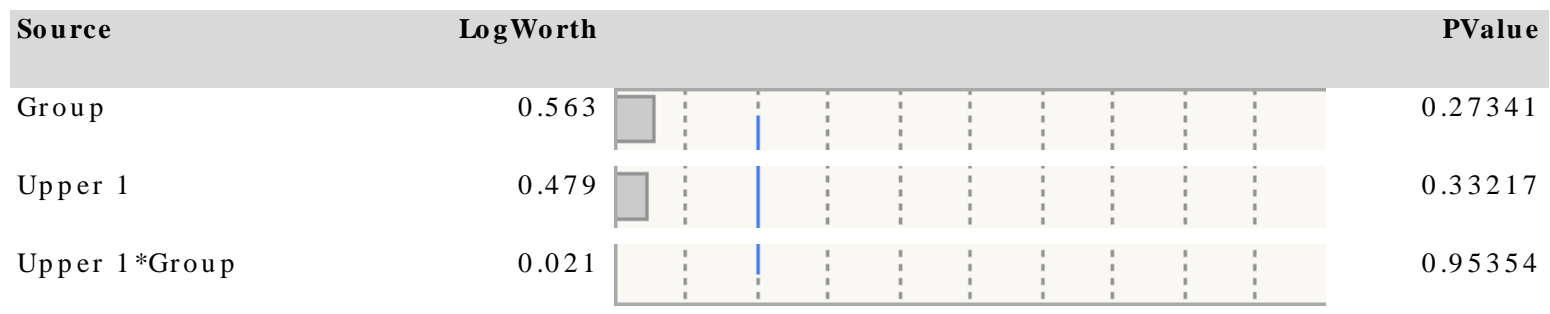


Regression Plot

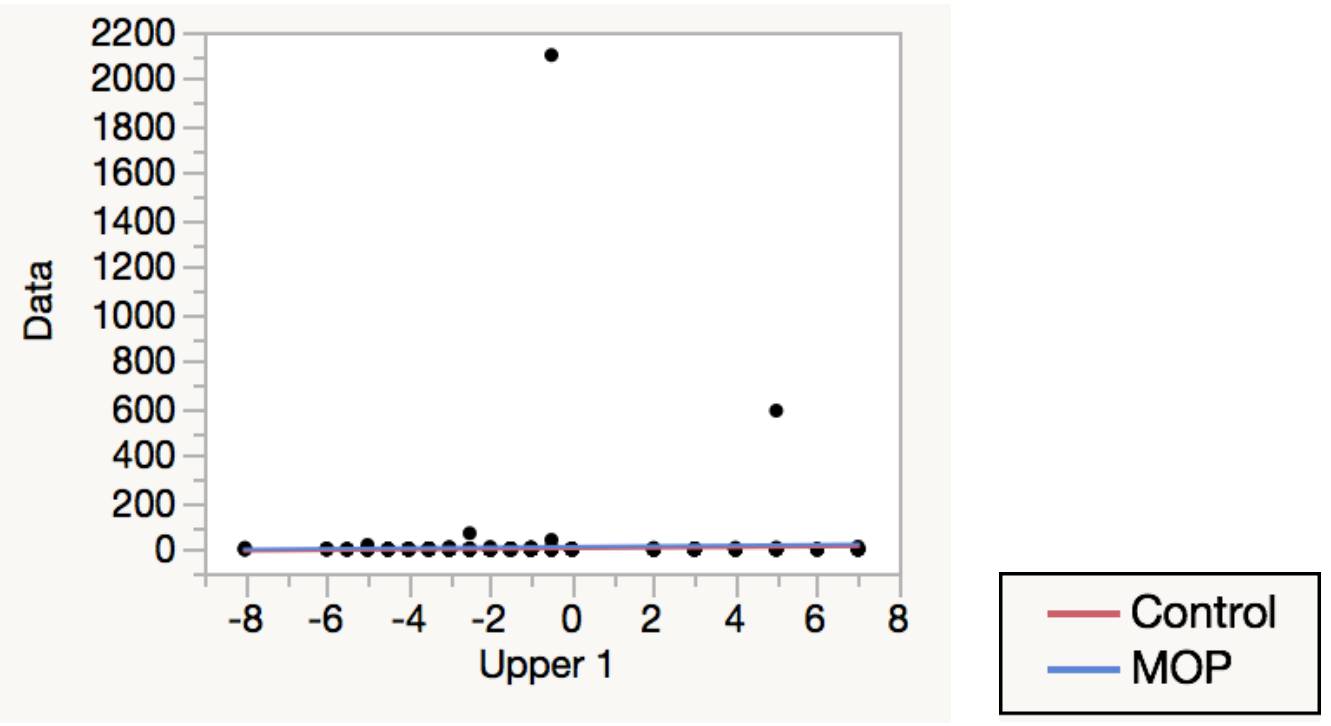

Summary of Fit

RSquare

RSquare Adj

Root Mean Square Error

Mean of Response

Observations (or Sum Wgts)
0.003209

$-0.00182$

89.23974

5.610982

599

Analysis of Variance

\begin{tabular}{lrrrr} 
Source & DF & Sum of Squares & Mean Square & F Ratio \\
\hline Model & 3 & 15255.4 & 5085.13 & 0.6385 \\
Error & 595 & 4738419.8 & 7963.73 & Prob > F \\
C. Total & 598 & 4753675.2 & & 0.5904
\end{tabular}

Lack Of Fit

\begin{tabular}{|lrrrr|}
\hline Source & DF & Sum of Squares & Mean Square & F Ratio \\
\hline Lack Of Fit & 29 & 382889.3 & 13203.1 & 1.7157 \\
\hline Pure Error & 566 & 4355530.6 & 7695.3 & Prob > F
\end{tabular}




\begin{tabular}{|c|c|c|c|}
\hline Source & DF & Sum of Squares & Mean Square \\
\hline Total Error & 595 & 4738419.8 & \\
\hline
\end{tabular}

\section{$\operatorname{Max} \mathbf{R S q}$}

0.0838

Parameter Estimates

\begin{tabular}{|c|c|c|c|c|}
\hline Term & Estim ate & Std Error & t Ratio & Prob $>|t|$ \\
\hline In tercept & 7.8260849 & 4.151615 & 1.89 & 0.0599 \\
\hline Upper 1 & 1.3920765 & 1.434338 & 0.97 & 0.3322 \\
\hline Group [Control] & -4.091309 & 3.732107 & -1.10 & 0.2734 \\
\hline$(\text { Upper } 1+1.1227)^{*}$ Group [Control] & -0.083609 & 1.434338 & -0.06 & 0.9535 \\
\hline
\end{tabular}

\section{FREQUENCY OF REFINEMENT}

Contingency Analysis of R or C By Group

Mosaic Plot

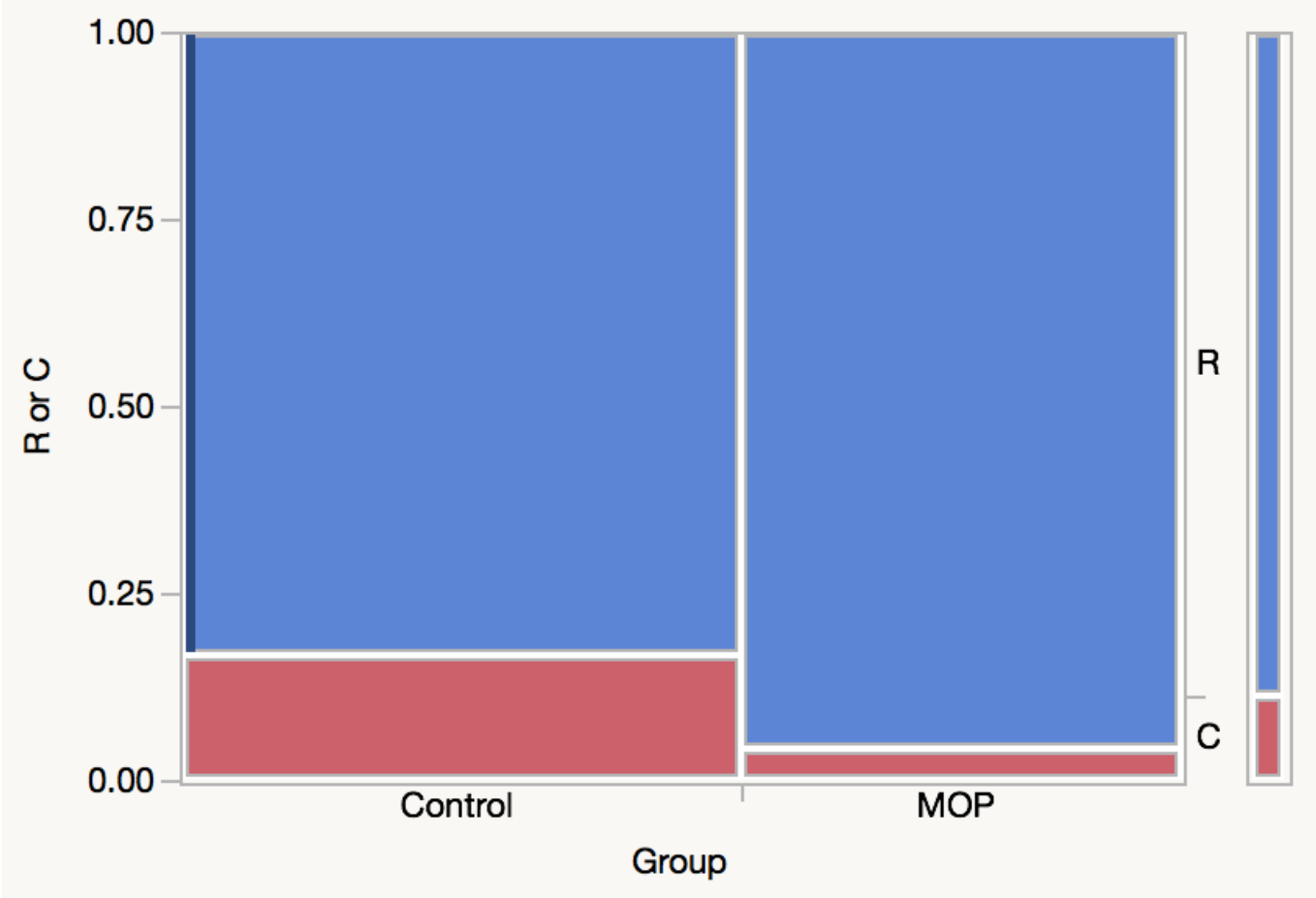




\section{Contingency Table}

Group By R or C

\begin{tabular}{|l|r|r|r|}
\hline $\begin{array}{l}\text { Count } \\
\text { Total } \% \\
\text { Col\% }\end{array}$ & $\mathrm{C}$ & $\mathrm{R}$ & Total \\
Row $\%$ & & & \\
\hline Control & 10 & 49 & 59 \\
& 9.52 & 46.67 & 56.19 \\
& 83.33 & 52.69 & \\
& 16.95 & 83.05 & \\
\hline MOP & 2 & 44 & 46 \\
& 1.90 & 41.90 & 43.81 \\
& 16.67 & 47.31 & \\
\hline Total & 4.35 & 95.65 & 105 \\
& 11.43 & 98.57 & \\
\hline
\end{tabular}

\section{Tests}

\begin{tabular}{|ccrr}
$\mathbf{N}$ & DF & -LogLike & RSquare (U) \\
\hline 105 & 1 & 2.2386745 & 0.0600
\end{tabular}

\begin{tabular}{lrr} 
Test & ChiSquare & Prob $>$ ChiSq \\
\hline Likelihood Ratio & 4.477 & $0.0343 *$ \\
Pearson & 4.055 & $0.0440 *$
\end{tabular}

Fisher's Exact
Test
Left
Right
2-Tail
0.9928 Prob $(\mathrm{R}$ or $\mathrm{C}=\mathrm{R})$ is greater for Group=Control than MOP




\section{Appendix F - Electronic Thesis and Dissertation Signature Form}

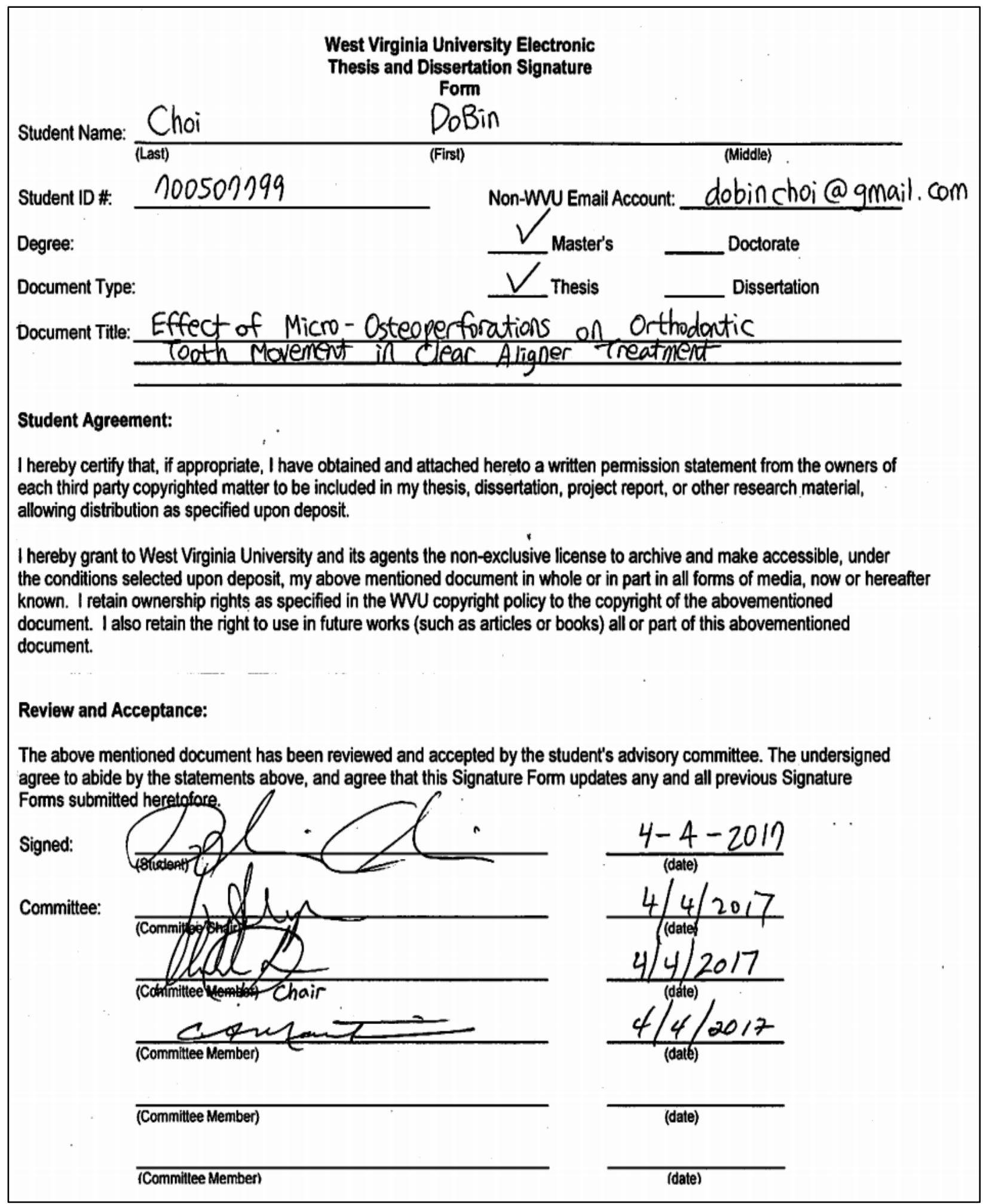

